\title{
Community, the state
}

\section{and Development Assistance:}

Transforming the Mahalla in Tajikistan

\section{Anna Cieślewska}

\section{A 813069





\section{Community, the State and Development Assistance: \\ Transforming the Mahalla in Tajikistan}


in memory of my grandfather, Stanisław Cieślewski 


\author{
Anna Cieślewsika
}

\title{
Community, the State \\ and Development Assistance:
}

Transforming the Mahalla in Tajikistan

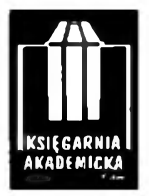

Krakiow 
Reviewer:

Dr hab. Sergei N. Abashin

Proofreading:

Dr Miłosława Stępicń

Cover design:

Agnicszka Stach'ra

ISBN 978-83-7638-558-7

Publication financed by The Faculty of Philology, Jagiellonian University in Kraków

Author: Dr Anna Cieślewska. acieslewska $a$ gmail.com

Title: Community, the State and Development Assistance:

Transforming the Mahalla in Tajikistan

Part of this book is based on the doctoral dissertation entitled: The Traditional Self-Governing Institution Mahalla in Relation with State Policies and International Organizations in Tajikistan written under the supervision of Dr hab. Stanisław Zapaśnik. Professor of the University of Warsaw, at the Institute of Applied Social Sciences. University of Warsaw.

All rights reserved.

No part of this publication may be reproduced. stored in a retrieval system or transmitted in any form or by any means, electronic. mechanical. photocopying or othenvise, without the prior permission of the publisher.

\author{
KSIĘGARNIA AKADEMICKA \\ ul. św. Anny 6, 31-008 Kraków \\ tel./faks: 124312743,124211387 \\ e-mail: akademicka@akademicka.pl \\ Online bookstore: www.akademicka.pl
}




\section{Table of Contents}

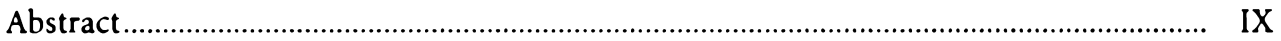

Acknowledgements ……...................................................................................... XI

List of Tables and Illustrations ......................................................................................... XII

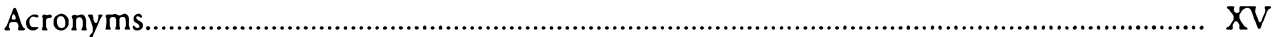

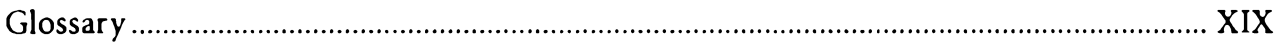

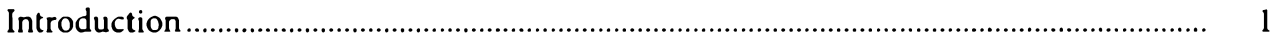

Methodology and Stages of Data Collection ...................................................................

Notes on Transliteration ........................................................................................... 14

\section{Chapter 1. Tajikistan: a Quick Overview of the Country's Modern History} and Development ............................................................................................. 15

1.1. Introduction to the History of Tajikistan ................................................................. 15

1.2. Ethno-Regional Identity and its Influence on the Contemporary Political Landscape of Tajikistan............................................... 19

1.3. Aggravation of Social Tensions before the Collapse of the USSR, and the Emergence of the Main Political Actors ..................................... 23

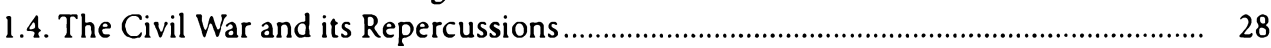

1.5. The Socio-Economic Situation in Tajikistan .......................................................... 31

1.6. Humanitarian and Development Assistance in Tajikistan .......................................... 33

\section{Chapter 2. Traditional Social Networks and Groups, the Mahalla Community} and its Institutions

2.1. Traditional Social Networks and Groups in Tajik Society.......................................... 41

2.2. Traditional Mahalla Institutions ............................................................................ 53

2.2.1. The Meaning of the Term 'Mahalla' ................................................................ 53

2.2.2. The Mahalla as a Social Organization .............................................................. 55

2.2.3. The Mahalla in the Pre-Revolutionary Past ................................................... 57

2.2.4. The Mahalla in the USSR ......................................................................... 61

2.2.5. The Mahalla Authorities............................................................................... 66

2.2.6. Everyday Communal Practices in the Mahalla .................................................. 82

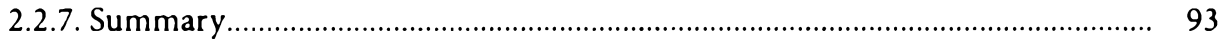


Chapter 3. The Jamoat and the Mahalla - Legal Framework and Practical Dilemmas 95

3.1. Reconstructing the Rural Relationship - Past and Present .......................................... 95

3.1.1. Collective Farms during the Soviet Period..................................................... 95

3.1.2. The Selsovet in Rural Areas.............................................................................. 99

3.1.3. The Land Reform and its Consequences....................................................... 100

3.2. Legislation Concerning the Jamoat and its Implications ............................................. 102

3.2.1. The Administrative Division of Tajikistan ....................................................... 102

3.2.2. The Legal Framework and Competencies of the Jamoat..................................... 104

3.2.3. The Jamoat and Jamoat Resource Centre ............................................................ 111

3.2.4. The Jamoat in the Context of the Civil War................................................... 113

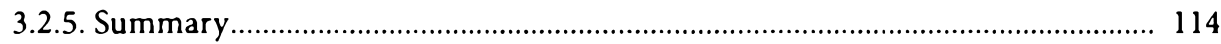

3.3. The Mahalla, State Institutions and Local Initiatives ................................................. 115

3.3.1. An Overview of the Legal Framework of the Mahalla ...................................... 115

3.3.2. The Mahalla Regime .................................................................................... 116

3.3.3. The State and Religious Affairs in the Mahalla ............................................... 121

3.3.4. Summary .................................................................................................... 123

Chapter 4. The Modern Concept of Civil Society and Traditional Institutions ........... 125

4.1. Civil Society, Donor Policies and the Local NGO Sector - An Overview .................. 125

4.1.1. The Concept of Civil Society .......................................................................... 126

4.1.2. Shaping the Development Agenda from the 1980s to the Present Day............. 128

4.1.3. International Assistance and the Emerging New 'NGO Elite' ............................. 131

4.1.4. The Local NGO Sector and Civil Society ......................................................... 136

4.2. The Mahalla and Civil Society ........................................................................... 141

Chapter 5. Village Organizations - the Concept of a New Mahalla ............................. 151

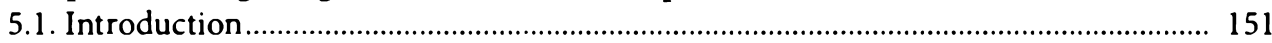

5.2. Village Organizations - A Theoretical Framework …………………………….......... 153

5.3. The Shuroobod District - A Quick Overview ................................................................ 157

5.4. Village Organizations in Practice................................................................................... 161

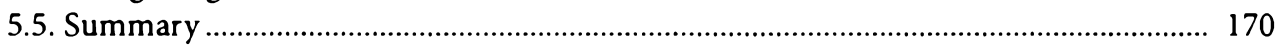

Chapter 6. The Kolkhoz, Selsovet, Mahalla and Jamoat Resource Centre on the Fringes of the State.................................................................................. 171

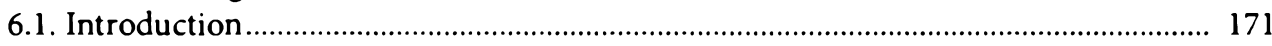

6.2. Vorukh and Its Surroundings ............................................................................. 172

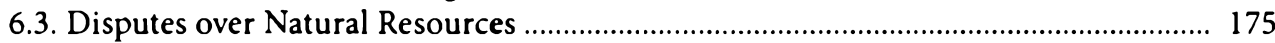

6.4. Islamic Practices in Vorukh ..................................................................................... 179

6.5. The Kolkhoz, the Jamoat, the JRC and the Mahalla in Vorukh................................. 181

6.5.1. The Kolkhoz ................................................................................................. 181

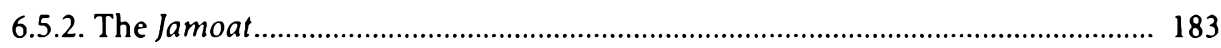

6.5.3. The Jamoat Resource Centre in Vorukh........................................................... 184

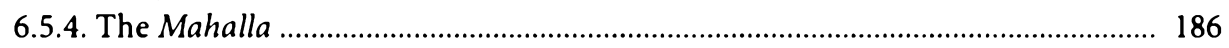

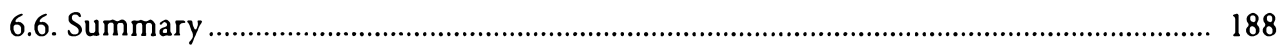


Chapter 7. Working with Communities, the Experiences of the Polish Center for International Aid in the Khatlon Region

7.1. Introduction

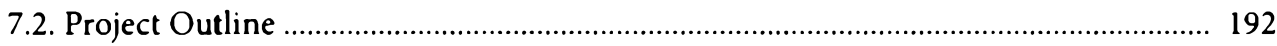

7.3. A Short Overview of the Area of Project Implementation ........................................ 194

7.4. Cooperation with Communities in the Districts: Bokhtar, Jillikul and Qumsangir ... 196

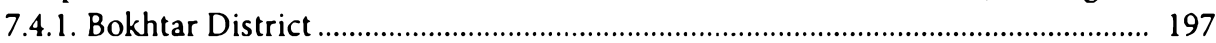

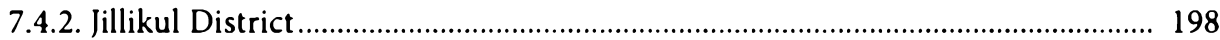

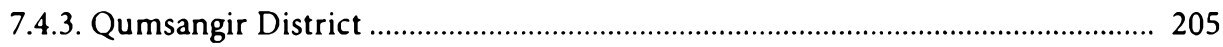

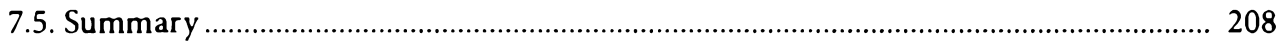

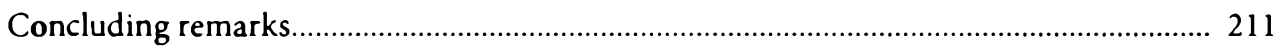

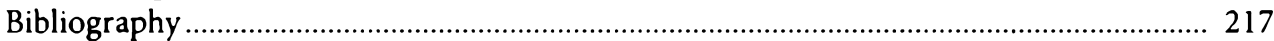

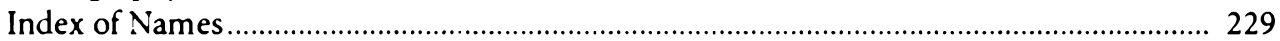

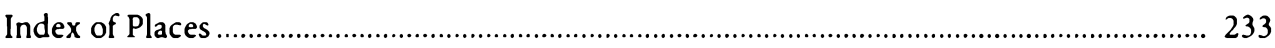

Index of Ethnographic Terms ................................................................................ 237 



\section{Abstract}

This study analyses various aspects of the interaction of the state administration, international organizations and the mahalla in Tajikistan, and investigates the social and economic changes which have influenced this traditional form of social organization. The text interweaves a theoretical approach with observations and research gathered during the conducting of fieldwork and the implementation of NGO projects. Particularly, three main questions are addressed in the text. The first of these is the relationship between the mahalla and the state administration, concerning which I provide insights into its legal basis as well as its practical implications. The second analysed issue involves the complex problem of donor policies regarding local development as pertains to adopting elements of traditional self-government into the tenets of their development strategies. Lastly, the socio-economic situation in Tajikistan is considered, including its impact on the transformation of the traditional social institutions of the mahalla. The main conclusion of this study is that neither the state nor international organizations have managed to develop a model of cooperation with the mahalla based on principles of equality and partnership. Instead, this traditional social organization is subjected to various modifications aimed at conforming it to the requirements of the various parties concerned. In addition, over twenty years of economic crisis have resulted in changes within the social structures of Tajik society, which have further contributed to reshaping communal institutions and traditional practices.

Key words: self-government, civil society, local development, traditional institutions, international aid, local administration 



\section{Acknowledgements}

I would like to express my sincere gratitude to my supervisor, Professor Stanisław Zapaśnik, for his invaluable support in the research and writing of this text, as well as for teaching me a particular approach to researching and analysing the practices and traditions of Central Asia I would also like to thank Professor Zbigniew Jasiewicz and Professor Jacek Kurczewski for their comprehensive reviews of my PhD dissertation, a large part of which is included in this book. Further acknowledgements go to Professor Usto Dzhakhonov, Mariusz Marszewski, Saibek Goziyev, Rahmoil Safarov, Mughbira Tiuriaeva, the MSDSP employees in Dushanbe, Kuliab and Shuroobod, and my friends from the Said NGO - Haimisso Rasulova and Mansur Makhmudov from Khujand, as well as friends from Jamoat Resource Centre in Vorukh.

I would also like to express my deepest gratitude to Agnieszka Makowska for our fruitful cooperation in 2012, which allowed me to collect data regarding local communities, for our endless and profound discussions regarding Central Asian cultures and societies, as well as for her advice and remarks regarding this book. The research conducted in 2012 would not have been so productive without the participation of our local employee from Sughd, Mavlankhon Temirov, who provided me with a lot of interesting information, and helped me to organize my work.

I also give special thanks to my friends and colleagues from the Polish Center for International Aid (PCIA) for all their support and the work we conducted together during the 2013-2014 project, especially Magda Kowalczyk (Gromek), Sylwia Wilk, and Kasia Szalbot, to whom I would also like to extend many thanks for reading and commenting on the last chapter of this book regarding the mahalla project implemented by the PCIA. I am also thankful to all the employees of NGO Mehrangez, as well as to the residents of the villages and their representatives with whom we cooperated, for the successful work conducted during the project, which has significantly enriched my understanding of local development and relationships within communities. My special thanks go to the President of the NGO Mehrangez, Mrs Sharofat Umarova. I am also grateful to all the other people who contributed to our work during the project, including Magda Rapińczuk, Adam Kowalczyk, Radek Stryjewski, and others. 
I am deeply indebted to our donor, Solidarity Fund PI., for the trust they showed us and for granting financial support to such an experimental project proposal written on the basis of anthropological research and targeting the very complex issues connected to cooperation with mahalla communities.

Similarly, I owe many thanks to countless people from Tajikistan whom I cannot name, for their trust and help which allowed me to conduct research and to finalize my work. I also cannot omit Karolina Krzywicka, from the Asia and Pacific Museum in Warsaw for organizing a number of events during which I presented part of my research and the NGO projects I participated in, and Zuzanna Blayet for helping me in transliteration of the Tajik language. Lastly, I would also like to extend my deepest gratitude to Professor Sergei Nikolaevich Abashin for his editorial review and helpful final remarks which have improved the content of my book. 


\section{List of Tables and Illustrations}

Map 1. Field Activities

Table 1. Basic Socio-Economic Indicators

Table 2. Tajikistan's ODA 1992-2012

Table 3. The Authorities of a Mahalla

Figure 1. The Administrative Division of Tajikistan

Figure 2. Diagram of Village Organization

Illustrations:

1. Cooking sumalak at the beginning of spring, Khujand (photo A. Cieślewska)

2. Hodoi (an offering) organized by women at the beginning of spring in the mazar in Istpisor village, Sughd region (photo A. Cieślewska)

3. Mourning women, old mahalla, Khujand (photo A. Cieślewska)

4. A village mosque, Spitamen district (photo A. Cieślewska)

5. Musicians, Hisor Town (photo A. Cieślewska)

6. Newlyweds at a wedding ceremony, Kurgan Tyube (photo A. Cieślewska)

7. A mazar on the border with Afghanistan, jamoat Sarichashma, Shuroobod (photo A. Cieślewska)

8. Chaykhona, jamoat Kistakuz, Sughd region (photo A. Cieślewska)

9. The mahalla's barber located next to the chaykhona building, jamoat Kistakuz, Sughd region (photo A. Cieślewska)

10. School students, qishloq O., Jillikul district, Khatlon region (photo A. Cieślewska)

11. Making bread, mahalla T., Qumsangir district, Khatlon region, (photo A. Cieślewska)

12. Taking water from the irrigation canal located three kilometres from qishloq O. populated by Kungrats, Jillikul district, Khatlon region (photo A. Cieślewska)

13. Bell in front of the mosque to call residents for special events, old mahalla in Khujand (photo A. Cieślewska)

14. A seminar organized by the Polish Center for International Aid and NGO Mehrangez, qishloq D. populated by Kungrats, Jillikul district, Khatlon region (photo A. Cieślewska)

15. A majlis with the participation of the PCLA and NGO Mehrangez, qishloq O. populated by Kungrats, Jillikul district, Khatlon region, (photo K. Szalbot) 
16. A majlis with the participation of the PCIA and NGO Mehrangez, mahallo $\mathrm{H}$. populated by Gharmis, Qumsangir district, Khatlon region (photo K. Szalbot)

17. A primary-care clinic built by the community with the assistance of the PCIA and NGO Mehrangez, mahalla N., Jillikul district, Khatlon region (photo A. Cieślewska)

18. The patients of a primary-care clinic, mahalla N., Jillikul district, Khatlon region (photo A. Cieślewska)

19. The Jamoat Resource Centre and Microfinance Institution in Vorukh (photo A. Cieslewska)

20. In the street in Vorukh (photo A. Cieślewska)

21. On the way to the bazaar in Vorukh (photo A. Cieślewska)

22. A village shop, mahalla $\mathrm{H}$. populated by Gharmis, Qumsangir district, Khatlon region (photo A. Cieślewska)

23. A cooking place, mahalla M. populated by Gharmis, Qumsangir district, Khatlon region (photo A. Cieślewska)

24. In the street, old mahalla in Khujand (photo A. Cieślewska) 


\section{Acronyms}

ACTED Agency for Technical Cooperation and Development

ADB Asian Development Bank

AIMS Aid Information Management System

AKDN Aga Khan Development Network

AKF Aga Khan Foundation

ASUDVO Association of the Social Union for the Development of Village Organizations

CBO Community-Based Organization

CIDA Canadian International Development Agency

CIS Commonwealth of Independent States

CRA Committee for Religious Affairs

DCC Development Coordination Council

DDC District Development Council

DFID UK Department for International Development

DPT Democratic Party of Tajikistan

DWUC Drinking Water Users Committee

EAEC Eurasian Economic Community (also EurAsEC)

EBRD European Bank for Reconstruction and Development

EC European Commission

EEDC East European Democratic Centre

EIDHR European Instrument for Democracy and Human Rights

FMFB First MicroFinance Bank of Tajikistan

FSB Federal Security Service of the Russian Federation (Russian: Federalnaia sluzhba bezopasnosti Rossiiskoi Federacii)

GBAO Gorno-Badakhshan Autonomous Oblast

GNI Gross National Income

GTZ German Organization for Technical Cooperation (German: GIZ - Deutsche Gesellschaft für Internationale Zusammenarbeit)

HMS Housing and Management Services

IDA International Development Association

IDPs Internally Displaced Persons

IFAD International Fund for Agriculture and Development

IKRF Imam Khomeini Relief Foundation 
ILO International Labor Organization

IMF International Monetary Fund

INGO International Non-Governmental Organization

IO International Organization

IOM International Organization for Migration

IRDP Integrated Rural Development Programme

IRO International Relief Organization

IRP Islamic Renaissance Party

IREX International Research and Exchanges Board

ISAF International Security Assistance Force

JCPS Joint Country Partnership Strategy

JICA Japan International Cooperation Agency

JRC Jamoat Resource Centres

KGB The Soviet Committee of State Security (Russian: Komitet Gosudarstvennoi Bezopaasnosti)

LNGO Local Non-Governmental Organization

MC Mahalla Committee

MHJ Self-Governance Organization (Tajik: Mekomoti Khudfaoli Jamoati)

MLOs Micro-Lending Organizations

MSDSP Mountain Societies Development Support Programme

NBT National Bank of Tajikistan

NDS National Development Strategy

NGO Non-Governmental Organization

NKVD National Commissariat of Internal Affairs USSR (Russian: Narodnyi Komissariat Vnutrennikh Del SSSR)

ODA Official Development Assistance

ODIHR Office for Democratic Institutions and Human Rights

OEF Operation Enduring Freedom

OMON Special Purpose Mobile Unit (Russian: Otriad Mobilnyi Osobogo Naznacheniia)

OSCE Organization for Security and Cooperation in Europe

PCIA Polish Center for International Aid

PRDP Pamir Relief and Development Programme

PRSP Poverty Reduction Strategy Paper

PRSs Poverty Reduction Strategies

RCS Red Crescent Society

RUBOP Tajik Regional Department for Combating Organized Crime

SADUM Spiritual Administration of the Muslims of Central Asia and Kazakhstan

SAPs Structural Adjustment Policies

SCISPM State Committee on Investments and State Property Management

SCO Swiss Cooperation Office

SDA Swiss Development Agency

SIDA Swedish International Development Cooperation Agency

SUDVO Social Union for the Development of Village Organizations

TACIS Technical Assistance for the Commonwealth of Independent States

TCRA Tajik Committee for Religious Affairs

TIKA Turkish International Cooperation and Development Agency

UN United Nations 
UNDP United Nations Development Programme

UNESCO United Nations Educational, Scientific and Cultural Organization

UNMOT United Nations Mission of Observers in Tajikistan

UNWFP United Nations World Food Programme

USAID United States Agency for International Development

USSR Union of Soviet Socialist Republics

UTO United Tajik Opposition

VO Village Organization (Tajik: Tashkiloti Dehoti)

VOP Village Organization Programme

WAMY World Assembly of Muslim Youth

WB World Bank

WML World Muslim League

WUA Water Users Association

ZAGS Record of Civil Status Act (Russian: Zapis Actov Grazhdanskogo Sostoianiia) 



\section{Glossary}

This glossary does not include all of the terms and phrases of foreign origin found within the text. Only the most important terms have been listed here. In the case of most other terms, their meanings have been explained within the text itself.

adab - traditional norms and customs

adat (odat) - customary law, custom

ak-suyak/ok-suyak (white bone) - a kind of aristocracy

aloykhona (a house of fire) - in some mountainous regions it serves as a place for meetings or hosting guests but also for performing rituals and prayers

aqsaqal/aqsaqol (white beard) - elderly man, with white hair

aryk - a water canal

avlod (also other terms) - an ethno-territorial community among the Tajiks/Uzbeks bibi otun (also other terms) - female religious leader

chaykhona - a Central Asian tea-house

dehot/deha - village

fatwa - an opinion issued by an Islamic scholar

galcha - a term for 'highlanders' used in the past

gashtak/gap (also other terms) - networks based on obligation and reciprocity prin-

ciples, also gatherings

guzar/kucha - a side street, a part of a quarter

hashar/ashar/assar - collective work

haus - an artificial water storage tank

hukumat - district/regional authorities

imam/imom - traditional meaning: a person who leads prayers

ishan/ishon (also other terms) - respected religious leader, usually within a Sufi group; descendants of ishons inherit a high social status from their ancestors Ismailism - one of the branches of Shia Islam recognizing seven Imams jamoa $(t)$ /jamomat - community, groups, such as neighbourhoods, groups of colleagues or friends, also gatherings, networking, etc. 
jamoati shahrak and jamoati dehot - municipalities in the towns (shahrak) and villages (dehot) in Tajikistan

kalonikhona - the head of the household

kaloniavlod - the head of an avlod

khodim (also other terms) - traditional women's representative in a mahalla

khutbah/khutba - a sermon in a mosque

kolkhoz - a collective farm during the Soviet period

Komsomol -Young Communist League, Communist Party youth organization

kuhistoni - highlander

madrasa - Islamic school

mahalla/guzar (also other terms) - a traditional urban settlement among sedentary

populations in Central Asia

mahalla committee - a primary semi-official authority in a community/village

majlis - a local communal gathering

mazar/mazor (also other terms) - a holy shrine or tomb

mehmonkhona - a house/room for guests

mirob - a person responsible for water distribution

$m u f t i$ - a Muslim scholar, an expert on Islamic doctrine

muysafed - see aqsaqal

mullah/mullo - a Muslim religious functionary

namaz/namoz/salat - a prayer

nisba - here, genealogy, a line of ancestors going back up to seven generations

nohiya - see raion

oblast - a region (province) in the USSR and post-Soviet region

Perestroika - reconstruction, a program of restructuration of the Soviet economic

and political system started in the mid-1980s

poykor - a deputy of the rais mahalla, a helper

qadi/qozi - a shiaria judge

qalandarkhona - see kalonikhona

qara-suyak (black bone) - a lower social class (opposite to white bone)

qawm - see avlod

qishloq - village

raisi guzar - the head of a side street in a mahalla, sometimes the head of a quarter

raisi mahalla - the head of a mahalla/quarter

Rastokhez - a Tajik political movement

raion - a district in the USSR and post-Soviet region

ruh - a soul, being, ghost, or essence

sayid - a reputed descendant of Prophet Muhammad

sardori kucha - the head of a side street in a mahalla

sart - a term associated with the sedentary population in Central Asia

selsovet - a local Soviet administrative organ

shajaranoma - genealogy, genealogical book

shiaria/shiariah/shariah - Muslim code of law 
shirk - the sin of practising idolatry or polytheism

shura/shuro - council

shuroi mashvarat/muysafedon/shuroi aqsaqal - a council of elders

sovkhoz - a state-owned farm during the Soviet period

Sufi-a Muslim mystic

sunna - the body of traditional social and legal customs and practices in Islam

tawhid - monotheism

toy - life-cycle celebrations, feast

umma/khalqiyat/omma - the universal community of Islam, encompassing all believers

vakil - a representative of a mahalla to a jamoat, also the deputy of the rais mahalla viloyat - see oblast

waqf/vaqf - Islamic religious land, property, etc., with a protected status used as an endowment fund

zakat/zakot - Islamic taxation

ziyofat - gathering, welcoming guests, hosting people in one's home 




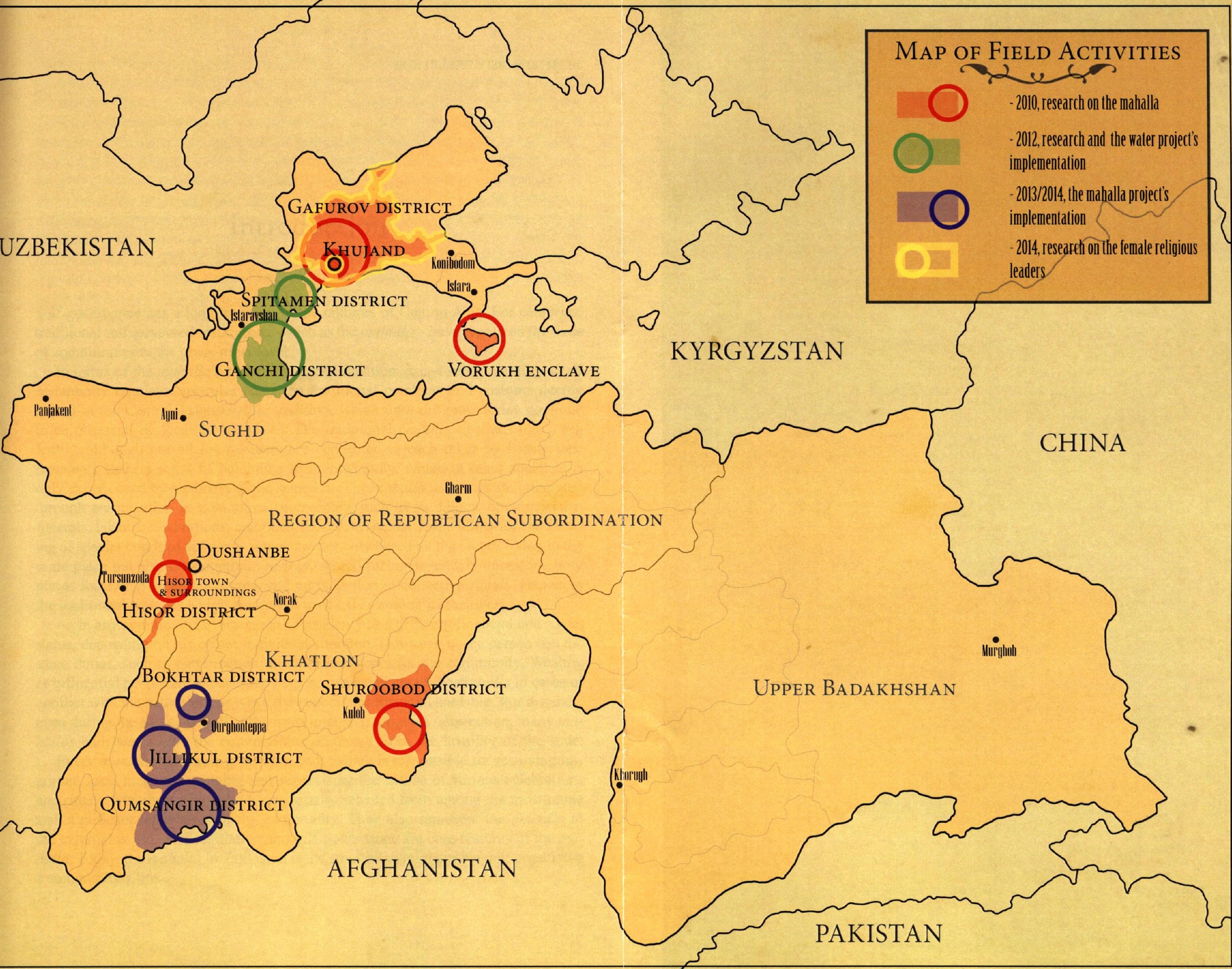






\section{Introduction}

Self-governance has a long tradition in the cultures of Central Asia. For centuries, traditional self-governed institutions - such as the mahalla - have regulated the lives of communities at the grass-roots level.

In terms of the mahalla's traditional social function, it is a self-governing small community regulated by rules based on traditional practices and customs deeply rooted in the Central Asian Islamic tradition, which until the present day continue to be observed by local communities. The traditional mahalla operates like a big family, although not all its members are connected to each other by family ties. Residents share a sense of belonging to a collectivity, which in other societies is only experienced by members of the same kin. The mahalla members are integrated through participation in communal ceremonies, such as weddings, circumcisions, funerals, Islamic celebrations, and other life-cycle rituals. These allow for the forming of special bonds of solidarity which are not only based on the fact of living in the same place but also on a common history, shared real or legendary ancestors, holy places located in a particular area, and participation in collective rituals. Hence, in the traditional mahalla a high amount of trust exists among its members.

As in any community, every mahalla resident has a different financial and social status, depending on his or her individual situation. However, every person has the same duties, such as participation in collective works for the community. Wealthy or influential people are expected to help poorer members of the mahalla in cases of conflict with the authorities or when they encounter financial hardship. For instance, even during the Soviet period of the most intensive religious persecution, many mahallas had imams who the communities protected from the hostility of the state.

Every mahalla has a self-governing body which is responsible for resolving important local matters, arranging and supervising the course of various celebrations and rituals. Members of this body are usually selected from among the most noble and significant inhabitants of the community. They also represent the mahalla to the external world. Self-regulation and self-governance are core features of the $m a-$ halla. Today, the mahalla in Tajikistan is the smallest administrative unit organizing a community's life. 
The transformation introduced by the Soviet Union influenced the entire pattern of the existing institutions; it changed the modes of production (for example, by abolishing guilds and the introduction of the kolkhoz system), as well as having an impact on the traditional structure of the communities. Nevertheless, the mahalla continued to play an important role as regards the preservation of traditional practices and Islamic tradition.

In the aftermath of the collapse of the Union of Soviet Socialist Republics (USSR) and during the turmoil of the civil war in Tajikistan, when state institutions ceased to function, in some places the mahalla provided a basis for fundamental social order at the local level. Other communities, however, were destroyed and decentralized. Subsequent to the end of the war, during the period of the post-conflict reconstruction of the country marked by the dissolution of the system of collective farms and introduction of unfair land reforms, as well as by the further collapse of the infrastructure and public services, the mahalla as a social organization has also undergone transformation. Unemployment and mass migration to other countries of mainly the male part of the population have influenced the mahalla's traditional structure and institutions, resulting in changing relationships within the existing social groups in connection to divisions based on gender, age and levels of income.

Meanwhile, despite the fact that the mahalla is a traditional form of Central Asian self-government at the local level, when the law on local self-governance was drafted in 1994 the mahalla was not included as a formal actor under state legislation. Conversely, in neighbouring Uzbekistan, the mahalla was incorporated into the legislative system at the beginning of the 1990s. Only recently, the Tajik government has attempted to integrate the mahalla into the state system by enacting "The Law on Public Self-Initiative Bodies" (Russian: Zakon ob Organakh Obshchestvennoi Samodeiatelnosti) in 2008, which in practice signifies that the mahalla will function as the smallest administrative unit of the state. While in urban centres the implementation of the new law is more likely to be achieved, the continuing weakness of the state hinders the progress of reforms in rural communities. Despite initial optimism about the new legislation, it evokes many questions, particularly in terms of the nature of the future relationship between the mahalla and state administration, but also regarding other issues related to local development.

Interest in the mahalla is not exclusively limited to Tajik state administration. The end of the cold war and the emergence of a new geopolitical order drastically altered the balance of power in a manner favourable to the West, with the USA holding a dominant position. Consequently, Western influence also spread to the region of Central Asia. At the core of Western interests was the idea of implementing the rules of a market economy in order to incorporate the new states into the global economic system. Ideologically, this is expressed through the doctrine of liberal democracy and in various associated concepts, such as civil society - in this context understood as a third element, as a link between the state and the market. The role of emissary of Western ideology in the region of the former Soviet bloc was assumed by international organizations, which became active in Tajikistan during the civil war. 
Despite the fact, however, that civil society is associated with cooperation among different social actors and institutions, when donors first appeared on the scene, most development agencies perceived the mahalla as a symbol of the restoration of national traditions and as an administrative unit of the government. Thus, the mahalla was seen as an institution which was both typically Central Asian and Soviet, an institution that could hamper or corrupt development projects (Abramson 2000). Some scholars, for example Boboyorov (2003) as quoted by Buxton, Earle and Giffen (2005: 27), even while considering the mahalla as an entity which could potentially be included within the group of civil society institutions, expressed the opinion that international NGOs should avoid working with mahalla committees since they were part of the conservative tradition and were closely related to the central authorities; therefore, promoting them could foster top-down power relations and even increase state control.

With time, the mahalla became 'popular' in development discourse, with some scholars and development workers advocating the mahalla as "a historical example of effective Tajik local self-governance" (Freizer 2004: 18). Buxton, Earle and Giffen indicated that increasingly, analysts of civil society in non-Western contexts acknowledged the need to re-define the concept of civil society, incorporating the idea of a 'traditional' or 'communal' civil society, arguing that traditional networks and indigenous institutions are deeply embedded in society and cannot be disregarded when working with local communities. Moreover, traditional and communal forms of social organization are more relevant to a definition of civil society in nonWestern contexts (2005: 54). "Traditional institutions shape the local organization, while leadership structures within the community and their functional roles ensure compliance with the rules, norms and beliefs on the part of the populace" (Kendie and Guri 2006: 333). Consequently, the benefit of having local communities take an active role in development projects involves people's abilities to incorporate ideas arising out of their actual life situation into the design of projects and into their implementation (Ibidem).

Subsequently, some organizations became interested in the mahalla as a traditional social institution whose rules can be incorporated into development projects based on participatory approaches - a concept which emerged as a response to modernization theories.' This was further conceptualized by Robert Chambers who defined the mainstream of the practical dimensions of participatory development. Jennings (2000: 1) summarizes Chambers's approach, ${ }^{2}$ according to which it is of

Modernization theories are within the mainstream of Western policies implemented in developing countries after the Second World War, based mainly on Western experiences from the colonial period, repeating the pattern of a top-down relationship between the center (the West) and the periphery (post-colonial countries).

2 Jennings (2000) is referring to Chambers's text entitled Participatory Development as . Vew. Paradigm: The Transition of Development Professionalism. a conference paper presented at the Community Based Reintegration and Rehabilitation in Post-Conflict Settings Conference. Washington: DC Kabeınba. 
paramount importance in the development process to change the unequal relationship between the 'haves' and 'have-nots'. The poor should be enabled to take matters into their own hands. This bottom-up approach is based on the principle that members of a community are the best source of information and have the best knowledge of their own real needs.

Since the 1970s, this concept has been widely accepted by development agencies, such as the World Bank, CIDA, USAID, IRDP, as well as by some NGOs. There is a belief that participatory practices address local needs in a more appropriate way and are generally more applicable to local populations than are traditional development approaches.

As far as Central Asia is concerned, all the main donors underline the need to take a participatory approach when assessing and facilitating participatory community planning to enable people to address social and economic problems (Buxton, Earle and Giffen 2005: 114). Different projects include elements of participatory methods aimed at increasing people's involvement in project implementation. Some organizations, such as the Aga Khan Development Network (AKDN), have even advocated designing an appropriate regulatory framework to make cooperation between communities and donors easier. This finally resulted in the enactment of the above-mentioned law. Consequently, Article 3 (6) of the new law states that a "body of public self-initiative (mahalla), in accordance with the laws of the Republic of Tajikistan, may cooperate with government, NGOs and international organizations working in Tajikistan to address social issues" (Law 2008).

However, the concept of participatory development has been increasingly criticized by both practitioners and theorists of development. First of all, there are some suggestions of 'a tyranny of participation', meaning that 'participatory' approaches are in many cases used to legitimize external intervention, and therefore to pursue donor interests rather than to facilitate the development of local communities. Also, the instrumental character of this method has been questioned. Local knowledge is modified and adjusted to the scheme of a project, which is based more on the projections of the designers of a certain programme rather than being a response to local needs. The means of participation is often determined by the organizational procedures, ideologies and cultures of the agencies involved. Furthermore, in some cases, participation can encourage inequalities within the group, creating a 'tyranny of the group' (Hauschildt and Lybæk 2006: 9). This issue is analysed in detail on the basis of particular examples in Chapters 4 and 5 .

A further contention has been voiced concerning the increase of social capital in communities by assisting them to create institutions at the community level. While there is no doubt that in such cases participation is beneficial, the risk exists, however, that only certain groups will profit from the creation of new networks while others will be excluded. As Hauschildt and Lybæk claim "the group obtains an excessive amount of public benefits or reaps the benefits of a natural resource at the expense of others and/or of long-term sustainability" (2006: 10). Consequently, social capital is weak in terms of development policy if it is not concentrated 
on the needs of the most vulnerable groups and does not pay enough attention to how wealth is distributed.

Lastly, it is essential to develop social capital at both the micro and macro levels, and to link them by including all social actors in the participatory process. Subsequently, if development projects aim at putting a long-term sustainable strategy in place, at a certain point in time international agencies should pass all responsibility over to the state with which the people participating in their own development will interact (Hauschildt and Lybæk 2006: 10).

In spite of the above doubts, the participatory approach is a strategy which allows for cooperation with local communities, as well as for the inclusion of various local practices and institutions into the development process. However, as Williams suggests, this method should not assume a predetermined outcome, and should simultaneously accept the unintended consequences of interactions with communities, both positive and negative (2004: 565-66).

Within this study, I will examine the various policies which have emerged in post-communist Tajikistan targeted at the traditional social organization of the mahalla. The main issues considered here are the nature of the current transformation of the mahalla in the context of the interplay of various approaches and practices with regard to Tajik state policy, various concepts of local development introduced by the aid agencies, as well as the socio-economic changes within the country.

Three main questions are of particular interest to this study. Firstly, the relationship between the mahalla and state administration represented at the local level by the jamoat (municipality) is discussed. I will provide insights into the legal basis of this relationship as well as into its practical implications. Secondly, an analysis is conducted of the complex and sometimes contradictory approaches of donors toward local development in the context of adopting elements of traditional self-government into the tenets of development strategies. The last issue applies to various socioeconomic factors related to the chaotic reforms introduced in order to transform the country from a central economy to a market economy, which resulted in a failed transition, a redistribution of wealth among the already privileged groups, an increase in poverty and labour migration, consequently establishing a change in the relationships and structures within the communities.

In the first section of the book, an introduction and a description of the methodology is presented, which is followed by the second section made up of seven chapters containing an explanation of various aspects related to the main thread of the study. Chapter 1 presents some basic information about the history of Tajikistan, with special attention paid to the period from the $19^{\text {th }}$ up to the $21^{\text {st }}$ centuries, especially focusing on the civil war. The second part of Chapter I provides an overview of the activities of the main intemational donors in Tajikistan, and some basic information on the socio-economic development of the country after the dissolution of the USSR. In Chapter 2, I provide a theoretical background for understanding the traditional social networks and groups in Tajikistan, including the mahalla community and its institutions. Chapter 3 focuses on the legal framework of the jamoat and inahalla, 
as well as on the practical dilemmas related to its implementation. This chapter also deals with state policies in relation to religion and their influence on the mahalla. The focus of Chapter 4 are the mainstream development policies implemented in the region of the former Soviet bloc, including Tajikistan, with special emphasis on the concept of civil society and the development of the third sector in Tajikistan. The following part of Chapter 4 explores ways in which donors incorporate particular aspects of what they view as 'traditional' civil society into development projects and what the potential implications of these approaches are for mahalla communities.

Finally, Chapters 5, 6 and 7 present three empirical cases. In Chapter 5, I examine the concept of Village Organizations (VOs) as 'new mahallas', a long-term project initiated by the Mountain Societies Development Support Programme (MSDSP), a local organization established by the Aga Khan Development Network (AKDN). The case study is located in a very specific environment, i.e. the poor Shuroobod district located in the mountainous part of the Khatlon region. In Chapter 6, I look at the Tajik enclave of Vorukh, which is situated within the borders of Kyrgyzstan (in the Batken district) but which administratively belongs to the Tajik Isfara district. The main issue of interest will be the relationship between the local administration (jamoat), the former kolkhoz, and a new actor - the Jamoat Resource Centre (JRC) - initiated by the United Nations Development Programme (UNDP). Another significant question in this chapter is the role of the externally-financed JRC in linking the jamoat with local communities. Chapter 7 describes the story of the development project targeting the development of mahalla committees as implemented by the Polish Centre for International Aid in partnership with the Tajik NGO Mehrangez. The project proposal was based on my research and conclusions reached during my work for the NGO sector, as well as on the experience gained by Mehrangez during their cooperation with local communities. The pilot project was implemented from March to November 2013 in the area of Kurgan Tyube (Khatlon region) in the Jillikul, Qumsangir and Bokhtar districts, and included ten villages. In 2013, I was the coordinator for the project on the Polish side. In March 2014, the second edition of the project was launched, entitled "Supporting local communities in rural areas in Tajikistan", with five more communities invited to cooperate. At present, I am working as a consultant for the project.

Within the framework of this study, I suggest that since each community develops its own practices and hierarchies, it is difficult to define one fixed pattern for mahalla organizations. Consequently, all theoretical conceptualizations of donors concerning how to efficiently cooperate with communities should be carefully verified in practice within a particular community. Various strategies will not bring the desired results if they are not adjusted to the particular encountered conditions. Donors should work out mechanisms which will not stand in contradiction with the traditions and practices of the communities, even if the latter are not in line with the ideological concepts widely accepted by the Westem system of values. Of course, this requires a high degree of flexibility, in-depth knowledge of local conditions and very close cooperation with local communities based on mutual trust. This is espe- 
cially difficult in Tajikistan, considering that the new government policies in relation to the mahalla do not reinforce the capacity of this social organization (despite what is officially stated) but instead bind it to the state. Consequently, the top-down relationship is retained, strongly limiting the mahalla's traditional ability to regulate itself. Finally, this leads to over-bureaucratization of this social organization which has been redefined as the lowest unit of state administration with decreased potential for social self-governance. Moreover, the state has shifted part of its responsibilities to communities and international organizations, but at the same time it reinforces control over the society. 



\section{Methodology and Stages of Data Collection}

The presented analysis is based on my various work experience in Tajikistan between 2010 and 2014. I used anthropological methods of research with participant observation as my main technique. I participated in rituals, communal gatherings and celebrations as well as observing people during their everyday activities. I also conducted interviews and observed focus groups, organized for the purpose of conducting research and implementing NGO projects, to gather detailed information and in order to gain knowledge regarding the structure and organization of the communities. Another source of information were the seminars and workshops organized within the framework of NGO projects. In this case, I had the opportunity to observe the communities' representatives in a dynamic environment requiring teamwork, acting spontaneously and expressing opinions on various issues regarding local development and relationships within and outside the particular community. My knowledge was further supplemented during the observation of process implementation of small initiatives by the communities participating in the NGO project.

The first part of my study was conducted within a project entitled "The relationship between self-governments and informal traditional institutions, and international and local NGOs in Tajikistan". The idea behind the project was developed as a result of my interest in the cooperation between traditional institutions and NGOs aimed at improving local development. The research team was led by Professor Stanislaw Zapaśnik of the Institute of Applied Social Studies, University of Warsaw, with the participation of Mariusz Marszewski, Ph.D. from the Institute of Eastern Studies, Adam Mickiewicz University of Poznan, and myself as researcher and originator of the project. A field study was conducted from June to September 2010 in Tajikistan in the following areas: the region of Republican Subordination (the central part of the country), particularly in the Hisor district, the Shuroobod district in the Khatlon region next to the Afghan border, and the Sughd region in the northern part of the country, where special attention was paid to the Ghafurov district adjacent to the city of Khujand, and the Isfara district with emphasis on the enclave of Vorukh. Addi- 
tional information was gathered in the cities of Dushanbe and Khujand. The research report was written in Polish and for a short time it was published on the website of the Institute of Applied Social Sciences at the University of Warsaw. In this book, I use the part of the report I wrote myself; specifically, information about the activities of international organizations in Tajikistan, as well as concerning the relationship between the local jamoat administration and the mahalla in terms of both its legal aspects and practical implications.

In total, the study covered 10 jamoats, while in-depth research was conducted in 4 of them. Interviews were conducted with employees of 15 local and international organizations, 30 representatives of the local authorities, and many mahalla authorities and residents. These conversations were mainly of an informal character, and were often conducted while observing people during particular activities. I lived in the houses of community members, where I had the opportunity to take part in formal and informal gatherings, religious rituals and celebrations, which expanded my knowledge and ability to understand communal practices and rituals. I also participated in seminars and other meetings coordinated by international organizations. In July 2010 , my colleagues and I also managed to arrange one four-hour-long informal workshop for the representatives of two mahallas in the Hisor district on the subject of formulating project proposals for donors. This spontaneously arranged gathering was for me an invaluable source of information regarding the methods of launching independent initiatives by mahalla communities and further became a nucleus for writing a project proposal regarding the development of mahalla committees. Subsequently, one focus group was organized with the participation of eight women in a mahalla located in the Ghafurov district not far from the city of Khujand. The focus group was mainly concerned with the issue of the mahalla authorities and the decision-making process.

The main language of all the conducted interviews was Russian, while the focus group with women was conducted in the Tajik language and it was translated to me by a local female NGO leader. During the gatherings and celebrations in which I participated, most of the conversations were carried out in the Tajik language translated for me when necessary by friends. In 2010, I spent about four months altogether in Tajikistan, from June to September.

More research was carried out in 2012 during my work as volunteer and consultant for the project "Increasing access to potable water in the Ferghana Valley through technical and institutional support to Drinking Water Users Committees (Kyrgyzstan and Tajikistan)" implemented by the Polish NGO the East European Democratic Centre (EEDC) in partnership with the Kyrgyz NGO Water Alliance, in the Spitamen and Ganchi districts located within the Sughd region. I spent one and a half months in the Spitamen and Ganchi districts (Sughd region). My main task was to examine how Drinking Water Users Committees (DWUCs), which were based on the mahalla structures in the villages where I was working, function. Consequently, I had the opportunity to observe some aspects of the interaction between mahalla leaders and the new structure (DWUCs), as well as their cooperation with external actors, such as 
the Polish NGO EEDC and the Kyrgyz NGO Water Alliance. My role as a consultant who acted on behalf of a social organization legitimated my presence in the villages. This situation allowed me to observe the communities and to discuss various topics which otherwise would have been difficult to broach, including some sensitive issues, such as the relationship between communities and the jamoat. I also participated in various meetings with a number of the community leaders, officials, NGO workers, and other people. During this period, I lived in the village, in the house of one of the local elite members. The gathered data was also used in the Polish-language book entitled Gdzie jest ta woda? Dostęp do wody w kontekście problematyki rozwojowej regionu Azji Centralnej [Where is the water? Access to water in the context of the social development of Central Asia], written in cooperation with Agnieszka Makowska and published by the EEDC (Cieślewska and Makowska 2012).

As mentioned above, from 2013 onwards, I worked within the frameworks of a social project aimed at the development of mahalla committees in three districts of the Khatlon region: Jillikul, Qumsangir and Bokhtar. During my stay in Tajikistan in 2013, I lived in Bokhtar, in the office of our local partner, working with the communities on a daily basis, participating in the fifteen focus groups organized at the beginning of the project, as well as taking part in a number of seminars, monitoring activities, meetings and gatherings with community leaders. Simultaneously to conducting my work as project coordinator, I managed to collect ethnographic data concerning the communities with which we cooperated. Subsequently, in 2014 , I became a consultant for the second edition of this project. During the two stages of the project, in 2013 and 2014, I also met a number of representatives of local administrations and foreign and local aid workers, which provided me with additional knowledge regarding the underpinnings of relationships between various social actors in the rural areas in Tajikistan.

Lastly, in 2014, I spent three months in the northern part of the country in order to conduct research on the social role of women religious leaders. ${ }^{3}$ This experience provided me with the opportunity to observe practices and rituals related to religion and religious figures, and their function within communities.

In addition to information gathered during fieldwork and the NGO projects, I also refer to my various experiences working for the NGO sector in different countries of the former Soviet bloc between 2006 and 2012, in order to provide insight into some of the mechanisms and ideologies of international assistance which have been implemented in that region.

For the purpose of this work, I also investigated various academic sources written by Russian, Polish and Central Asian scholars, as well as Western academics and researchers. The reports of international organizations, including the internal re-

The project was entitled "The social role of women religious authorities in Central Asia in Ferghana Valley (Tajikistan and Kyrgyzstan)" , funded by the Polish National Science Centre ivithin the framework of the post-doctoral fellowship “Fuga 2", decision number EC-2013/08/S/ HS1/00205. 
ports of the PCIA, press articles and documents issued by the Tajik state have also been used as sources of additional information about the relevant topics discussed in this book.

The main problem in researching a topic like the mahalla stems from a scarcity of in-depth analyses which would bring us closer to understanding the complex issues connected to Tajik traditional institutions. The existing Russian or Soviet ethnographic sources are only partly updated by current research mainly but not exclusively conducted by Western scholars or people who are affiliated with Western academic institutions. Despite many interesting and valuable studies, the collected data only provides a fragmentary account of the situation and further research is needed to investigate current changes within the social structure which have resulted in the transformation of the communal institutions and practices.

Another challenge involved in conducting field studies in Tajikistan is related to the general low level of trust among Tajik people towards those not belonging to their own kinship/network group. The extraordinary hospitality of people in Tajikistan is unquestionable. However, simultaneously, there is a strong cultural block against discussing internal affairs with people from the outside, especially foreigners. Successful research, therefore, depends not only on asking well-formulated questions or attentive observation, but also sensitivity to various gestures and seemingly insignificant signals. Perhaps the most important issue is connected to gaining the trust of key informants, which can be built only gradually, by showing respect for Tajik culture, customs and traditions, as well as by developing long-standing relationships.

Another aspect related to trust is that people frequently perceive a researcher as someone who is linked with the secret service, since invigilation was part of the Soviet system, and conceivably this could still pose a real danger. Accordingly, the collection of some data, especially regarding communities and their institutions, can evoke suspicion and commentary. For this reason, as previously mentioned, my participation in various NGO activities was very useful, since the questions I asked were justified by the circumstances. Another source of suspicion and mistrust in relation to a foreign researcher is related to the current government propaganda regarding the coloured revolutions, which have supposedly been imported to Tajikistan from abroad.

All these factors have influenced my research process. I quickly learnt that not everything should be asked in a direct manner and frequently the more effective method is to obtain information by using ambiguous expressions. Consequently, it is difficult to work on the basis of a particular questionnaire prepared in advance within the framework of a strictly scheduled interview. Sometimes conversations took a few minutes, an hour, half a day or even longer, or else certain information was obtained spontaneously. In other cases, a few conversations are needed in order to exhaust a topic. Everything depends on the circumstances and the individual approach to a particular person. Despite all these limitations, thanks to many Tajik, Uzbek and Polish friends as well as my various co-workers I collected a lot of data which allowed me to write this book. 
Therefore, many initial assumptions and hypotheses had to be verified when confronted with reality. Accordingly, my study on the mahalla does not exhaust the debate on the complex relationships between communal organization, the state and other actors in Tajikistan, but only provides a basis for further discussions and investigations.

Most of the interviews were conducted by me mainly in the Russian language, which I know to an extent allowing me to communicate freely and to undertake any subject. The conversations with representatives of international organizations were conducted in English. During the seminars, meetings, rituals or ceremonies I attended, the Tajik and Uzbek languages were the main ones in use, partially translated for me into Russian, but in some situations I also communicated independently in Tajik. Additionally, I possess a basic knowledge of Arabic, which is particularly helpful when interpreting religious terminology.

As regards the methods of research employed, in his paper "The Goals of Development", Samuel P. Huntington presented a severe critique of the entire achievement of social science theories concerning the development of countries outside the circle of Western culture. He indicates that all these theories failed both as forecasting instruments and as tools of government policy because none of them took into account the role of culture as an important factor in the development of societies. Both the very concept of development and its objectives as prescribed by social science and politicians are drawn from the experience of the West.

Due not only to Huntington's authority as a scholar, but also to the convincing arguments he presents in his essay "The Goals of Development", many readers realized the need to develop a medium-range theory in the social sciences which would take into account culture as a factor in social change. To date, no such relevant theory has been developed. For this reason, while conducting research in Tajikistan, I tried to avoid distorting Tajik culture in my description of it by not referring to any particular theory as well as by conducting the research using methodological principles from anthropology, the first of which was the principle of methodological relativism. This principle discourages describing the institutions and patterns of behaviour within an investigated society according to the concepts which function in the culture of the researcher. Over the many years of various contacts with non-European cultures, I could not help but notice that the analytical categories of Western science do not appropriately describe the social processes and conditions functioning in nonWestern cultures, and my research and work in Tajikistan only confirmed this belief.

Another methodological principle I tried to incorporate is formulated in Bronislaw Malinowski's principle of holism. It states that, in order to understand the meaning of an institution or behaviour in another culture, a researcher should include the widest possible range of phenomena of that culture. Compliance with this rule is a condition sine qua non for implementing the principle of relativism. Only by describing a phenomenon - even one which in some essential respects resembles phenomena known to us from our own past or contemporary culture - with reference to the greatest possible range of other phenomena in the culture being studied 
can we avoid interpreting it according to concepts developed by our own culture. As pointed out by Professor Zapaśnik in his lectures, the principle of holism provides a researcher with an essential criterion which enables him or her to avoid taking the creations of his or her own imagination as an accurate description of the reality being studied.

My study focuses mainly on mahallas in rural areas, with some references to the urban mahallas. Due to the nature of the relationship between the Tajik authorities and society, in this paper I do not specify (except where necessary) the names of the organizations which were interviewed, details on the jamoats and mahallas where the research was conducted, or the names of interlocutors.

\section{Notes on Transliteration}

Transliteration is a challenge when writing about Central Asia, mainly due to the various languages and alphabets used there during different periods. In pre-revolutionary Central Asia, most local languages were written using the Arabic script, which was changed at the beginning of the Soviet era to the Latin script and then to the Cyrillic. Many of the terms and names written in various languages differ slightly from their original form, since transferring certain words from the Arabic to the Cyrillic script was not always done very accurately. Another difficulty is that many terms are used interchangeably by various linguistic and ethnic groups, or in the case of some complex terms the languages as well as the grammatical structures are mixed. Consequently, in this book I have employed simplified forms of transcription for Asian languages, mainly Arabic, Tajik, Farsi, and Uzbek, as well as for Slavic European languages, such as Russian and Polish. I came to the decision to write only Polish surnames in their original form. 


\section{Chapter I \\ Tajikistan: a Quick Overview of the Country's Modern History and Development}

\section{I.I. Introduction to the History of Tajikistan}

Tajikistan is a landlocked country most of which is covered by mountains, glaciers, and isolated plateaus interspersed with inaccessible valleys. Presently, it borders A fghanistan to the south, Uzbekistan to the west, Kyrgyzstan to the north, and China to the east. Nature has always made living conditions difficult for residents of this area. The various parts of the country are separated from each other by mountain ranges divided by passes, largely closed as a result of snow for several months of the year. Even nowadays, communication between regions is sometimes disrupted or limited during the colder seasons. The mountainous landscape contributes to the isolation of the inhabitants of this area, as well as to their diversification into many groups speaking various dialects, and sometimes languages; groups which differ from one another in terms of their ethnicity, traditions and customs. Centuries of activities by various political powers have also left their mark on the heterogenic character of the region.

An in-depth discussion of the history of Tajikistan and Central Asia is beyond the scope of this work, especially considering that numerous historical sources provide detailed narrations regarding different issues related to past events. As a result, this subchapter deals only with selected aspects of the history of Tajikistan in the context of the political and socio-economic development of the region. Consequently, the main emphasis is placed on the period encompassing the $19^{\text {th }}$ century and the Soviet era in order to provide background for the further discussion of contemporary developments in Tajikistan and the changes which have taken place within the traditional institution of the mahalla. 
In the $19^{\text {th }}$ century, the territory of modern Tajikistan was formally part of two states: the Khanate of Kokand and the Emirate of Bukhara. As regards the territory of Bukhara, the topography of the land created a natural border dividing the Emirate into an eastern and a western part. The western part mainly consisted of steppeland, and sometimes a desert plain, with a height generally not exceeding 1000 feet above sea level and only some mountainous areas. In contrast, the former eastem part was covered by mountains of considerable height, belonging mostly to the Pamir and Alai ranges. Consequently, due to their geographical isolation and despite the formal protection of the Emirate of Bukhara, the small principalities located in the eastem part were governed by independent rulers and the Bukhara emir held only nominal power.

A separate part of modern Tajikistan is Badakhshan - remote, covered by high mountains and spread over an area belonging to three modem states: Tajikistan, Afghanistan and China. The region was absorbed by the Emirate of Bukhara relatively late, and only partially. The majority of the population of the region are Muslims of the Islamaili branch of Islam ${ }^{4}$ and speak eastern Iranian languages (which are not understood by other Tajiks). In the past, Sunni Muslims used to capture and sell inhabitants of Badakhshan into slavery, considering them kafirs (English: infidels). In the late $19^{\text {th }}$ century, part of Badakhshan came under the influence of the Russian state, which - at least formally - protected the autochthons from persecution and the predatory behaviour of the Bukhara. Apart from followers of Ismailism, the area is inhabited by Kyrgyz and other smaller groups who adhere to Sunni Islam.

The western part of Bukhara, which contains the famous cities of Samarkand and Bukhara, was for centuries a cultural hub of Central Asia, where Persian literature came into being and flourished together with the fine arts and science, and Islamic thought developed and spread across the entire Islamic world. The unique atmosphere of the cities of Westem Bukhara created excellent conditions for cross-cultural exchanges among people arriving here from various parts of Central Asia, Europe, the Middle East, India and China.

At the beginning of the $18^{\text {th }}$ century, the Khanate of Kokand emerged from the Bukhara Emirate. It included much of the fertile Ferghana Valley with its urban centres of Andijan, Osh, Ferghana, Namangan, and others. Despite some insignificant differences, the political and economic systems in both the Bukhara Emirate and the Kokand Khanate were similar, and only Russian colonization changed the situation in the region.

The Khanate Kokand was gradually weakened by internal unrest throughout the $19^{\text {th }}$ century, which was further inflamed by Bukhara and Russian incursions. Finally,

4 Ismailism is one of the branches of Shia Islam recognizing seven Imams. It was developed as a result of the conflict for power after the death of the sixth Imam - Jafar al-Sadiq. Ismailis believe the line of the Imamate ended with the son of Jafar al-Sadiq - Muhammad ibn Ismail. The doctrine of Ismailism developed under the influence of neo-Platonic and Gnostic philosophies. 
the Russians occupied the Khanate area, initially signing a peace treaty with the Khan of Kokand. Subsequently, due to a number of small rebellions against Russia and the generally unstable situation, the Duchy was abolished in 1876 and incorporated into the Turkistan Governor-Generalship (Lukawski 1996: 253-258).

At the same time, due to pressure put on Russia by the British Empire, the Bukhara Emirate managed to retain its autonomy, but formally lost the rights to formulate independent foreign policies. In terms of the administrative structure of the Bukhara Emirate, there were no major changes, and the old system of governance was maintained. Nevertheless, the intensification of relations with Russia resulted in an economic revival, especially in the western part of the Emirate; in the eastern part, the changes were less noticeable, and the region remained on the fringe of the development processes initiated in the region by the Tsarist government (Lukawski 1996: 253-258).

Once the Kokand Khanate was incorporated into the Turkistan Governor-Generalship, it became subject to the emerging capitalistic reforms introduced by the Russians. At the same time, its elite came under the influence of modern trends from Russia, Western Europe and Turkey. Consequently, a gradual change in economic structures, an increase in trade and cultural exchanges with Europe, the development of urban centres and finally an influx of people of Slavic origin, all affected the socio-economic transformation of the former Kokand, and also simultaneously contributed to an increase in the already-existing gap between this region and Eastern Bukhara (Lukawski 1996: 284-285). ${ }^{5}$

In the process of the formation of the Union of Soviet Socialist Republics (USSR), the region of Central Asia underwent various political changes. In the early period of revolutionary struggle, different centres of political power were established in the area. In 1918, the Turkestan Autonomous Soviet Socialist Republic (TASSR; initially, the Turkestan Socialist Federal Republic) was formed, and later, the Bukhara SSR (replacing the Khanate of Bukhara) and the Khoresm SSR. In 1924, the Uzbek SSR and the Turkmen SSR were founded, and the old political entities were soon abolished. Initially, the Tajik Autonomous Republic was created within the territory of the Uzbek SSR. The Kirgiz (later Kazakh) Autonomous Soviet Socialistic Republic

The Tajik SSR (within the USSR) consisted of a part of the former Kokand - the north part of the Tajik SSR named Leninabad (presently the Sughd region), and the southern part - former Eastern Bukhara. The difference in the level of development of the two entities, which deepened in the $19^{\text {th }}$ century, had an impact on the process of transformation initiated by the Soviet authorities after the October Revolution. It was found that Leninabad adapted much Inore easily to the standards of the new state than the southern part of the Republic. Even today, there is a visible difference in the level of development between the north and south parts of the country, and, with the exception of Dushanbe, the former Soviet Leninabad is still commonly considered the most advanced region of Tajikistan. It is also worth mentioning that the north and south of the country are separated from each other by high mountains, which also contributes to the fact that they are very diverse, not only in terms of economic and social developinent but culturally as well. 
and the Kara-Kirgiz (later Kirgiz) Autonomous Oblast were formed within the Russian Soviet Federative Socialist Republic (Russian: Rossiiskaia Sovetskaia Federativnaia Socialisticheskaia Respublika) to be finally reshaped into the Kyrgyz SSR and Kazakh SSR in 1936. The Tajik SSR was founded only in 1929, consisting of the territory of the former Eastern Bukhara Khanate, including the Gorno-Badakhshan Autonomous Oblast (GBAO); (which made up 44 per cent of the area of the Republic), and a part of the Ferghana Valley taken from the Uzbek SSR. Finally, the Soviet Constitution confirmed the status of the Tajik SSR in 1936 (Abazov 2008: maps $35,36,37,38)$. As a result of this political engineering, the area of Western Bukhara, together with the famous cultural centres populated by Tajiks, was included into the Uzbek SSR. In this way, the newly-created Tajik Republic consisted of Eastern Bukhara and part of the former Kokand Khanate. The Republic became a buffer zone which separated the USSR from Afghanistan, i.e. the British sphere of influence at that time. Nevertheless, at the beginning of Soviet rule, the region was still very unstable and the future of communism uncertain due to the activities of the anti-Soviet Basmachi movement, which was supported informally by the United Kingdom. ${ }^{6}$

The collectivization introduced in the 1930s brought a lot of changes to the Republic. First of all, large areas of the country were reoriented towards cotton cultivation, and this innovation strongly affected the water system, which was adapted to irrigate the cotton fields. New agricultural areas were often created on the territories of drained swamps or wetlands, and the resident autochthones were moved to these regions from different parts of the Republic, together with representatives of various nationalities, such as Russians, Belarusians, Ukrainians, Germans, and others. They were all settled in kolkhozes and sovkhozes, in many cases against their will. Additionally, private enterprises and family-businesses were liquidated or nationalized. Consequently, large-scale agricultural projects and mass industrialization were introduced, which brought about the development of light industry, food processing and heavy manufacturing. At the same time, an influx of a population of European origin was observed, mainly settling in the bigger industrial centres and employed in industry, construction and transport. Autochthons were less willing to work in these branches, being more inclined to undertake traditional occupations, such as in agriculture and services, as well as work in the fields of bureaucracy, academ$\mathrm{ia}$, the arts and in other non-productive spheres. Subsequently, much of the indigenous population settled in cities and towns, where they had more opportunities to intermingle with Europeans; thus, they were more exposed to Soviet/European

6 The Basmachi was a Central Asian social and military movement organized in early 1918 to oppose the Red Army. It consisted of various groups operating at that time and forming a loose coalition of local people, such as religious leaders, intellectuals and political leaders, who did not agree to be controlled by the Soviets. Though never unified, Basmachi forces were active in the Ferghana Valley as well as in the region around the Aral Sea until the 1930s. Poliakov believes that some Basmachis were active even as late as 1941 in the Ferghana Valley: (1992: 19). 
influences. At the same time, people who continued to live in rural areas followed a more traditional way of life, preserving many indigenous values and practices. Nevertheless, mandatory primary education resulted in a significant reduction in illiteracy in the whole area of Tajik SSR, while free medical care and the availability of other social services contributed to raising the standard of living, and in the long term this resulted in rapid population growth (Nourzhanov and Bleuer 2013: 61-69). According to Lubin (1991: 46) as quoted in Roche (2014: 45), the Tajik SSR had the highest fertility rate in the Soviet Union with an average of 6.6 children per family, with many families having more than seven children.

While the modemization of social and economic life in all probability met with relatively wide approval, the issue of the extent to which autochthonous residents of Tajik SSR accepted Soviet/European categories of thought and how these new ideas influenced indigenous culture remain open questions and require separate detailed research. The structure of the Soviet State was merged into the existing traditional social pattern, and traditional Tajik culture was re-defined within the concept of social, economic and political modernization introduced by the USSR. Nevertheless, various local relationships still existed within the Soviet model. Later, during the period of the USSR's decline, they resurfaced, taking on the form of a struggle between various interests groups, which finally led to an armed conflict.

\subsection{Ethno-Regional Identity and its Influence on the Contemporary Political Landscape of Tajikistan}

Since the 1990s, a considerable number of theories have been created to analyse the relationships among various ethno-regional groups in Tajikistan and their influence on the formation of political alliances after the USSR collapsed and during the civil war. Despite divergent ideas on this matter, there is little doubt that regional diversification contributed to the shaping of relationships in the country. However, to avoid oversimplifying the interrelations between different ethno-regional groups and in order to define the mechanisms of regional identification, we should first discuss the ethnic composition of Tajikistan, historically and at present.

According to the census from 2010, the main groups are as follows: Tajiks (84.3\% - including Pamir groups), Uzbeks (12.2\%), Russians (0.5\%), Kyrgyz $(0.8 \%)$, Lakais $(0.9 \%)$, Turkmen $(0.2 \%)$, Tatars $(0.1 \%)$, Kungrats $(0.5 \%)$, Arabs $(0.1 \%)$, Katagans $(0.1) \%$, Afghans $(0.1 \%)$, Yuz (0.1\%), Barlas $(0.1 \%)$, Durmans $(0,1 \%)$, as well as Gypsies, Ukrainians, Koreans, Germans, Armenians, Kazakhs, Azeris, Belarusians, Moldavians, Mingis, Georgians, Latvians, Lithuanians, and others (TAJSTAT 2012: 7-11).

The last twenty years have brought many changes in the ethnic makeup of Tajikistan, due to an outflow of people of European origin, such as Russians, 
Germans, Ukrainians, Belarusians, and others. In addition, many Tajiks, especially well-educated professionals, decided to migrate during the civil war. Presently, there is a considerable amount of labour migrants who have left the country due to a lack of employment opportunities. All these factors have had a significant impact on the current ethnic situation. Nevertheless, to understand the contemporary process affecting the ethnic composition of the country and its impact on interrelations between various ethno-regional groups, first of all it is necessary to discuss the traditional structure of the population as it was at the beginning of the $20^{\text {th }}$ century.

Prior to the October Revolution, the whole area of present-day Tajikistan was populated by many different groups, although they were classified according to ethnic or national origins only at the end of the $19^{\text {th }}$ century, by the Russians. Throughout Central Asia, the main divisions were based on lineage, either black- or whiteboned, ${ }^{7}$ religious affiliation (descendants of Muslim saints, ${ }^{8}$ Sunni, Shia, Ismaili, as well as various Sufi brotherhoods), economic and cultural factors (sedentary, nomadic and semi-nomadic, inhabitants of mountainous regions), regional (Bukhara, Samarkand, Khujand, Darvaz, etc.), and according to tribe or other kinship groups (Abashin 2004: 26).

A strong difference was visible between the sedentary and nomadic populations, connected also to a dual system of administration based on differences in lifestyles and interests. The two groups played different roles within the structures of the courts of the duchies and khanates. Some of the nomads who led a semi-nomadic way of life were closely bound to the ruling dynasties through ties of personal loyalty and military service (they served in the cavalry, organized according to tribal divisions). Other nomads were mainly cattle breeders who moved to higher areas during the summer and returned to low-lying pastures when the snow began falling.

The settled population comprised artisans, traders, and farmers, as well as influential notables, including part of the clergy. Although the mutual exchange of goods and services created a balance in relations, the two groups also competed with each other, with the sedentary people still remembering the hordes of nomads who had invaded the towns and villages of Mawarannahr.

7 In the past, Central Asian society was divided into two main classes. The upper class was named ak-suyak (also ok-suyak; English: white bone), which can be understood as 'blue blood" (a kind of aristocracy). The lower class was termed qara-suyak (English: black bone). These terms were used in different ways in various regions of Central Asia. For example, Tajiks and Uzbeks only used the term "white bone' to designate people who were believed to have sacred origins, while among the Kazakhs ak-suyak referred to people who were descendants of Genghis Khan. Turkmen used the word ovlyad to refer to people with sacred origins (see Abashin 2001).

* Formally, in Islam, there are no saints in the sense of the understanding of this term by Christians; however, the term w'ali/ plural aw'liy $a^{\prime}$ exists, meaning friends of Allah, in short people who possess a spiritual power/God's blessing (baraka), and in this way they are closer to God than common people. 
Despite the considerable role ethnic or national categories play today in the identity of the peoples of Central Asia, the traditional model of social relations still functions within the social structure.

As regards Tajikistan, Bushkov and Mikulskii (1996) proposed the following classification, based on years of ethnographic research conducted by different Russian and Soviet scholars. It should be borne in mind, however, that although this model is undoubtedly useful in describing the ethnic mosaic of Tajikistan, it does not exhaust the complicated subject of ethnicity in the country.

According to the above-mentioned authors, at the turn of the $19^{\text {th }}$ and $20^{\text {th }}$ centuries, various Tajik communities were living in the north part of the country - the Sughd region; some of them settled in isolated mountainous areas, such as, for example, the territory of Matcha (the upper part of the Zarafshan Valley), where the older members of the community speak the Eastern Persian language (not understood by other Tajiks), or the inhabitants of the Yagnobi Valley, who also used the Eastern Persian dialect (both groups are reputed to be direct descendants of the ancient inhabitants of Sogdiana), and others. Nevertheless, most of the Tajik population spoke dialects derived from the Western Persian language (modern Farsi). The north part of the country was also populated by different tribes speaking Turkic languages and considered to be Uzbeks and Turks divided into various groups and branches, such as Yuz, Barlas, Kipchaks, Karapches, and others. In addition, there were smaller groups of Kyrgyz and Kazakhs, and some Russians, as well as other groups (Bushkov and Mikulskii 1996).

As mentioned before, the territory of the modern Gorno-Badakhshan Autonomous Oblast was inhabited mainly by people who spoke eastern Iranian languages and followed Ismaili Islam, such as Shughni, Bartang, Roshani, Wakhis, Ishkashmi, Yazgulami and others, as well as some Kyrgyz (Sunni). South Tajikistan was divided into various principalities, such as Karategin, Darvaz, Hisor, Kuliab, Baldzhuan, Qabodiyon, Kurgan-Tyube, etc. The population of Karategin consists of Tajiks and Kyrgyz - the ichkilik group akin to the Kyrgyz of the South Ferghana. Among the residents of Darvaz, there were local Tajiks and migrants from Pamir, as well as other small groups of differing origin, including the Kyrgyz. The population of Baldzhuan was predominantly Tajik. The composition of the Kuliab region was slightly more complicated, and included migrants from the Pamir region, as well as Turkic-speaking tribes of differing origin, such as Lakais, Katagans, Mugols, Turks, Karluks, Merishkors, Mangits (36\% in total), groups of Arabs, as well as some groups from Afghanistan, including Hazars; the number of Tajiks in Kuliab was relatively small (only 23 per cent) (Bushkov and Mikulskii 1996). ${ }^{9}$

The ethnic composition of the Kurgan-Tyube and Qabodiyon principalities was also complicated; the majority of the population consisted of different Uzbek tribes, as well as Turkmens, Arabs and Hazars; in the Qabodiyon region, most of the residents were probably Uzbeks from various groups. Tajiks in Kurgan-Tyube composed

For more on the ethnic composition of South Tajikistan. see Karmy sheva 1976. 
only 3.2 per cent of the total population. A slightly higher number of Tajiks lived in Qabodiyon, although at the beginning of the century they constituted barely more than 10-13 per cent of all the residents (Bushkov and Mikulskii 1996).

In Hisor, $65 \%$ of the people were Tajiks, $34.3 \%$ - Uzbeks, $0.7 \%$ - Turkmen, Kyrgyz and Afghans. The Turkic-speaking tribes who lived in Hisor belonged to the Yuz, Lakai, Durman, Karluk, Musabazari, Kaltatai, Barlas and Kungrat tribes, as well as to some other groups. Many Uzbeks, Turkmen, Kyrgyz, Kazakhs, and others, living in Central Asia at that time led a nomadic or semi-nomadic way of life (Bushkov and Mikulskii 1996).

It should be mentioned that, at the beginning of the $20^{\text {th }}$ century, the term 'Tajik' was not widespread. The Iranian-speaking residents of the mountain areas were named galcha or kuhistoni (English: highlander). When talking about themselves, they used names derived from regional centres (Matchi, Kuliabi, etc.) or the names of small territorial communities (Karategini, Yagnobi). Additionally, part of the sedentary Turkic-speaking population, as well as the Iranian-speaking residents of the plains, were colloquially called sarts - a term associated with the sedentary way of life which is an economic and cultural rather than an ethnic classification (therefore, sart can be considered a social group). In the south of Tajikistan, an analogous concept was defined by the term chagatay, ${ }^{10}$ and by tat in Khorasan. The Turkicspeaking groups who came to Central Asia in the late $15^{\text {th }}$ and early $16^{\text {th }}$ centuries with Sheibani Khan were named Uzbeks. The tribes which came in the pre-Mongol and Mongol periods were called Turks. However, there are also some exceptions to this rule (see Chapter 7). Thus, at the beginning of the $20^{\text {th }}$ century, the territory of contemporary Tajikistan was inhabited by different groups of Iranian-speaking populations, some of them using various Eastem Iranian languages, as well as by numerous Turkic tribes of differing origin (Bushkov and Mikulskii 1996) and by Jews, Luli (Gypsies), Indians, Europeans, and others.

Later, in the Soviet period, primarily due to the shift in agricultural production towards cotton, many communities were moved from one place to another. Extended family networks were mainly settled together, but some larger ethno-regional groups were partially separated (some groups went back to their regions of origin shortly before and after the USSR collapsed). In some cases, the kolkhozes created were monoethnic, while others consisted of people of different nationalities, including Europeans.

10 In the beginning. the term chagatay only referred to the Turkic-Mongol population related to Chagatay-Khan (a son of Genghis Khan) and his descendants ( $13^{\text {th }}-14^{\text {th }}$ centuries), that is, the Turkic population of Mawarannahr and Eastern Khorasan. In about the $14^{\text {th }}$ century, due to the mutual relationships between Turkic nomads and settlers, a separate Chagatay 'culture' evolved, and Tajik speakers were also included into the Chagatay group. This Chagatay' historical and cultural formation was manifested in Chagatay languages and literature. After the dissolution of the Timurids state and, consequently, the Chagatay Ulus - the sedentary population of Turks and Tajiks still called themselves Chagatay as distinct from Uzbeks. In this way, the term chagatay expanded its initial meaning, and is comparable with the tenns sait and tat (Karmy sheva 1976: 125). 
In reality, due to the policy of integration under the common concept of the "New Soviet Man' (Russian: Novyi Sovetskyi Chelovek), which was to surpass national identity, religion or ethnicity, based on the Marxist ideal of internationalism, some people intermingled and were integrated into the Soviet system, considering USSR citizenship as one component of their identity. Nevertheless, the majority resisted assimilation, especially since the geography of Tajikistan, with some regions isolated as a result of high mountains, contributed to developing strong regional disparities. Members of particular communities often more closely identified with their region of origin and their kinship group than with any other kinds of group.

A person's identity can be mixed. Someone may identify him- or herself according to ethnic group/community/family/tribe affiliations, for example, someone might consider him-/herself to be an Uzbek of Kungrat origin living in the Vakhsh Valley, but if the same person visits Dushanbe, he will say that he comes from KurganTyube, and finally, outside Tajikistan, he will present him- or herself as an Uzbek of Tajik nationality (concept borrowed from Olimova 2002: 86-119, example from own research).

Consequently, in the aftermath of the thaw of Perestroika (English: Reconstruction), various identities emerged again or were re-defined under the new circumstances, especially since deteriorating living conditions during the late 1980s and early 90 s resulted in increasing competition over access to resources, leading to an escalation of tensions between different groups. In Tajikistan, despite the changes of the Soviet period, the traditional composition was largely preserved and its importance increased after the collapse of the USSR, affecting the pattern of relationships in the country, where regional, territorial and tribal identifications overlap and often prevail over any sense of national unity.

\section{I.3. Aggravation of Social Tensions before the Collapse of the USSR, and the Emergence of the Main Political Actors}

The political crisis in independent Tajikistan which led to the civil war was preceded by a series of ethnic and regional clashes which affected the development of the situation after the collapse of the USSR. One of the major factors that had an impact on the course of events was the deterioration in the living standards of a large part of the rural population due to the stagnation of the economy which had begun in the 1970s. At that time, the level of investment bottomed out, and the agricultural sector became increasingly inefficient. In addition, degradation of land and water caused by the Soviet authorities' mindless management of natural resources turned out to be an issue of high importance. Due to the high birthrate during the decades after the Second World War, since the 1970s rural areas had been suffering from underemployment that was not reflected in official Soviet statistics. Consequently, the lack 
of job opportunities resulted in many young people migrating to big cities, where in turn many of them experienced difficulties in integrating into the labour market. As mentioned above, shrinking resources accelerated competition among various actors, who even more than in the past tended to distribute wealth within their own groups (Akiner 2001: 26; Bushkov and Mikulskii 1996).

Matveeva, in her paper The Perils of Emerging Statehood: Civil War and State Reconstruction in Tajikistan (2009a), points out that the distribution of power within the Republic strongly contributed to increasing the frustration of excluded groups, and this was further expressed in the division between opposition and pro-government factions before and during the conflict. Consequently, most of the power in the Republic was held by Leninabad, traditionally considered the most developed part of the country, while the Kuliabis" and Hisoris (in the centre of the country) backed the North and were incorporated into the ruling establishment as of the 1970s. The Pamiris in turn were known for their intellectual interests and good education but also tended to work in the police structures. The most underrepresented group were people from Kurgan-Tyube and Gharm, with the latter dominating the informal sphere, gaining profit from the opportunities created by the kolkhoz economy. ${ }^{2}$ Despite holding significant assets, however, they were almost absent from government structures. Therefore, when appropriate conditions developed during Perestroika, they started to openly pronounce their grievances against the performance of the government (Matveeva 2009a: 7).

In addition, as a result of the war in Afghanistan, drugs and weapons were now available in the Republic. Additionally, during the same period, sports clubs specializing in martial arts took in some footloose youngsters, many of whom were prone to criminal behaviour (Akiner 2001: 26; Bushkov and Mikulskii 1996). All the above factors created good conditions for triggering tensions within society.

The most significant conflicts of that period, and which have in fact continued to cause tension up to the present day, took place along the border with the Kyrgyz SSR, in the region of North Isfara (Tajikistan) and Batken (Kyrgyzstan) between the Tajik and Kyrgyz populations. They were connected to competition over land and water (a detailed account of these events based on the example of the Vorukh enclave is provided in Chapter 6). Similar clashes took place between Uzbeks and Tajiks in Ganchi and Penjikent, and between Arabs and Karateginis in Kobadian. The authorities of all the republics blamed one another for the course of events, but in fact

"It should be mentioned that Kuliab was an oblast during the Soviet times and it was merged only in 1992 with the Kurgan-Tyube Oblast to create the Khatlon region. Presently, only the Kuliab district remains; nevertheless, commonly people associate residents of all districts formerly belonging to the Kuliab oblast with the regional group termed 'Kuliabis'.

12 It should be noted, however, that not only the Garmis were involved in such practices. By and large, to make additional income, a common occupation of many rural residents was to sell the agricultural surpluses at kolkhoz bazaars (Russian: kolkhoznye rynki) in Tajikistan or other parts of the USSR. Such activity was based on well-organized, informal regional groups (for more details, see Chapter 6). 
none of them managed to reach any form of reconciliation. In this way, initially local conflicts based on economic problems were transformed into ethnic clashes of a political nature, which, after the dissolution of the USSR, were further reshaped into never-ending international disputes over the demarcation of borders and access to natural resources (Akiner 2001: 26; Bushkov and Mikulskii 1996).

Yet another clash (in this case based on political motives) took place in Dushanbe in February 1990. There were widespread rumours that Armenian refugees from Azerbaijan were to be accommodated in flats initially allotted to residents of Dushanbe who had been waiting for them for a long time. The authorities of Dushanbe did not confirm this information officially, but there were disturbances in the form of anti-government demonstrations organized on the streets of Dushanbe, with people shouting slogans such as "Tajikistan for the Tajiks", "Remove the Armenians" or "Remove Mahkamov" (the first Secretary of the Central Committee of the Communist Party of the Tajik SSR of that time). A crowd consisting of a few thousand people clashed with government forces supported by military units and tanks. Finally, the authorities of the Republic began negotiations with a hastily formed 'People's Committee', and the situation was settled, but only after 22 people had been killed and 700 injured. The victims included Tajiks, Russians, and members of other nationalities. This triggered further changes which, in the period of the political reforms adopted by the Communist Party of the Soviet Union, and commonly associated with the Perestroika and Glasnost (English: openness), determined the course of events in the Republic (Akiner 2001: 26; Bushkov and Mikulskii 1996).

Earlier, in July 1989, a law "On Language" was passed which awarded Tajik the status of an official language; subsequently, in 1990-91, other important laws were adopted, such as the law "On the Sovereignty of the Tajik Soviet Socialist Republic", the law "On Freedom of Conscience and Religious Organizations", as well as the law "On Public Associations in the Tajik SSR", which considerably contributed to increasing the politicization of public life in Tajikistan. At the same time, new political movements were emerging and demanding political, economic, and social changes (Bushkov and Mikulskii 1996).

As regards secular organizations, the most important group founded during this period was Rastokhez (English: Revival), which later evolved into a nationwide political party. It gathered together people from different regions of Tajikistan, with a majority of its members coming from the educated families, united under slogans calling for democratization and the promotion of Tajik culture. Besides Rastokhez, there were other similar movements created all over the Republic. Despite the fact that most of these organizations did not last very long. they were an important phenomenon in terms of an awakening of political awareness among the Tajik population (Akiner 2001: 26; Bushkov and Mikulskii 1996). They will be discussed further in Chapter 4.

The second significant political actor which emerged at that time was Lal-i Badakhshan, founded by people from Badakhshan shortly before the demise of the USSR in 1991. Its main aims were to support political reforms and to serve the 
interests of the minority from Pamir. However, in spite of its democratic slogans, the representatives of Lal-i Badakhshan in fact sought to achieve greater independence for their region. The third political force of high importance was the Democratic Party of Tajikistan (DPT). It was established with the huge participation of members of Rastokhez, and also contributed to the discussion on the political future of the Tajik SSR. In the late 1980s and early 90s, the main political struggles in the Tajik SSR were related to the issues of freedom of speech and assembly, the right to form social organizations, matters related to Tajik culture, and they were mainly of an anti-Soviet nature. All these debates led to a polarization of different political forces into supporters and opponents of the Soviet political reforms (Akiner 2001: 26; Bushkov and Mikulskii 1996).

Besides the secular movements, there was another significant force which appeared at that time - the Islamic Rebirth Party of Tajikistan, ${ }^{13}$ which was initially a branch of the all-Union Islamic Renaissance Party founded in Astrakhan (Russia) in June 1990 (in fact, it was the first political party registered during Perestroika, and a political force which supported the idea of preserving the USSR). ${ }^{14}$ Despite the fact that the Russian party was officially recognized by Moscow, the Tajik branch was initially denied registration in Tajikistan. It was founded in October 1990 during an underground assembly, but formally registered only in November 1991, just before the USSR was officially dissolved. ${ }^{15}$ The ideological background of the IRP of Tajikistan was founded in the 1960s and 70s, when informal Islamic groups began to emerge in Tajikistan and elsewhere in Central Asia. As regards ideology, the IRP combines the notion of a renaissance of society on the basis of the social order proposed by Islam combined with the modern idea of social development. Nevertheless, the ideology of the Party was inspired by some ideas of the Egyptian Muslim Brotherhood. ${ }^{16}$ This further triggered allegations that the organization advocates establish-

1) It was later renamed the Islamic Renaissance Party of Tajikistan (IRPT); Tajik: Хизби Нахзати Исломии Точикистон Hizbi Nahzati Islomii Tojikiston, and is commonly referred to simply as the Islamic Renaissance Party (IRP).

It The party ceased to function at the beginning of the first Chechen war, when it was replaced by the Union of Muslims of Russia. After the assassination of its president, the Deputy of the State Duma, Nadirshah Khachilaiev, the Union of Muslims practically ceased to function. In 1991, during the presidential elections in Tajikistan, because of its pro-Soviet sympathies, the Russian branch backed Rahmon Nabiev, the former head of the Tajik Communist Party. Since the Tajik IRP endorsed the candidacy of Dawlat Khudanazarov (an Ismaili from Pamir). it finally detached itself from the Russian party, creating an independent organization (Roy 2000: 9; some information added).

is Initially, there was a plan to set up a single regional structure of the IRP in Central Asia, but the leaders of the Tajik branch protested against this idea because they did not want to be incorporated into one structure with Uzbeks and other Turkic representatives (Bushkov and Mikulskii 1996).

in One of the leaders of the organization was Said Abdullo Nuri, who based his ideas on the teachings of Hassan al Banna, as well as on those of the brothers Muhammad and Said al Qutb. Said Hawwa and Abulalo Mawdudi. 
ing a Muslim state. Currently, the Party's ideologists often focus on the issue of the purification of Tajik traditions in accordance with the principles of Islam, which is criticized by various social circles, including part of the intelligentsia. Some people believe that promoting Islamic orthodoxy leads to the devastation of Tajik tradition. ${ }^{17}$

At the same time, the IRP promotes the national interests of Tajikistan and equal participation of all political forces in state-building. Presently, the IRP is the only legally-operating Islamic party in Central Asia, with $8.2 \%$ of the seats in Parliament ( 2 seats out of 63 until the last election). ${ }^{18}$ Recently, the IRP has been gradually suppressed by the Tajik government. ${ }^{19}$

In terms of organizational structure, the IRP is based on traditional social institutions, such as the mahalla and the kinship group (avlod), as well as regional divisions merged with a typical party system, and is strongly rooted in networks of Muslim clergy, including some Sufi families. The IRP became a major promoter of the Islamic revival in the aftermath of the changing political atmosphere around Islam in the 1980s, which resulted in unofficial mosques being registered, many new religious facilities being opened, and the activities of Muslim religious leaders intensifying. The party gradually came to have a significant voice on the Tajik political scene, later creating an alliance with the DPT, Rastokhez, and Lal-i Badakhshan, supported by Gharmis and Pamiris, against the communist faction commonly associated with the elite from Leninabad and Kuliab. It should be emphasized, however, that strong regional divisions appeared only following the development of the conflict, when regional interests began to dominate over political ideology, creating what is commonly known as a war of political clans, which was mainly regional in nature (Bushkov and Mikulskii 1996).

17 Information based on research conducted in 2014.

18 Following parliamentary election which took place on $1^{\text {st }}$ March 2015, the IRP holds no seats in the Parliament.

I4 In 2014, Kabiri`s chairman, Saidumar Husaini, and some party activists were attacked by a group of people attempting to interrupt gatherings organized in Khorog and Kuliab. The IRP offices in the northern towns of Khujand, Penjikent, Isfara and Spitamen were closed by local authorities on the basis of the alleged reorganization of the territories. In addition, the office in Khujand was literally crushed by bulldozers. Moreover, in April 2014, the Sakhovat Market in the western part of Dushanbe which belonged to Kabiri's wife was taken over by the authorities to create 'a new sports centre' (Qayumarsi 2014). 


\section{I.4. The Civil War and its Repercussions}

The attempts made to hastily implement reforms did not bring any significant changes in the USSR, which was gradually plunging into chaos. In August 1991, the first election in the Tajik SSR was organized, and the First Secretary of the Tajik Communist Party, Qahhor Mahkamov, became president. On 9 September 1991, Tajikistan was officially declared an independent state, and, as is widely known, in December of the same year, the Union of Soviet Socialist Republics finally ceased to exist.

There are no reliable written sources of information on the course of events during the civil war due to the fact that most of the documented stories are biased towards one side or the other, and reports released by the international community give only a partial picture of the situation. The period before the conflict was preceded by increasing instability and a loss of control by the government over the situation in the new state, the creation of which was an unexpected as well as an unwelcome event for the ruling elite and most citizens. Matveeva indicates that "Tajiks, much like other citizens of the USSR, wanted more powers to be given at the local and national levels, and wished for pride of place for their national culture and identity, but did not want the end of the whole country and its political and economic system. Independence occurred too rapidly for the national authorities to be prepared for its future" (2009a: 16). Nearly one month before independence, Mahkamov's open support for the August coup d'état in Moscow undermined his position in Tajikistan and resulted in a further consolidation of the opposition and the intensification of anti-government riots. ${ }^{20}$

People demanded that the president resign and the organization of a new election, which eventually took place in November 1991 and was won by Rahmon Nabiev of Leninabadi, who had previously held the post of Party First Secretary (Akiner 2001: 35-36).

Following the power struggle between opposition and government forces, instability and riots spread to different parts of the country. Mutual hostility was widespread, and included kidnappings, murders and the persecution of opponents. Only the north part (Leninabad) was relatively stable. Simultaneously, Tajikistan experienced an unprecedented scale of emigration of its European population, mostly of Slavic origin. By the end of May 1992, about 300,000 Europeans had left Tajikistan (Akiner 2001: 34). About 700,000 refugees, mainly civilians, escaped to Afghanistan. In 1993, approximately 145,000 people went to Russia, and a similar number to other countries of Central Asia. Altogether, one sixth of the population (more than 778,000 people) fled the country (Matveeva 2009a: 17). Each region attempted to organize its own defence by hiring 'military staff'. Most of these local governments

2) The coup d'état attempt (19 $19^{\text {th }} 21^{\text {st }}$ August 1991) was organized by a group of members of the USSR government who opposed the reforms and wanted to take over power in the country from the current president, Mikhail Gorbachev, commonly called the August Putsch or August Coup. 
consisted of some former Soviet officials, heads of collective farms and various political leaders who had emerged during the conflict, including warlords controlling the local economy who were not subordinated to any power. Civilians suffered across the country, persecuted by armed bands claiming to represent this or that political option. Famine and poverty were widespread, humanitarian aid was inadequate, and a large part of it never reached the most vulnerable part of the population. In addition, infrastructure, factories, and other facilities fell into ruin. Officially, the conflict in Tajikistan resulted in 157,000 casualties, although unofficial sources put the death toll at up to 300,000 , which makes the Tajik civil war the bloodiest conflict in the CIS after the collapse of the USSR (Akiner 2001: 38; Bushkov and Mikulskii 1996; Matveeva 2009a: 2, 19).

One of the most ground-breaking moments of the conflict was the election of a new government under the leadership of Emomali Rahmonov (presently Rahmon) in November 1994, a little-known former director of a kolkhoz from Kuliab and member of the Central Committee of the Communist Party. Symbolically, the election of Rahmonov meant a shift of power from Leninabad to Kuliab (Akiner 2001: 38; Bushkov and Mikulskii 1996).

The first talks regarding national reconciliation took place in Moscow in April 1994 under the patronage of the United Nations." However, three years had to pass before a final document regarding a peace agreement was signed. A key role in launching the negotiations was played by the international community, though the interests and degree of involvement varied. The major players were Russia supported by the CIS countries, as well as Iran. Uzbekistan's stance was always controversial due to its engagement in the fighting on the official government side. There was also some commitment by Afghan leaders, with Shah Ahmad Massoud as a leading figure. The United Nations, which joined the negotiations at the request of both Tajik sides and a number of CIS countries, supervised the whole process. Finally, the General Agreement on the Establishment of Peace and National Accord in Tajikistan was signed in Moscow on 27 June 1997 with the assistance of a UN delegation, President Boris Elcin, and the then foreign minister of Iran, Kamal Kharazi. The peace treaty was rejected by some opposition groups until 2000 , since they had been excluded from the talks concerning conditions. On the basis of the agreement, 30 per cent of government posts should have been handed over to the opposition, but this promise was never fulfilled (Akiner 2001: 55).

Following the end of the war, Tajikistan was quite quickly brought to relative stability. However, despite the fact that under the peace agreement a number of former opposition figures initially filled important government posts, Rahmon went to many lengths, including murder, to replace them with people loyal to him. He

2 The UN Mission of Observers in Tajikistan was founded in January 1993 (UNMOT). Later. in 1994, it established offices in different parts of the country to inonitor the ceasefire. Following the signing of the 1997 general peace agreement, UNMOT's mandate was expanded to help monitor the implementation of the agreement. The mission tinished in 2000 ((INMO)T 2000). 
also managed to eliminate most of the warlords who had supported him during the conflict. It should also be noted that the civil war is a sort of taboo in Tajikistan. If the war is mentioned in the official media, it is almost always presented in a biased way as, for instance, in the movie entitled Innocent dead (Russian: Nevinnaia Smert, Tajik: Margi Begunoh) based on the novel by the Tajik writer Karomatullo Mirzoyev (Sarvinoz, 2013). Both reports and articles published in the press during the war have been removed from the public libraries, newspaper offices and other places; thus, they are difficult to obtain without special effort. To this day, many people are afraid to talk openly about the war, especially in a political context. ${ }^{22}$

Presently, Rahmon shares power mostly with Kuliabi, giving advantages to his compatriots from Dangara (the settlement from which he comes) and certain other allies. Rahmon has been governing Tajikistan, yet steadily losing a sense of reality, separating himself from the Tajik society - a society which is increasingly frustrated by failed reforms, rampant corruption, ubiquitous poverty and a lack of any real hope for improvement.

Some recent episodes, such as a fight between the government troops and mujo$h_{i d s^{23}}$ in the Rasht Valley, which took place in the autumn of 2010 , clearly show that the Rahmon government does not fully control the former opposition regions. The clash was related to an earlier breakout of 25 criminals from a Dushanbe prison in August of the same year. Soldiers were sent to the Rasht Valley to capture the fugitives reputedly hiding there, but were then confronted by mujohids. In spite of the common view that the conflict was the beginning of an uprising against the state or a rebellion organized by 'Islamists', it is more likely that the local commanders in Rasht decided to act independently against the incursion of Dushanbe forces into 'their territory'. However, the event was used by the government as a pretext to intensify the operation against Islam and the Islamic Renaissance Party (Heathershaw and Roche 2011: 1-2, 11-12, Shustov 2010).

In August 2010, almost in the same period, there was a suicide bomb attack on the building of the RUBOP - the regional department for combating organized crime in which 4 people were killed and at least 30 people injured. Two years later, on $24^{\text {th }}$ July 2012 , a special security operation was set up by the security forces in GBAO's capital, Khorog, targeted at former civil war field commanders and informal leaders. They were accused of killing a high-ranking security official as well as other crimes. As a result, a number of people died and were injured (some sources stated up to 200 casualties; see IPHR 2013). The next incident took place in Khorog, in May 2014, and was connected to a fight between alleged drug dealers and police, triggering a clash between angry residents and authorities which resulted in burning govemment buildings, including a police station, the prosecutor's office and a court build-

22 I based this information on the opinion of the Polish scholars Paulina Niechciał. PhD and Elżbieta Olzacka. PhD who have conducted research regarding Tajik culture in the 1990s.

23 .Mujohids. Mujahideens are Muslims who fight following the path set out by God (a term derived from the Arabic word jihad - to struggle). In this context, it signifies 'guerilla fighters'. 
ing (Trilling 2014). There are also other 'political trouble spots' in the country, such as the already mentioned border between the Tajik Isfara district and the Kyrgyz Batken district. To this day, no comprehensive solution for this long-term conflict over natural resources and the demarcation of boundary lines has been introduced.

All these episodes undermine the perception of Tajikistan as a stable place, showing that there are a lot of hidden tensions in the country. Opinions exist claiming that only the fact that most young men have migrated to Russia to find work has saved the country from another civil war.

\section{I.5. The Socio-Economic Situation in Tajikistan}

The Tajik SSR was always the most underdeveloped republic of the Soviet Union, and presently Tajikistan is the poorest country of the Commonwealth of Independent States. The civil war exacerbated the negative consequences of the shock triggered by the collapse of the USSR, damaging the already poor infrastructure and hampering industrial and agricultural production. Presently, the repercussions of the global economic crisis and local energy shortages have had a further negative impact on the ailing economy of the country. Tajikistan's peripheral location and the uncertain political situation of the whole of Central Asia are additional factors which make reforms difficult to implement. In addition, rigid regulations and rampant corruption discourage foreign companies from investing in Tajikistan..$^{24}$

Despite the fact that 49.8 per cent of the people live off agriculture, less than 7 per cent of the land is arable (CIA n.d.). The considerable share of the crops is cotton, although this brings wealth only to a small elite group. Apart from cotton, wheat and other cereals comprise a substantial proportion of the agricultural production. Other crops include potatoes, vegetables, and fruit, while dried fruits are a traditional export commodity. Mineral resources comprise silver, gold, uranium, and tungsten. The most important industry is a large aluminium plant; ${ }^{25}$ there are also hydropower facilities, and small factories for light industry and food processing.

Energy challenges represent one of the most important issues in the country. Tajikistan experiences regular shortages in its power supply, especially in the winter season, due to a long-standing disagreement with Uzbekistan and its own

24 Johan Engvall, in his book about corruption in Kyrgyzstan, expressed the opinion that the state was 'privatized', and it became a market where everything, including state posts, were for sale. In my opinion, a similar phenomenon has taken place in Tajikistan (see Hedfors 2011 for an interview ivith Engvall).

26 The entire aluminium production in Tajikistan is provided by the Tajik Aluminum Company Talco located in Tursun-Zade. It is one of the largest aluminum smelters in the post-Soviet area (with a production capacity of 512 thousand tons of aluminum per year). Talco is controlled by the family of President Rahmon (Falkowski 2009). 
neglected infrastructure. The country has the potential to make use of its water system as a source of energy. There are a few hydroelectric facilities, such as the largest hydroelectric dam in Nurek built in the 1970s. The Sangtuda-1 hydroelectric plant was constructed in 2009, largely financed by Russia. Recently, the smaller Sangtuda-2 was finished with partial Iranian investment. The most important project of the government of Tajikistan is the construction of the huge Roghun dam, which is planned to be the tallest dam in the world with enormous capacity. The project is causing a lot of controversy, with Uzbekistan arguing that the facility will limit water resources needed for Uzbek agriculture. Uzbekistan also indicates that the planned 335-metre-high dam will be located in a high-risk seismic zone, and, in the case of an earthquake, it could be calamitous for the whole region. The World Bank funded feasibility studies for the dam. According to the reports released in September 2014, which included technological and environmental assessments, the construction and operation of the dam are feasible under the condition of appropriate application of technical standards. In addition, downstream countries should also participate in the project (Garcés de Los Fayos 2014).

One of the most pressing problems in the country is endemic unemployment. The official rate of unemployment was 2.5 per cent in 2013, but real unemployment is much higher and difficult to estimate. To a large extent, the country is supported by remittances from migrants working primarily in Russia ( 93 per cent of all migrants). The total number of labour emigrants in 2010 was 791,618 , although the unofficial estimates are much higher. For about 60 per cent of the households in Tajikistan, such remittances make up more than half of their incomes, and in 2012 they composed 44 per cent of the country's GDP (UNDP 2014: 58).

Almost every sphere of state activity is neglected. Education, health care and the social system are all in appalling condition and require urgent reforms and investment. The current economic growth does not indicate sustainable development as almost half of the country's GDP is produced by the migrants' work, and the remittances they send are susceptible to fluctuations in the world market, especially in times of crisis. Additionally, even if some economic growth has been observed as compared to the period of war, it is still not enough to reduce poverty and improve the condition of the Tajik economy due to a lack of appropriate market mechanisms that are needed to develop the economy in the long term.

In fact, the state is incapable of fulfilling its basic duties towards its citizens, and the façade of order artificially maintained by the Rahmon regime might collapse at any time under the pressure of potential social tensions. Needless to say, over 20 years of poverty and uncertainty have taken their toll on society. Mass labour migration, mostly among males, has altered the social structure and relaxed family ties. A number of men have left their wives and children behind without any support, starting new families abroad..$^{26}$ Another side effect of migration is the spread of HIV

26 According to the State Migration Service in Dushanbe, there is an increasing number of female labour migrants ( 15 per cent of the total number of labour emigrants in Tajikistan in 
and other infectious diseases by returning migrants. In addition, an increase in drug use, prostitution and child labour are other negative results of the country's unsuccessful transformation.

Table 1. Basic Socio-Economic Indicators (after the World Bank [2013])

\begin{tabular}{|l|r|r|r|r|r|r|r|r|r|r|}
\hline \multicolumn{1}{|c|}{ Year } & 1992 & 1996 & 1997 & 1999 & 2001 & 2003 & 2005 & 2007 & 2010 & 2013 \\
\hline $\begin{array}{l}\text { GDP growth } \\
\text { annual \% }\end{array}$ & -29.0 & -16.7 & 1.7 & 3.7 & 10.2 & 11.0 & 6.7 & 7.8 & 6.5 & 7.4 \\
\hline $\begin{array}{l}\text { GDP per capita \$, } \\
\text { current USD }\end{array}$ & 346 & 178 & 155 & 178 & 172 & 238 & 340 & 523 & 740 & 1037 \\
\hline $\begin{array}{l}\text { Poverty ratio } \\
\text { at \$2 a day \% } \\
\text { population }\end{array}$ & - & - & - & 82.2 & - & 68.5 & - & 36.9 & - & - \\
\hline
\end{tabular}

\subsection{Humanitarian and Development Assistance in Tajikistan}

Since the civil war, development assistance has been noticeably present in Tajikistan, with some parts of the country dependent on aid. During the conflict, international organizations mainly provided humanitarian relief and participated in the peace process between the warring parties. In the post-war period, international donors have contributed to the country's reconstruction and development; nevertheless, after the war, the amount of aid decreased (in comparison with the period of the conflict), to be again accelerated in the aftermath of the events of 11 September 2001 and the war against terror launched in Afghanistan and worldwide. In the new geopolitical situation, one of the main reasons for the activities of the most important bilateral donors (with the exclusion of Japan) and the other international organizations in Tajikistan has been to prevent the spread of Islamic radicalism, potential armed conflicts, and drug trafficking (Wiegmann 2009: 31). Since Tajikistan borders Afghanistan, the country acts as a buffer zone for the war area. ${ }^{27}$ Moreover, most international donors are interested in retaining their influence in Central Asia in order to create a counterbalance to the policies of

2011). In comparison, in 2003, women made up only 6 per cent of this category of workers. Analysts believe that this phenomenon is related to divorces and consequent female poverty (Eurasianet 2012).

27 Since 2001, not only Tajikistan but the whole territory of Central Asia has played an important role for the American Operation Enduring Freedom (OEF; the official name used by the U.S. government for the War in A fghanistan) and the International Security Assistance Force (ISAF) in Afghanistan. Due to the international coalition withdrawing from Afghanistan in 2014, the question arises about the impact of the situation in Afghanistan on the Central 
Russia, ${ }^{28}$ Iran and China. Both China and Russia have their own considerable share in financing support for Tajikistan, although their goals and politics do not always coincide with those of Europe and the USA; with every party having its own reasons for maintaining links with Central Asia.

Tajikistan cooperates with donor countries, multilateral financial institutions, non-govermmental organizations (NGOs), foundations, and other entities. Donor countries also provided assistance to Tajikistan through bilateral inter-governmental agreements, as well as through governments, embassies, agencies for cooperation and development, banks and other government agencies. The most significant international institutions in Tajikistan are as follows: the Asian Development Bank (ADB), Islamic Development Bank, the World Bank group (WB), the International Monetary Fund (IMF), the European Bank for Reconstruction and Development (EBRD), the European Commission (EC), United Nations agencies, the Organization for Security and Cooperation in Europe (OSCE), the International Labor Organization (ILO), the International Organization for Migration (IOM), and the International Development Association (IDA). A considerable amount of aid is also provided by the governments of Germany, Switzerland, and the USA (operating through the US Agency for International Development (USAID) and other American organizations). Moreover, the Swedish International Development Cooperation Agency (SIDA), the Swiss Cooperation Office (SCO), the UK Department for International Development (DFID) and the Canadian International Development Agency (CIDA) and the Japan International Cooperation Agency (JICA) all contribute to Tajikistan's development. Other European countries - such as France, Italy, Norway or Poland - have also been operating in Tajikistan, mainly by means of various non-governmental organizations or embassies. There are also organizations from regions with Islamic roots which have a share in the develop-

Asian region. including Tajikistan. Part of the troops and equipment are transported through Tajikistan.

28 Russian assistance to Central Asia. including Tajikistan, is part of Russia`s policy in their traditional region of influence. At the beginning of Tajikistan's independence, Russian aid was of a military nature, while other aid was targeted mainly at people of Russian origin; Russia also wrote off the Tajik debt, valued at $300 \mathrm{mln}$ USD. Recently, Russia has contributed to international initiatives aimed at poverty reduction, including those of "The Group of Eight" (SCISPM 2011: 73). In 2009, the Eurasian Economic Community' (EAEC or EurAsEC) set up a new mechanism of assistance for humanitarian relief amounting to 10 billion USD. of which Russia s contribution makes up 7.5 billion. The main purpose of the fund is to provide assistance to poor countries according to the rules of the ODA. The first beneficiary of the fund is Tajikistan, which in 2010 received 63 million USD (from the Russian contribution) (Kaczmarski and Wierzbowska-Miazga 2011: 5). Russia also channels aid via Rossotrudnichestvo - the Federal Agency for CIS countries for compatriots living abroad and humanitarian cooperation. In addition, the country cooperates with international organizations, such as the WB and UN agencies. For example, Russia is the largest donor to the United Nations World Food Programme (UNWFP). In 2011, Russian assistance to Tajikistan amounted to $6.3 \%$ of all of its aid (ASIA PLUS 2012). 
ment assistance to the country, such as the Turkish Cooperation and Coordination Agency, the Aga Khan Group (AKG), the Red Crescent Society (RCS), and others. Aid is also provided directly by the governments of Iran and the Gulf countries. As already mentioned, China and Russia contribute to financing various projects, as does a new actor - India (SCISPM 2014, some information added).

Table 2. Tajikistan's ODA 1992-2012 (after the World Bank [2013]) ${ }^{29}$

\begin{tabular}{|c|c|c|c|}
\hline Year & $\begin{array}{c}\text { Net ODA } \\
\text { and official aid M.\$ }\end{array}$ & $\begin{array}{c}\text { Net ODA } \\
\text { \% of GNI }\end{array}$ & $\begin{array}{c}\text { ODA } \\
\text { per capita \$ }\end{array}$ \\
\hline 2012 & 393910 & 5.2 & 49 \\
\hline 2010 & 436560 & 7.8 & 57 \\
\hline 2007 & 222110 & 6.1 & 31 \\
\hline 2005 & 251500 & 11.3 & 37 \\
\hline 2003 & 148110 & 10.1 & 23 \\
\hline 2001 & 165300 & 16.0 & 26 \\
\hline 1999 & 122500 & 11.6 & 20 \\
\hline 1997 & 85940 & 9.6 & 14 \\
\hline 1996 & 103140 & 10,7 & 18 \\
\hline 1992 & 11860 & 0,6 & 2 \\
\hline
\end{tabular}

In $2013,40 \%$ of all aid facilitated the development of infrastructure sectors: Transport (27.2\%) and Energy (12.5\%). The Government Administration sector consumed $8.6 \%$ of the aid, while Agriculture and Irrigation received $7.4 \%$. Furthermore, Education took $8.4 \%$ of the available aid, and Health $-11.7 \%$. Social Welfare and Labour received 6.7\%; while Water, Sanitation and Housing and Management Services (HMS) $-6.5 \%$ of the total aid. The proportion of aid provided to the support and development of the Private Sector and Industry was 3.8\%, while more than 54\% of the total aid is provided through joint investment projects. It is worth mentioning the leading role of China as aid provider. The country mainly invests in the sectors of Transport (91.2\%) and Energy (8.8\%) (SCISPM 2013: 6, 18, 22). In contrast to the Western countries, China does not impose 'ideological' conditions, such as principles of democracy, human rights, women's rights, etc. Usually, the aid provided by China is in the form of grants and loans given in return for investments in a certain

According to the report "Real Aid Agenda for Making Aid Work", prepared by Action Aid International, a large proportion of assistance is 'phantom aid'. As a result, this aid never materializes for the poor countries, but instead is channeled through the aid system for other purposes. For example, in 2003 , only $39 \%$ of ODA in the global aid sy stem was spent on assistance to the poor. At least $61 \%$ of the total ODA was used to service debt, overstated administrative costs or technical assistance, transaction costs, fees charged for goods and services supplied from donor countries, immigration costs, as well as other activities unrelated to poverty reduction (Action Aid International 2005). 
sector. In addition, Chinese assistance is also delivered through international agencies such as, for example, the UNDP. Simultaneously, the decreasing role of the USA in providing aid is an indicator of the gradual withdrawal of this world power from Central Asia.

Since Tajikistan has moved from post-war reconstruction to long-term development, a State Committee on Investments and State Property Management has been established as a government body which focuses on coordinating foreign aid, managing public property, overseeing and monitoring corporatization and privatization processes, and providing support to entrepreneurial activities on behalf of the State. The other main coordination units include:

1) The Ministry of Economic Development and Trade, which participates in designing government decisions made in order to implement agreements signed with donors regarding funding foreign aid, and it also functions as an authorized body for the registration and management of humanitarian aid provided to Tajikistan;

2) The Ministry of Finance, which participates in negotiations with foreign creditors, manages public loan funds and decides about the contribution of the government of Tajikistan to joint venture projects with international donors;

3) The Development Coordination Council (DCC), which coordinates work between donors and the government. The heads of all major multilateral and bilateral development bodies are members of the DCC. However, it is not clear what the role of this additional coordination body is and how it influences the effective channelling of aid;

4) The Principals' Group, a coordination body of ambassadors who represent donors from a particular country.

In addition, there are also Development Forums organized from time to time to discuss various issues between the government, main donors, representatives of civil society and the private sector. Various aid sectors also organize different clusters or consultative meetings to oversee activities in their area of specialization. With the purpose to collect, store, update, process, analyse and present foreign-aid related information, in 2012 the Aid Information Management System (AIMS) was launched by SCISPM, with the support of the UNDP and DFID (SCISPM 2010; 2013; see Aminjanov, Kholmatov and Kataev 2009; also browse the following websites: http:// www.aideffectiveness.org; http://www.untj.org).

The general direction of government policy and the development policies of donors is determined by a key document: the National Development Strategy, which focuses on sustainable economic growth, expanding people's access to basic social services, and poverty reduction. The NDS is the main strategy for cooperation among development agencies, NGOs and business in implementing foreign aid projects. Tajikistan is currently in the final implementation stage of the NDS (up to 2015). The NDS includes a long-term strategy document for the development of Tajikistan as well as some medium-term development strategies. The Poverty Reduction Strat- 
egy Paper (PRSP) ${ }^{30}$ was included as part of the medium-term strategy until 2012 (SCISPM 2010: 13; 2013: 10). ${ }^{31}$

However, due to the scarcity of domestic and foreign investment resources to facilitate the country's development, achieving the objectives established in the strategy is dependent on donor funds. Both the NDS and PRSP have been designed on the basis of the recommendations of international institutions. Tajikistan's adoption and implementation of the strategy is a condition for receiving assistance in the form of grants and loans. The NDS determines the main direction of donor strategies, although it does not guarantee that donors will not implement their own policies, since they represent the interests of various political actors. Consequently, in spite of agreements, declarations and coordination efforts, each donor carries out its own strategy, implementing different concepts of development assistance, and there is no single institution which would be able to supervise the whole process of implementing these policies. Theoretically, organizations exchange experience and information as well as design common goals, but - in reality - aid is too decentralized, which negatively influences its effectiveness and puts limitations on how it is monitored (see Aminjanov, Kholmatov and Kataev 2009). This dilemma applies not only to the aid provided to Tajikistan but also to development assistance worldwide.

A serious impediment to the effective implementation of development assistance is corruption. It is particularly problematic when aid is channelled through state institutions. However, fund misallocation is also an issue of concern within IOs and local NGOs. One of the most famous stories, which received wide coverage in the foreign press and drew the attention of international donors, was a scandal in which the main actor was the National Bank of Tajikistan (NBT). Toward the end of 2007, the IMF was informed by the NBT that since 2001 reserves of the NBT had been used as collateral for foreign bank loans channelled to a private institution which financed the cotton sector. The sum of 310 million USD was quoted, of which 240 million had been transferred as a guarantee to banks in Kazakhstan and Germany to cover debts contracted by a private financial company - Credit-Invest which had been established to manage bad assets made by Agroinvestbank since 2001 (Crisis Group 2009: 13).

The fact that the NBT was involved in such an operation was investigated by the IMF. Subsequently, it turned out that the Central Bank reports submitted to the IMF were not consistent with the actual financial situation. By providing false data, Tajikistan was able to obtain loans and debt relief from the financial institutions. Consequently, this situation jeopardized the country's foreign exchange reserves,

30 Tajikistan has followed the PRS since 2000, developing its first strategy for the years 2002-2005. The second PRSP was designed for the period between 2007 and 2009 as a mid-term strategy for the country's long-term development plan as laid out in the National Developinent Strategy (NDS) for 2006-2015. The third PRSP was implemented in the years 2010-2012. (I will discuss the issue of the PRSP in detail in Chapter 4).

$\because$ To improve the effectiveness of international assistance in Tajikistan, the government and twelve donors signed the Joint Country Partnership Strategy (JCPS). 
especially its strategic reserves which, in the period when the story was disclosed, were only enough to cover two weeks of imports in the case of an emergency. Finally, the NBT Chairman, Murodali Alimardon, was dismissed, but oddly enough he was soon nominated to the post of Deputy Prime Minister responsible for agriculture (Crisis Group 2009: 13) .

According to Euroasia.net and Tjknews.com, an international audit made by Ernst \& Young revealed that Credit-Invest belongs to Mr Alimardon's family. He took about 850 million USD which, instead of the planned investment in agriculture, was used for other purposes. By the end of August 2008, Credit-Invest owed over 295 million USD to the NBT. In addition, the audit discovered that 221.5 million USD of the state funds that had been allocated from 2004-2007 for projects to facilitate the cotton industry had disappeared. There are estimates that finally at least 1.07 billion USD was used in non-transparent deals (about the annual revenue of the Tajik govermment in 2008; see Eurasianet 2009; Tjknews 2010). This extreme situation depicts the mechanisms of channelling aid in Tajikistan well, whereby development assistance is largely used to support the governmental elite. As a result, the country receives little of what is given on its development, and most citizens continue to live without hope that their situation will improve.

Out of these concerns arise the rules according to which donors determine their priorities in supporting a particular field. For example, one of the key areas of the NDS and PRSP is institution-building, which is undoubtedly important in the context of the transformation in Tajikistan. However, in my opinion, the way in which it is implemented leaves much to be desired. A lot of effort goes into establishing neu laws and regulations, but most of these run into structural and administrative difficulties when being put into practice, such as, for example, the laws on jamoats and mahallas, which are described in Chapter 3. It might also be the case that some programs, strategies and approaches are designed in other countries without reflection on and adjustment to another country's conditions (Aminjanov, Kholmatov and Kataev 2009: 32; Bliss 2013: 95; some information added).

Moreover, despite the considerable amount of aid provided to Tajikistan, the issue of its distribution raises many questions. Apart from the significant investment that has been put into Transport and Energy sectors by China as well as other countries, Western donors are primarily focused on the border regions, such as the frontier with Afghanistan: Badakhshan or the traditionally pro-governmental Khatlon, including Vakhsh Valley as well as some sensitive parts of the Ferghana Valley, Panjikent or the politically unpredictable Rasht Valley. Residents of some parts of these regions benefit from aid provided by non-governmental organizations and international institutions. Nevertheless, these are also the areas preferred by donors. It is worth noting that in some parts of the country where development assistance is certainly needed international organizations for unknown reasons have never appeared (for example, in some mountain villages in the Hisor district). ${ }^{32}$

$\therefore \quad$ My own field observations 2010-2014. 
It is difficult to explain the lack of donors in places where, since the USSR disappeared, there are almost no signs of investment or infrastructure reparation, poverty is rampant, and due to a lack of employment opportunities, most of the men migrate to Russia to find work. On the other hand, in some parts of the country donors are almost 'fighting' each other for beneficiaries, implementing similar types of projects though sometimes based on different concepts, such as, for example, those designed to resolve the conflict over water resources in the Ferghana Valley. ${ }^{33}$ Moreover, in many cases, assessments are done ad hoc; therefore, the projects implemented do not actually correspond to people's needs. In the opinion of Aminjanov, Kholmatov and Kataev (2009: 33-36), private NGOs - as executive agencies funded by either bilateral or multilateral agencies - do not make plans longer than one year ahead, with most of the projects targeting the achievement of quick results. Moreover, analytical and analysis-related work is conducted relatively infrequently since good quality research is time-consuming and expensive; also data is often difficult to obtain in Tajikistan.

As a result, beneficiaries are the subjects of various experiments which often contradict one another. Additionally, organizations prefer to work in areas where local communities have already had contact with international assistance. This makes project implementation much easier; therefore, the outcomes can be later reported to the donor without any complications. On the other hand, in many cases, vulnerable communities are ignored because organizations are afraid of the unexpected difficulties they might encounter in a new area. One more impediment for development organizations is the fact that they are obliged to spend money over a certain period of time within the framework of a project, which also negatively influences aid effectiveness. The rigid schedules set up by donors determine how a project is implemented. Emergency projects are notoriously carried out hastily, and sustainability is not the main goal. Donors rarely monitor the impact of a project after a few years have passed (Wiegmann 2009: 163; my own experience).

The next reservation is related to the monitoring of projects which frequently is superficial or carried out by people without relevant experience. Many experts hired by donors to carry out so called 'independent monitoring' have worked in the top-donor institutions but rarely in the field. Even if they possess impressive CVs or work and research experience gained in the major cities, such as Bishkek, Dushanbe or Almaty, their knowledge of the conditions of everyday life in Central Asia is poor; not to mention their frequent insufficient knowledge of Russian and the local languages, making it impossible to effectively communicate during evaluations conducted outside the big urban centres. Thus, often their opinions about a certain project are based on preconceived assumptions and stereotypes which have little in common with reality. Unfortunately, these improbable assessments influence donor strategies. Aminjanov, Kholmatov and Kataev indicate that there is a tendency for international consultants to be 'assigned' to a certain country, irrespective of the

For more details, see Bichsel 2009. 
area of their specialization, which leads to a 'migration' of experts from one project to another without properly taking into account their performance and experience (2009: 32).

Even when a project is successful, a given organization has no guarantee that it will be funded again, since donor policies are unpredictable. Obviously, such a situation does not assure the sustainability of NGO activities, which may not be prolonged because they do not receive funds for the continuation of their projects. Undoubtedly, one purpose behind the work of organizations is to reinforce and encourage local development, and after a certain period to allow beneficiaries to function independently, but in many cases, assistance is cut off not because it is not needed but because donors change their ideas about how funds should be allocated.

At this moment, in some parts of the country, international assistance has to some extent replaced the subsidies received by Tajikistan in Soviet times, but this is not a solution ensuring the country's development in the long run. Due to misallocation and corruption, a lot of donor funds are wasted. As the Crisis Group report points out, "until donors establish independent mechanisms to monitor the use of funds, publicize their internal evaluations of project effectiveness and government progress reports, and are prepared to withdraw support, financial mismanagement and theft will continue" (Crisis Group 2009: 4). Aid for Tajikistan bears a resemblance to that in Sub-Saharan Africa, where decades of intermational assistance have not brought any tangible benefits to the well-being of the region. In Chapter 4, I investigate development aid in the context of civil society and traditional institutions, and some mechanisms of aid delivery will be examined again in more detail.

It is needless to say that the last twenty-five years have brought significant changes for the whole region of the former USSR. For a few countries, such as Lithuania, Latvia, Estonia, Ukraine, Moldova and even the Russian Federation, Georgia, Armenia or Azerbaijan, the collapse of the USSR signified liberation from the shackles of the regime. However, for most of the newly-emerged Central Asian states, at least at the beginning, national sovereignty was an unexpected event and was associated with great uncertainty about the future of statehood. For Tajikistan, the first years of independence were a period of chaos and civil war. Due to scarce funds and enormous corruption, post-conflict reconstruction has been slow and ineffective. To this day, the transformation has not brought any tangible results; instead, from a peripheral but stable republic of the USSR, Tajikistan has been reshaped into one of the poorest countries in Asia. The model of development introduced by the Soviets has disappeared to be replaced by a system which can be described as a combination of pre-revolutionary feudalism, the last vestiges of the USSR, and an extreme version of neo-liberal capitalism. 


\section{Chapter 2}

\section{Traditional Social Networks and Groups, the Mahalla Community and its Institutions}

\section{2.r. Traditional Social Networks and Groups in Tajik Society}

Before turning specifically to an analysis of the origins and development of the mahalla in Tajikistan, it is necessary to explain the nature of the Tajik social structure most clearly manifested in family and kinship relations. Since the Tajik social system differs significantly from that of the West, an understanding of it is crucial to an analysis of traditional indigenous organizations such as the mahalla.

Prior to the October Revolution, the residents of Central Asia were divided into sedentary and nomadic populations (some groups led a semi-nomadic lifestyle). Most of the nomads inhabited the present territory of Kazakhstan, Kyrgyzstan and Turkmenistan, and they had developed a specific tribal system based on mythical and real kinship ties which were a part of larger tribal organizations. The sedentary population lived in most areas of present-day Uzbekistan, Tajikistan, and partly in South Kyrgyzstan. ${ }^{34}$ Contrary to the nomads, they were not part of a large tribal system, but they had their own social organization based on territorial bonds and kinship ties. At the beginning of the creation of the Soviet state and the modemization of Central Asia, the forced collectivization of nomads signified that they had to adopt a sedentary way of life, though this only partially influenced the existing relationships since many tribes were settled as a group, and thus the traditional tribal system was preserved. This situation fostered the merging of pre-revolutionary forms of social organization with the new Soviet system. Hence, even today, the traditional

it Some groups of nomads also lived within the territory of contemporary Uzbekistan, and South Tajikistan (former Eastern Bukhara). 
social organization has a great impact on the social structure of the native population of Central Asia.

In terms of traditional social organization, most Tajiks are divided into large, inseparable kinship groups. Diverse groups of the Iranian-speaking Tajik population use many different terms to denote the same concept of 'group'. Most often the word 'avlod' (Arabic: [pl.] children) is used, although the Yazgulami use the word 'qawm', the Shughni - 'gru', the Wakhis - 'tuhm', the Matcheni (the Upper Matcha) - 'heysh', and other mountain Tajiks - 'qaw'm/qabila', 'toyfa' and 'kynda', with some lowland Tajiks also using the word 'qawm'. All of these mean a social formation whose members derive their descent from the same (mythical or real) ancestor in the male line of the family, and which is based on kinship bonds and/or territorial relationships and is characterized by a strong identification with the group. Family members are exclusively men, their children and their sisters. Each member is expected to know their background, history and line of ancestors seven generations back (Bushkov and Mikulskii 1996). ${ }^{35}$

In the past, the most desirable pattern of relationships among the sedentary population (farmers and urban dwellers), not only in the area of contemporary Tajikistan but also in other parts of Central Asia, was endogamy. Marriage between cousins was not only widespread but even considered appropriate, whereas marriage between non-relatives was seen as a violation of social standards. Marriage with a member of the group who owned the same land was the most accepted pattern of relationships, since it encourages group solidarity and ensures greater control over group resources. Consequently, the practice of marriages between cousins along both opposite and parallel lines led to a situation in which all members of the group were closely related to each other (Jasiewicz 2004: 117; Zapaśnik n.d.). As a result of many changes, endogamy is less important today, although in some cases it still continues, for example in families of a noble origin such as among ishon, sayids.

It should be underlined that an avlod is viewed as a closely united group of both the living and their deceased relatives. It is based on the assumption that the spirits of ancestors always assist the living members of a group. The role of the avlod

35 Tajiks described this as shajaranoma, which means 'knowledge of genealogy', 'the genealogical book of a family.' Shajaranoma is carefully checked. especially by noble families before a decision is taken concerning their children's marriage or to legitimate someone's rights to certain assets, positions, or in other cases. Classical Islamic sources refer to this kind of relationship with the term nisba - 'noun of relation' - one of the component medieval Arabic proper names. It describes the relationship of the individual to a group. person, place, concept or thing. Inherited, the nisba links the individual to a group, such as a tribe. tribal subdivision. dynasty, family, eponymous ancestor, etc.; to a place, such as a country, region, city. village. quarter or street: or even to a nickname or profession. The nisba indicates which tribe someone belongs to, either as a result of his/her origin or through links of clientage. In such cases, tribal nisba consists of the genealogy of the tribe. In general, nisba is inherited from the father, although there are some exceptions. such as the female line of the family of the Prophet Muhamınad (Sublet 1995: 53-51). 
network is well illustrated by the Tajik proverb "If God leaves you - it is nothing! But if your ancestor leaves you, your life becomes meaningless!" (Bushkov and Mikulskii 1996). ${ }^{36}$

Formerly, kinship groups traditionally settled together in a village or settlement (rural or urban). Apart from household premises, all land belonged to the avlod. Nowadays, however, avlods frequently have no opportunity to live compactly, and the members settle in different places. However, according to my observation, even if members of the same avlod live in different regions of the country, they identify with their group. An avlod is divided into smaller units (extended families) living in the same household. These usually consist of three generations: grandparents, parents and children. In northern Tajikistan, the word 'tup' is used for the extended family. However, in some southern parts of the country the word 'avlod' describes an extended family which is part of a larger kinship group, a 'qawm', 'qabila' or 'heysh'. Basically, according to some interlocutors, a qawm is a larger group which at a certain stage incorporated avlods as well as some families of different origin; for example, with time a Tajik avlod could accept into its fold some Uzbek families which had settled on the territory of the avlod, mostly as a result of kinship gained through marriage ties. In this case, the mutual relations became more durable if they had been consolidated by the qawm network. At present, the nuclear family is also a group within the social structure, although it is usually part of the larger network (Bushkov and Mikulskii 1996, some information added). However, Jasiewicz (2004: 116-117) indicates (citing Sukhareva 1966) that even in the early $20^{\text {th }}$ century in Bukhara, the average family had five members (therefore, it was a small family); he further acknowledges that following social changes this tendency increased at least in bigger urban centres in Uzbekistan.

As far as the avlod is concerned, in those that are strong, there should always be a head of the group. I had the opportunity to listen to the story of one of our coworkers ( 57 years old, a former teacher), who became the chief of his avlod (Tajik: kaloniavlod, English: elder of avlod, also the Russian word vazhak is used), which originated from Istaravshan. This happened despite the fact that the members of his family lived in different places, including Dushanbe and Kurgan Tyube, and some of them occupied important posts, such as a minister or army general. My co-worker

36 In Central Asia, after death, the ruh (understood as 'the soul, being, ghost, or essence') is still related to the living, and has the power to affect the course of action in this world. Ruh can see. listen, feel emotions, and - most importantly - participate in the affairs of living relatives, who are expected to look after the ruh by perfonning certain rituals. It should be indicated that. during celebrations connected with death such as funerals and gatherings to commemorate an ancestor, his/her descendants - when talking about the deceased - use the plural form of the word, i.e. e(a)rvah, also anvohlar, which could further indicate that, in the collective consciousness of people, a human being cannot exist in separation from his/her family (for more on the subject of the soul in Central Asian cultures, see Zapaśnik 2006: 47-48). Many Tajik families perform a special celebration for the spirits of ancestors, involving reading prayers and sometimes cooking certain dishes every Thursday and Sunday evening. 
became the head of his group following the death of a former leader. The selection was made by the male members of the family at a meeting on the occasion of a wedding. According to his words, the family selected him because he is generally wellliked, people respect him, he has never refused to help people and he has listened to the problems of avlod members regardless of the social position they occupied. The fact that he became the leader of his avlod was further widely commented by our Tajik co-workers. ${ }^{37}$

In terms of the structure of the extended family, there should always be a family elder, the 'qalandarikhona' (English: head of the household) or 'kaloni khona' (English: big man of the household). The successor of the head of the household is the eldest son. However, in certain specific cases, one of the younger brothers can sometimes become the head of the household. Qalandarikhona represents the family to other people. He has the final say in all family matters and is responsible for the behaviour of the family members and their relations with the external world. He also assigns duties to other male relatives (Bushkov and Mikulskii 1996).

It is essential to point out that in the Tajik traditional social system the life of the individual is subordinated to various powers; therefore, informal authorities are just as important as formal authorities. In societies where there is a strict hierarchy which organizes the lives of their members, it is indisputable that a younger person should obey his or her elders. Even if there was consent for expressing one's own autonomy, a young person would never openly manifest it. In most cases, a person cannot follow her/his own desires, even in the most fundamental matters, such as the choice of a spouse, which is often a decision made by the parents (Zapaśnik n.d.). The hierarchy existing within the extended family is seen as an element of the natural unquestionable social order.

Research on extended kinship groups, such as the avlod/qawm, has always been very complicated due to the variable and ambiguous nature of such groups. For instance, in some cases, a particular kinship group absorbed smaller groups with a different origin than that of primal kinship, which - over the course of time - became part of the same group, creating a kind of community. In this way, a group comprises different units which are parts of the same network and which have access to political or economic assets. Also, a small number of avlods/qawms have been unified into bigger formations which extend beyond the territory of a particular avlod/qawm. In this way, such a group can comprise a complex set of work, family, political and other relationships, creating a phenomenon which is in the ethnography of Central Asia commonly called 'a clan'. ${ }^{38}$

37 On the basis of a personal conversation with this person, October 2014.

Since division into clans is very common in the descriptions of Central Asian societies, there is also a great deal of misunderstanding that has developed around this issue. In reality, clans are not units which are formally registered and structured, and so their formula is flexible and undefined. They can consist of various heterogeneous hierarchies - lower kin are connected to those more powerful, links and alliances are forged through marriage or various reciprocal favours, gashtak'gap networks, business and so forth; their members are bound by rational 
My work experience and field studies as well as some academic sources demonstrate that such family networks are still significant in the various regions of Tajikistan. However, there are also some signs of the weakening of these structures, especially in large urban centres. Not infrequently young people do not know their shajaranoma, or who exactly the members of their avlod are. In the opinion of Davydov (1969: 12), who conducted research on the social structure of the Tajik population in Afghanistan in the 1960s, the hypothesis about the dissolution of extended kinship groups was justified mostly in the case of the Tajiks who lived in the lowland areas, while the mountain Tajiks of Afghanistan still preserved a patronymic system of large families. Additionally, Rakhimov (1990: 63) points out that in Tajikistan, in the mountains and remote villages, family networks are more hermetic than in the cities, as is demonstrated by the descriptive terms used to identify family and neighbourly ties.

Indisputably, in Tajikistan, different historical and social circumstances have had an impact on the transformation of the avlod system. For instance, at the end of $19^{\text {th }}$ and the beginning of the $20^{\text {th }}$ centuries, owing to a famine caused by a population increase, a significant number of avlods began splitting up into smaller families. Frequently, however, these families resettled not far from their patrimonial lands (Bushkov and Mikulskii 1996).

Subsequent to the changes introduced by the Red Revolution, a different approach to social order was introduced. Transferring the land ownership from avlods and waqf to kolkhozes and sovkhozes, ${ }^{39}$ forced collectivization, resettlement of people, a change in the state structures and the introduction of communist ideology - all these factors strongly influenced local social relationships. Nevertheless, the traditional social organization showed a great ability to adapt to the new conditions. For instance, it was a common practice for kolkhozes to be created on the basis of previous avlod lands. In this way, the form of ownership was changed only formally, and the patronymic families still functioned as they had prior to the revolution, with the same hierarchical system within its structures.

Despite the current changes and the transformation of Tajik society, family networks which are still based on avlod/qawm structures remain the most important

(practical), and cultural ties. This interconnectedness of social. economic, and political relations and blurring of the public and private spheres is typical of clan/kin-based relationships (Collins 2006: 27-28, some information added). It is also worth pointing out that. due to the changes in the recent period, clan-based networks have been transformed; new alliances created, and new people have gained power and influence, bringing their own groups along with them (Akiner 2002: 172-173).

39 Waqf - a type of religious and charitable foundation, generally holding property but also sometimes farm animals, which provides income for purposes recommended by Islam. There are basically two ty pes of foundations: public (religious schools, hospitals, libraries. irrigation systems, bridges, etc.). and family foundations for the poor. Islamic law defines the conditions to be met by the founder (waqfir). It also defines the subject of donation (mauquf). the inain goal of the foundation and how a donation is to be implemented (Dziekan 2001: 359). 
basic social groups. $82 \%$ of the Tajik population and $46 \%$ of the Uzbeks belong to an avlod structure (in the case of Uzbeks, the avlod structure is characteristic only for communities which have lost their tribal divisions - Uzbeks who, prior to the Revolution, led a nomadic lifestyle are more likely to follow a tribal pattern of social organization; see Olimov and Olimova 2001, my own observations). In countries such as Tajikistan, which are characterized by a weak, unwieldy but also repressive system of governance, durable family bonds provide support in facing the daily difficulties of life.

The large kinship group is perceived as an integrated whole in relation to the external world. Consequently, the behaviour of each member is seen in the context of the entire family's performance. The achievements of an individual, as well as his or her failures or bad deeds, are the success of the whole group. In fact, space for individual development is often limited.

This system is not confined exclusively to Tajikistan but applies also to most nonWestern cultures. A person's high social status raises the prestige of the entire family and is expected to benefit all of its members, a system which also involves supporting less affluent relatives. Someone who is a reader at the University of Baku, the owner of a photographic agency in Riyadh or a project manager in an international organization in Dushanbe is expected to support his/her poorer cousins.

One disadvantage of this type of arrangement is that individual attitudes, values. preferences and aspirations are determined by what is sanctioned and approved collectively. In Western cultures, most people work for themselves or only for the benefit of their own nuclear family. A person is able to follow his or her individual choices. Certainly, the Western social system allows for more freedom and independence. However, whenever misfortune strikes, a person can rely only on a limited circle of people. In most non-Western social models, the individual is supported by the various members of his/her extended family. Obviously, this model has also changed, and there are cases in Tajikistan in which the elderly are abandoned by their children, but these are not frequent situations. Mostly, in traditional Central Asian families, the younger son is expected to remain with his parents to look after them in the autumn of their lives. For most representatives of Western/European cultures, this would be seen as uncomfortable and awkward.

As far as social structure is concerned, another issue which is difficult for Western/European people to understand is that, in the majority of cultures which follow a non-Western model of social relations, there is no universal code of ethical behaviour which would be equally applicable to all members of society. We assume $a$ priori that all good and bad deeds are subject to the same moral evaluation, irrespective of a person's social status and our relationship with him or her. Therefore, a sense of justice requires us to take appropriate measures against an individual, regardless of whether it is our cousin or a complete stranger. In contrast, in most societies based on kinship networks, a different system of values is adopted in relation to one's own family members or those of another network one belongs to than toward people from outside the network. When someone commits a wrong, his or her behaviour is 
judged and sanctioned by the group according to that person's position within the hierarchy, which largely determines the nature of any potential retribution. The most important issue is to what extent the misconduct affects the prestige of the whole group. A despicable act committed in relation to someone who functions inside local social networks is subject to harsh criticism, while the same deed committed against a stranger can be judged more leniently.

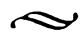

Difficulty in understanding this mechanism frequently results in the frustration of many Westerm people working for international institutions and organizations. They function outside any network of local relations, unless a long period of living within a given community and knowledge of the local environment allow them to develop appropriate bonds. In order to illustrate this phenomenon, I will refer to my own personal experience while working for a humanitarian organization in Chechnya.

The organization implemented two projects in Chechnya related to improving sewage infrastructure and the water supply. Due to the political situation, our office was located in Nazran, a former capital of the neighbouring Republic of Ingushetia. We employed a number of people, such as office workers, security guards, an accountant, and a driver. We were in the habit of taking money for office costs in cash and keeping it in cupboards next to our desks. Since there had never been a case of a theft in the office, the cupboards were unlocked. However, at some point, a relatively small amount of money began to disappear. When we noticed this, we started looking for the thief. After some time, unable to find the perpetrator, we asked for help from the head of the local FSB,$^{40}$ who was also the brother of one of our bodyguards. Both of them were members of a kinship network of the then president of the Republic of Ingushetia - Murat Ziazikov, a former KGB general. The FSB official proposed that we sprinkle some special powder on the money, which would be deposited on the hands of anyone touching the item and visible only under ultraviolet light, and that we always count the money at the end and at the beginning of the workday. We followed his advice and, after a few days, some money vanished once again. At that time, three of us were working in Grozny, and only one expatriate worker was present in the Nazran office. When our co-worker noticed that more money had disappeared, he told all the employees that they were not allowed to move from a particular room until the FSB chief arrived and checked everyone's hands. A young girl called Fariza (the name has been changed) turned out to be the thief; she had been hired a short time before at the recommendation of our secretary. She was immediately dismissed, although we did not report the theft to the police,

41) The Federal Security Service of the Russian Federation (FSB) (Russian: Federalnaia sluzhba bezopasnosti Rossiiskoi Federacii). During Soviet times, it was an agency of the Soviet Committee of State Security (KGB). 
since the FSB chief suggested that her case would be resolved informally among the families involved.

The atmosphere in the office was tense, and the most victimized person was our secretary, who had recommended the girl for work. The secretary seemed to feel guilty, since she had been working for our organization for many years. However, after a few days, while shopping at the local bazaar, we saw her walking with the dismissed girl; subsequently, suspicions grew. She was accused of having dealings with Fariza and her loyalty to her employer was questioned. All of the foreign workers were outraged by the secretary's behaviour, although the head of the mission, who was not experienced at that time with different cultural environments, did not allow us to speak with her about the situation. He tried to sort out the issue on his own, which only made things between the expats and the locals worse. Since I felt that the secretary did not deserve such treatment, I spoke with her informally, saying that I could imagine that this situation was also hard for her. She confirmed this and thanked me for understanding, though our relationship never really improved.

For all the foreign aid workers, the situation was difficult. They felt deceived and surrounded by locals whom they could not trust and who plotted against them. In Ingushetia, the unemployment rate stands at roughly $80 \%$, and so if any vacancy appears, it is provided to a member of the family network or is sold to someone informally for a predetermined amount of money. Working for a humanitarian organization is especially lucrative, since the wages there are higher than in the local job market. For this reason, it was obvious that Fariza was a member of the same network as our secretary, even if this was never directly expressed. The situation might have harmed their relationship on a personal level, but the process of resolving the issue was determined by a group decision. From this point of view, the grievances of the foreign workers against the secretary for maintaining personal contact with Fariza were overstated, and resulted from a misunderstanding of the local social relationships. The situation was intensified by the emotional involvement of the expats, which strongly influenced their judgment of the secretary's behaviour. Of course, the humanitarian organization played an important role as a service and job provider, even though it functioned at the edge of the local social relationships. However, the words of one of our Chechen employees, which I had the opportunity to hear on another occasion, can serve as an apt summary of the above case, "the organizations will stop working here at some point, but we will continue to live here together"."

Although Ingush and Chechen cultures differ from Tajik culture, the problemsolving mechanisms in relation to group members versus those from outside the group are similar. As my Tajik friend stated, "an issue is always settled differently within and outside of the avlod." 42

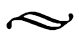

4 On the basis of a conversation with a Chechen employee. Nazran. Ingushetia, December 2006.

12 On the basis of a conversation with a Tajik friend. Warsaw. November 2010. 
Let us return to the main thread of this part of the paper, the communal/family system in Tajikistan. Needless to say, the social structure of Tajik society is different from the Western model, and all attempts to transform it will only have superficial effects. The kinship group - the avlod - determines a person's identity, and the extended family is the primary cell of this society. Conversely, in Western culture, the nuclear family is the smallest unit of social structure. An avlod community has a full range of life-support systems, from territorial to spiritual, cultural and ideological, and these shape social relationships.

Nevertheless, the changes over the last twenty years have also affected social structure. The unstable political situation, widespread poverty and labour migration have all had an impact on communal and kinship ties. The harsh conditions of daily life have cemented informal family networks, since the state possesses neither the power nor the willingness to provide adequate protection for its citizens. On the other hand, years of war and the problems in the ensuing reconstruction have encouraged various forms of predatory behaviour, including cases of people trafficking their own relatives (mostly women and children), and other forms of exploitation within the group (Olimova and Mamadzhanova 2006: 16, 34). Undoubtedly, in recent years the mechanisms which govern social relationships have undergone various transformations which have also affected communal organizations and kinship networks.

According to the report prepared by the Aga Khan Development Network entitled Civil Society Development in Tajikistan, "a consanguineous patrimonial group, this is the strongest traditional institution of informal authority in Tajik society" (Yusufbekov, Babajanov and Kuntuvdiy 2007: 18). It has endured to protect Tajiks against the worst calamities. For instance, during the civil war in 1992-1994, due to the almost total disintegration of the Tajik state structures in some regions, the avlod networks took over the role of the state and maintained fundamental social order. In addition, during the peace-making process, the role of family networks was crucial to conflict resolution. It is difficult to make any assumptions regarding the future development of this social institution or its role and function in the process of state building, but there is evidence that the avlod has demonstrated great flexibility in adapting to different conditions. "The cultural basis of these institutions gives them legitimacy, and this should be taken into account while looking for ways of involving people in management and development at the local level" (Yusufbekov, Babajanov and Kunturdiy 2007: 18).

In Central Asia, including Tajikistan, there are also other forms of communal institutions created to expand the ties of family members outside the circle of their close kin, based on age division (Tajik: piru-javon. English: old-young) and gender (Tajik: mardu-zan. English: men-women). In the past, there were from four to seven age classes which were linked to the human life cycle from early childhood to old age (Rakhimov 1990: 61,74). A peer-group was named katar, katarlar (TajikPersian) or tengkur, tenggur, tenggurlar (Uzbek), as well as hel (Tajik; English: group. composition). The word dawra (Tajik; English: circle, company) was also used. Men addressed each other using the word jura (Arabic; English: neighbour. 
also understood as friend), while for women the term chikon/dugona (Uzbek-Tajik; English: [girl]friend) was reserved ${ }^{43}$ The friends of a wife's husband as well as the husband's friends who belong to the same katar were called kurdas. The terms javon (Tajik), yosh (Uzbek), (English: young), miyonsolo (Tajik), (English: middle-aged men), aqsaqal (Uzbek), muysafed and pir (Tajik) (English: elderly) for men, kampir (Uzbek) for women describe the basic age classes. Members of a peer group were expected to help each other with domestic or field work, preparing for certain events, such as weddings, circumcision, house-building, and so forth (Rakhimov 1990: 57-61; Lobacheva 1989: 83). Among the members of the same peer group, there was a relatively similar pattern of relationships in terms of power and interactions with peers, although there was always a certain hierarchical division among people. The same etiquette was impossible in relation to a person who belonged to a different age group (Zapaśnik n.d.).

People who belonged to one peer group (within a community) established informal companionships. A person would usually join a group in early youth and stay within its folds until old age. These informal institutions were present at every level of society, interpenetrating family and neighbourhood relationships. Despite the fact that division into age classes applied to groups of both men and women, in the available ethnographic literature information regarding male social institutions predominates.

Various terms described the phenomenon of folk groups formed on the basis of age and territorial bonds, such as gap (Tajik; English: conversation, social contacts. exchanging ideas - the Ferghana Valley, Tashkent, Samarkand), gashtak (Tajik; English: a turn, in rotation, to give back in turn - a region of Tajikistan, some parts of the Ferghana Valley and other places); also tukma (Uzbek; English: contribution, collection - the Ferghana Valley), ziyofat (Tajik; English: hosting in a house - among Uzbeks as well as Tajiks), as well as other rarely-used words (Rakhimov 1990: 23-25). These social institutions continue to play an important function in terms of creating networks based on obligation and reciprocity principles. Their most tangible manifestation is expressed by the communal gatherings organized by a certain group, which are financed in turn by each member. ${ }^{44}$

Representatives of older generations remember that groups of men used to gather after the harvest during the autumn and winter time, though some meetings were also organized during the summer. Membership in a particular group was voluntary. Meetings were organized at private houses or in special buildings called mehmonkhonaloshkhona (Tajik; English: a guest-house, mostly in the lowlands) or

43 Rakhimov (1990: 63) points out that the term 'friend' was used mainly by the inhabitants of' the plains, while the mountain Tajiks called each other using kinship terms.

H Despite migration in recent times, due to the development of communication technologies, members of a certain peer group manage to keep in touch; for example, my Tajik friend who is currently living in Warsaw participates in the gap organized by his friends in Dushanbe online via Skype. 
aloykhona (Tajik; English: a house of fire - existing in some mountainous regions), which served as places for meetings or hosting guests (sometimes to perform rituals). Gatherings were funded through contributions from all the participants, or in turn by each member of the group. Gatherings financed through earnings resulting from the exploitation of a group's common ownership of certain property, i.e. land, constituted an exception to this rule. At the meetings, the men would eat, talk, exchange information, and also play games, sing, dance and recount old legends and religious parables. The gatherings also served as an opportunity to educate the young, who by participating could learn about their own history and mythology, traditions, customs, norms of the Islamic faith, and so forth (Rakhimov 1990: 27; Zapaśnik n.d.). To date, the group gatherings operate with similar principles and are an integral part of social culture in Tajikistan. They are also very important from the point of view of relationships, as well as various matters connected to business, work, transactions, the issue of arranging marriages between the members' children, and so forth, but the group hierarchies are not as strict as they were in the past.

New members were accepted into a group through a secret voting process. The group paid special attention to such factors as the candidate's behaviour, social position, and the opinions others had of him. Groups of men-companions usually consisted of 10 to 30 members, or sometimes even more. Frequently, the group's structure was rather complicated. Each group had a leader, i.e. a jura-boshi (Uzbek), (gap) or eshoni bobo (Tajik). (gashtak). The head of the group was responsible for organizational matters, conflict resolution, determining punishments, and so on. The members of the group were obliged to follow certain moral standards, and infringements were subject to various sorts of penalties, such as reprimands, fines, flogging, and, in extreme cases - expulsion from the group (Rakhimov 1990: 27-32). During meetings and group activities, each member claimed a seat in accordance with his place within the hierarchy of the group (Rakhimov 1990: 19).

In some respects, the above-described companionships might seem to resemble the relationship between brothers within a family, maintaining bonds between a younger and older brother; however, in the case of the folk group, an 'older brother' has much greater powers over a 'younger brother'. These groups express an ideal of culture in which an individual is related to a network of people who provide support, forbearance and understanding. At the same time, participation in the group is associated with learning the social order and correct behaviour, including the proper attitude towards authority (Zapaśnik n.d.).

A similar concept can also be introduced outside the confines of a village, mahalla or a particular territory by maintaining a wide circle of friends. This social institution is described by the term jamoa(t) (among Uzbeks) and jamomat (among Tajiks).

Literally, jamoat/jamomat signifies a group of neighbourhoods, colleagues, friends, as well as a community, society, assembly, or simply people who gather in the same mosque. In the context considered here, jamoat/jamomat is a kind of wide network based on kinship, geographical proximity or an occupational relationship, in which the members are obliged to provide help to the other people in the network. 
Informal membership can be inherited from friends or relatives. Frequently, though not always, the main selection criterion is that of regional origin. Desirable members for a jamoat/jamomat include people with high social status and extensive personal contacts, such as governmental officials and businessmen. By and large, a jamoat/ jamomat can be understood as the Central-Asian equivalent of the Chinese notion of guanxi, which also means integration of trust, reciprocity, responsibility, and obligation into economic and social exchange processes. I have borrowed the concept of guanxi from Biliang Hu (2007: 52-60) and adapted it for the purpose of describing the concept of jamoat/jamomat in Central-Asian societies. In short, such relations can be understood as a connection between persons. A jamoat/jamomat is a social institution which binds together a 'group of insider people' called 'insiders-we' compared to 'outsiders-they'. These people create relationship networks based on rules of obligation and reciprocity.

As already mentioned, the available information on women's groups is not extensive, but we do know they are organized on the basis of similar principles as men's groups, in most cases by middle-aged and older women during various female gatherings, such as weddings and other ceremonies, and rituals, such as Mushkulkushad $^{45}$ and Bibi-Seshanba. ${ }^{46}$ Such meetings play an important role in terms of exchanging information, socializing, and discussing important community matters (Rakhimov 1990: 53; Yusufbekov, Babajanov, Kuntuvdiy 2007: 18; Gorshunova 2006: 22-24). For example, the friend-circle of my host from Istpisor village in the Ghafurov district (a woman about 60 years old, a former teacher) organizes gaps once a month, and every member of the group gives 100 somoni (about 20 USD). This money is used to organize gatherings, sometimes to buy a birthday gift for one of the group members, and for other similar purposes. ${ }^{47}$

Despite almost seventy years of Soviet rule, under which traditional institutions were considered to be relics of a bygone feudalism (Russian: perezhitki feodalizma), the jamoat/jamomat has continued to play an important social role in the life of the sedentary population. In my opinion, the same concept also shapes relationships

45 Tajik: Bibi Mushkul-kushod - (English: Lady of Solution). Bibi Mushkul-kushod is a very popular ritual among women in Central Asia perfonmed to ensure the fulfillment of someone s wishes, to find a solution for their problems or just 'to clean the path' - to make life happier. It is organized exclusively for women, mostly on Wednesdays, and it is led by women religious leaders (Bibi otuns). The ritual is based on the old legend about Bibi Mushkul-kushod who helped a poor woodcutter to become wealthy and involves reading the Quran, prayers and other rituals.

46 Persian-Tajik: Bibi Seshanba - (English: Lady Tuesday). This is also a ritual exclusively for women conducted by an otun and performed on Tuesdays. The ritual is based on the legend about Bibi Seshanbe, and involves reading the Quran. prayers, and other rituals, as well as consuming special dishes including omoch (a kind of noodles that cannot be eaten by men). The main goal of performing this ritual is to provide a blessing during various family events. such as marriage. pregnancy, etc., or to give thanks for wishes fulfilled. 
between the local population and Slavs, who at some point started forming relationships with the locals based on the aforementioned informal rules. Such networks have to some extent survived the collapse of the Soviet Union and become the basis for the formation of new interest groups, sometimes of a transnational character.

The life of the individual in Tajik society depends on a wide range of social hierarchies. The avlod/qawm kinship is as a genuine part of the social structure as the jamoat/jamomat or the other networks which determine the way in which a person functions within society. Understanding the relationships between the various segments of Tajik society is the subject of further discussion in the following part of the text, concerning the mahalla and its institutions.

\subsection{Traditional Mahalla Institutions}

\subsection{The Meaning of the Term 'Mahalla'}

The literal meaning of the word mahalla in Arabic is 'district'. It derives from the Arabic verb halla (English: to stay at. to settle down). However, in the context of Central Asia, the original sense of the word 'district' does not provide a precise understanding of the concept of mahalla. Apart from mahalla, among the sedentary population of Central Asia, there are other terms which describe similar ideas, such as ku (Tajik; English: quarter, a part of a city) - a term which, according to Sukhareva (1965: 101), went out of circulation in the $16^{\text {th }}$ or $17^{\text {th }}$ centuries. Other words also exist, such as guzar (Tajik/Farsi; English: passage), rooted in the word guzarashtan (English: to pass by; the word guzar is also used to describe a small street within a mahalla), as well as elat (Uzbek; English: tribe, family, country), which is characteristic for some rural areas of Uzbekistan ${ }^{48}$ (Sukhareva 1965: 101; Jasiewicz 2004: 192; Abramov 1989: 4). In some places, for example in Sokh (presently an Uzbek enclave populated by Tajiks located within Kyrgyzstan), the rarely-used term chakar also exists or, in the mountainous regions of Tajikistan, sometimes the word dehot/ deha (Tajik; English: village) appears, as well as - rarely - hat (Tajik; English: line. border) are used (Khamidzhanova 1974: 27). The oldest source which mentions the word mahalla/ku is the history of Bukhara written in the $12^{\text {th }}$ century by Narshakhi (Sukhareva 1965: 101).

4* According to Jasiewicz (2004: 192), the term elat might be evidence of the strong decentralization of tribes and ethnic groups in the past within the same territory. As mentioned abov'e. elat is characteristic for rural communities in present-day Uzbekistan. mostly in the region of the former Khorasan. In terms of social organization, the concepts of mahalla and elat are similar. 
The meaning of these various terms has evolved over time as well as within different regions. Nowadays, the most commonly used is the word mahalla, although the other terms are also widespread. Nevertheless, all of the words listed imply an integrated cluster of houses based on territorial, professional, family, or/and ethnic relationships of one type or another, incorporated into the city, town or settlement where a particular community lives. As Niyazov indicates (2007: 154), the problem with a precise definition of mahalla is related to its geographical form, which is determined by the place where a given mahalla is built - mahallas located in the centre of a city or town are usually smaller. A mahalla can consist of several dozen or even several hundred houses built along a big street with small side streets, or a big street is sometimes divided into few mahallas. In this context, a mahalla is a quarter. In the past, it was the basic administrative and socio-economic unit of a city in Central Asia. One mahalla was separated from another by streets with houses built side by side without windows on the street side. The entrance to the mahalla was usually in the form of a big gate (Tajik: darvozi kalon). Houses were connected by small back gates, so it was possible to move from one house to another without entering the main street. Due to shortage of space for building new houses, the residences were large and situated very close to each other, divided inside into separate units occupied by small families. Each residence also had a small internal courtyard (Poliakov 1980: 118-121; also see Abramov 1989; Mukhtarov 1995; Sukhareva 1965).

The mahalla was a quarter within a city, but relations between rural and urban areas were very flexible. Many wealthy city dwellers had parcels of land in the countryside, which were cultivated by other people or rented out to them (Poliakov 1980: 118-121). Moreover, it was frequently difficult to distinguish between bigger villages and towns; thus, the mahalla understood as a communal organization also functioned in rural areas. Today, all the houses located within a single village usually make up one mahalla, or a particular settlement is divided into a few smaller entities. In Tajikistan, a mahalla is the smallest administrative unit which organizes the life of a community. Several mahallas usually constitute one jamoat.

Every mahalla has a name which can provide hints about its history, function, the origin of its inhabitants, and so forth. Sukhareva (1976: 18) divides the names of the mahallas in old Bukhara city into six groups. The first group of names refers to famous historical figures, people who founded the mahalla's mosque or holy people; for example, the Khalifa Hudojdod quarter, the Khalifa Husain quarter, the Khoja Porso quarter, the Khoja Zayniddin quarter or the Khoja Tungun quarter. In addition, mahallas could similarly be named after people who had made a pilgrimage to Mecca, e.g. Madali-hajji mahalla, Kul Mohammed-hajji mahalla, or after the names of Islamic religious leaders, or occasionally, merchants or other people. The second group of names is derived from local holy places or the tombs of saints, such as Imam Muhammad al Ghazali mahalla or Khoja Halim mahalla. In Sukhareva's classification, the third group of names is taken from a particular ethnic/kinship group which settled in the quarter, e.g. mahalla Arabon - in Old Bukhara (where mainly, but not only, Arabs lived), the Kalmuk quarter and the like. If a mahalla's vicinity 
was populated by large amounts of representatives of a particular professional group, its name could refer to that profession, i.e.: Pachta-bofandagon (English: mahalla of weavers [of cotton]), Ravghangaron (mahalla of those who make butter), Sarrodjon (English: mahalla of leatherworkers). The fourth group of names derives from various commercial and cultural terms, such as Bozori Gul (English:a mahalla named after a flower bazaar), Machiti Balang (English: the high mosque) or the Kosh-madrasa mahalla. ${ }^{+9}$ The fifth group includes names taken from a particular place, e.g. Tai Pushta mahalla (English: near the cemetery/kurgan) or Tai jorbogh (English: near the orchard). Finally, the sixth group comprises names having different origins (see also Abramov 1989; Mukhtarov 1995). Nowadays, mahallas' names can be classified in an analogous way, but apart from the traditional names of heroes and saints, the names of contemporary important people, e.g. Gagarin, can be used, and there are also modern names, such as mahalla I" of May (the date of Labour Day), and even mahalla Frunze (named after a famous Bolshevik leader).

\subsubsection{The Mahalla as a Social Organization}

The history of neighbouring-territorial communities as social organizations regulating the lives of its inhabitants is rooted in the distant past. According to Avesta (the holy book of Zarathustra), between the $2^{\text {nd }}$ and $1^{\text {st }}$ centuries BCE, separate kinship groups had begun to establish bigger formations. Gradually, between the $8^{\text {th }}$ and the $6^{\text {th }}$ centuries BCE until the beginning of the $1^{\text {st }}$ century $\mathrm{CE}$, a community consisting of families which were no longer bound by blood ties became the basis of social organization. The members of a community were integrated through the practice of communal rituals, group work and military service. Due to communal land ownership, all irrigation works were also performed collectively. At the beginning of the $1^{\text {st }}$ century CE, the communities began to pay shared taxes. Until the $7^{\text {th }}$ century CE, the neighbouring-territorial community was termed nafa, while after the Arab conquest of Central Asia it received the name mahalla (Shaniiazov 2011: 416).

The concept of a neighbouring-territorial community is embedded in collective consciousness, as it refers to the norms and identities of the sedentary population of Central Asia and expresses the ideal of a social organization. Even if at present the state administration or international donors use this concept to pursue their own policies, the mahalla, as a self-governing body and a model of a community, continues to influence the organization of social life even in places where the traditional mahalla has been replaced by modern forms of housing, such as residential blocks of flats or others.

Sievers (2002: 96), referring to Uzbekistan, classifies mahallas into four types: rural inahallas (in the former areas of kolkhozes and sovkhozes), urban area apart-

t9 Madrasa, also madrasah or inadrassah - a school teaching Islamic theology and religious law. 
ment mahallas (modern apartment complexes), contemporary mahallas (blocks of relatively spread-out family dwellings), and traditional mahallas (blocks of densely organized pre-Soviet single-family dwellings).

Until recently, the remains of some traditions of the mahalla were preserved in modern apartment blocks and functioned alongside the Soviet-type block committees organized for administrative purposes. The organization of weddings, funerals or circumcisions by block residents was performed according to the same pattern as in the traditional mahalla. In the Soviet past, in many cities of Central Asia, dwellers of traditional mahallas were relocated to apartment blocks. Thus, it was not uncommon that the residents of one mahalla were settled in one apartment block. For this reason, the new residences partially preserved its traditional character. For a certain period, I lived at a housing estate in Dushanbe, where there was a place to store goods, such as furniture and kitchen stuff used for residents' communal social enterprises. It is still sometimes possible to see an entrance or gate leading to the grounds of a modern housing estate which resembles the old gate to the mahalla.

A Tajik PhD student, when asked about her understanding of the mahalla, answered that the community of people living in a student dormitory is also a kind of mahalla. In this case, the term mahalla acquires a new meaning, and can be understood not only as a traditional institution or administrative unit, but also as any social organization of people inhabiting the same place and forming a social network. Thus, in order to understand mahalla in the context of its genuine social function, it should be analysed through the lens of both terms - social relations and the model of a given community's territorial organization.

Traditionally, mahallas were populated by one or more kinship groups based on ethnic and/or territorial relationships. In the past, the area of a mahalla was often occupied by one professional group tracing its lineage from the same real or fictitious ancestor. In addition, mahallas were frequently inhabited by various professional and ethnic groups, as well as by representatives of different religious factions, such as Sunni and Shia. Quarters based on family bonds are more frequent in mountainous regions. In lowland regions, the social organization of the quarters more often tends to be based on neighbourhood relationships (Rakhimov 1990: 63; Poliakov 1980: 117).

Khamidzhanova (1974: 27) describes the social organization of quarters in the region of Upper Matcha (northern Tajikistan), where one quarter belonged to a certain kinship group which also had separate pastureland and hunting areas, as well as its own space in the cemetery. There are places populated by a few kinship groups (in this case, a particular hierarchy is established among them). Nowadays, kinshipbased mahallas are more likely to be found in the rural areas, while in the cities mahallas are more frequently inhabited by different sorts of people (representatives of various ethnic groups, professions, families, and so forth). Social bonds are not as strong in cities as in rural areas; thus, mahallas tend to function more as administrative units and their social aspect is of a lesser importance. Nevertheless, there are mahallas based on kinship ties or which include the only ethnic group living 
in a given quarter (e.g.: Uzbeks), even in big cities such as Dushanbe (Wiegmann 2009: 147). There are also cases in which people who decide to migrate to a city try to find living accommodations with a group from their own region. In the old historical cities, such as Istaravshan and Khujand, with mahallas which were built several hundred years ago, organizations which have a more traditional approach have been preserved to some extent to this day. According to my interlocutors, in some wellintegrated old mahallas, the traditional structure still functions, but in many mahallas the social ties have become more relaxed and communities are not as integrated as in the past; as a result, it only plays the role of an administrative unit.

Abdullaeva and Tyuryaev point out that "in the mahalla what is most significant is social capita, that is, the place of each kinship group and each of its representatives, as well as the image of each member in the eyes of his/her community (...). It is necessary to emphasize that social capita is accumulated by representatives of an avlod from generation to generation; certain negative traits of previous generations will also adversely affect presently living representatives of the group" (2004: 17-18).

The authors further indicate that even if someone leaves the mahalla for some reason and lives in a different place that person still 'spiritually' belongs to the home mahalla. Despite the fact that at present many people migrate to Russia, Kazakhstan and other countries and live abroad for years, they always continue to participate in the life of their mahalla through their family or other traditional social networks (Abdullaeva and Tyuryaev 2004: 17-18). The observations resulting from our NGO project show that migrants substantially contribute to the facilitation of community initiatives launched during project implementation (see Chapter 7).

To summarize, a mahalla as a social organization is based on neighbourhood relationships, including informal networks of families, relatives, neighbours, and extended kin, who consider themselves members of a single community (Collins 2006: 70). It performs both regulatory and mediation roles with regard to the internal affairs of its residents and their relations with the external world. It should be underlined, however, that the main difficulties in analysing the mahalla stem from it being neither a static nor a homogeneous institution. Moreover, the nature of the mahalla has transformed over time. Any description of the mahalla should consider the various aspects related to its role, practices and institutions.

\subsubsection{The Mahalla in the Pre-Revolutionary Past}

Prior to the Russian conquest of Central Asia, rural communities were concentrated in settlements and villages (qishloqs). A community was represented by an aqsaqal, who protected its interests and supervised all works, including those organized by the state administration. The state had a vested interest in preserving the collective forms of community for the purpose of tax collection. Since the members of communities were bound by relationships based on mutual trust, tax evasion was rare. The activities of craftsmen and merchants were concentrated mainly in the urban 
areas. Important cities were situated in oases on the banks of rivers, and until the $19^{\text {th }}$ century preserved a medieval structure. As mentioned above, a quarter (mahalla) was a basic unit of a city consisting of houses clustered together. Every quarter had an aryk (a small water aqueduct), haus (an artificial water storage tank), a mosque, sometimes a madrasa and chaykhona. The head of a quarter was responsible for representing a community to the city administration. He was also in charge of collecting taxes. In terms of its functions, a mahalla was similar rural communities (Poliakov 1980: 116-121).

All land within the territories of quarters belonged to individual families or was owned by the state. Ownership over land was expressed in the form of eligibility to build a house on a particular plot. This kind of 'property ownership' applied to private buildings and public facilities, such as caravanserais, merchants' shops, bath houses, and so forth. As in the case of rural areas, water was considered to be state property for which people had to pay, in most cases in kind. All works related to water were collectively carried out by the locals. The society was organized according to occupations, such as artisans, craftsmen, state officials, soldiers, as well as the clergy, but these were not rigid categories. Artisans were organized into guilds. A person became a member of a guild after many years of apprenticeship with a master (Poliakov 1980: 116-121).

The mukhtasib (rais) performed a major role in the system of town management, since this person was responsible for maintaining order according to the principles of shiaria law.50 (including monitoring participation in daily prayers in quarters, fasting during Ramadan, honest trading in the bazaars, or other matters related to public order). The main authority in terms of the judicial system belonged to the qozikalon $^{51}$ (English: supreme judge), who supervised the work of the lower-ranking qozi judges, deciding in cases of lesser importance based on the opinions of mufti scholars. ${ }^{52}$ In most quarters in Bukhara, there were public buildings which were in-

so Shiaria, also shiariah, shariah - The rules and regulations as well as the moral code of followers of Islam. which was revealed by God and transmitted by the prophets, fonning the underpinnings of the Muslim faith, obligatory for all members of the community (Arabic: umma). There is no separation between secular power and the principles of religion in Islam or therefore between law and theology. On the basis of the general rules of the religion. Islamic doctrine (Arabic: fiqh; which corresponds to the European concept of jurisprudence) formulates a detailed legal system using the primary sources of Islam: the Quran and the sunna (the tradition of the Prophet Muhammad; in Shia Islam, also the tradition of imams). In addition, an important part of the law included the methods used by jurists and scholars, such as ijma (the consensus of theologians). qiyas (the process of deductive analogy), and ray (the personal opinions of scholars). Separate legal sy'stems have been developed by the various schools of Islamic law (Arabic: madhhab, pl., madhahib), while the most recognized schools are as follows: Hanafi, Hanbali, Maliki, Shafii (Sunni Islam), Jafari (Shia Islam) (Dziekan 2001: 339).

sI Arabic: Qadi; Tajik: Qozi - a Muslim judge issuing judgments based on shiaria and local customary law. He is responsible for all matters involving inheritance, waqf, marriage. and divorce. In some cases, his jurisdiction extends over both civil and criminal matters.

$52 \quad$ Mufti - a Muslim scholar, an expert on Islamic doctrine, officially authorized to issue decisions and opinions (fati'a) under shiaria law (Dziekan 2001: 283). In the case of Central 
habited by various state employees, including judges, guardians of the public order, soldiers, and others. Additionally, the qozi and the rais were present in every village (Sukhareva 1976: 17; 1966: 86, 294; Litvinski and Mukhtarov 1992: 75-76).

Many aspects of the functioning of the mahalla - primarily as related to social issues - were based on traditional practices legitimized by customary law, adat (odat), ${ }^{53}$ which was partly incorporated into Islam during the period in which the principles of the Hanafi school, the dominant school of Islamic law in the region, were formulated $\left(7^{\text {th }}-9^{\text {th }}\right.$ centuries CE). ${ }^{54}$ During that time, the secular and religious authorities were merged, and the state system adopted elements of shiaria and pre-Islamic customs. In many cases, Islamic theologians sought to legitimize local practices by accommodating them into Islamic law. People's knowledge about the practices, standards and requirements of Islam was based on interpretations made by the local clergy, including Sufi masters, ${ }^{\$ s}$ closely connected to the local communities. Consequently, a kind of 'popular religion' emerged within the mahallas, clans, tribes, guilds, ethnic minorities, and - despite Islamisation - the local population continued to live according to the old customs and traditions. A more sophisticated knowledge of religion - 'classical Islam' - was exercised by well-educated intellectuals, such as scientists, theologians, priests, teachers, and so forth. In fact, customary law and shiaria interpenetrated each other. In the cities, the influence of official state law was stronger, whereas in rural areas local traditions and customs legitimated by Sufi teachers dominated over the classical interpretation of Islam (Muminov 1999: 81-83).

Consequently, many aspects related to the daily life of communities, such as performing celebrations, funerals, weddings, rituals associated with the annual cycle of seasons, cults of saints or visiting 'holy places', were also integrated into Islam. Therefore, they were considered to be 'Islamic', despite the fact that they originated

Asia, Qadis (who are also scholars of Islamic Law and thus belong to the class of 'clergy') were expected to have their judgments confirmed by muftis, who drew up explanations for the decisions of judges in reference to a particular part of shiaria law.

is Adat (Arabic: 'ada, pl. 'adat; also known as urf) - custom, a set of traditional institutions, rules and customs which were not included into shiaria or sometimes contradicted it. Adat refers to three basic concepts: 1) customary law; 2) judgments on the basis of customary law; 3 ) rules outside of the official law. In the beginning, some principles of customary law were adapted to shiaria; later, adat was practiced to regulate cases which shiaria did not consider. Adat was mostly incorporated into the Hanafi, but also the Maliki and Shafii schools of Islamic Law, while the Hanbali school practically rejected adat completely (Dziekan 2001: 18; Bobrovnikov 2006: 22).

is Hanafi inadhhab became the major school of Islamic law in Central Asia, and finally dominated over Shafii madhhab and the influence of Shia Islam.

s5. In Sunni Islam, there is no official hierarchy among the various spiritual and religious leaders; thus, the word 'clergy' is not entirely accurate. In Arabic, the word rijal ad-din is used to describe Islamic religious professionals as a group. An official hierarchy aınong servants of God is established in Shia Islam, and in this case, a member of the clergy is described by the term ruhoniyat (Persian: ruhäniyat), which is also used in Central Asia in relation to religious professionals of Sunni Islaın. 
in the pre-Islamic period. Simultaneously, institutions such as mosques and madrasas, which transmitted Islamic thought to the population, served the community but at the same time were linked to the official state system. It should be emphasized that parts of the administrative functions of the mahalla which can be defined as 'secular' (according to Westem categories) were organized according to the rules of the Muslim state. Thus, despite the fact that the mahalla had been shaped by various syncretic religious traditions, its structure reflected the ideals of the Islamic social organization, and in this form the mahalla survived until the times of the October Revolution. Despite changes, to this day the mahalla remains strongly embedded in Islamic values and any analysis of its institutions should take into consideration Islam and its influence on communal practices and the relationships among members of a community.

In the aftermath of Russian colonization and the establishment of the Turkestan Governor-Generalship in 1867 , the administrative system was reorganized in the regions absorbed by Russia. The whole territory was divided into several oblasts (provinces), which were further divided into uiezds (districts), and then into smaller administrative units, volosts. The volosts were further broken down into rural settlements (Russian: sielskie obshchestva) - aqsaqalstva (for the sedentary population) and ayilnye obshchestva (in the regions populated by nomads). Local governance was left in the hands of the local authorities (including at the volost level). Members of the lower administration were elected by inhabitants, but their candidacies had to be approved by representatives of the Tsarist government. The cities populated by Europeans and the indigenous population were divided into two parts: 'the Russian part' and 'the native part'. The part inhabited by the local population was administered by 1) a senior aqsaqal (a post corresponding to the head of a city), 2) aqsaqals (members of council), who also headed the urban quarters (mahallas), and dealt with public order issues as supervised by the rais, and 3) the qozi, who ruled over the courts. The heads of villages and towns were elected for a period of three years (but this rule was not always observed). The mahalla was still the lowest level of state administration. At the same time, the judicial system was reorganized. There was an administrative judiciary of the Russian style, parallel to the traditional court system, to consider the cases concerning only the European citizens, the issues between Europeans and locals, as well as serious crimes. The indigenous population was subject to the local juridical system (Russian: tuzemnoie sudovotstvo) - biy courts based on the adat, and dealing with matters related to customary law (for nomads), while the qadi/qozi courts examined cases under shiaria law for the sedentary population. Judges were elected and then approved by the Tsarist authorities (Litvinski and Mukhtarov 1992: 75-75; Vasilev 2008: 97-100).

In terms of attitudes toward religion, the Tsarist authorities followed a policy of ignoring Islam. Consequently, they did not interfere in the traditional practices of communities. At the same time, however, the Russian administration confiscated a part of the waqf endowment, which weakened the influence of the Muslim clergy, at least at the level of state administration. Nevertheless, the mahalla still functioned as a self-governing institution regulating social order at the local level. 


\subsubsection{The Mahalla in the USSR}

In the aftermath of the October Revolution, the Soviet government attempted to incorporate the mahalla into the structure of the local administration in the Uzbek SSR. In 1922 and 1923, the National Commissariat of Internal Affairs (NKVD) of the Turkestan Autonomous Soviet Socialist Republic established mahalla commissions within the old quarter of the cities (where the non-Russian population lived). At the beginning, the 'new-Soviet mahalla' was based on the model of the traditional mahalla (including tax collection), which had functioned during the times of the Turkestan Governor Generalship, complemented by new elements taken from Soviet ideology. In 1928, after the formation of the Uzbek SSR, the act regarding "Provisions for Mahalla Commissions" was issued. Under the new law, the mahalla commissions were subordinated to the municipal councils, but they exercised fairly broad powers, including supervision of social matters within communities, assistance in strengthening law and order, and spreading communist ideology. In 1932, yet another similar act was approved, "On Mahalla (district) Committees in the Cities of the Uzbek SSR". Abashin (201lb) notes that the commissions were transformed into committees, a term which remains in use to this day, both in Tajikistan and Uzbekistan. In 1941 and 1953, the Council of Ministers of the Uzbek SSR issued other versions of the provisions regarding mahalla committees (also see Masaru 2006: 346-348).

Jasiewicz (2004: 195-198), who conducted field research in the 1960s in Uzbekistan, points out that different forms of Soviet institutions began emerging from the 1920s, such as mechetkoms and guzarkoms, with the intention of fusing the ideas of the new communist ideology with local traditions. In this way, the new communist power attempted to integrate elements of Central Asian culture into the Soviet structures. The appointment of the head of a mahalla was often supervised by the local party apparatus. The chairperson was supported by the mahalla committee. There were also sub-cells, such as a women's committee, a sports committee, a youth committee, and so forth. In some cases, the office of the mahalla committee resembled any state Soviet institution, decorated with Soviet symbols and portraits of Party leaders. The purpose of establishing mahalla committees was to create a link between native communities and the Soviet state apparatus. They fulfilled both a traditional social function and a new role as introduced by the Soviet authorities (Jasiewicz 2004: 195-198; Masaru 2006: 348-350).

Dadabaev (2013: 185) remarks that given that the mahalla was popular among the local population, the Soviet state did not want to dismantle this institution. Instead, the communist administration sought to use the mahalla structure to pursue its own goals, such as spreading anti-religious propaganda, advertising socialistic events and lifestyles, as well as supporting the national activities of the Soviet Union. For example, the social institution of chaykhona (English: Tea-house) was transformed into the 'red chaykhona', which was a place where communist agitation was carried out (Dadabaev 2013: 185). Mahalla committees, besides their numerous 
social responsibilities, passed on certain political information aimed at popularizing the new ideology (also Sievers 2002: 53; Koroteyeva and Makarova 1995; Dadabaev 2013: 185; Masaru 2006: 346-350). Abashin (201lb) indicates, however, that the ideological role of the mahalla was formulated with a certain amount of caution; the mahalla's role was perceived as that of 'an assistant' in incorporating Soviet rules and not as an independent unit.

To a certain degree, the concept of Soviet sports committees, youth committees, women's committees, and so forth, has been maintained until the present day. For example, these kinds of units were incorporated into the project of 'village organizations' (MSDSP) in the Shuroobod district, but they were rather weak institutions (see Chapter 5). The women's committees also still function in some parts of Kyrgyzstan, Tajikistan and Uzbekistan (as do sometimes other committees). l came across this structure in various places in Tajikistan: in the Spitamen district, also the Ghafurov district (the Sughd region), as well as during my work in Kyrgyzstan in Naryn as a structure within the Kyrgyz village (ayil). According to the NGO Nurjolber from Naryn (Kyrgyzstan), women's committees are active in the family and micro-finance fields, passing on knowledge concerning financial issues to village women. ${ }^{56}$ In Tajikistan, structures exist which are similar to women's committees and they are sometimes organized within the jamoat or rarely within large mahallas. It is difficult to estimate how big this phenomenon is without further research, but my observations show that at least the women's committees in Tajikistan frequently serve as a tool of the state to strengthen its influence over the female part of society, especially regarding activities related to religion and traditional celebrations. Particularly, their primary aim seems to include the supervision of female religious figures and other traditional leaders.

In 1961, a new provision was passed "On the Mahalla Committees (quarters) in Towns, Villages and Ayils of the Uzbek SSR". The most important changes were targeted at increasing the bureaucratic powers of the mahalla, which received the right to have its own stamp and to issue different types of documents. However, the mahalla committees were not authorized to manage financial issues. This act was approved not as previously by the administration of the Uzbek SSR but by the Supreme Soviet of the Uzbek SSR. As a result, the mahalla was granted a high legal status. In addition, under the new law, the mahalla structures and competences were defined in more detail than in the past. Moreover, the mahalla committees were also now introduced in the rural areas (Abashin 2011 b; Masaru 2006: 348-349).

Subsequent amendments regarding the mahalla were issued in 1983. In 1990, the administration of the Uzbek SSR, just before the collapse of the Soviet Union, published a draft law "On Local Government and Property", under which it was proposed that the mahalla committee - as "a body of territorial self-government" obtain the status of a legal entity and the right to maintain "mahalla property", which

56 Information obtained in October, 2011, in Naryn, Kyrgyzstan, during an interview with a representative of the NGO Nurjolber. 
was a major innovation in the process of the institutionalization of the mahalla. Simultaneously, the Uzbek authorities seriously considered redefining the formula of the mahalla as an ideological instrument used in order to enable exercising control over society. It should be noted that with time the Soviet authorities in Uzbekistan attempted to incorporate some distinctive features of the mahalla community, such as collectivism, mutual aid, social support for the disadvantaged or the patriarchal ideal of a 'strong family', into its 'progressive tradition' ideology, which functioned as part of Soviet demagogy. In this way 'national forms' were mixed with 'socialistic elements', which made the mahalla a legitimate part of the official ideology. Later, in the 1980s, this was further reshaped and the mahalla was promoted as a kind of 'Uzbek brand' (Abashin 2011b).

At the same time, authorities of the Tajik SSR put less effort into transforming the traditional social institutions according to the ideological framework of the Soviet state. In the opinion of Abashin $(2011 \mathrm{~b})$, first of all, the reason behind such a situation could be related to the low number of old cities, especially in the southern part of Tajikistan, and predominance of rural villages and towns with a fluid intemal structure. The author indicates that the capital of the Tajik SSR, Dushanbe, was founded from a village, thus the urban structures - including quarters - were not firmly established. Hence, the Tajik authorities could have been much less motivated to take into account the symbolic and social significance of a mahalla as a social organization.

On the other hand, however, there were also historical cities in the north part of the Republic, such as Khujand, Istarafshan (Ura Tyube) or Panjikent, where the traditional mahalla structures were strong. In addition, in the southern part of the country, despite the fact that until the October Revolution urban centres were of a smaller size and the boundary between rural and urban areas flexible, the mahalla functioned as a quarter inhabited by the representatives of a particular profession or kinship group. Furthermore, the villages were also organized into quarters (see Karmysheva 1976: 39-41; Pisarczyk and Kisliakov 1970: 17-18). Abashin (201lb) further indicates that possibly the Tajik authorities did not want to copy the ideas introduced by the Uzbek SSR and officially fit the mahalla into the Soviet structures. He also points out that the poor and small Tajik SSR could not afford to design and implement an administrative reform targeting the mahalla, especially since there was no urgent need to do so. Another reason behind such a choice might have been the general weakness of the Tajik SSR, and consequently the fact that the Soviet system was in many cases implemented in a superficial manner, resulted in neglecting structural changes, including the transformation of the mahalla.

In the 1980s, the government of the Tajik SSR issued a directive regarding the formation of public self-government bodies (mahalla councils) within the territory of cities and villages. The tasks of these bodies were to fulfil the state's duties but the procedures needed in order to form the councils were not strictly defined (in contrast to the situation of the Uzbek mahalla committees). In 1991, a law was passed "On Local Self-Government and the Local Economy in the Tajik SSR", in which "the bodies of territorial self-government" included organs of local social self-governance, 
such as neighbourhood councils, mahalla committees, house and qishloq committees, communal organizations, and other forms of direct democracy. They could be issued the status of a legal entity so that they would be able to become involved in economic activities under the control of local councils (Abashin 2011b). Thus, slowly, the mahalla was also formalized in the Tajik SSR, and in spite of their shallow character, the introduced changes influenced relationships within the mahalla and continued after the collapse of the Soviet Union.

In order to conduct an analysis of the relationship between the Soviet state and the mahalla, the attitude of the new state toward religion should also be considered. The policy of atheisation, the persecution of religious activities, closures of mosques and religious institutions, discrimination against religious leaders, the confiscation of Islamic literature, and changing the Arabic script to the Latin and later the Cyrillic alphabet - all these factors contributed to a transformation of Islam, whereby it was pushed back into the informal sphere of life (Niyazi 1998: 42-43). As a result, most of the traditional practices associated with religion, including traditional institutions within the mahalla, began to operate on the fringes of the official system.

Islamic customs were excluded from the public sphere but were still followed in private life. The ideology of atheism was taught at schools and universities to show the harmful influence of religion, but - in fact - a considerable number of Tajiks declared themselves to be Muslims. Officially, religious schools and mosques (apart from a few institutions recognized by the state) did not exist, but in practice Islamic knowledge was passed on during informal religious classes, and hundreds of mosques and madrasas operated in the region within networks, such as hujras (English: circle, cell) (Niyazi 1998: 42-43; see also Muminov, Gafurov and Shigabdinov 2010: 224-250).

Many of the mosques were organized within communities in remote areas and in the cities, and were often informally protected by the local communist elite. Funeral rites, weddings, circumcisions and other ceremonies were mostly performed according to the old practices and Islam. In this way, despite the attempts to transform the mahalla into a semi-formal institution subordinated to the state, Islamic tradition was preserved by the mahalla community (Arifkhanov 2009, some information added).

In every community I visited during my work in Tajikistan, I have always asked about religious activities under communist rule. Heretofore, almost in all the communities located in rural areas where I was a guest, during the communist period there were prayer rooms or informal mosques organized in various, sometimes unexpected places, e.g.: in the kolkhoz not far from Khujand city people gathered to pray in the tractor park. The older men who did not have professional obligations usually participated in religious life more intensely, as the case of the sovkhoz located in Ganchi district shows. The imam, who functioned there in the late 80s, was the former director of the sovkhoz. He was replaced as head of the sovkhoz by his daughter when he retired. In the territory of the former kolkhoz in the Isfara district, where I conducted field research in 2010 , underground schools operated during the Soviet period, gathering hundreds of students from different parts of the region. It is worth mentioning that the director of the kolkhoz had previously worked in the 
district office of the KGB. According to my informants, informal Islamic activities were booming when this man was in power. ${ }^{57}$

Dadabaev (2013: 187-192) points out, as also confirmed by my research, that despite the various competences given to the mahalla during the Soviet times, this institution was not granted significant financial support. The Soviet state attempted to weaken the influences of the religious and traditional authorities by introducing the ideologically-based Soviets (councils) and executive committees, but in reality the official structures maintained a very low profile. In fact, the traditional informal human networks and mutual support embedded in moral and religious values dominated over the Soviet structures. The Soviet administration interfered only superficially in some spheres of social life. Local networks based on family and neighbourhood relationships frequently absorbed the formal rules imposed by the state administration. In consequence, during the Soviet period, the mahalla as a social organization was situated between the public and private spheres, and the border between them tended to blur.

It should be noted, however, that contrary to common opinion concerning the oppressive nature of the Soviet state, the communist ideology brought with it the ideal of social justice. Many social privileges, such as medical care, education, and so forth, were at that time provided free of charge. Due to stable employment, the financial situation of people was also relatively secure. ${ }^{58}$ The communist state offered its citizens a full array of options which had not been available in the pre-revolutionary period. As a result, seemingly artificial institutions (such as the above-mentioned committees) introduced into Central Asian communities were accepted by society because they brought tangible benefits, and these consequently influenced relationships also at the level of the mahalla. In the Soviet period, the mahalla's role as a social organization protecting people from poverty or other forms of vulnerability was partly shifted to state administration and the collective farms.

Without a doubt, the Soviet era contributed to transforming the mahalla as a social organization. Certain administrative and legal concepts, introduced before the USSR collapsed, still hold influence on the state administration's approach to the mahalla at present, in Uzbekistan as well as in Tajikistan. With the institutionalization and bureaucratization of the traditional institutions, the mahalla has gradually become subjected to state control. I will return to this topic in the following chapters of this book.

$\$$ On the basis of tield research conducted between 2010 and 2014.

is A more detailed analysis of the mutual influence of Islam and communism goes beyond the scope of this work. However, in my opinion, in the case of Central Asia, communist ideology has also significantly influenced the development of contemporary Islamic thought, even if it is often condernned by the latter. For instance, the ideals of the Marxist-Leninist concept of social justice are visible in the ideas of the IRP (see the statute of the Party), as well as in the concepts governing various illegal groups, such as Hizb ut-Tahrir. Both of these aforementioned groups are popular among the most vulnerable inembers of society, those living in overcrowded cities, as well as in villages in remote areas of Tajikistan. 


\subsubsection{The Mahalla Authorities}

\section{The basic structure of the mahalla}

The mahalla, as a self-governing institution as well as a unit of state administration, has authorities responsible for all of a given community's affairs. They regulate and organize all matters in accordance with the law and tradition.

Every mahalla has a head (Tajik: rais or amin of the mahalla), who - in accordance with tradition - was elected by the community. The most popular term used in the past was aqsaqal (English: white beard. Tajik: arbob. muysafed), which continues to function in some parts of Tajikistan. According to tradition, the position of the head of a mahalla has always been very prestigious, and a person elected to this role should be held in high esteem by the entire community. He should also be a trustworthy and distinguished man. According to custom, his work is unpaid, though he could draw some profit from various services rendered to the community. Traditionally, candidacy for head of a mahalla was nominated by the imam of the mahalla on the recommendation of a group of respectable men - preferably rich and influential people as well as honourable elders. They gathered in the mosque during majlis (English: assembly) to decide on a particular candidate. Women and young men were excluded from the formal process of voting (Sukhareva 1976: 33-34).

The high social status of the head of a quarter and his assistants was associated with the concept of serving the community - khizmat (English: service). As a result, the community always elected a person of average wealth to fulfil this role, frequently selected from among middle-income merchants and craftsmen. In addition, he should not have too many other commitments in order to be able to serve the community well. His average wealth tended to make him resistant to various sorts of influences which functioned within the mahalla (Sukhareva 1976: 32-33).

Nowadays, the raisi mahalla is often recommended by the local authorities. This has seriously undermined the previous high social status of the function and is a clear sign of the weakness and degeneration of the mahalla as a social organization. In some cases, even women have been selected to perform the task of raisi mahalla. Women can play the role of the head of a mahalla in neighbouring Uzbekistan, where the old organisation has almost completely decayed and is a tool of state control over society. In many cases today, the authorities of a mahalla represent a narrow interest group more related to business and the state than to the community itself. Due to increasing social stratification, respect is shown to people according to their wealth, not their virtues, and so decent community members who are less affluent no longer enjoy the same esteem they once did. All these factors contribute to the fact that the mahalla has been gradually losing its significance as a self-governing social organisation. ${ }^{59}$

s9 The above-quoted opinion was repeatedly expressed by different interlocutors during various interview's. 
During the focus group organized in 2010 , in response to a question about the ideal raisi mahalla, the interlocutors outlined the following characteristics: he should have life experience (which is associated with an appropriate age), be intelligent, open-minded and possess good organizational skills; other desirable features included strong leadership abilities and engagement in the community's affairs. Additionally, a rais should protect orphans, the poor, widows, and other vulnerable residents. $^{60}$

The study further revealed that the present rais of the mahalla (in which the focus group was conducted) had been recommended by the jamoat authorities (during the majlis, his candidacy was only formally approved through an open vote). The rais is a school director and he is respected by the residents; however, in the opinion of the respondents, he is not too involved in community affairs, and so in fact is not a good candidate to perform the duties of rais. Consequently, hardly anyone approaches him with problems and his work is limited to administrative tasks.

However, the subsequent part of the conversation disclosed that in this particular mahalla the situation is very complex. The most active social activist is a middleaged woman who is also the head of a primary-care clinic and enjoys considerable authority. Many people approach her with their problems. She works mostly with her son and daughter-in-law (the couple established a local NGO organization). Despite the fact that she enjoys high respect within the community, customary law prevents her from being nominated for the position of raisi mahalla.

In light of the fact that she cannot be nominated as rais, most of the residents felt that her son could be selected instead of her, since he is also involved in social work. Finally, however, people decided that her son was too young (just 32 years old in 2010). Consequently, the school director was elected upon the recommendation of the local authorities. However, his nomination has not changed the situation in the mahalla, since in reality it is not him but the female leader who is still engaged in most of the community's affairs.

Nevertheless, it would be a faux pas for this woman to communicate problems directly to the rais as, first of all, this could undermine his authority, and secondly, the gender division also creates some limitations in contacts. Consequently, if there is an important issue about which the rais should be informed, the female leader passes information on through her son. Thus, the circulation of information in this particular mahalla is as follows: in the first stage, people approach the woman with important matters (in most cases, men by means of their wives), the woman then conveys the message to her son, and he delivers the information to the rais.

The above example shows the complexity of relationships within this mahalla, as well as the significance of tradition, which regulates community life. Tradition

(1) The focus group was organized in a mahalla in the Ghafurov district (Sughd region) in August 2010. Eight women between the ages of 24 and 50 participated in the group. All conversations were carried out in the Tajik language translated into Russian by a female NGO activist. Due to privacy issues, it was not recorded. 
requires that the rais should be a man - since he chairs community meetings, which frequently take place in a mosque (where women are not allowed), handles difficult issues, and conducts discussions with government officials. The performance of these tasks would require acting in the public sphere and they are traditionally considered to be the duties of the male part of the community in Tajikistan. The reversal of roles which takes place if a women is selected for the position of rais, as sometimes happens, requires a change in the traditional pattern of the mahalla organization, not only with regards to the issue of leadership, but also to matters associated with religious practices or relationships between different social groups, i.e. women and men or between the young and the elderly. Thus, this particular community chose a compromise which was closest to the ideals of the traditional mahalla community - the male candidate proposed by the local administration became the rais, but the female leader and her son are still involved in social activities. Nevertheless, the participants of the focus group expressed the opinion that the mahalla should have one strong leader capable of bringing everyone together.

It should also be noted that this particular mahalla located in a district not far from Khujand city was not well integrated due to its residents' constant movements (migration and inter-migration). An additional issue would be that of the relative weakness of the traditional authorities, as a result, social activity was taken over by one energetic person - in this case, a female leader. During the NGO project implementation in the Khatlon region, in one of the villages where the PCIA worked, an analogical situation was observed. In a qishlog populated by various ethnic groups which are not well integrated with one another, the most active person is a middleaged woman but formally the position of rais of the mahalla committee is taken by a man (see Chapter 7).

While conducting a seminar regarding community mobilization in 2013 within the framework of our NGO project, the representatives of ten communities were asked the question: "who is a good leader?" The following answers were given by the participants:

Only one person can lead a community, not everyone can be a leader: The leader should be a person who is selected by' a community. A leader is one who knows the right w'ay, is not afraid of any problems. Instead, he should know' how to challenge them. He should treat all people with respect at all times. A person of good education and upbringing, also, he should be cultured, responsible, honest and modest; someone who trusts his people. Moreover, the leader should possess a wide know'ledge of world issues as well as of religious matters, and he should pass this knowledge on to others. In addition, he should be sociable and forthcoming. The leader should have a 'pure heart'.

The duties and role of a raisi mahalla were defined as follows:

A rais should support Islam; also he should organize celebrations and national enterprises; he should give people good advice, act on behalf of the residents, as well 
as assure access to high-quality products for the mahalla's residences. The rais should help the poor, and protect the health of people and animals in a community. He should know how to lead official meetings, and how to work with the hukumat and jamoat. Other tasks include: urging young men to serve in the army. Also, the rais should lead the mobilization of people during the cotton harvest, as well as during collective works (hashar). He should also explain various issues related to Tajik low, particularly those related to knowledge of the law concerning customs and traditions (see Law 2007/2008). ${ }^{61}$

The above answers demonstrate that the position of the raisi mahalla depends on interactions between a leader and the people in a particular context. Undoubtedly, the trust which a community bestows on its leader is the basis of this relationship. However, the rais is expected to fulfil certain requirements and duties towards a given community in order to earn this trust. The study also reveals that people perceive the rais not only within the category of a traditional leader but also as a person who closely cooperates with the state administration. The question of the relationship between the mahalla authorities and the state administration will be addressed later in this work, although it is important to indicate that in the traditional mahalla, the rais represented the community's interests to the local administration. He was not a civil servant or a person who served only a narrow, cliental group, as is common today.

During the implementation of our NGO project, the most difficult and challenging issue was related to achieving cooperation with communities which were not well integrated and in which the rais was only nominally appointed by the state administration. The solution was to identify the real community leaders, if possible. For example, in qishloq $\mathrm{H}$. located in the Qumsangir district (not far from Kurgan Tyube), populated by a religious and well-organized community resettled from the Gharm region (in the south of the country), the rais was a man in his late thirties who used to work as an accountant in the district hukumat. The local administration designated him as the raisi mahalla; however, he did not enjoy much esteem within his community. Despite numerous attempts to approach him, he almost completely ignored our presence in this mahalla. The real leader was a local mullo, who in addition to his religious duties was involved in various aspects of community life. In 2014 , the above-mentioned rais was replaced by another person. ${ }^{62}$

61 The above quotations are based on notes made by a volunteer, Magda Rapińczuk, during seminars on the topic of community mobilization conducted in April and May 2013, in ten villages within the project "Reinforcing local community development through institutional support for mahalla committees in Tajikistan", implemented by the Polish Center for International Aid and the Tajik NGO Mehrangez. Altogether about one hundred people participated in the seminars.

62 The mahalla consisted of people who originally came from the Gharm region and were re-settled to Vakhsh Valley during Soviet times. They were identified as the political opposition during the civil war, and despite the many years which have passed since peace was established in the country, the state administration continues to scrutinize communities belonging to the 
The next discussed case involves a community led by a person who conforms to the ideal type of a raisi mahalla - a man held in high esteem by the members of his community, who at the time of research (2010) lived in a mahalla located in jamoat Vorukh, Isfara district (north of the country). The rais was a social activist as well as a good organizer. People willingly approached him to express their problems and worries. He made an effort to integrate the community as well as to launch various initiatives to improve their quality of life. Nevertheless, some of his acts could be considered controversial from the perspective of civil rights. The account presented below shows to what extent respect for and trust in a strong leader can legitimize actions which, under different circumstances, might be regarded as an abuse of power.

During the interview, ${ }^{63}$ which was of a rather informal nature, there was a discussion about alcoholism in the context of the social problems in Poland, Russia and Tajikistan. The rais said that he had successfully managed to resolve the problem of alcoholism in his community despite difficulties. According to his own words, there had been three heavy drinkers in his mahalla in the recent past. These men often started brawls after drinking or annoyed their wives, whose complaints had reached the rais through his wife. The rais decided to ask the men to stop drinking, but in vain. On another occasion, when the men got drunk again, he caught them and tied them to posts next to the school premises. He then kept them there for a while to shame them in front of all the members of the community until the men promised to seek medical help and stop drinking. This was how he resolved the problem of alcoholism in "his community". The story was later confirmed by one of these men, an employee of a local jamoat who was also a former English teacher, so a person of quite a high social status. Despite the harsh treatment which he had received, the man expressed his gratitude to the rais for helping him solve his drinking problem.

This situation confirms the extent to which strong leadership is valued. Even if the methods used to restore order might seem inhumane or contrary to the law, people trust that the rais acts for the benefit of all. His actions are not judged by common standards, but are estimated in relation to his overall performance towards the community. The residents understand that the rais punished the men not because he is cruel by nature, but because the alcohol abusers were a threat to the social order. It was the rais's duty to do everything he could to resolve the situation.

Customarily, each rais also has deputies. Sukhareva refers to the position of poykor (literally: one working using one's legs) - a messenger/courier who carried out the requests of the rais regarding various matters related to the business of the mahalla. He was recruited from among the poor inhabitants and sometimes also took responsibility for cleaning the quarter. Nowadays, the term poykor is used inter-

former opposition. It is possible that the government places loyal people within the mahalla authorities in order to monitor the community's affairs.

63 On the basis of an interview' with a 52-year-old raisi mahalla, August 2010. Vorukh. Isfara district (Sughd region). 
changeably with the word vakil (English: lawyer), also used to describe a representative of a mahalla to a jamoat.

In traditional communities, various terms were used to designate important female leaders within local society, though the most typically used terms were koybonu (English: a master of wonderful dishes), khodim, as well as dastarkhani - a word originated from dastarkhan (English: tablecloth) and raisi sano/bonu. According to Sukhareva, a koybonu had a deputy, a khodimi guzar (English: servant of a quarter). The koybonu is elected exclusively by women, without the participation of men, although the head of the quarter has the right to express his opinion about a candidate. The koybonu organizes all rituals and celebrations, such as weddings, funerals, circumcisions, and so forth. She supervises the correct sequence of their observance and helps to receive guests in accordance with the rules of etiquette. She should possess sound knowledge of the norms of behaviour and customs, and good social and organizational skills (Sukhareva 1976: 31, 33; Kandiyoti and Azimova 2004: 335).

Today, in Tajikistan, the social institution of koybonu/khodim has almost completely vanished, especially in big urban centres, since celebrations are often organized by a special Toi Khona (Tajik; English: House of Celebration), which provides all the necessary facilities. For example, in Khujand city, according to my interlocutors, the institution of khodim became extinct in the $80 \mathrm{~s}$. However, in some rural mahallas, the khodim/koybonu remains a key figure in various celebrations and events.

In 2014, I conducted an interview with the khodim of a mahalla located in the Ghafurov district. Mohnisso (64) has been a khodim for twenty-four years. She comes from a poor family, and because of her parents' early demise, she was taken from school after finishing the fourth grade. She was 40 years old when she replaced the older khodim in her community; earlier she had been the khodim's assistant, attending the celebrations with her, learning the customs and traditions and gaining knowledge of all organizational issues. Mohnisso was recommended by Sharifa (the school director at that time) to be the khodim, and she was accepted by the women during a gathering. Later, her candidacy was approved by the amin (raisi) mahalla. In her opinion, a good khodim should be perceived by the community as a clever and sociable person, and she should possess a sound knowledge of customs and traditions. "No event in the mahalla can take place without the participation of the khodim!", she stated during the interview. A khodim should always show respect toward the people who ask her to organize a celebration in their home. She should not touch their belongings or food products unless she is given permission to do so. Customarily, after each celebration is finished, she receives a small remuneration and some goods for her services.

Apart from organizing rituals and celebrations, the khodim and amin of the mahalla mediate in various family matters, i.e. they sometimes even assist in the division of property during divorces, checking if everything is fairly distributed between the involved parties. They can also help to solve a variety of other disputes within the mahalla. In family conflicts, the other local authorities can also become involved, such as the female religious leaders (bibi otuns) and mullos. Within the jamoat 
where she lives, there are twenty-two khodims, though Mohnisso is the main khodim ruling over the others. The women selected her for the position of the head of all the khodims and her candidacy was formally approved by the jamoat authorities. Presently, one of the khodim's tasks is also to observe whether people who organize a certain celebration follow the legal regulations laid out in the Act "On Re-ordering Traditions, Celebrations, and Customs in the Republic of Tajikistan" issued in 2007 (Law 2007/2008).

It should be emphasized that both a rais and khodim are in charge of the practical and organizational aspects of mahalla life - they act as 'managers of the mahalla'. However, not only the khodim but also other female leaders frequently play the role of go-between for the female and male parts of the community.

Every side-street has its leaders, who closely cooperate with the rais/amin of the mahalla, i.e. the rais of a guzar/kucha (Tajik; English: the head of a side-street) or, in north Tajikistan, the sardori kucha (Tajik; English: the elder of a street). A raisi guzar should be selected on the basis of his personal assets, such as good health, a strong personality, honesty, and a record of helping in the organization of various activities and initiatives. He is responsible for the community affairs on a particular street. The raisi guzar also sometimes has deputies. At present in Tajikistan, due to the high level of male migration to Russia, quite frequently women have been selected as raisi guzars. Many of them enjoy high esteem within a given community as they also perform other important social roles, such as those of religious leaders, khodims, teachers, and so forth.

The mashvarat/shuroi muysafedon/shuroi Aqsaqal (English: council of elders) is an important informal mahalla institution. This is a group of respected people who do not occupy any governmental post. The council of elders plays a regulatory role in community life and contributes to resolving a variety of mahalla matters. The elders take part in mediating conflicts within the mahalla and make important decisions, for example accepting candidatures for the mirob (a person responsible for issues related to water and irrigation), considering some family affairs, etc. They also play a vital role in protecting residents from external risks. In some areas, even nowadays, the council autonomously decides on a particular course of action, and the community is obliged to follow their decision (Yusufbekov, Babajanov and Kuntuvdiy 2007: 18, some information added). The council consists mostly of significant members of the community who are well established within the local networks.

Respect for the elderly is part of Central Asian tradition, and it is well-described by the following Tajik proverb: "No elderly, no wisdom". In Tajikistan, the elderly have always been a group of 'first-class citizens', representatives of village-democracy forming the core of the local majlis and expressing the opinion of the whole quarter (Rakhimov 1990: 93, 94). Nowadays, however, due to the many changes triggered by the civil war and the economic crisis, the old model of social relationships has been altered. The rapid transformation has forced people to adapt to new conditions and unforeseen events. Clearly, young people became accustomed to the new environment more quickly, gaining more wealth and authority than they had 
previously enjoyed. Thus, the traditional social pattern has transformed, and the role of the council of elders has also changed.

Periods of turmoil and transition are always associated with a conflict between tradition and change. On several occasions, I had the opportunity to hear the opinions of young people in Tajikistan, Kyrgyzstan and Chechnya, where there is a similar pattern of age-group relationships, who commented on the changing role of the elders. Many young interlocutors presented the view that today, though they respect their elders, the younger generation has more control over social and personal matters. In addition, migration is an important factor bringing change to the relationships within communities.

Young men go to Russia and earn money, so they get more power and freedom. That is why they do not want to listen to the elderly anymore. There have been so many changes during the last wienty years. I am 56 years old, an engineer, I used to be a vice rais of a kolkhoz, I am still professionally active, but sometimes I am not able to keep up with the changing world. Maybe it is good that the young are given more powers and responsibilities. ${ }^{\text {th }}$

Twenty years ago, when an older person from the mahalla asked a young person about something for example in the street, it was 'a law' (eto byl zakon!)! Now', the young do not listen to the elders like they used to do in the past. ${ }^{65}$

Even if the above views do not represent the opinions of all the people in Tajikistan, they demonstrate a particular trend involving a change in the traditional relationship between the generations. However, in the traditional mahalla, elders still have a significant role to play in protecting the long-established social order.

\section{Imams, mullos, shaikhs and others}

Prior to the Communist Revolution, the authority of religious leaders in Central Asia was very strong on every social level, and the leaders were divided according to a specific hierarchy. The categorization of the official clergy included the highranked ulama (well-educated theologians), such as lawyers (qadilqozi) and teachers (mudarris) in well-known madrasas. as well as muftis, imams, etc. Among religious professionals of lesser importance one could list ordinary mullos, sufi (muezzins), and other clerics serving in small mosques, performing different duties connected with religious services. There were also the ishans/ishons (Tajik/Persian; English: they), spiritual leaders, and their followers who belonged to various Sufi brotherhoods and who functioned in various religious centres and mosques. Despite their different functions, religious professionals were granted a high level of prestige in society,

on On the basis of a conversation with a former vice rais of a kolkhoz in a village not far from Khujand city, July 2012.

65 On the basis of a conversation with a mullo from a mahalla not far from Kurgan Tyube city. April 2014. 
since their activities were legitimized by Islamic law originating in the Quran and the Sunna, i.e. indisputable sources of knowledge for every Muslim. Sufi leaders were especially considered to have a direct connection with God through performing various spiritual practices, many of which originated in the pre-Islamic period. Furthermore, there were 'spiritual professionals' who were believed to have possessed the gift of special powers that are not even available to many well-educated ulama. Because of their esoteric abilities, they enjoy great respect, irrespective of their age, gender or family origin until now. This group includes shamans, healers, and clairvoyants.

In the aftermath of the Communist Revolution, restrictions imposed on religion resulted in driving most religious activities underground. Various informal religious networks were developed on the fundaments of the loyalty and trustworthiness of the Muslim community. Nevertheless, many Islamic religious personas were killed or imprisoned, but those who survived managed to pass their Islamic knowledge on to the next generation. They upheld Islamic practices, norms, dogmas and traditions. What is more, they contributed to developing Islamic thought and maintaining ties with the Islamic world. The official clergy (Imain-khatibs ${ }^{66}$ ) employed in mosques under the jurisdiction of the Spiritual Administration of the Muslims of Central Asia and Kazakhstan (SADUM [Russian: Dukhovnoe upravlenie musulman Srednei Azii $i$ Kazakhstana]) were not held in as much esteem as the unofficial religious leaders (Sufi shaikhs, underground teachers - often descendants of famous Islamic scholars, imams of unregistered mosques or so-called 'itinerant mullos'). Thus, despite persecution, the high social status of religious leaders was preserved and they were always involved in the life of the communities. Following the Perestroika and religious thaw, Islam regained its official status, and the activities of many underground mosques and religious leaders became registered (Niyazi 1998: 42-43; Olimov and Olimova n.d.).

As in the past, religious leaders continue to play a significant role in the community. At the local level, apart from the formal religious practitioners, such as the imam khatibs and mullos guzar/kucha, there are also informal spiritual leaders, i.e. ishons, healers, hajis, ${ }^{67}$ as well as other people who possess a relevant understanding of Islamic issues, whose authority is sanctioned by different sources of knowledge and traditional practices. In terms of formal power, the most important religious professional is the imam khatib, since he is bound to higher religious authorities. The imam and mullo are responsible for leading prayers (Tajik/Persian: namaz/namoz, Arabic: salat $\left.{ }^{68}\right)$, performing religious wedding ceremonies (nikoh), reading the Quran during circumcision, reciting funeral prayers (janoza-namoz), accompanying the deceased to the cemetery, and participating in other celebrations. The religious figures receive

66 The imam khatib is an officially employed person who is responsible for the religious affairs in a village.

6* In Islam, a salat namaz'namoz can be led by any person who has some knowledge of suras and the Quran. 
remuneration for their services. The amount depends on the status of a particular person in the mahalla as well as his clients' wealth.

The authority of religious leaders goes far beyond performing religious services. Mullos, shaikhs and other people related to spiritual life have considerable influence on the decision-making process in a mahalla. Religious leaders are very close to the community, since they have been involved in mahalla life for many years. For this reason, they are able to deal with the various problems faced by the community.

In all the communities participating in our NGO project, we have cooperated with religious authorities. In a few cases, mullos have been actively involved in all project activities. For instance, in 2013, in one of the villages, there was a problem with collecting money for a primary-care clinic, which the community had planned to construct with some financial assistance provided by the PCIA. The raisi mahalla and local female leader suggested that I should visit the mullo and ask him to announce during the hutba that money are going to be collected for the construction. We went together with our trainers to talk with the mullo who promised to help us, and as the situation had occurred just before the end of Ramadan, he devoted part of the zakat-Al Fitr ${ }^{69}$ given by the community to facilitate the construction of the primary-care clinic. Obviously, information regarding this fact was very quickly disseminated around the village, and it had a very positive influence on people's opinions about the initiative. Due to a low level of integration and social trust in this particular community, money collection took a lot of effort, but when the mullo legitimized the initiative, the people's attitudes changed to some extent. Finally, when the primary-care clinic started to function in June 2014, the residents expressed a lot of gratitude towards the village's activists, the PCIA and our local NGO partner Mehrangez.

Needless to say, religious leaders differ from one another, from the point of view of the authority they possess within a community, as well as the influence they have, including in relation to politics, culture or economy. In 2010, not far from the Afghan border, in the Shuroobod district, I interviewed a local mullo who was also a Tajik poet and had published several books. He was well-respected by his community, and for this reason he had become a religious leader. However, in the past, the mullo had not been religious, and as a member of the Komsomol organization ${ }^{70}$ had never considered becoming involved in any religious matters. Nevertheless, his father had been a religious professional teacher at the informal madrasa operating under the protection of the head of the kolkhoz; thus, the poet had always had contact with religious life. Over time, he gradually underwent a spiritual transformation and began to teach religion to other people, although during the interview the poet admitted that his preaching was more spiritual in nature rather than being based on a proper

(14 Zakat-Al Firl - charity given to the poor and usually collected by the mosque at the end of Ramadan.

71) Komsomol - the Young Communist League (Russian: Kommunisticheshi Soinz Molodezhi). the youth division of the Communist Party of the Soviet Union. 
knowledge of the principles of Islam. In addition to the formal religious institutions, the tomb of a famous Islamist teacher and clairvoyant (Shaikh Muhhamad Amoni Wali) is also situated in this village. It is a pilgrimage destination. The holy place is protected by the living descendants of the saint, who perform various religious services mostly related to the person of the late shaikh." The qawm of the saint has a very high status in this particular region, and its members are involved in various activities related to business and politics (e.g. the head of Kuliab city was reputed to be a member of the same kinship group). ${ }^{? 2}$

Families who derive their origins from the tura, sayid, ishon, shaikh or khoja ${ }^{73}$ still enjoy a high social status, especially within well-integrated communities, such as the social group of ishons who live not far from Khujand city, in Spitamen district, located in the vicinity of the tomb of the famous theologian and clairvoyant Abdu Rahmon Ata (Langar Ata mazar). A few metres further, there is another grave of a wise man, who according to local legend was the companion of Khoja Ahmat Yassavi (the founder of one of the most important Central Asian Sufi brotherhoods - Yassaviya). This group claims to derive their origin from Abdu Rahmon Ata. The ishons are a heterogeneous ethnic group (the majority are Uzbeks but some consider themselves to be Tajiks), though they are a socially hermetic community. To this day, the ishons of Langar Ata practice endogamy, which is observed especially in the case of the female members of the group. During the Soviet times, ishons were among the authorities of collective farms. At present, they occupy posts in the jamoat, and they perform the role of rais in a few mahallas, as well as having taken over other formal and informal social positions, including those related to religion. ${ }^{74}$

To what extent 'noble families' influence politics at the local level and within small communities requires a separate comprehensive study. Networks of saints' families originated in the pre-revolutionary period, and the religious persecution which took place during the USSR loosened these ties only to some extent. Kinship

"Apart from the tomb, there is a second smaller holy place associated with the shaikh. In the courtyard of the house belonging to the members of his family, there are two stones from the tomb of the saint. This place is especially popular among unmarried women. who come to perform a ritual consisting in pouring water on the stones and saying the dua (a supplication to Allah) asking that they find a husband. The ritual is supervised by a female family member of the shaikh. There are also some other holy places in the village.

72 Based on an interview with the mullo from a village next to the Afghan border, Shuroobod district in the Khatlon region (July 2010).

73 In short, turas are believed to be descendants of Genghis Khan; khojas and sayids are reputed to be the progeny of the Prophet Muhammad or his companions who brought Islam to Central Asia; ishons (also ishans, etc.) and shaikhs are descendants of saints and Sufi masters. Although these categories can be merged with each other, as well as vary from region to region; they constitute special groups which for centuries have been held in high esteem within society, and have exercised great authority in Central Asia. High social standing is hereditary - offspring enjoy the same respect as their ancestors (for more details on the descendants of the saints, see Abashin 2001).

7t On the basis of information gathered during field research conducted in 2012. 
groups created a kind of social class based on a given family's origin. This social class still holds a special place within Tajik society. Boboyorov (2013: 75) indicates that to legitimize the political and economic claims of a certain group, its members use their Islamic identity to govern over social affairs, to integrate other members of the community to harness support for particular economic or political claims. People refer to their sacred origins and spiritual places they are tied to in order to legitimize their privileges and actions. It should be noted, however, that contemporary ideas of the modernization of Islam through cleansing it of old traditions have also undermined the status of 'noble' families. With access to modern types of Islamic education, young scholars of different origins have appeared who criticize the privileged position of the descendants of 'saints', especially in terms of their knowledge of Islam and authority as religious leaders. ${ }^{75}$

Aside from religious leaders, a special place in the communities is designated for a different kind of figure, known for their spiritual abilities, such as shamans (bakhshy), clairvoyants/charm-removers and healers (tabibs). They can be representatives of both genders. They sometimes simultaneously perform the role of informal religious leaders, such as that of ishons or otuns. These 'spiritual specialists' are respected by people, even by those with a more secular approach to life. Some of them are famous within a specific area of the country and many clients come to visit them. Recently, the Tajik authorities have attempted to limit and discredit the activities of 'spiritual specialists'.

Female religious leaders

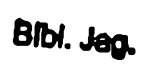

Among the different sorts of religious authorities in a mahalla, a separate role is assigned to female spiritual leaders, bibi otun/bi otun (in Farsi/Tajik, bibi literally means grandmother/aunt/Mrs; the term is used in relation to respectable persons; the other terms include: bibi otin/bibi khalifa/halfa/holpa, oy (ui). otyncha, bibi mullo, etc.). In traditional Muslim communities, there is always a separation between the world of women and that of men. Socially, this has resulted in the development of specific institutions and rituals in many parts of the Islamic world. It also created the need for separate education for women. In the case of the sedentary population of Central Asia, this separation applies to almost all aspects of life, including the architecture of houses, which traditionally were divided into a family part [for women and children, male relatives] (Tajik: darun (English: inside), Turkmen/Uzbek: ichkari), and a front space available to outsiders (Tajik: berun (English: outside), Turkmen/Uzbek: tashkari). In most cases, women are also excluded from public life and the process of formal decision-making in the community. Moreover, traditional law prevents women from entering a mosque; they are allowed to pray at home. In consequence, women have created a separate world with their own traditions and rules, including religious institutions, rituals and practices (Sultanova 2011: 122-125).

75 On the basis of field research conducted in 2014. 
The main tasks of otuns include dealing with religious matters and rituals, as well as teaching religion to children and women. Otuns perform prayers and rituals for women during different community celebrations, such as hayyit in the months of Ramadan and Muharram, mavlud (the birth day of Prophet Muhammad), weddings, funerals, and other similar events. Otuns frequently duplicate the prayers carried out by the mullo in mosques or by men at home. However, they do not lead prayers like an imam - standing in front of the faithful, but rather they pray together with all the women in the first row. They also sometimes lead pilgrimages to mazars. ${ }^{76}$ Furthermore, they perform rituals, specifically for the development of women's spiritual lives (such as Bibi Mushkul-kushod, Bibi-Seshanba) or even provide different forms of healing. In some cases, otuns begin practicing as a result of a spiritual vocation which is preceded by an illness or a series of visions. Some of them are trained in the Arabic language and possess a sound knowledge of Islamic texts (Kramër 2006: 321-322; Kandiyoti and Azimova 2004: 333-335; Gorshunova 2006: 258-261; Peshkova 2009: 8). An otun should have the following characteristics: good family origins (preferably with a religious background), knowledge of religion and tradition, musical/poetic talent, good communication skills. Moreover, she should be distinguished by high moral standards, honesty, kindness, a broad worldview (not only associated with religion). An otun should treat her profession as a service to the community. Additionally, otuns should not participate in gossip, disputes and quarrels; she should also have a stable family life (Sultanova 2011: 127; Cieślewska 2014).

It is difficult to generalize about the influence of women religious leaders on the community. Certainly, since the division of genders applies to almost all aspects of life, they contribute to creating a homogeneous women's world with its own traditions and rules, which consequently merges with the life of the mahalla. Abashin (2006: 14) makes some interesting remarks about the role of women in the conflict between various religious authorities which he came across during his research in the Ferghana Valley. According to him, in village O., various opposing groups tried to gain control over religious activities, using all possible means. One of the groups introduced important innovations during prayers in the mosque - women, especially older women, were allowed to take part in daily prayers, and they were even given an honourable place in the mosque. In this way, the reformers tried to influence and take control over the female part of the community. The author does not refer exclusively to female religious leaders, but such a situation indicates that the separation of men's and women's religious lives can lead to the development of different spheres of influences, which consequently shape the internal affairs of the mahalla.

Kandiyoti and Azimova (2004: 331 ) indicate that otuns played an important role in preserving Islamic tradition during communism, which was confirmed by my

76 For instance, during Ramadan, every evening a night prayer (Arabic: tarani ih) takes place in mosques for men. women sometimes also gather at home where they are led in prayer by a bibi otun. 
research. While the men were more frequently engaged in work outside the community and were exposed to external influences, including atheisation, the women tended to stay at home. Hence, they led a more traditional way of life, adhering to the old customs and practices and passing this knowledge on to their children. Most women's religious activities were led by the otuns, who were an important channel of religious knowledge and practices for the local population. Undoubtedly, otuns are significant actors in the fields of teaching, religious practice and socio-religious activities, as they represent the interests of women in the community. In many cases they also provide recommendations on important community matters to men (see Peshkova 2009).

As my research regarding the social role of female religious leaders has shown, at present in Tajikistan, otuns - like all other religious leaders - are under the close supervision of the state. Particularly, the ban on religious education in places other than officially registered religious schools has impacted the activities of many religious professionals, including otuns. The authorities claim that a person should pass an exam to be eligible for teaching others, but in reality the relevant conditions to obtain a certificate by an individual religious figure do not actually exist. As a result of the imposed restrictions, most teachers of religion (including otuns) have ceased to teach people or they have continued their activities informally. ${ }^{77}$ There are reports of secret police raids on religious classes set up at private houses, with searches for illegal literature, and other forms of intimidation and repression of religious activities (Mamurzoda 2011; USCIRF 2011; my own research). The restrictions imposed on Islamic education may in the long term decrease the otuns' authority and limit their role in the performance of rituals and celebrations.

Moreover, in 2011, the hukumat of Khujand city (municipality) established the Council of Bibi Otuns (Tajik: Shuroi Bibi Otunho). According to an official from the Religious Affairs Department in the hukumat of Khujand, the most important task of this entity is to shape the otuns' views on religion and society. In fact, however, the main goal of the shuro is to control female religious leaders and their actions. ${ }^{78}$

Strengthening the links with the rest of the Islamic world in the Middle East and South Asia has brought with it a trend in Islamic teaching advocating the purification of Islam of local practices and traditions, which are considered to be innovations (bida) and even sometimes idolatry (shirk). As a result, the traditional otuns have been criticized, especially concerning rituals which have to do with pilgrimages to mazars or other celebrations of a heterodox character. The disapproval of otun traditions is especially evident in big cities or religious regions, such as Isfara, as some people consider them to be backward and standing in conflict with standard Islam. Many modern female teachers also do not support the otuns and their practices. ${ }^{79}$

"Information obtained between 2010 and 2014, in different places throughout the country.

7* Based on information gathered during field research conducted in 2014.

74 Based on information gathered during field research conducted in 2014. 
Nevertheless, otuns still enjoy popularity among a certain part of the society, such as among those women who live in rural areas, in close-knit communities where the status of religious leaders is high. Rites and rituals performed by female religious figures are important from the point of view of the consolidation of a community. People participate in communal rituals, pray and socialize together. Otuns pass on certain moral values and teach a specific pattern of behaviour, especially to the younger generation of girls, in accordance with Islamic and Tajik/Uzbek cultural norms.

\section{The mahalla committee}

The mahalla committee (MC) derives its origin from the Soviet times; however, only recently has their registration within the territory of a jamoat been regulated by a new law: the Act "On Public Self-Initiative Bodies" (Law 2008). The MC is comprised of 5 to 15 people who are members of the local elite. In most cases, they would be rich farmers, religious leaders, former kolkhoz elite representatives, as well as teachers, medical doctors, and others. According to the above-mentioned act, the main purpose of the MC's activities is to regulate the mahalla's affairs and to represent the community to jamoat authorities. In addition, the MC should gather information on the situation of the residents, including its most vulnerable families, and about the most pressing needs within the community. The members are responsible for initiating and arranging public works, such as repairing infrastructure, building new objects, launching enterprises, the mobilization of the youth for army service, and so on. The MC is also expected to collect money for the common fund of the mahalla, which can be used to help poorer residents and to arrange enterprises or events. The performance of the MC depends on the level to which a particular community is integrated. In reality, however, the MC holds little significance in many areas of the country, and it is only a unit which is formally established by the jamoat. In some places, residents are often not even aware who the members of the MC are in their community.

As the experience gained during the implementation of our NGO project has shown, there are different sorts of units within the structure of the MC, including a women's unit. However, in reality they often do not function. Moreover, the composition of MCs has changed over the years. The main reason behind these changes is labour migration to Russia, since a significant number of men from the communities stay in Tajikistan only during the winter season, while they work abroad during the rest of the year. As a result, some of the MCs admit any people who have stable jobs as their members (teachers, farmers, businessmen, etc.), but not always those who are respected by their community or those who are social activists. A side effect of male migration is the increasing participation of women in the MCs but their role remains relatively minor. In traditional mahallas, the rais/ amin, religious leaders and elders are the most respected members of local society, and - despite the formal registration of the $\mathrm{MC}$ - it is they who are the decisionmakers within the communities and it is also usually they who are members of the 
MC. In such cases, the MC institution established by the state merges with indigenous/traditional institutions.

\section{The structure of the mahalla hierarchy}

The mahalla's authorities include: the head of the mahalla, mullos, the imam khatib, and sometimes the shaikhs of mazars, healers, as well as members of the council of elders, mirobs, and various professionals. Additionally, there are always various informal actors who participate in the decision-making process, such as wealthy businessmen, representatives of the state authorities and, in rural areas - the managers of farms (a former kolkhoz elite), and others. All these people represent different types of power structures, which influence the mahalla's internal affairs. The female circle is separated from the men's world, and in most cases women as well as young men are excluded from the formal decision-making process. However, as mentioned above, some female leaders can mediate in different kinds of matters, especially related to family affairs, but they also mobilize women to influence their male relatives to advocate certain issues. Women leaders include: otuns, khodims, teachers, medical professionals, local healers, clairvoyants, momo-doya, ${ }^{80}$ as well as other respected persons. The mahalla committee is a formal organ established by the jamoat, and its members belong to the above-mentioned category of residents.

Table 3. The authorities of a mahalla

\begin{tabular}{|l|l|l|}
\hline \multicolumn{1}{|c|}{ Category } & \multicolumn{1}{|c|}{ Characteristic } & \multicolumn{1}{c|}{ Role in community } \\
\hline $\begin{array}{l}\text { Head of the } \\
\text { aminalla: rais/ }\end{array}$ & $\begin{array}{l}\text { Traditionally, a person elected by } \\
\text { the community, or nowadays often } \\
\text { appointed by the state authorities. }\end{array}$ & $\begin{array}{l}\text { Supervision over the mahalla's } \\
\text { affairs, performing organizational } \\
\text { duties, responsible for represen- } \\
\text { ting the mahalla before the state } \\
\text { authorities and other social actors. }\end{array}$ \\
\hline Council of Elders & $\begin{array}{l}\text { Respected community elders } \\
\text { (men) without any formal affilia- } \\
\text { tion; members of the local elite. }\end{array}$ & $\begin{array}{l}\text { Regulatory and advisory role with- } \\
\text { in community life, participation in } \\
\text { the decision-making process. }\end{array}$ \\
\hline Committee & $\begin{array}{l}\text { Selected residents of the mahalla } \\
\text { including the vice rais, the raises } \\
\text { of guzars/kucha, religious leaders, } \\
\text { and others. It is a formal unit which } \\
\text { should be officially registered in } \\
\text { the jamoat. }\end{array}$ & $\begin{array}{l}\text { Executive body of the community, } \\
\text { which is expected to facilitate the } \\
\text { work of the head of the mahalla } \\
\text { regarding community affairs. }\end{array}$ \\
\hline
\end{tabular}

kn In the past, the momo-doya performed the role of traditional midwives, but at present in inost cases their role is limited to performing rituals related to pregnancy and new-born children. such as the practice of blessing women during certain stages of their pregnancy. or gavora handon (the cradle ceremony). which is organized 40 days after the birth of an infant (involving the ceremonial placing of a baby in a cradle), and other life-cycle rituals. In remote villages, the momo-doya sometimes assists during labour but - according to Tajik law - this is illegal. 
Chapter 2. Traditional Social Networks and Groups...

\begin{tabular}{|l|l|l|}
\hline \multicolumn{1}{|c|}{ Category } & \multicolumn{1}{|c|}{ Characteristic } & \multicolumn{1}{c|}{ Role in community } \\
\hline $\begin{array}{l}\text { Women's } \\
\text { representative } \\
\text { - khodim/koy- } \\
\text { bonu }\end{array}$ & $\begin{array}{l}\text { A respected woman with a sound } \\
\text { knowledge of tradition and good } \\
\text { organizational skills. Nowadays, } \\
\text { this social institution is slowly dis- } \\
\text { appearing. }\end{array}$ & $\begin{array}{l}\text { Responsible for organizing mahalla } \\
\text { activities within the female circle; } \\
\text { representing women to the mahal- } \\
\text { la authorities; mediation in family } \\
\text { affairs. }\end{array}$ \\
\hline $\begin{array}{l}\text { Mullo/imam/ } \\
\text { other spiritual } \\
\text { leaders }\end{array}$ & Spiritual leadership. & $\begin{array}{l}\text { Performing rituals and celebra- } \\
\text { tions, religious education of men, } \\
\text { informal influence over decision- } \\
\text {-making processes, mediation in } \\
\text { family affairs. }\end{array}$ \\
\hline $\begin{array}{l}\text { Bibi otun/other } \\
\text { terms }\end{array}$ & Spiritual leadership. & $\begin{array}{l}\text { Performing rituals and celebra- } \\
\text { tions, informal religious education } \\
\text { of women and girls, conveying } \\
\text { knowledge regarding traditional } \\
\text { customs and practices, mediation } \\
\text { in family affairs. }\end{array}$ \\
\hline
\end{tabular}

The model of a mahalla's hierarchy differs from community to community, and depends on the level of the internal integration of a particular mahalla. Communities which have lived together for many years as well as those of a homogenous ethnic composition are the most integrated. The consolidation of a community can also be stimulated by common economic and social interests. To understand the specific pattern of relationships within a mahalla, it is also necessary to distinguish the traditional division of the community in accordance with the hierarchy of social standing, age, gender, education, and profession. In most cases, the mahalla elite act as an intermediary between the state authorities, external actors (including INGOs and LNGOs) and a given community. Due to rising income disproportions and the unequal distribution of wealth resulting from neglecting to introduce necessary economic and social reforms, disparities among groups have increased. Consequently, members of the elite tend to use its power and influence to gain control over major resources and redistribute them within their own network groups. This situation has led to the further degradation of the mahalla's role as a self-governing communal organization, reshaping the mahalla into a bureaucratic administrative unit.

\subsubsection{Everyday Communal Practices in the Mahalla}

\section{Hashars}

The hashar (Tajik/Uzbek), ashar (Kyrgyz) or assar (Kazakh) is the collective work of a community. This is a traditional form of mutual help, popular in Central Asia, as well as in other parts of the Muslim world. It involves the participation of representatives of all households in work for the community. Hashar is practiced 
among relatives and neighbours as a form of self-help in building houses, organizing festivals, preparing for funerals, weddings and circumcisions. In addition, the institution of hashar applies to collective work at the village level, such as cleaning irrigation canals or repairing infrastructure. In such cases, it is often ordered by the jamoat authorities and the raisi mahalla and a committee are in charge of its organization. The institution of hashar is sanctioned by local customary law and refusal to participate in it may be socially stigmatized.

Nowadays, the de-collectivization of previously collective farms and the land reform have disturbed the balance in Central Asian societies, which for centuries had been based on communal (collective) institutions. This has resulted in a decrease in the significance of the hashar in many regions. Wealthy villagers sometimes refuse to participate in the hashar and they simply pay money as compensation. Single women (often wives of migrants) do the same. In other cases, people demand payment, in cash or in kind. The labour migration of part of the male population has had a significant impact on changing the hashar institution - in some households there are no adult males who could participate in collective work. There are examples of women who carry out the infrastructure works within the hashar due to the lack of men in their village. The hashar is also currently less frequently organized as a neighbourhood initiative, for instance in order to build someone a home (unless only the close family circle is involved). ${ }^{81}$

Boboyorov (2013: 93), providing examples from the southern Khatlon region, states that the hashar is nowadays practiced only within large extended families which cooperate with each other to organize family events, construct houses or perform other works, but due to distrust stemming from indigenous moral norms people do not participate in common works outside of their family circle. Hashars which involve more than one big family are currently only organized by the mahalla and state authorities.

The institution of the hashar was also employed by the Soviet authorities within the framework of the so-called subotnik (English: organized collective works), and in this form it has survived up until the present day. International organizations have also recognized the potential of the hashar, which is used as the cashless contribution of local communities in projects implemented by international donors. In this case, the hashar is used to implement specific project tasks. It should be noted, however, that the transformation of traditional institutions depends on many factors, and so all of the assumptions presented here regarding the hashar are given in rather general terms. Further research on this issue should be conducted to analyse the potential changes within this practice.

*I This statement is based on my own observations, confirmed by Agnieszka Makowska`s experiences during the implementation of projects targeted at improving water infrastructure with the participation of local communities in Kyrgyzstan and Tajikistan. 
Communal places in a mahalla: mosques, shrines and chaykhonas

A mosque is not only the centre of religious life but also a place where people gather and solve important local matters, as well as a place of learning moral and ethical values. Particularly, the mahalla mosque serves not only as a place of worship, but also as a kind of club for elder men, a place of communication for the male members of the community. As mentioned above, customary law excludes women from attending mosque.

The Central Asian tradition of women not being able to enter a mosque is controversial from the point of view of classical Islamic thought and the Quran; however, it is customarily legitimized by some Islamic scholars. Currently, the custom has provoked vivid discussions and much controversy, not only in Tajikistan but also in the other countries of the region and worldwide. In 2004, the Tajik Council of Ulama issued a fatw $a^{82}$ prohibiting women from attending mosque, claiming that the buildings lack enough space for men and women to pray separately, but some argue this decision resulted from government concern that women would participate in banned Islamic groups, such as Hizb ut-Tahrir.

This has further triggered a lot of tension between the pro-governmental clergy and the opposition, represented mainly by the Islamic Renaissance Party of Tajikistan (IRP). The country's only mosque that officially allowed women to pray, which was also the IRP's Dushanbe cultural centre, was destroyed in a fire in October 2010. Thus, now there is no mosque available for women in Dushanbe. However, in the central mosque in Khujand city there is a hall where women can pray, but few attend the mosque for daily prayers. On Friday, no woman is allowed to enter a mosque during namoz al-jamah (English: a Friday prayer). Women can pray in mosques built on the territories of holy places (mazars). In this case, sometimes, even a separate place for women is organized.

The importance of the mosque as a hub for male social life in the mahalla is rooted in the old tradition of merging a house of worship with a meeting place (Sukhareva 1976: 23). This theory can be confirmed by the fact that up until the present day, in the upper regions of Tajikistan, there are 'houses of fire' (Tajik: aloykhona), where men socialize and perform rituals. According to some of my interlocutors, they attended aloykhona in the 1970s and 80s. An aloykhona is sometimes a building located next to a mosque, and thus only serves as a place for holding meetings (also see Rakhimov 2007: 306, 6).

Most mahalla mosques are built with funds collected by the community. In the pre-Soviet period, a mosque was often a separate legal entity, a part of the waqf property, and typically consisted of buildings with a plot of land as well as other goods. According to Sukhareva (1976: 25), the renovation of a mosque was usually paid for by the community or financed by wealthy residents. This was considered an act

*2 In classical Islamic jurisdiction, a fati'a is considered to be an opinion regarding a certain topic. In Tajikistan, fantas issued by the official Ulama are treated as an obligation by pro-governmental religious leaders. 
of thanksgiving (savob) and raised the prestige of the potential donor. Almost every mosque ran a madhhab for boys. In some mahallas there were also schools for girls organized by female teachers in their houses.

As described above, during the Soviet period, many mosques were shut down or turned into storehouses. The community gathered to pray in private houses, teahouses, clubs, 'red corners' (recreational rooms in factories) or in solitary places outside populated areas, as well as other places. Officially, there were only a few dozen mosques during the Soviet period, but in fact, there were hundreds of informal mosques across the country (Niyazi 1998: 42).

There are different types of mosques, but a typical small mosque in rural areas consists of at least two halls: a bigger hall for praying, and a smaller place for meetings often with an ivan attached to it. ${ }^{83}$ There is also sometimes a bower which serves as a rest area for the elderly as well as for performing prayers in the summer. Additionally, a separate small room (a kind of cubbyhole) is also often included, used to store fumiture, utensils and other things which are the common property of the community and are used during gatherings and celebrations. Most mosques have a takhoratkhona - a place to do takhorat - the ritual ablutions before namoz. Pisarczyk (1974: 47-55) also describes another space which is sometimes attached to mosques - the chillkhona, where chilla (English: forty) is performed. ${ }^{84}$

Apart from its religious role, the mosque serves as a place of gathering for men and for organizing meetings with outsiders, such as representatives of the state authorities or NGOs. All important community matters are considered within the mosque. In bigger mahallas, there are a few mosques (kucha mosques). Frequently, one kinship group is associated with one kucha mosque. In the case of settlements inhabited by a few ethnic groups, each kucha mosque serves as a place of gathering for a particular ethnic group. For example, in village F. (Bokhtar district), where our NGO operates, there are three mosques divided between two ethnic groups: former migrants from Faizabad (two mosques) and people from Gharm (one mosque).

In some mahallas, there is a chaykhona (a tea-house), where men gather to discuss things and for entertainment purposes. Official meetings can also be held there.

Apart from mosques, shrines are another important place in terms of a community's spiritual life in Central Asia. They are known by a variety of Arabic/Per-

83 An ivan is a space, usually with a roof. walled on three sides, with the front side entirely open. The ivan is a characteristic element of many buildings in Central Asia, including homes and mosques.

$x+$ In this context, the chilla is a forty-day long seclusion from the outside world. The chilla usually involves fasting, reading the Quran and mystical revelations, sometimes contact with spirits that indicate which mystical path to follow. The chilla can be performed in a private house or in special places attached to mosques or mazars (chillkhona). During the period of seclusion. a person is expected not to see or communicate with other people. The person samily usually provides him/her with basic food and drink, as well as any other necessary things. In Tajikistan, I saw a place set aside for the chilla only in mazars; however, in Bukhara, I also observed a space set aside for chilla in an abandoned mosque (also see Rakhimov 2007: 185, 261). 
sian and Turkic terms, with mazar being the most popular in Tajikistan ${ }^{85}$ These shrines can take on different forms. The simplest can be a mound of stones over a graveside, a brook or a tree (often big plane trees are found in mazars). The trees can also be decorated with votive pieces of cloth. Another popular type of mazar is the tomb of a holy person or saint - they may take the form of small humble graves or monumental buildings, which can attract thousands of pilgrims every year (McChesney 1996: 72).

In some cases, the cult of pre-Islamic local saints and real or fictitious heroes was adapted to Islam, and legendary heathen figures became Muslim saints. Both men and women can visit a shrine to ask a saint to provide them with protection (although mazars are frequently associated with the religiosity of women). There are also separate mazars only for women or only for men. Some places are widely known for their healing features, such as the treatment of infertility, various diseases, disabilities, and so on. The act of visiting places of particularly revered imams, shaikhs, and other 'holy' people can even be regarded as a 'little pilgrimage' to Mecca (Malikov 2010: 118 , some information added).

Mazars are places which function in-between reality and the sacred world, the living and the deceased. They function as a bridge between human beings and God, providing a pilgrim with a direct link to Allah. Shrines are pilgrimage destinations visited by both men and women, and they are attended according to the specific characteristics of a particular place, such as during select days of the week, religious feasts, or a particular time of the year. It is important to emphasize that the rituals and prayers performed at shrines are a fusion of pre-Islamic practices and Islamic traditions (Malikov 2010: 123).

As already mentioned, the Soviet state's promotion of the ideology of atheism resulted in the closure of many mosques. However, as McChesney (1996: 73) points out, the government's attitude toward shrines was ambivalent. The performance of pilgrimages and rituals in mazars was prohibited by law, yet many historic holy places were renovated and protected by the state. Nevertheless, visiting shrines was easier than visiting mosques, since the formal character of the latter exposed them to constant supervision by the state. Subsequently, mazars contributed to preserving part of the Islamic tradition in Central Asia.

Contrary to the opinion that the cult of saints and mazars is at variance with the principles of Islam based on strict monotheism (tawhid), ${ }^{80}$ pilgrimages to holy places

"s. Mazar or ziyaratgah (rooted in the Arabic word: 10 visit) - a place (gah) one visits [on a pilgrimage]: gadamgah (a stepping place [a site where a saint is believed to have stopped or rested]); rawzah (garden, enclosure [a metaphor for paradise or the next world]), dargah or astanah (doorway or threshold [symbolic crossing from material life to the sacred world]): mashhad and nazargah (a place of witnessing [the power of God]); marqad or mazja (bed [resting place]). There are also other terms which describe the same phenomena (McChesney 1996: 72).

*6 Tawhid - the doctrine of the Oneness [of God], which is strict monotheism based on the belief that God is the one and only (wahid) and that he is unique (ahad). 
are important communal practices and symbolize the spiritual cohesive ties of the community, which are inextricably linked with the cult of ancestors. ${ }^{87}$

In terms of the role of mazars for a mahalla community, many mahallas have their own holy place. Some of them are widely known in a certain region and are visited by many pilgrims. In such cases, the community (or avlod of a saint buried in a particular place) profits from having a shrine. The living descendants of a saint who protect the shrine usually enjoy high esteem, which they have inherited from their holy ancestor. In many cases, these avlods form the local elite who hold a variety of powers, including 'secular' influence over important resources, such as land, water and important posts in local administration. The afore-described group of ishons settled around Langar Ata mazar, and the qawm of Shaikh Muhhamad Amoni Wali can be given as examples of these privileges. Without this hereditary social status, it would sometimes be difficult to achieve certain benefits (also see Boboyorov 2013: 74-76, 86-87).

\section{Celebrations and events}

There is a wide choice of literature regarding Tajik celebrations; however, most of it is concentrated on ethnographic descriptions of practices and rituals, and less on analysing their influence on relationships within a community. Celebrations are an important part of mahalla life, linking its members and helping to build and maintain social relations.

Sukhareva (1976: 26-29) describes ritual feasts and celebrations organized in $19^{\text {th }}$ century quarters with the participation of all the members of the community. Muslim celebrations, weddings, circumcisions, funerals, celebrations associated with annual cycles, such as Navruz, the end of Ramadan (Eid al Fitr/Uraza-Bayrain - the Festival of Fast-Breaking), Kurban-Bayram (the Feast of Sacrifice), commemorations of the deceased and other smaller events to celebrate the birth of a child, putting an infant into the cradle, and so forth, all provided an opportunity to meet with people and to maintain neighbourly relations. Events sometimes lasted several days and were attended by many guests. Each feast was performed in line with tradition, taking into account specific expenditures, the preparation of particular dishes, the seating arrangements for guests, and the like.

The whole community participated in the preparation of big events. Men were required to chop wood, fetch water, chop carrots for the traditional plov, ${ }^{88}$ as well as serving guests. Women were expected to help in the cooking or performing of other tasks. They also brought food or a small gift for the host. In this way, the host was only required to receive and serve the guests, even though this in itself was not an easy task. For less affluent residents, inviting a large number of people was often

*7 It should be mentioned that mazars can serve only as a place to pray to God. Pray ing to "saints" is considered to be shirk and is strictly forbidden by Islam.

* Plov (also Pilav) - a dish made of rice and meat with finely chopped carrots cooked in a big pot. Traditionally plov should be prepared by men for big communal celebrations. 
associated with expenditures exceeding their financial capabilities. The narrowest circle of guests consisted of the closest relatives and the elders of the mahalla. At large events, all residents of the mahalla were expected to participate (not only permanent inhabitants, but also temporary residents). Participating in such events was considered the sacred duty of each mahalla member - not taking part was tantamount to an insult to the host (Sukhareva 1976: 26-29).

The organization of events was associated with attending communal rituals. For instance, in the case of a death, all adult residents of a quarter were required to visit the house of the deceased to take part in prayers. All the men performed a prayer for the repose of the soul (janoza-namoz) and accompanied the deceased to the cemetery. The women mourned at home together with the female relatives of the departed. All the women of the mahalla were obliged to wear special mourning clothes during the funeral rites. Active participation and assistance in organizing events in the mahalla sustained neighbourhood ties and raised the community's spirits (Sukhareva 1976: 26-29).

Each quarter maintained a number of communal everyday articles for organizing events, such as dishes, vessels, furniture, tablecloths and the like, which were stored in a room at the mosque. It was also common for all mahallas to have certain special items used during funerals, such us biers or pairs of shoes worn during bad weather by the men who carried the bier (Sukhareva 1976: 22).

Aside from the members of a given mahalla community, representatives of other quarters also participated in such events. Mutual invitations to various events and ceremonies served to maintain neighbourly relations. Quarters which were related by social ties were called oshkhur-u obkhur or toy-khur in Tajik (English: eating and drinking [together] or eating during the [same] gathering [toy]). The head of the quarter usually decided who should be invited by the organizer of a certain event. Thus, rich families were obliged to invite more people from the other mahallas than poorer ones. Reciprocal visits to neighbouring quarters were performed mainly by men. Women were limited to their own community, with the exception of visiting relatives who lived in other places (Sukhareva 1976: 46).

The tradition of communal enterprises and events continues to exist. Inviting guests and socializing is a part of Tajik culture. Weddings and the circumcision of boys are particularly important, and - as in the past - they involve many days of feasting and rituals. Family members, relatives, neighbours, friends and co-workers are invited to celebrate together. Organizing celebrations is vital for maintaining social networks and relationships.

To arrange a grand wedding reception, parents frequently begin to collect funds during the first years of a child's life. In the case of a boy, money is also collected for his circumcision. All of a family's savings are often spent on the wedding reception, and afterwards the family can be left in hardship. Many young men go abroad to earn money for the purpose of organizing a wedding. This subject has come up regularly during conversations with people in Tajikistan. Many people have been working for years to save thousands of dollars to be spent during a weeklong event. As a result 
of their wedding, some young couples fall into debt for years. While organizing big events is rooted in tradition, the custom was maintained and even expanded during the Soviet period, especially in the Khrushchev era, when the relative prosperity during that time resulted in organizing elaborate events in a truly Eastern style, especially by wealthy officials.

In the rural areas and in the urban mahallas, frequently all the residents living at a certain place were invited to the various celebrations. Some kolkhozes maintained a special fund to facilitate weddings and other events. One of my interlocutors and former co-workers, who used to be the vice director of a kolkhoz located in Spitamen, told me that when important celebrations were planned by his kin (he comes from a family of ishons), he would drive around in a car throughout the area of his kolkhoz talking through a megaphone and inviting everyone to come for the event. In urban settings, the residents of neighbouring communities were also invited for important events in another mahalla. At present, this tradition is no longer followed.

In 2007, in accordance with the recommendations of the Tajik President, the parliament adopted the above-mentioned Law "On Re-ordering Traditions, Celebrations, and Customs in the Republic of Tajikistan", popularly called the "Tanzim law" (Law 2007/2008). The act was passed so as to regulate expenditure for weddings and other ceremonies, and to deal with the negative consequences of the organization of big events on the family budget. The new law laid out certain conditions. Only 150-200 guests can be invited to a wedding and only one hot meal may be served. There should be no more than four cars in the wedding cortege, and the musicians can play for only three hours during the celebration. The families of both the groom and bride should participate equally in the financing of the ceremony. In terms of circumcisions, limitations were also introduced in the number of guests. In contrast, a funeral can be attended by an unlimited amount of people but additional celebrations, such as the events organized forty days and one year after a person's demise, are also regulated to 80 and 100 guests, respectively. The penalty for abusing the law is 2000 somoni - roughly 350 USD (Marat 2008).

The Tanzim law is implemented at the local/jamoat level through the introduction of a special committee and a post for a person who is responsible for implementing the law (a kind of an event and religious specialist, also sometimes called the Tanzim). He is employed in the jamoat and is expected to monitor all events, as well as the mosques and imams within the territory of a particular municipality. Any conversation with such a specialist should always involve the art of diplomacy because of his controversial role within the community. The people who perform the role of a Tanzim can have a variety of functions within local society, including being members of the local religious elite.

In order to control the number of guests, jamoat representatives attempt to supervise the expenditures made by the event organizer. For example, they have the right to see how many kilograms of rice were bought to cook the traditional plov dish in order to calculate the number of people invited (usually half a kilogram of rice per person is considered appropriate). They can also visit a wedding at any moment to 
monitor the event, the musicians' performance, and so on. The mahalla's authorities also participate in monitoring celebrations, including such people as the rais, mullos, bibi otuns and khodims. ${ }^{89}$ Additionally, the khodim's work is also appraised in order to determine if she observes legal regulations. If a khodim does not follow the principles of the law, the jamoat can limit her activities and negatively influence her reputation. ${ }^{90}$ In addition, repeatedly bibi otuns are asked by the jamoat to talk with women about limiting expenditures for such celebrations. The otuns are also requested to monitor events and to inform the authorities about any violations. ${ }^{91}$

In practice, however, the law is not easy to enforce, since social pressure to organize big events is strong and many people evade the formal rules. In addition, 'the celebration specialist' is usually a member of the local network, and so in some cases he cannot or does not want to monitor his relatives or neighbours.

\begin{abstract}
Monitoring celebrations and events is a very' difficult job. The 'Tanzim' is only an administrative post. A person who holds this post is under constant pressure from many sides, such as from the jamoat, the secret service $(K G B)$, the prosecutor's office, everyone wants to find some cases of violations. But the person is also a member of his community: If he informs on someone then people will not respect him, nohody' will shake his hand, and he will be not invited to communal ceremonies. He alw'ay's has to be very careful and find a balance between the authorities and the people. $^{\text {.2 }}$
\end{abstract}

Some people provide informal gifts to the specialist or the authorities of the $j a$ moat to 'cordially' thank them for turning a blind eye to the way a party is organized. More wealthy citizens, who are obliged to invite a significant number of guests because of their wide circle of personal contacts, decide to pay the penalty in advance, including this expense into their wedding budget. For instance, my acquaintance's wedding was attended by about 5,000 people, but his family was not particularly concerned about the law. There is also another way to evade the law: one can extend the number of wedding days and invite guests in stages, i.e. only a particular number of people come for the reception itself, while others are invited to participate in celebrations organized on subsequent days.

The legal act has raised a lot of controversy, with the majority of my interlocutors expressing the opinion that placing a limit on expenditures is a good idea since many families go bankrupt only because they want to meet social expectations by organizing an elaborate ceremony. However, some people also indicated that big events are

*u I interviewed three 'celebration specialists"; the first was interviewed in the Shuroobod district (Khatlon region) in July 2010; the second - in the Isfara district (Sughd region) in August 2010 ; the third - in the Ghafurov district in July 2013.

92 The quotation comes from an interview with an employee of a jamoat in the Ghafurov district in June 2014. 
rooted in Tajik tradition and they serve to cement relationships among people. Some hesitate between obeying the law and following tradition. Others say that the law does not bring many benefits, because hosts invite a smaller number of guests, but simultaneously they do not limit their expenditures, organizing sumptuous celebrations, in this way raising the prestige of a family. Undoubtedly, the law is favourable for families who are not capable of organizing grand events.

Regarding the mahalla, despite the advantages of limiting expenditures, the act has impacted the relationship among residents of mahallas, especially in terms of maintaining ties between the rich and the less affluent members of a community. In the past, all inhabitants were able to meet during communal events and socialize with each other, irrespective of their social position. Traditional practices and ceremonies maintained the collective identity of a community. Today, since the amount of guests is restricted, wealthy residents tend to organize celebrations to which they invite only members of the local elite. The poor residents are often marginalized, which further deepens the existing social gap and weakens the mahalla as a selfgoverning, social organization.

\section{Traditional norms and customs - 'adab'}

The life of a small community, such as a mahalla based on bonds of kinship and neighbourliness, has its own rules which regulate social relationships. These rules are described by the Arabic term adab which signifies a habit or hereditary norm of conduct, a custom derived from one's ancestors and other authorities, who have passed it on as a model of behaviour (in the religious sense, the sunn $a^{93}$ of the Prophet Muhammad also constitutes such a model). The $a d a b$ has content of both an ethical and a practical nature, including the "high quality of the soul, good upbringing and courtesy" (Gabrieli 1986: 175). Additionally, apart from its social and ethical meaning, $a d a b$ applies to the sum of knowledge which makes an individual courteous and cultured (as distinct from 'ilm. learning [in the religious sense], Quran, hadiths, and figh) (Gabrieli 1986: 175-176).

In a mahalla, adab means the customs and rules passed on from generation to generation and which are part of the informal education of children. The relation of this term to Islam once again shows the influence of religion on all the social and family systems within a community.

4: Sunna, also spelled sunnah (.1rabic: habitual practice) - the body of traditional social and legal customs and practices of the Muslim community. Its inost common usage denotes the examples, deeds, sayings and unspoken approval of Muhammad as recorded and systemized in the hadiths. The sunna of Muhammad has generally come to be considered obligatory by mosı Muslims and comprises a source of knowledge as well as a basis for the interpretation of Islamic law - the shiaria (Dziekan 2001: 331 ). 


\section{Social control in the mahalla}

In view of the fact that a mahalla consists of a complex set of social institutions and rules regulating social order, it possesses great potential for controlling almost all areas of its residents' lives. People identify with a particular mahalla not only as the place where they live but also as a community whose rules are determined by certain social norms and behavioural patterns which must be followed by all residents. Breaking the rules can be severely condemned by the community. In this context, the mahalla regulates even very private aspects of life, such as family issues, clothing etiquette and whether or not one attends mosque. Since people are concerned about public opinion, they attempt to follow communal rules to avoid gossip and being ostracized.

Conforming to certain norms is also related to compliance with the rules of etiquette in relationships between members of different social groups, such as men/ women, the young/the elderly, and so forth. Moreover, organizing weddings or circumcisions is not simply a private matter within an individual family, as in Western cultures, but is an important issue for the whole community and is also subject to social control (Urinboyev 2011: 49-52).

Feuds among neighbours, serious disputes between family members, such as divorce and domestic violence, are frequently resolved by the mahalla authorities mediating between the opposing parties. The existing social norms seal the solidarity of mahalla members and form the social order (Urinboyev 2011: 49-52). As my research and work experience have shown, religious leaders, raises of a mahalla, khodims, teachers, as well as other respectable people are often seen as capable of assisting in solving family problems, if the internal domestic mechanisms of conflict resolution fail.

According to my various interlocutors, such as bibi otuns, khodims, jamoat representatives, at present - due to the high divorce rate resulting from male migration to Russia - the need for mediation between parties in conflict has increased. Apart from issues between newlyweds, who are often very young people, relationships between the mothers-in-law and daughters-in-law are a frequent cause of divorce. In large multigenerational families, a new wife is alone with her husband-migrant's parents; thus, there is a high probability of entering into disputes. Consequently, if the issue reaches the mahalla authorities, they try to achieve reconciliation between the two parties. Obviously, this is not always possible and depends on people's willingness to compromise. The mahalla mediators frequently refer to Islamic norms as well as to the set of traditional rules when they are requested to become involved in family affairs. Additionally, the level of respect held by a particular mediator, their life experiences, as well as their knowledge of psychology are all useful in resolving disputes within the community.

Boboyorov (2013: 90-92) sees mediation mechanisms within mahalla communities as hierarchical practices and institutions which function inside nuclear and extended families, and are exercised through religious and neighbourly networks. The hierarchical pattern of relations is reinforced by parents, the elders and teachers. 
Local institutions, such as mosques, chaykhonas or schools, serve to maintain the existing order. The same author expresses the opinion that mahalla authorities prevent people from seeking justice in official courts or other state institutions by referring to the collective identity and solidarity of the group. Since state structures also serve to expand the influence and networks of local notables, members of the elite attempt to convince the involved parties that a certain case should be kept a secret and strangers should not be informed.

The mahalla's internal affairs and disputes are always a sensitive issue, especially in terms of family matters, but also regarding land and other property claims. It cannot be excluded that members of the elite attempt to protect their interests by alluding to traditional principles. It should be noted, however, that the judicial system in Tajikistan is very corrupt. For instance, it is not uncommon for a woman to be deprived of her rights to property by a court during divorce proceedings, despite the fact that she should receive her share, because the husband uses various informal means to convince the judges to settle the case in his favour. Many such similar cases have resulted in a situation in which people frequently do not seek justice through the official judicial organs and they prefer to mediate with the help of the traditional authorities.

It should also be noted that the mahallas regulate the model of behaviour according to traditional rules and practices. Therefore, if someone wishes to lead a different lifestyle than that accepted by common principles, he or she may be exposed to severe criticism from co-residents. In this sense, the traditions of the mahalla community leave little space for individualism - a value highly regarded in Western cultures. In my opinion, this different approach to the place of the individual in relation to the group (i.e. the mahalla community) is one of the main reasons for the confusion and frustration experienced by international aid workers while implementing projects aimed at promoting local development or those related to women's empowerment. In the following chapters, I intend to address this issue by analysing various aspects of development assistance in relation to the mahalla community.

\subsubsection{Summary}

The distinctive features of a mahalla differ from quarter to quarter. More integrated mahallas are those whose inhabitants have been living together for generations, and those which constitute an ethnically homogenous group. The above description only provides a general picture of the mahalla from a historical perspective up until the present day, taking into account the complexity of the relationships between various social actors. Thus, it does not exhaust the subject of the mahalla as a social organization, since the particular elements or terms may vary depending on a given region or historical period. The recent changes in legislation regarding communal organizations in Tajikistan have also impacted the transformation of the structure and function of the mahalla. 



\section{Chapter 3 \\ The lamoat and the Mahalla- \\ Legal Framework and Practical Dilemmas}

The main purpose of this chapter is to investigate the issue of the mutual relationship between the local administration (jamoat) and the mahalla from the point of view of the legal status of both entities as well as the practical implications of the existing legislation. First of all, to understand the pattern of social relationships at the local level in contemporary Tajikistan, it is essential to provide some information about the role of the kolkhoz as a former economic and social unit, and the selsovet as a form of local administration. The other question to be addressed here is how restructuring the agriculture and the introduced land reforms influenced the transformation of social relations in rural areas following the system shift. Next, I will analyse how the jamoat functions according to Tajik law and in everyday practice. Additionally, I will provide an example of a jamoat's cooperation with an international organization - the UNDP - within the framework of the Jamoat Resource Centre programme. Separate attention will be paid to the situation of the jamoat during the civil war. Finally, the legal framework of the mahalla will be considered, taking into account various aspects of this organisation's relationship with the state administration, including the issue of religion.

\section{I. Reconstructing the Rural Relationship - Past and Present}

\section{3.r.I. Collective Farms during the Soviet Period}

Commonly, in Eastern and Central Europe, the kolkhoz is associated with the imposition of the communist regime and is seen as a negative phenomenon which should 
have been wiped out together with the dissolution of that system. In Central Asia, however, where the traditional economic and social models had been shaped in a different way, collective land ownership system was not seen as oppressive and imposed as in Europe.

First of all, as Poliakov (1980) indicates, there was no private land ownership - in the European understanding of this term - within the territory of pre-revolutionary Central Asia. Within the area of contemporary Tajikistan (the former Emirate of Bukhara and Khanate of Kokand), the land was formally the state's property and any decision about its allocation was taken by the emir/khan. There were three main types of land ownership, i.e.: 1) amliak - lands which belonged to the emir/khan but were in fact managed by a large group of people; 2) mulka type of private ownership, but the land was endowed by khans or adopted by people through irrigation, or in another way; 3) waqf lands belonged to endowment funds run by the clergy (waqfi mutlak) or the avlods of religious leaders (waqfi avlod). The lands which were inhabited by a tribal population belonged to the entire tribes (mostly pastures) and were also considered to be mulk. In Eastern Bukhara, within which the different duchies enjoyed a high level of autonomy, in many cases the whole communities owned the land (mulki avlod), but this form of ownership was also popular in other parts of the Emirate. Land ownership was subject to flexible rules, with the rights to lands often being passed by sovereigns into 'private' hands, but this 'private ownership' could also be understood as part of the category of 'collective-private ownership'. In addition, there were different types of land leases, which resulted in the development of various forms of relationships between groups and individual owners. The water resources almost exclusively belonged to the state which managed and supervised them (Poliakov 1980: 88-92).

At the beginning of the Soviet period, following collectivization, land previously owned by khans was reshaped into kolkhoz/sovkhoz land, and so was considered to be 'state property' - similarly as prior to the revolution. The rules of ownership were changed, but in fact the basic structure was not, and the existing local relationships were fitted into the new kolkhoz context. Apart from kolkhoz 'common land', there were also various other types of land allocation. First of all, each small family who worked in a kolkhoz had the right to possess its own 0.15 hectares, considered to be mulk (private property). To increase the amount of land they owned, families frequently married off their children as early as possible, since every new family was eligible to obtain its own small plot. In view of the fact that in the rural areas of Tajikistan, the extended family (consisting of many nuclear families) is the basic unit, marriages guaranteed that the amount of private land would increase, and in fact this land remained the common property of the extended family (Poliakov 1992: 14-18, 30-31, 40).

Another way to increase land ownership was to buy it informally by paying a bribe. In addition, according to customary law, a person was qualified to own a certain plot if he/she had started to irrigate it. Moreover, there was land which could be 
rented from the kolkhoz for a particular period of time, as well as community-owned pasture land (Poliakov 1992: 14-18, 30-31, 40). ${ }^{94}$

Large families worked together on their private plots, which generated important income, although part of it was informal. Crops were sold at marketplaces (Russian: kolkhoznye rynki) in the bigger cities of the Tajik SSR and in other parts of the Soviet Union. It is worth noting that most technical equipment, such as fertilizers, irrigation systems, transport and so forth, was provided by the kolkhoz free of charge or for a very low fee. Different regions specialized in certain crops; for example, Vorukh traditionally specialized in the production of dried fruits. This has continued up until this day, with some families having made a fortune by selling such products, which they deliver to different regions of Tajikistan and the Russian Federation. The wealth of some families originated in the Soviet period, when they managed to establish appropriate 'transnational' networks with other regions of the former USSR, which continue to be maintained even today. Furthermore, Poliakov also suggests that despite the formal cancellation of waqf property in the early Soviet period - in some kolkhozes in Central Asia, waqf lands still existed under the protection of kolkhoz authorities. The official status of such land was undefined since it was unregistered, but in fact it belonged to religious institutions. Income from these properties supported religious buildings and the clergy. As regards the organisation of kolkhozes, former dehqon $(s) /$ nomads were divided into brigades and teams, in line with the traditional pattern of mahallas/tribes/avlods (Poliakov 1992: 19, 14-18, 30-31, some comments added, also see Abashin $2011 \mathrm{lb})$. $^{95}$

Roy (1999: 110-115) describes the Central Asian kolkhoz as an entity which combines administrative, economic and social functions based on collective identity. He argues that the Soviet system was adjusted to Central Asian conditions, creating its own structures. On the other hand, Abashin $(2011 \mathrm{a}: 4,12)$ sees the kolkhoz as a new type of community and a new type of management, within which communal life was synchronized with economic activities. At the same time, the kolkhoz system merged with the local way of life. People's perceptions of social order, as well as individual

4t In terms of pastures, in most of the kolkhozes of Central Asia and the Caucasus, despite restrictions imposed by the state which significantly limit the number of animals one family can own, some residents managed to possess a considerable amount of animals. Iarlykapov (2012) provides an example from Dagestan, where in the 'Lenin's Path' sovkhoz located in the Nogai district, shepherds working on the state farm had a large number of their own cattle, and usually also looked after cattle belonging to party apparatchiks, which gave thein a kind of guarantee against potential inspections. Of course, all the necessary technical assistance was provided informally by the sovkhoz. For shepherds, it was a great opportunity to earn good money - naturally, without paying taxes or fees to the sovkhoz or the budget of the Republic. I heard similar stories about private herds of animals in kolkhozes in the Naryn oblast in Kyrgyzstan, wherein some of them comprised more than 200 animals.

4.5 For example, in Vorukh in 2010, I was told that the manager who was in a charge of the collective farm at that time still linancially supported the shaikh of the most important local mazar. Such a tradition may be a remnant of the Soviet period. 
and family strategies were inextricably intertwined with the kolkhoz economic and social structure.

It was not uncommon in Central Asia that at the beginning of the creation of $\mathrm{kol}$ khozes people were often relocated onto the land of particular kinship groups. In the case of the new kolkhozes, where people were moved from other regions, families were settled in an order similar to that in which they had been living in the previous place. For instance, there were cases of the joint re-settlement of entire communities which had previously lived next to a particular mazar. Such a policy was aimed at decreasing the possibility of conflicts between kinship groups living in the same kolkhoz. Thus, many relationships in the new collective farms were formed on the basis of the traditional order, according to hierarchies within particular kinship groups mixed with the ideological concept of the socialist cooperative. ${ }^{96}$ However, collective farms with complex ethnic compositions were also not uncommon, which frequently created tension (see Chapters 1 and 7).

The kolkhoz elite consisted of party officials who usually came from important families with relevant regional networks. Since they were related to their communities by various family and social ties, as well as mutual interests, they were also involved in communal life, playing the role of notables who protected 'their people' rather than the party apparatchiks or the communist-type landowner, as is sometimes depicted by scholars (Roy 1999: 110-115; Zapaśnik 2006: 32; also see Abashin $2011 \mathrm{~b}$ ). A former vice-director of a kolkhoz stated during an interview, " $A$ director of a kolkhoz had to be a member of the Party, well-educated and he had to come from a good family". ${ }^{97}$

By and large, the kolkhoz was an independent unit which organized the lives of its residents, providing a full array of services. The big kolkhoz centres consisted of various facilities, they also contained a selsovet building with relevant official units, such as 'ZAGS' (Russian: Zapis Actov Grazhdanskogo Sostoianiia; English: Record of Civil Status Act) and others, the premises of the kolkhoz administration, shops, a kindergarten, post-office, canteen, chaykhona, a primary-care clinic, micro-bank, club with library, sometimes a sauna, sport facilities, squares, boulevards, and so forth. In many Tajik collective farms, these were complemented by informal institutions, such as mosques, mazars or even sometimes an underground madrasa, jointly creating a micro kolkhoz world. ${ }^{98}$ Through such means, Soviet policy development led to the paradoxical effect of the re-traditionalization of local practices simultaneously with the introduction of modernization. Obviously, this process took years in conjunction

46 A typical 'ideological description' of a kolkhoz is as follows: "Form of agricultural production cooperative of peasants that voluntarily unites for the purpose of joint agricultural production based on collective labor"; "the kolkhoz is managed according to the principles of socialist self-management, democracy, and openness, with active participation of the members in decisions concerning all aspects of internal life" (Wikipedia).

47 The quotation is taken from a conversation with a former deputy director of a kolkhoz in the Spitamen district, conducted during research done in 2012.

The smaller kolkhozes had much more limited facilities. 
with the development of the whole Soviet system, and the collective farm as a social and economic organization also evolved over time. Consequently, the kolkhoz of the period before the Second World War and the post-war kolkhoz were very different from those existing in the period from the 1960s to the 1980s. At the beginning of the formation of collective farms, the standard of living had been low, especially in farms located in remote, mountainous regions. During the Second World War, a large part of the food supplies was sent to the front for army use, and life was very hard in the collective farms, where practically only women, children and the elderly remained. ${ }^{99}$

\subsubsection{The Selsovet in Rural Areas}

Prior to independence, the smallest administrative body at the local level were local councils in villages and settlements (Russian: soviet $v$ poselkakh $i$ selakh), acting pursuant to Article 14 of the 1978 Constitution of the USRR. The law was further amended in 1991, and soviets were established as bodies of local self-administration, but at the same time they had always been part of the state structure. The law did not define the areas of competence of the soviets at different levels of governance.

In the USSR, the central government operated at the local level through its local representatives, who were attached to various institutions which enabled them to exercise power, such as to the siel-soviets which were part of the Soviet rural system. Siel-soviets were subordinated to the kolkhoz in rural areas. Therefore, the management of kolkhozes decided on all important matters related to siel-soviets and could also influence the appointment of selsovet authorities.

Nevertheless, according to the law, soviets had a wide range of powers and responsibilities, including managing state projects and cultural events, approving plans for social and economic development, supervising public works, drafting demarcation lines within villages, as well as renaming streets, villages and settlements within the area of their administrative jurisdiction, and other organizational duties. A soviet was expected to cooperate with social organizations, associations, and the like (Law 1978).

Paradoxically, however, in spite of the control imposed by the state apparatus, the local administrative representatives had a relative amount of freedom to pursue their own ideas, especially in the remote regions where the influence of the central government was weak. At the same time, the financial resources provided by the state allowed for the implementation of various projects and enterprises. Consequently, while the political and ideological freedom of the soviets was curbed, they enjoyed a certain degree of operational independence. ${ }^{100}$

49 Information gathered during various interviews with different people between 2010 and 2013 . A good description of life in the country side in Central $\Lambda$ sia during the Second World W'ar can be found in the famous book by the Ky rgyz writer Chingiz Aitmatov entitled Jamila.

100 This opinion, which might seem controversial if we consider the structure of Soviet power. was confirmed by a few interlocutors during research conducted in 2010. 


\section{3.r.3. The Land Reform and its Consequences}

In Tajikistan, land is the property of the state; land is allocated for use and is transferable by inheritance. The state authorities have legal power to revoke land rights. The country launched a programme of land reform with the first legislation issued in 1992, although a serious agricultural reconstruction programme was initiated only in 1995. Between 1995 and 1996, the country began to reorganize the traditional collective and state farms into a tripartite farm structure consisting of various forms of ownership, from small household plots, through mid-sized dehyon farms, to large corporate farms. Since then, land can be divided among individual farmers who can work alone or create larger units which consist of smaller plots. For example, there are 'family farms', which are comprised of several small plots belonging to members of one extended family, or farms combining many small plots of land owned by different people headed by a manager. Occasionally, an owner of a particular parcel does not cultivate the land, leasing it out informally to a farm manager. In accordance with the law (described below), a person who does not cultivate land for three years loses it to someone else. Average-sized farms which are located in the area of a former kolkhoz tend to be integrated in the form of an association (but this is not always the rule). The main goal of associations is to facilitate the activities of smaller farms and to provide mutual aid to its members, as well as to represent their interests to the local administration. By and large, associations attempt to maintain the remnants of the former kolkhoz system. However, a lack of resources and sometimes the conflicting interests of their members are among the main reasons why many of them have weak operational capacities. ${ }^{101}$

Simultaneously, a majority of the small dehyon plots are incorporated into collective dehqon farms converted from kolkhozes and sovkhozes into share-based farms operating on leased land. In reality, they function as large corporate farms, copying the kolkhoz model despite the new name. As already mentioned, from the very beginning the land reform in Tajikistan was highly non-transparent. Only recently, under the pressure of international institutions, has the land reform process made some positive progress. Initially, it was a common practice for the directors of the former kolkhozes to become the managers of collective farms, gaining by such means the majority of the wealth. They often passed managerial positions on to their own kin, creating 'kolkhoz dynasties', re-casting the traditional social patterns based on networks of solidarity groups as clientelism and patronage. Nonetheless, it should be mentioned that due to the changing socio-political environment, old elites are being replaced by new actors, forming new cliental networks. It is also worth noting that, despite twenty years of changes, many people still do not have basic knowledge

111 Information gathered during interview's conducted with a local NGO from Khujand and with the former vice-director of a kolkhoz. currently the manager of a middle-sized fann (August 2012). 
about the mechanisms of market economy. Therefore, the remnants of the collective kolkhoz system often supply them with some sense of stability (Lerman and Sedik 2008: 24; Roy 2002: 138-139; see also Bliss 2013; Boboyorov 2013, some comments added).

However, the main difference between kolkhozes and collective farms is that at present the state does not guarantee a number of privileges previously enjoyed by the residents of rural areas during the Soviet era. Moreover, the managers of collective farms are linked with state officials, enabling the former to reap huge profits from the distribution of land and crops, while farmers suffer poverty. Land distribution is subjected to informal deals and corruption. While by using relevant 'contacts', it is possible to obtain a parcel of land without major difficulties, at the same time, it sometimes happens that a village is not able to obtain permission from the local authorities to use a small piece of land so as to build a primary-care clinic (see Chapter 7). Moreover, there are also incidents of land being informally taken from vulnerable persons who are not able to defend their rights, such as single women.

The following example of such a situation was described to me during an interview with the director of an NGO. A farmer, who for some reason has not cultivated a particular plot for 2 or 3 years, is asked by a collective farm manager to let another person use a few hectares of his/her land for a period of one year. In the following years, the situation is repeated, and finally, the land is being systematically used by someone else. In extreme cases of this type, a farmer may even lose his/her certificate of land ownership to a new owner. ${ }^{102}$ I am of the opinion that such 'law' may be sanctioned by the pre-revolutionary principle based on shiaria, according to which arable land that had not been cultivated for a period of three years was considered to be fallow land belonging to the state, and could be given to any farmer who wished to cultivate it (information found in Eshonkulov 2007: 335). It is also worth mentioning that many members of the collective dehqon farms do not have certificates of land ownership. They are sometimes not even aware that they possess rights to a parcel of land (Lerman and Sedik 2008: 33).

My various interlocutors expressed the following opinion:

The land reform was very unfair and unjust. The land was taken by those who knew who should be paid bribes for the good land while others were put on waiting lists to finally receive poor, almost infertile land. The rich often do not work their own land but instead they lease it to other people.

In Tajikistan, the agricultural restructuring led to the re-traditionalization of rural relationships, creating a contemporary class of feudal landowners who now possess the economic means to increase their influence over the population. However, according to a certain viewpoint, since the new managers/former kolkhoz elite

11:- On the basis of an interview with the director of an NGO which provides consulting and tinancial services for agricultural enterprises, August 2010. 
(or presently - their younger relatives) are in most cases members of significant avlods and are well established in the local environment, they can offer some protection to peasants, and the latter do not even need formal land ownership because the hierarchical solidarity network to which they belong guarantees stability. ${ }^{103}$

Nevertheless, the liquidation of the state farms after the transformation was not, as has been commonly described, a smooth transition from one type of ownership to another. The land reform should be perceived rather as a transformation of the existing social and economic relations. In consequence, there was an increase in social stratification and the pauperization of many kolkhoz residents. Increasing competition over shrinking resources provoked different forms of predatory behaviour, including the exploitation of poorer members of the farm by the new landowners (see Bliss 2013; Boboyorov 2013).

Contemporary land management in Tajikistan can be described as a combination of the Soviet system, pre-revolutionary feudalism and the neo-liberal economic model introduced by international institutions, mainly the IMF, WB, and TACIS (who were the model's main promoters in the whole region of the former Soviet Union). They imposed 'a template land reform', the core policy of which was based on the dissolution of kolkhozes and sovkhozes seen as an impediment to people's independent initiatives. The hasty and ill-designed land reforms mainly based on the privatization of the former collective farms have created a lot of difficulties in many parts of the former USSR.

\subsection{Legislation Concerning the Jamoat and its Implications}

\subsection{The Administrative Division of Tajikistan}

Tajikistan is divided into administrative regions and districts which are mainly determined by its geographical zones. The administrative-territorial divisions in Tajikistan consist of three tiers of local government: 1) the first tier, community level: local administration in villages and towns in rural areas (jamoati shahrak - town administration and jamoati dehot - village administration); ${ }^{104}$ 2) the second tier, district level: administrations of cities and districts subordinate to oblasts, those of Dushanbe city

103 On the basis of a discussion with a number of employ ees of a Tajik NGO from Khujand which provides consulting and financial services for agricultural enterprises, July 2012.

104

Jamoats are subdivided into 'Jamoati Shahrak', which refers to a 'town', and 'Jamoati Dehot, which refers to a group of villages in a geographic area under a single governance body similar to a "township in a number of countries. Thus, within this translation from the Tajik language version of the law. the tern 'town' shall refer to a 'Jamoati Shahrak' and the term 'township' shall refer to a 'Jamoati Dehot' (Law 2009). 
districts, as well as those of the thirteen districts directly subordinate to the Republic; 3 ) the third tier, the oblast level: the administrations of Dushanbe, the GBAO and Khatlon and Sughd oblasts, all of them directly subordinate to the national government (Ilolov and Khudoiyev 2001: 608). Jamoats are at the lowest level of public administration and their jurisdiction covers smaller entities. Since 2008 , an attempt has been made to incorporate villages and mahallas into the administrative structure.

The area of the country comprises the following administrative units:

- viloyat(ho) (English:province(s), Russian: oblast(i))

- nohiya(ho) (English:district(s). Russian: raion(y))

- towns of national significance

- towns of provincial significance

- towns of district significance

- shahrak(ho) (English:settlement(s)/town(s), Russian: poselok (poselki))

- qishloq(ho), dehot(ho), mahalla(ho) (English: village(s). Russian: selo(a)) (Kamoludin 2004: 9, some modifications made).

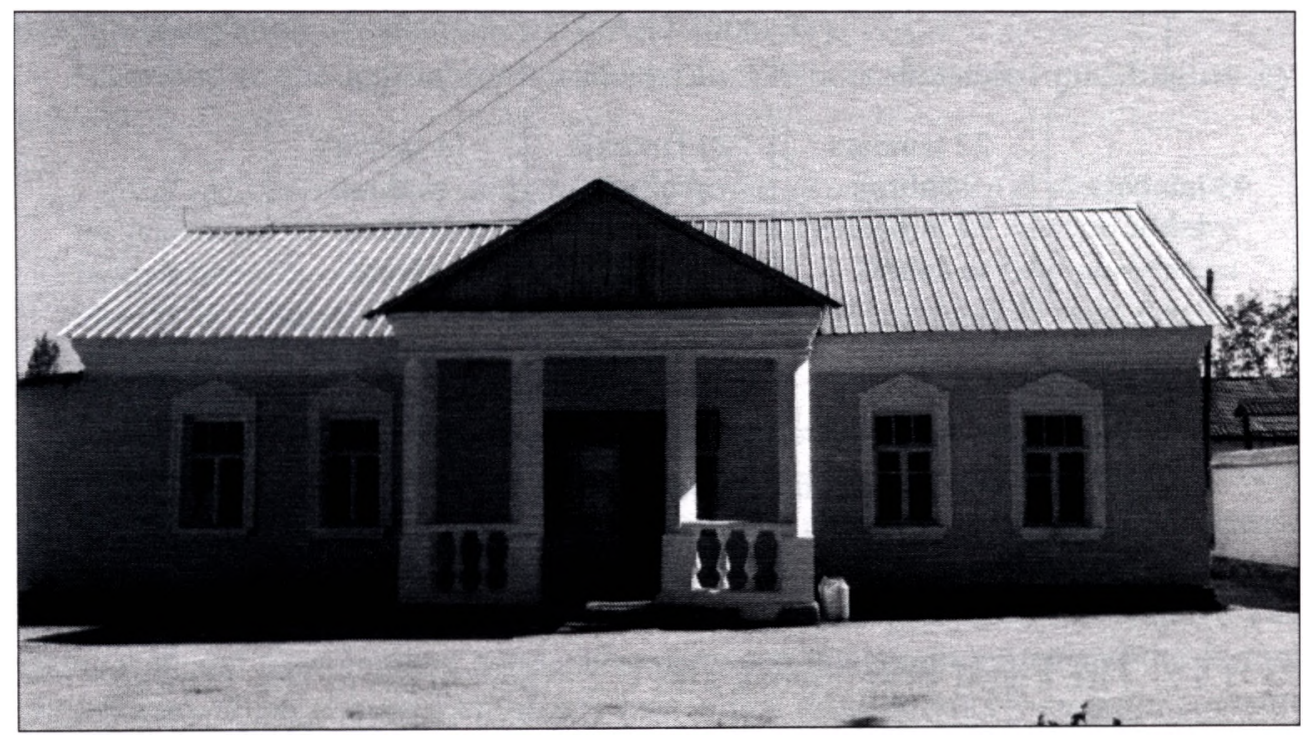

A building of jamoat (a local administration), Qumsangir district, Khatlon region. 
Chapter 3. The lamoat and the Mahalla...

Figure 1. Administrative division of Tajikistan ${ }^{105}$

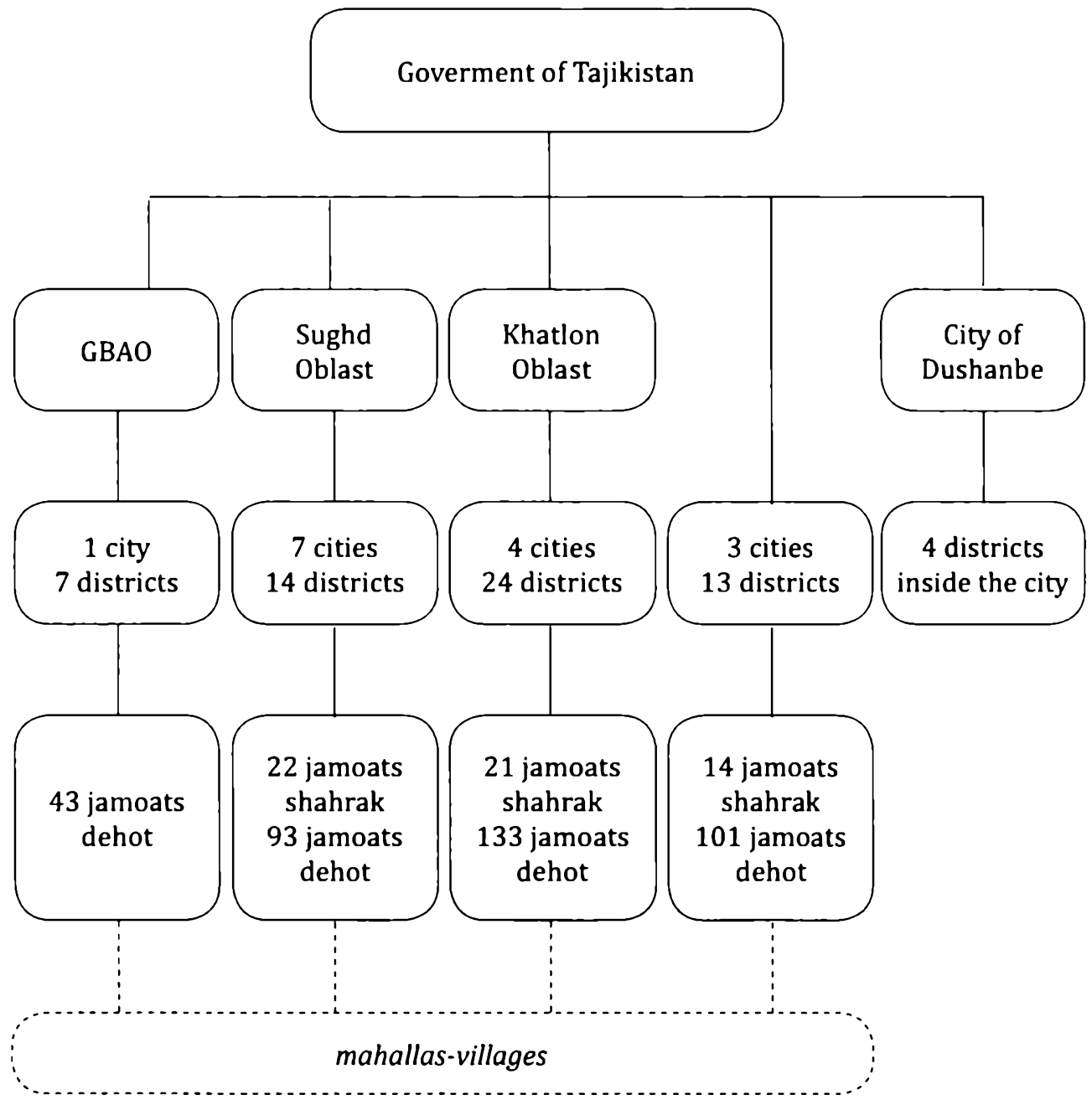

3.2.2. The Legal Framework and Competencies of the Jamoat

After the collapse of the USSR, a new law was established (on 1 December 1994) "On Self-Government in Towns or Townships" aimed at decentralizing the local power system to improve the effectiveness of government at the local level (Law 1994). Former council soviets were replaced by self-government jamoat shahraks in

105 The number of administrative-territorial units is provided according to the division introduced as of 1 January 2014 (TAJSTAT 2014). 
towns and jamoat dehots in villages, which cooperate with representatives of mahallas, block committees and villages at the local level (Olimov and Olimova 2001).

Needless to say, the decentralization of public administration and institutions requires a lot of time, a very consistent stable approach, and comprehensive financial reform. Only then does it have any chance to strengthen cooperation among the various actors at the local level, which - in the case of Tajikistan - is mainly expressed by the relationships between oblast governments, the city/district administration and the jamoat. Unfortunately, in Tajikistan the reform of self-government was carried out only partially, creating a façade that has in fact not really introduced much change in the top-down relationship between the various levels of public administration.

Further amendments to the law of 1994 were made in 2009 (see Law 2009). Basically, the most important of these pertain to methods of budget management and selection of councillors for the jamoats. The new act was passed only in 2009 and some of its modifications - particularly those relating to the budget - were supposed to have been introduced in 2011 . However, until the present day, the budget for jamoat has not yet been implemented.

The main goal of the reform of local administration is to enable citizens to participate in administrative management and to consolidate them in order to resolve social and economic problems at the local level. Moreover, jamoats should facilitate the implementation of state policy (USAID 2006: 31).

According to the legislation introduced in 1994, as translated into English by USAID,

...local self-government is understood as a system of organization of the activity of the population for the solution of local issues directly under their responsibility. or independently through the bodies elected by them (...). Bodies of local government directly or through their representatives solve the issues related to their competence (USAID 2006: 31).

Furthermore, both the competence and the structure of the new self-government were transformed. Previously, the local soviets in settlements and villages were elected bodies of local administration headed by a chairman. Currently, representatives from neighbourhoods are delegated to the jamoati shahraks (towns), and representatives of villages participate in the work of the jamoati dehots (villages). The changes aimed to strengthen cooperation between the communities and the formal state bodies. Each jamoat administers over a few smaller units - mahalla committees, which should be formally registered within the territory of a particular jamoat.

The head of a jamoat is a chairperson elected at a jamoat council meeting from among its councillors by the majority of the total number of councillors, following nomination of a candidate by the city or district chairperson. The deputy chairperson(s) and secretary of a jamoat are nominated by the chairperson of the jamoat from among the jamoat councillors, and they can be elected and/or removed from their position at a jamoat meeting by a majority vote of the total number of councillors (Law 2009: Art. 19). 
In practice, the rules of appointing a chairman raise many questions. Since he/she is nominated by the regional or municipal authorities and the jamoat council only confirms the candidacy in an open voting process (by the raising of hands!), nothing has changed and the jamoat chairman is still selected from above. The same rules apply to his/her potential dismissal. Thus, despite the amendment to the law, the jamoat is still subordinate to state authority due to the method of electing its head. Due to various formal and informal shifts, raises of jamoats are often changed and replaced by new people by the district authorities. It is reputed that the former kolkhoz elite and their associates still hold considerable influence over who is appointed as rais ofjamo$a t$ - usually someone selected from among the members of the same clientele group.

The amendments introduced in 2009 allow for the relatively independent election of jamoat councillors, which theoretically can be seen as a significant improvement over the previous situation. Currently, the number of jamoat councillors is defined and should amount to between fifteen and forty people. Each village, regardless of the number of its electors, should be represented in a jamoat council by at least one councillor. In addition, the competence of the jamoat council is more clearly defined than within the framework of the 1994 legislation (cf. Law 2009: Art. 8, 9 10); for instance, the council has the right to appeal against a decision taken by the head of the jamoat. However, jamoat councillors are usually the heads of mahallas, whose candidacies are often recommended by the head of a given jamoat; therefore, they are bound to the jamoat by common interests and obligations.

A local government has a number of competences, such as planning improvements to the available social services, cooperating with the population to organize events, the development of infrastructure within its territory, controlling and planning expenditures, auditing, dealing with the legal aspects of creating small businesses, cooperatives, workshops, arts and crafts enterprises, all issues pertaining to changing the borders of the jamoat's territory, naming and re-naming streets and other facilities, supervising the process of observing traditions, customs, ceremonies and rituals, and designing and presenting offers to relevant state bodies (Law 2009: Art. 11, 13).

In addition, the jamoat chairman should decide on land ownership, temporal use or rental of land by businesses, offices and private persons; termination of the rights of ownership or use of land, withdrawal of land within settlements that are not part of the landed property of agricultural and forestry enterprises. All the decisions of the chairman should be approved by the jamoat council (Olimov and Olimova 2001).

This last issue raises a lot of questions. Frequently, important decisions regarding property are taken without the authorities of the jamoat, who only formally approve the decision made by the managers of the local collective farms, local businessmen, as well as by the hukumat (district/regional administration). As described above, land distribution is a core issue in local power relations and is subject to corruption and informal transactions. Theoretically, there are four procedural levels for transferring land to private users. In the first stage, a decision about using a certain plot of land should be taken by the mahalla, and then it should be approved by the jamoat, which 
issues a certificate further accepted by the hukumat. The final decision is taken by a commission which grants a particular person a life-long certificate to use the land.

Despite the many competences of a jamoat, its real power is limited and many of the functions of formal self-governance bodies are unclear. The most controversial issue is connected to the finances of local self-governments. According to the law introduced in 2009, the Jamoat Council "adopts the budget of a Town or a Township, introduces amendments and changes therein when appropriate, monitors the budget implementation and approves the relevant reports" (Law 2009: Art. 10).

In reality, however, the financial resources of a jamoat are meagre and barely cover the salaries of employees and overhead (Olimov and Olimova 2001; my own research). It is considered that the jamoat's lack of its own budget, as decided by the latest introduced legislative amendments, was the result of deliberate state policy aimed at controlling the jamoats' activities, especially in the regions that were part of the anti-governmental coalition during the civil war. After the situation in the country stabilizes, jamoats will obtain more power. ${ }^{106}$

According to the legal act introduced in 2009, each jamoat should have had its own budget in 2011. However, the implementation of the new directive has been slow and frequently suppressed. In July 2010 , thus just about a year after the legislation had been passed, I interviewed one of the managers of the UNDP who did not attempt to conceal the fact that during the process of drafting the new law the financial mechanisms connected to its implementation were not consulted with the Ministry of Finance. Subsequently, a UNDP employee from Khujand, who had participated in conducting a survey in district hukumats in the Sughd region, expressed the opinion that the authorities of many of the hukumats were not fully aware that as of 2011 they were expected to introduce different rules for budgeting jamoats. Moreover, according to our research in 2010, jamoat employees lack adequate knowledge of the procedures of implementing the legislative decisions introduced by the 2009 amendments to the legislation. They frequently did not know what transformation to self-financial management actually means. There were cases of jamoat chairmen not even being aware that a new law had been passed. The main problem is that - even if a jamoat is granted its own budget - apart from the limited state funds there is no guarantee that other financial resources will be made available.

During my work in Tajikistan in 2012, 2013, and 2014, as well as while conducting research and participating in NGO project implementation, I investigated how the issue of the local budget was developing during this period. In 2012, I discussed the budget with the raises of two jamoats in the Spitamen district (the Sughd region), who were fully aware of the principles of the new legislation and they even expressed many ideas concerning how to supplement the jamoat budget from local sources. However, at the same time, they knew the limited influence of local administration on fiscal decentralization. On the other hand, in the provincial jamoat located in the

I the This opinion was expressed on a number of occasions by different people. including scholars and NGO workers in Tajikistan. 
mountainous area of Ganchi district, the rais did not know any details of the new legislation, including the introduced innovations regarding financing. In 2013, the PCIA began the implementation of a project reinforcing mahalla committees. As the project started, the PCIA and Mehrangez staff visited all the heads or vice-heads of five jamoats, where we continue to operate until this day. No one was able to provide even an approximate date by which the jamoat would obtain a budget.

As the issue of jamoat financing is important from the perspective of the future of our project, I visited the UNDP office in Dushanbe once again in 2013, hoping to obtain detailed information on the future of financial decentralisation. However, I was told that no significant changes have been made since 2010, but the UNDP and state institutions (including the Ministry of Finance) have been working on developing the appropriate mechanisms. In 2014, our local partner obtained information that a pilot project on finance decentralization was on-going, financed by USAID, and implemented by a working group consisting of various governmental bodies (such as the Ministry of Justice, Ministry of Finance, the President's office, authorities of regional and relevant district hukumats, donors and INGOs). The project aims to apply the budgeting mechanism in four jamoats located in four regions of the country. This information was further confirmed by the MSDSP and Deloitte Consulting - the outsourcing company which facilitates the project. If the pilot project on the implementation of budgets is successful, financial decentralization will be carried out throughout the country. ${ }^{107}$

According to the current legislation (Law 2009), jamoat financial resources should consist of:

- the budget of the Town or Township;

- funds allocated for specific purposes, transferred from the state budget in the form of grant assistance (subsidies);

- financial assistance (subventions);

- charitable donations;

- revenue from fee-based services as provided by law;

- revenue from performing specific state duties delegated to a Town or Township;

- revenue from property ownership of a Town or Township;

- revenue from grants and investments (Article 26);

- other sources which are not forbidden by the laws of the Republic of Tajikistan.

A jamoat can eam profit from taxes or voluntary donations from citizens, but in practice, the majority of the population is too poor to pay taxes, and there are no comprehensive mechanisms of tax collection. In fact, the jamoat chairmen who were asked about the sources of financing the jamoat, in most cases indicated international organizations as possible sources of income.

Needless to say, international organizations only operate in some parts of Tajikistan, and their operational and financial capacity is limited. They cannot replace the state in providing social and public services. Nevertheless, this has al-

119) Information oblained in June 2014. 
ready happened to an extent in some parts of the country. In 2010, the head of one of the jamoats in the Shuroobod district did not mention state funds when asked about how enterprises undertaken by his jamoat were financed, only grants from foreign donors. ${ }^{108}$

In theory, a jamoat has the competences necessary to develop and approve socio-economic development projects. However, the jamoat's representatives frequently fail to identify the real needs in their area or their decisions are not taken into account by the regional council, and the plans drafted remain only on paper. Moreover, as the regional council is not able to finance projects at the local level, in practice, there is no mechanism for delegating public and social tasks to the jamoat. As a matter of fact, the state does very little to improve the dilapidated infrastructure, which remains largely as it was at the end of the Soviet era, often side-tracking new investments.

In addition, the jamoat is expected to participate in establishing small businesses, cooperatives, workshops, and arts and crafts enterprises, which could facilitate local development, although a lack of basic financial resources and organizational capabilities are the main hindrances to implementing reasonable solutions in this area. ${ }^{109}$

A subsequent concern is related to the qualifications of jamoat employees. Due to the extremely low wages they receive, there is a scarcity of skilled workers who would be willing to carry out the jamoat's tasks and responsibilities. Training and other forms of education are sporadic, and low wages are a poor motivation for people to work efficiently.

What is more, most jamoat employees seem not to understand the concept of selfgovernment within the framework of local administration, despite the fact that they are accustomed to the type of self-governance represented by the mahalla. Theoretically, it should be less difficult to implement ideas of local development based on cooperation among all actors if the traditional forms of self-governance are rooted in the communal culture of the society. However, in the case of Tajikistan, people have become used to the top-down policies of the state which have left little space for independent decision-making. Since the jamoat is naturally perceived as a state tool to supervise the performance of local communities, it is not easy for people to accept that it could undertake autonomous initiatives with the participation of the citizens to resolve social and economic problems. Additionally, if the jamoat became a real self-govermment, the state would lose control over communities. In my opinion, misinterpretation of the main principles of the role of local self-government administration is one of the major obstacles to its development.

tix On the basis of an interview with the rais of a jamoat in Shuroobod district. Khatlon region. July 2010.

iw Apart from the above-Inentioned obstacles, the predatory behaviour of the state is an impediment to business developinent. Due to the enormous level of corruption, it is better to avoid any cooperation with state bodies. 
Relatively, the better organized jamoats are those operating in the area of cotton production, since Tajikistan's government insists on promoting cotton as it is a strategic cash crop for the country. The jamoat administration organizes all the works related to cotton harvests under the control of the district administration. In this case, cotton is a factor which links jamoats and communities, as well as providing the jamoat administration with a certain degree of influence on farmers and cotton producers. It should be noted, however, that the cotton industry fosters unequal relationships between social groups, as the state and former kolkhoz elites derive huge incomes from cotton. At the same time, the people who work in the cotton fields (mostly women and children) earn meagre wages which are not able to cover their basic needs (also see Bliss 2013; Boboyorov 2013).

Another source of the jamoat's power comes from the supervision of celebrations and events, and assistance in monitoring the religious life of communities (see Chapter 2). These tasks are both a source of informal income as well as a tool of pressure on disobedient community leaders. Land distribution is also an informal means of power, with the jamoat as one of the decision-making actors (as described above). In addition, the jamoat assists with army recruitment. As the Tajik Army offers quite poor conditions for the soldiers, families resort to various measures, including corruption, to prevent their children from being called up. Bribes paid by desperate parents are a source of income for jamoat employees as well as Tajik military officials.

In other cases, the role of the jamoat is mostly limited to fulfilling purely administrative tasks, such as registering births, deaths, marriages, divorces and other civil matters, issuing documents to citizens confirming their place of residence or familial ties, certificates related to land and property ownership, and so forth.

While being asked how the jamoat contributes to village development, most interlocutors answered that the local administration is too poor to provide any assistance to people. The role of the jamoat is understood as that of a state organ which follows the orders of the hukumat as well as mobilizing the residents during the organization of state events or hashars, supervising people's work during the cotton harvests, and controlling events and celebrations.

Nevertheless, under certain circumstances, the cooperation of an INGO with a jamoat is possible. During implementation of an NGO project aimed at reinforcing the mahalla committees, in some cases jamoat employees participated in the mobilization of the local people, in the hashar works, or they even provided some technical equipment for undertaken enterprises. However, it is difficult to discern to what extent this support was provided within the framework of the jamoat's formal responsibilities and whether or not it was the result of informal relationships with some residents of a particular qishloq.

According to the project coordinator of a Polish NGO (the East European Democratic Centre, which implemented a project developing the capacities of the Drinking Water's Users Committees (DWUC) on the territory of four jamoats), the authorities of two jamoats from Spitamen district (the Sughd region) actively supported the project. The raises of the jamoats participated in meetings, seminars, as well 
as monitoring water infrastructure repairs. The raises of the jamoats also provided small financial contributions collected from the residents to facilitate the repairs. ${ }^{110}$

One may pose a certain question which paves the way for a more in-depth discussion regarding the approach of IOs toward working with local communities. Bliss (2013: 101) points out that the strategy of bypassing the jamoat, which is often considered as corruptive and ineffective, and cooperation with CBO organizations (such as the mahalla) is unsustainable since donors will leave at some point, and local administrative structures will assume these responsibilities. This point of view is undoubtedly well-founded, especially since international aid is uneven and temporary. On the other hand, however, under the current circumstances in Tajikistan it is difficult to develop an effective strategy for cooperation with the jamoats, especially in terms of channelling financial resources, but also due to the frequent difficulties in establishing communication with the local authorities.

\subsubsection{The lamoat and Jamoat Resource Centre}

The jamoat as a self-governmental body of the state administration has also drawn the attention of international organizations. One of the most significant projects implemented by foreign donors is the Jamoat Resource Centre (JRC) launched by the UNDP in 1997 as part of its local governance initiative. By 2010, JRCs had been established in 120 jamoats in various parts of the country."'

JRCs are supposed to be grass-roots community-based organizations supporting a jamoat's work. JRCs aim at creating links between communities and jamoat authorities. The project promotes good govemance and poverty reduction with vital community participation. JRCs are registered NGOs (UNDP 2007: 5-6). They generally have offices in buildings provided by the jamoat administration and renovated by the UNDP with community participation.

JRCs are mainly financed by international donors. Their only independent source of income is possibly revenue from microfinance operations (many organizations have established microfinance activities), from which the potential profits should be partly invested in community development. However, they are expected to operate without external funding in the future, when implementing local development projects (UNDP 2007: 5-6). On the district level, a similar role is ascribed to the District Development Councils (DDCs), whose purpose it is to bring government authorities, civil society and the business community together for wide-ranging development planning and investments.

110 On the basis of information gleaned from a conversation with the project coordinator einployed by the Polish NGO, EEDC. in September 2014.

'II Information obtained during an interview with a representative of the UNDP. Dushanbe. June 2010. 
The main areas of JRC activity are the following: (a) mobilizing communities to prioritize and resolve their problems, (b) enhancing dialogue between social actors and authorities, (c) capacity building of local authorities at the jamoat level, (d) reinforcing infrastructure rehabilitation, (e) providing advisory services to local communities, (f) facilitating unemployment reduction and income-generating opportunities targeted at vulnerable households, including supporting local microenterprise and small business initiatives, $(\mathrm{g})$ promoting the equal participation of all social actors, (f) facilitating the work of Micro Finance Institutions at the local level (UNDP 2004: 81-82).

JRCs attempt to work closely with the jamoats. Members of the local jamoat council can be employed within a JRC but are prohibited from holding high-ranking positions, although this rule is not always followed. With the participation of all social actors and representatives of the authorities, the JRCs have the competences and capacity to analyse and resolve important community problems. This self-governance body can monitor the transparency and accountability of local government work and facilitate communication between citizens and local authorities (UNDP 2004: 81-82).

JRC activities are also aimed at promoting the public awareness of communities, particularly through organizing trainings and seminars about important matters related to local development. These are either done within the framework of a donor project or by skilled members of the community, and include trainings on public health, legal rights, and so forth. Beneficiaries of microfinance projects also receive training on financial practices from JRC members and UNDP. Moreover, a JRC should organize committees in order to consolidate the community with regard to particular issues, such as business, agricultural advice, assistance to vulnerable women, employment for young people, etc. (Ibidem).

The development of a particular JRC depends on the initiative of its members and their ability to raise funds. In some cases, with access to financial resources provided by international donors, JRCs are able to deal with local problems more effectively than jamoats. Moreover, some JRCs advocate citizen's matters, for example, those related to providing land certificates which frequently foster tensions between the JRC and the jamoat. However, many JRCs are reshaped into microfinance organizations with no reason to work on local social issues. Other existing JRCs are weak organizations without any real power to introduce positive changes in their communities.

The position of a JRC in relation to a jamoat is controversial. Those which remain inactive and rely only on external funds are not sustainable, and their role as a link between the community and the jamoat is minor. They usually represent the interests of local clientele groups and serve as one more source of income for members of the local elite. On the other hand, a dynamic JRC which responds successfully to social needs can be seen as competition by the jamoat. A JRC is expected to facilitate a jamoat's activities but at the same time is an independent organization with external financial resources. As a result, a JRC often has different interests and priorities than 
the jamoat. Clearly, there is room for cooperation between both institutions; however, the reason for founding JRCs as an additional body is unclear. Why does the UNDP not provide direct support to jamoats in the form of employee training or by funding certain projects? A further question is whether JRCs are true grass-roots organizations representing the 'voice of the poor' or just one more NGO which implements projects financed by international donors according to their priorities. In Chapter 6 , I discuss the issue of the JRCs in more detail, providing a specific case study.

\subsubsection{The Jamoat in the Context of the Civil War}

To provide a complete picture of institution-building at the local level in Tajikistan, it is necessary to discuss briefly the impact of the civil war on the performance of jamoats. In some parts of the country, the development of local governmental structures was severely hampered by the conflict. Many local jamoats were disrupted by military action and consequently ceased to function. In other regions, however, jamoats became the last bastions of statehood. Jamoats participated in the distribution of humanitarian aid or provided other services to citizens. Hence, to some extent, under the extreme circumstances of the war the independence of some jamoats was relatively increased. On the other hand, jamoats were under constant pressure from various military and criminal groups involved in the conflict.

One of our interlocutors, who used to be the rais of a jamoat in the Shuroobod region (relatively less affected by the war), stated that during the chaotic period of the civil war both the armed groups of the Popular Front of Tajikistan (jurchiki) and representatives of the political opposition (vovchiki) posed a threat to the civilian population, as did ordinary bandits. All these groups made attempts to grab relief supplies or extort other goods from civilians. Twice he faced the threat of being shot. Finally, he managed to arrange the defence of his jamoat by organizing a selfdefence group. They received some weapons from government sources which they returned after the end of the war. The jamoat cooperated with various humanitarian organizations which delivered basic goods. However, transferring the humanitarian aid to beneficiaries was the subject of much controversy. In many cases it did not reach the most vulnerable groups but ended up in the hands of local notables, tied to various informal networks which profited from humanitarian assistance. Similar stories were repeated to me during my conversations with various interlocutors in the territory around Kurgan Tyube, where ethnic diversity was one of the main causes of severe warfare. Humanitarian aid was also channelled there through the jamoats, but due to the open struggle between various antagonistic ethnic groups, the situation was much more complicated than in the case of Shuroobod, and local authorities were forced to maintain a precarious balance between different powers. ${ }^{12}$

112 1) Interview with a former rais of a jamoat from the Shuroobod district, Khatlon region: July $2010 ; 2)$ interview with a former rais of a jamoat from the Vakhsh district. Khatlon region. 
Conversely, in northern Tajikistan, which was less affected by the civil war, the local govermment functioned in a quite stable way, and the classical soviet structure was preserved (Olimov and Olimova, 2001).

Following the stabilization of the country, the local administration began to function in all regions. Nevertheless, despite minor changes in legislation, local government bodies operate on principles similar to those in place during the Soviet era, except that they do not receive central funds to carry out their projects. Therefore, contrary to popular opinion, their operational capacity is even lower than in the previous era. Their main task is to control society. Such a 'half-baked' handling of decentralization is characteristic of many countries of the former USSR. The development of institutions has not followed the chaotic market reforms, and the new capitalist rules have failed to frame appropriate state structures. Superficially adopted democratic ideas and main principles of democracy, such as the attempt to shift competences and power to the local administration, are treated in the category of slogans, and mainly serve as a means to obtain donations from international organizations rather than as values which could contribute positively to state building.

\subsubsection{Summary}

If the role of the jamoat is to become a self-governing body, it should be granted more autonomy in terms of its decision-making capacities so as to create a link between the citizens and the state. This would require large financial resources. Nevertheless, without rebuilding the whole structure of the relationships at the top, including issues connected to the cotton business and land distribution, real changes will not take place. Additionally, a shift in thinking about the role of the jamoat as a self-governmental organ must occur, whereby the jamoat would no longer be considered a subordinate institution within the state structure, as this also influences the effectiveness of its cooperation with communities. Moreover, without fiscal decentralization, the reform of the jamoats will not achieve full decentralization. New legislation has brought a lot of hope, but there seem to be no real intentions on the part of the central government to rebuild either local administrative bodies or the institutional structures in the country. Decentralization was recommended by international donors as part of the National Development Strategy and Poverty Reduction Strategies. However, in practice, the law is employed only partially due to the weak state institutions and lack of relevant mechanisms for its implementation. In fact, in many cases, formal institutions are little more than a façade, and informal norms and practices undermine formal legislations. This model is not only typical of Tajikistan but also of many other developing and transitional countries.

conducted in Dushanbe. September 2010;3) I carried out a number of conversations on this subject in 2013 . 
The following part of this chapter will be devoted to the relationship between the jamoat and the mahalla. I intend to examine to what extent these two concepts of self-governance - the traditional model represented by the mahalla and that of the jamoat - can function together and cooperate with each other, and what the outcomes and consequences of this collaboration are for local development.

\subsection{The Mahalla, State Institutions and Local Initiatives}

\subsection{An Overview of the Legal Framework of the Mahalla}

According to the law on jamoats, this institution extends jurisdiction over smaller administrative units, such as mahallas. It "may cooperate with community self-governing bodies, such as mahallas, facilitate the performance of their duties, register them and may delegate some of its authorities to them on contractual basis and by financing these authorities" (Law 2009: Art. 7).

Jamoat committees, which should facilitate the work of the jamoat, consist of representatives of mahallas or other local bodies. In practice, the raisi mahalla is often also a member of the jamoat committees as well as a jamoat councillor. It is his role to represent the community's interests before the local administration.

Despite the fact that a mahalla is a traditional self-governing organization, until recently its legal status was not determined by Tajik law. As mentioned above, in 2008 a new law was passed "On Public Self-Initiative Bodies" to regulate the activity of mahallas and other community organizations. The new law, commonly known as 'the Mahalla law' was issued after consultation and upon the recommendation of international organizations, including the Aga Khan Fund and MSDSP. A specific legal solution was proposed to reinforce the potential of traditional social organization in order to support development at the local level. ${ }^{113}$

The law indicates that each "body of self-social initiative" (hereinafter mahalla) should be registered in the territory of the jamoat in which it is located. Following registration, a mahalla receives a rubber stamp and the right to open a bank account. In order to address social issues, a mahalla can cooperate with the government, local NGOs and international organizations working in Tajikistan.

A mahalla should act as an independent social institution representing its residents to the public administration, which is expected to create the necessary legal, organizational and other conditions for organizing the activities of social bodies. However, the state administration should not interfere in the activities of a mahalla, except in cases listed in the new legislation (Law 2008).

11 On the basis of a conversation with an MSDSP representative. Dushanbe, July 2010. 
The structure of the social organization (mahalla) and the procedure of its formation should abide by certain described legal regulations. The authorities of a mahalla comprise a mahalla committee led by a raisi mahalla. All decisions should be taken during a public gathering with the voluntary participation of the mahalla's residents. There is also a commission of financial control which administers the mahalla's finances. A mahalla's activities are regulated by its statute, approved by the residents of a particular community. Control over the activities of the mahalla is exercised by an authorized state body within the limits defined by the legislation of the Republic of Tajikistan.

If a mahalla is to participate in development at the local level, it should have the possibility to obtain the relevant financial resources. According to the law, possible sources of financing a mahalla are as follows:

- funds allocated from the budget of the local executive body of state power;

- income received from commercial activities;

- funds raised from members of a mahalla;

- donations and gifts from businesses and individuals;

- other financial sources not prohibited by the legislation of the Republic of Tajikistan (Law 2008).

Incorporating the mahalla into the legal system is explained by the need to strengthen its operational capacities. A mahalla has become the smallest administrative unit, and a raisi mahalla is an unpaid civil servant (though it has been suggested that perhaps they should receive remuneration for their services). Gaining legal competence should enable mahallas to operate in a way similar to NGOs; for instance, the mahalla committee can write project proposals and apply for grants. In addition, a mahalla may derive income from commercial activities.

Theoretically, the new law provides substantial opportunities for mahallas to function as independent, self-governing organizations. However, after careful examination of the legislation and its implementation process, many doubts and questions arise.

\subsubsection{The Mahalla Regime}

The law "On Public Self-Initiative Bodies" was only passed in 2008; hence, there are no comprehensive analyses of its impact on the mahallas in Tajikistan. The Uzbek government incorporated the mahalla into its legal structures under "The Law on Institutions of Self-Government of Citizens" in 1993, and subsequently revised the law in 1999. In Uzbekistan, the mahalla became a part of the state administration. According to a report released by the Human Rights Watch, there are 12,000 registered mahallas in Uzbekistan comprising between 150 and 1,500 households (UNHCR 2004). In Tajikistan, the situation is more uncertain since the state does not exercise as much control over society as is the case in Uzbekistan. Nevertheless, some similarities between the two systems can be identified. 
Most opinions on the transformation of the mahalla in Uzbekistan emphasize the oppressive nature of the relationship between the state and the mahalla. Legal interventions have transformed the mahalla into a system of social control. The mahalla has become a 'hybrid' institution which is now charged with enforcing both the law and social norms. Since the Uzbek state started to transfer state responsibilities to the mahalla, the mahalla 'social organization' was transformed into a mahalla 'administrative system' (Troschke 2012: 27; Sievers 2002: 144-145; Urinboyev 2011: 53).

Since 1999, the head of a mahalla is a civil servant paid by the state and elected for a 30-month term of office. Despite the fact that the rais and members of the mahalla are elected by mahalla residents, the head of the administrative government nominates the candidates or they have to be approved by the authorities. He/she has many administrative functions and acts as intermediary between the community and the state administration. He/she also participates in distributing state services, and is therefore very closely related to the state administration. The role of the head of a mahalla is to supervise all activities of a community on behalf of the state administration (Kassymbekova 2003; Sievers 2002: 121; Urinboyev 2011: 43).

Notwithstanding, the Uzbek state claims that the mahalla reforms have increased civic participation in self-governance since 'the modernized mahalla' is a nucleus of the Central Asian model of democracy. In 2003, the cabinet of ministers of Uzbekistan issued a resolution proclaiming the year 2003 to be 'The Year of the Mahalla'. According to President Islam Karimov, the program aimed to reinforce the mahalla as a component of civil society. However, there are a number of reasons which could lead one to believe that the state policy in relation to the mahalla (commonly termed the mahallisation policy) has nothing in common with the development of civil society, and that the mahalla has become increasingly subordinated to state structures; for instance, in the past there was one district inspector, a militiaman per every two or three mahallas. Today, about 30 out of every 100 mahalla residents work for the secret service (Carlson 2003; Sievers 2002: 121; Urinboyev 2011: 43).

In spite of the state's penetration of the mahalla, paradoxically, the mahalla's responsibility for providing social services to the community has increased while the state has almost withdrawn from any activities at the local level. At the same time, international organizations have begun to channel small-scale aid through the mahalla. This could have also contributed to the further bureaucratization of the communities. Former voluntary actions have been reshaped into the (legal) responsibility of the residents (Abramson 2000; Troschke 2011: 25).

In Tajikistan, the newly introduced legal principles have functioned only superficially as a result of the general weakness of administrative structures, as well as the lack of relevant mechanisms for the implementation of the mahalla law. Despite the various elements of the law aimed at reinforcing the operational capacity of the mahalla, similarly to Uzbekistan the main emphasis has been placed on the formalization of the various networks of the traditional mahalla rather than on their development. 
All settlements located within the territory of a particular jamoat are expected to establish mahalla committees. Accordingly, MCs have been established in most settlements and towns in Tajikistan, irrespective of the traditional structures of the targeted communities, even if they have never had the tradition of a mahalla as a social organization.

One example of such a situation involves two villages situated in the Jillikul district (Khalton region) and inhabited by Kungrats (an Uzbek tribe), where we worked within the framework of our NGO project. To this day, Kungrats are organized according to a tribal system, whereby the individual kinship groups (qawms) function within ayils, and - more precisely - one qaw'm lives on the territory of one ayil which is headed by an aqsaqal. The mahalla committee was established in 2009, and today consists of the representatives of all ayils located within the territory of the big village. Nevertheless, the committee is rarely recognized by people, and no list of the members of the committees can be found in the local jamoat. ${ }^{114}$ The mahalla committee? It is just a state institution. It has a minor impact on our lives! - the Kungrats say. ${ }^{115}$

The mahalla came to us 'from the top'. It has operated since 2000). The authorities decided that there would be such a division, and then they established the territory of the mahalla. The rais was also installed 'from the top'. In 2009, Save the Children came to our village. It was their idea to organize the MC. They wanted 10 disseminate humanitarian aid through the MC, but there wasn't any $M C$ in our village. So, it was established to redistribute aid (....). At the same time, a meeting was organized and they chose a deputy, the rais remained the same. Later; they also selected the members of the MC. (a conversation with a member of the MC. qishloq O. populated by Kungrats; after Stryjewski 2013, my translation).

As the above case shows, the traditional mahalla social organization has been formalized by the state and become an official institution which is imposed by the authorities even in places where other traditional structures are present. Our twoyear-long NGO project among such groups has shown that the formal structure of the mahalla, which was artificially implemented into Kungrat communities, remains a façade only, behind which the indigenous institutions continue to function. In this context, the goal of reinforcing cooperation between the communities and the state has not been achieved. Quite the contrary, the 'mahalla regime' mechanism has been implemented with the traditional mahalla social organization reshaped into a state organ. I will return to this topic later in Chapter 7.

It should be mentioned that the state administration has also reorganized the mahallas in the cities. For example, in Khujand, previously about one hundred and twenty mahallas had been registered. Recently, the local administration divided the city into twenty-two mahallas and established administrative authorities in each of them.

114 A similar situation exists within other communities, which also lack lists of MC members.

IIs Information based on personal conversations with members of a community. 
In reality, residents frequently do not know who the heads of the big new mahallas are. In well-integrated communities, the amin of mahalla retains informal authority as he did in the past. Most mahallas in Khujand, however, have already lost their traditional character and become simple administrative units within the city. Oddly enough, the administration of Sughd established 2013 as the year of the mahalla. ${ }^{116}$

There is also another 'modern version' of the mahalla, such as for example two villages which I visited in 2012 located in the Sughd region, Spitamen district, populated mainly by Uzbeks who have lost their tribal division. Part of the population had lived in the same region before the October Revolution under the leadership of an ishon group (see Chapter 2). During Soviet times, villages were organized into kolkhozes, and many people were resettled there from other parts of the Ferghana Valley. As previously mentioned, ishons continued to hold a key position also within the kolkhoz hierarchy, often occupying important posts.

Today, in the aftermath of the dissolution of the kolkhoz system, the two villages function as separate units. Both possess mahalla committees which are registered in the jamoat. The villagers call the committees mahalla-dom-koms, which is a compilation of two terms - mahalla and committee of the house (Russian: domovyikomitet). ${ }^{117}$ In accordance with traditional social organization, the area of the villages is divided into smaller quarters termed here 'small mahallas' (guzar, kucha). Village M. has a well-developed administration. In 2012, the raisi mahalla-kom had his own office, as well as being the head of the Committee of Drinking Water Users (he was finally replaced by another person) and of the sewing room established by an Italian NGO for women from the village. He also had his own small business which processed fruit and vegetables. The rais comes from an ishon family, as does the local mullo and shaikh of the mazar. According to tradition, all important decisions (such as the election of the mirob, etc.) are made in the mosque by significant men, with some of them also being members of the mahalla-dom-kom committees. Decisions reached in the mosque are formally approved by the MC. Selected members of the mahalla committee are also vakils to the jamoat, while the rais holds a small formal post in the jamoat office. In the neighbouring village L., in 2012, the structure was similar with the head of the mahalla also holding the position of the director of the Committee of Drinking Water Users. He also belonged to an ishon group originating from a much respected avlod, while his wife was the local bibi otun.

Due to the low level of knowledge about the mahalla law among the MC members, at the beginning of our work in the NGO project in Khatlon, we decided to conduct a seminar regarding the rights and obligations of the MC under the new legislation. The raises and members of the committees participated in the seminars.

$11 \mathrm{~h}$ Information obtained during research in 2014.

117 Dom-kom committees were introduced during communism with the purpose of organizing the lives of people inhabiting apartment blocks; for example, dom-kom(s) collected money for repairs, etc. Presently, in Central Asia, there are house committees. mainly in the cities. but the majority of such committees perform a minor role in the communities. 
According to the evaluation of the project in 2013, many issues addressed during the seminar aroused the interest of the MC members as the majority were unfamiliar with the law. The discussion of the cooperation between the MC and the jamoat raised the most controversy. Most of the participants were surprised that the MC should cooperate with the authorities of the jamoat as equal partners. They were convinced that the MC was founded only to carry out the orders of the jamoat and that it is subordinated to the local administration. The following quotations show people's opinions concerning various aspects of the mahalla law, as they were expressed during conversations conducted within the framework of project evaluation prepared in October 2013 (see Stryjewski 2013).

Until the seminat; we had thought that the rais was the 'law'. After the training we realized that our cooperation is supposed to be teamwork, and that we do not have to be subordinate to the jamoat (a conversation with a member of the MC. qishlog H. populated by Tajiks, my translation).

So far; our MC in many respects has only existed on paper: The brochure with the Mahalla law was given to us... yes... but no one read it... (a conversation with a member of the MC, qishloq F., populated by Tajiks; my translation).

Before the seminar; the mahalla was just a name, we did not know the law'... (a conversation with a member of the MC, qishloq D., populated by Kungrats: my translation).

Until the seminar; the committee consisted of 3 people, I also participated. We worked with the people, but it was mainly some help for the poor, implementation of the Tanzim low, preventing people from spending too much money on celebrations - that was our role... (conversation with a female member of the MC. qishloq D.. populated by Tajiks; my translation).

Formally, the MC should be registered by the authorities of the jamoat and should receive a rubber stamp. Following registration, the $\mathrm{MC}$ can also establish a bank account. However, most of the committees which were included in our NGO project were organized by their jamoats but they were not registered. Only one committee was registered due to the requirements of the donor - the MSDSP - in Jillikul district, where they were implementing a project.

Formal manifestations of administrative status, such as a rubber stamp and bank account, are useful for performing financial operations. However, mahallas rarely possess enough financial resources to place them on a bank account. Traditionally, mahallas had a common fund which was spent in accordance with the needs of the community and was independent of official control. Maintaining a bank account and bookkeeping can be of practical use, but they also provide an opportunity for the state administration to check the financial affairs of the mahalla at its leisure.

Despite the new regulations, the status of the mahalla is still uncertain. The law provides funding for projects undertaken by a mahalla and financed by the state 
administration. However, if the state does not have sufficient financial resources to cover a jamoat's basic needs, it is unlikely that it will participate in financing initiatives at the mahalla level. Therefore, the idea of delegating tasks to a mahalla is purely theoretical. In addition, most MCs have little experience and knowledge regarding cooperation with external organs, such as the state administration and IOs.

The withdrawal of the state from activities related to local development has resulted in mahallas being forced to solve their problems on their own. It is highly controversial what responsibilities should be held by the mahalla community. In fact, in developed economies, the state administration does not force communities to assume the state's tasks since the citizens pay taxes which cover public needs, such as the construction of schools, reparation of infrastructure, maintenance of medical facilities, etc. In my opinion, the fact that communities have replaced the state in providing basic services is an indicator of the erosion of state structures, and this regress will be difficult to overcome quickly.

\subsubsection{The State and Religious Affairs in the Mahalla}

The new law has increased state control over religious matters in the mahalla. According to Article 8, a "mahalla committee should supervise the performance of religious ceremonies and rituals in accordance with the Law of the Republic of Tajikistan regarding 'Freedom of Conscience and Religious Associations', and other normative legal acts of the Republic of Tajikistan" (Law 2008). Recently, the Tajik government also issued a number of directives aimed at monitoring religious activities. This intensification of control over religion stems from the fact that the Tajik government is afraid of grass-roots social movements, which could potentially challenge the existing political order.

Consequently, the government's actions against religion target the most important social institution in the mahalla community - the mosque, while also being aimed at various religious leaders. In January 2011, the Committee for Religious Affairs (CRA), ${ }^{118}$ in cooperation with the state-backed High Council of Ulama, announced a list of 60 topics that can be dealt with during sermons (Arabic: khutbah) in mosques. Imams have been instructed to conduct khutbah in line with these recommended topics. The strongest oppositional political force - the IRP - criticized this decision, decreeing it an attempt by the state to extend power over imams, and thus over local communities. Addressing the allegation, a representative of the CRA

11* The Committee for Religious Affairs, Kumitai Limuri Dini Tojikiston (Kumitai Dini), was established in 2010. It is an official organ which controls religious affairs in Tajikistan. It has branches in all districts of the country. It also supervises the Shuroi Olii Llamoi Tojikiston (The High Council of Ulama [Shuroi L/lamo]), which replaced Tajikistan's muftiat (religious administration). when the latter was dissolved in the late 1990s. The Shuro was registered in 1997. 
said that the decision had been made in order to promote Islamic values and reduce the influence of extremist organizations (Najibullah 201la). The authorities explained cases of closing down mosques or refusing to issue a permit for their activity using similar justifications. Many masjids have been kept waiting for registration (USCIRF 2011). In some cases, mosque buildings have been changed into clubs a practice which was also common during the Soviet era. ${ }^{119}$

Moreover, the Friday mosques are obliged to install a camera inside the main hall to register the course of action during prayers and meetings. At fairly regular intervals, a person from the CRA district branch visits the mosques and collects the records. The state administration has also determined the salary amount to be paid out to imams who work in the Friday mosques (160-400 USD), depending on the position and the mosque. However, in June 2014 , I was told that it was paid out irregularly to the imams. The religious leaders employed in the official mosques are subordinated to the state. Most of them are insignificant religious figures. The respected independent-minded religious leaders have been marginalized and removed from their posts. ${ }^{120}$

The relationship between religion and the state in Tajikistan is a complex issue, beyond the scope of this work, although it should be stressed that the war against terrorism is an excuse for all governments in Central Asia to suppress potential outbreaks of public discontent resulting from the very difficult socio-economic situation throughout the entire region. Any attempt to protest against government policy is classified as a manifestation of extremism and society is constantly threatened with the vision of radical Islam and terrorist attacks.

It should be noted that, at this stage, the state of religious matters in Tajikistan is subject to dynamic changes triggering heated debate among traditionalists, modernists (both supporters of religious transformation as well as enthusiasts of the Western style of life), people who support the government, and those who support the political opposition. Nevertheless, religiousness is deeply rooted in Tajik culture, and the hostile policy of the government towards Islam has prompted criticism not only from religious people but also from part of the moderate 'secularist' Tajik intelligentsia.

Additionally, religious tensions can be placed within a wider context and understood as a class struggle between the majority of the poor and the small privileged group of the rich, who occupy government posts and control the country. The frustrated citizens frequently perceive the ideal of social justice expressed in Islam and shiaria law as an alternative to the dysfunctional oppressive state. According to the tradition of the renowned Sufi Order Naqshbandiyya, the work of farmers (who constitute a majority of the Tajik population) is sacred and contempt for, it is sacri-

119 Information provided during an interview conducted with the project manager of an international organization which implemented a project on local development in 55 mahallas in an area near Dushanbe, January 2012.

120 On the basis of various personal observations made and research conducted between 2010 and 2014. 
legious and undermines social order (Niyazi 1999: 182). Thus, attempts to discredit religion can be seen by ordinary citizens as a lack of respect for the working masses.

It should be noted that despite similarities in the main principles of the religious policies in contemporary Tajikistan and in the Soviet Union, the ideological bases are different. At present, the authorities declare themselves to be Muslims, ostensibly acting to eradicate foreign 'dangerous' elements within Islam in Tajikistan. Some citizens support this approach, feeling concern about the spread of radical Islam, and consequently about the threat of an 'Islamic state' being established.

Nevertheless, the state remains too weak to penetrate all areas of social life, even if the administration attempts to establish a mechanism of close supervision of religious life through developing various means of control at every administrative and social level. Controlling mosques and religious leaders or issuing anti-religious laws while ignoring important problems such as poverty and chronic unemployment only has a superficial effect and increases the reluctance of society towards the state.

\subsubsection{Summary}

The implementation of the mahalla law has not yet been completed. At present, the state administration is concentrated on the formalization of various traditional institutions. Little attention is paid to the development of mechanisms for pursuing social and economic development at the local level, including reinforcing cooperation between the jamoats and the mahalla committees. As a result, the new law only ties the local communities to the state structure. The sudden withdrawal of the state from local development has forced communities to seek alternative solutions. Nevertheless, the mahalla community is capable of organizing minor renovations or infrastructure projects, but works which require significant financial resources are beyond a community's means. It should be noted, however, that not every community can undertake independent initiatives. In the poor regions of the country which have no direct contact with urban centres, development opportunities are much scarcer. The most pressing problems include a lack of funds but also limitations on the operational capacities of communities. In most cases, people have little awareness of the mechanisms of cooperation with the state administration, not to mention with local or international NGOs.

In the following chapter, I will analyse the possible outcomes of the relationship between mahallas and international organizations in the context of donor policies aimed at developing civil society in Tajikistan. The chapter attempts to provide an answer as to whether the approaches of international organizations to community development correspond with the daily practices and traditions of mahalla communities, and whether they actually foster the expansion of civil initiatives at the local level. 



\section{ChAPTER 4 \\ The Modern Concept of Civil Society and Traditional Institutions}

\section{I. Civil Society, Donor Policies and the Local NGO Sector- An Overview}

The conjunction of war and post-communist transitional chaos has functioned as a catalyst, intensifying the activities of international donors in Tajikistan. Most organizations aim at contributing to reconstructing the country, reducing poverty or reinforcing civil society. The last of these concepts is realized through the implementation of a number of programs which focus on increasing the potential of local NGOs and the participation of citizens in local development. Despite a number of programs aimed at reinforcing the capacities of CBOs, not many donors and nongovernmental organizations regard a mahalla as an equal partner in the process of civil development.

Nevertheless, noticeably, the mahalla is described by some donors as an example of a 'traditional self-government', which corresponds to the popular concept of a 'communal civil society'. First of all, in Uzbekistan in the late 1990s, the Counterpart Consortium established the Mahalla Initiative aimed at strengthening cooperation between mahallas, community groups and NGOs. Subsequently, other initiatives targeting mahalla communities have followed suit. As already mentioned, in Tajikistan, the MSDSP set up hundreds of village organizations (VOs), a concept of a 'new mahalla' based on the idea of participatory development. There are also other similar projects, such as the one run by Oxfam Great Britain, which established community-based organizations, or the projects introduced by ACTED, Christian Aid, as well as by UNDP, which intend to provide institutional support for the $m a-$ halla committees. 


\section{I.I. The Concept of Civil Society}

First of all, to provide a satisfactory answer as to whether the mahalla can become a nucleus for the development of civil society, it is necessary to consider how the term 'civil society' is understood in the context of development policies pursued by international organizations, which are its main promoters in Tajikistan as well as in other countries of the former Soviet Union Bloc.

Civil society remains a matter of much dispute among scholars of political theory and of the history of ideas. The modern concept of civil society was shaped during the Enlightenment, when the political and social circumstances of the period created the need to reformulate the relationship between the state and the increasingly powerful bourgeoisie. The main concern of that time was society's opposition to the extreme and arbitrary power of the absolutist state.

According to Bobbio (1988: 81, 84), Georg Hegel described civil society as the sphere where citizens, autonomously from the state, associate in order to pursue their interests and aspirations. "It is in civil society that Hegel concentrated his critique of political economy and of political science, inspired respectively by the principles of natural liberty and the state of law" (Bobbio 1988: 81). Hegel distinguished civil society from the family and from the state.

The French political thinker and historian Alexis de Tocqueville's contribution to the debate on civil society in the context of the political and social system in the United States has been particularly important due to its influence on formulating the development policies of the 1990s. He believed that the modem state was so powerful that individuals, increasingly atomized by capitalism, were not capable of resisting it independently. The emergence of civil society was a logical reaction, creating a counterbalance to this power and establishing equilibrium between the state, civil society and the market (Lewis 2002: 571).

Civil society also became an important aspect in Karl Marx and Friedrich Engels's works. Both scholars concentrated on the economic relations between the state and society, i.e. "the state, the political order, is the subordinate, and civil society, the realm of economic relations, the decisive elements" (Engels qtd. in Bobbio 1988: 81). According to their view, civil society is reduced to its economic functions within the system. They ultimately advocated the removal of the distinction between the public and the private sphere, and reunification of state and society.

In Bobbio's (1988: 83-94) discussion of the Italian Marxist, Antonio Gramsci, the latter is described as having introduced an important innovation to Marx and Engel's theories. Gramsci posed the following question: why did the communist revolution not take place in Westem countries with a strong working class? In his search for explanations, he introduced the concept of 'cultural hegemony'. According to his view, the ruling class (the bourgeois state) exercises its power over citizens, not only through an 'apparatus of violence', but - much more significantly - through imposing capitalist ideals and values on the proletariat. Civil society, according to Gram- 
sci, is not only based on material relationships (as in Marxist thought) but includes all ideological-cultural relations, i.e. "not the whole of commercial and industrial life but the whole spiritual and intellectual life" (Bobbio 1988: 83). He distinguishes the area of political institutions (the police, the armed forces, the legal system) and political and civil society (the family, the educational system, trade unions), which are capable of exercising control over the state. Consequently, social changes must be done through reformulating all social relationships, values and ideas (Bobbio 1988: 83-94). Civil society was portrayed by Gramsci as "a special nucleus of independent political activity, a crucial struggle against tyranny" (Carothers 1999-2000: 19).

Gramsci's concept became popular among leftist intellectuals in the 1970s and 80s, especially in the West, but also in Eastern Europe and Latin America (Carothers 1999-2000: 19). Simultaneously, Eastern European intellectuals, such as Andrew Arato and others, criticized the Marxist theories. They indicated that the reunification of state and society leads to an authoritarian system. According to their view, civil society can be a force of resistance against the communist state. A significant analysis of civil society prepared by Arato and his colleague, Jean L. Cohen, is presented in their book entitled Civil Society and Political Theory (1992). The book provides critical insight into different concepts of civil society, as well as identifying possible perils for civil society within various political systems. They provide a definition of civil society as a mediating sphere through which social organizations exert influence on the political and economic sphere. Civil society consists of family, voluntary associations, social movements and different forms of public communication. The political sphere encompasses political parties and government structures. The economic sphere is composed of organizations of production and distribution (Arato and Cohen 1992: $x$-xii). The book provides a summary of the various analyses of the nature of civil society, carried out by a wide variety of Western, South American and Eastern European intellectuals and activists.

In recent decades, civil society has become an important concept in terms of reformulating social relations not only in Eastern Europe but also in the West. This has coincided with changes in the economic policies conducted in the early 1980s, initiated by the governments of the USA and the UK.

At that time, the governments of these countries developed a set of policies aimed at reducing the state's role in the economy. They took steps towards privatization, decentralization and decreasing inflation. Simultaneously, to limit state expenditures, the governments decided to reduce public spending on the social sphere by transferring part of the responsibility for social services to non-state actors, such as non-governmental organizations (NGOs). Consequently, civil society was almost entirely reduced to bureaucratic organizations managed by professionals who were to deal with very diverse spheres of social activities. Later, the above approach to civil society was included as an element of development policies introduced in developing countries, and after the collapse of communism also in Eastern Europe and the former Soviet Union.

In this context, civil society can be defined in the following terms: 
Civil society is, together with the state and market, one of three 'spheres' that interface in the making of democratic societies. Civil society is the sphere in which social movements become organized. The organizations of civil society, which represent many diverse and sometimes contradictory social interests, are shaped to their social base, constituency, thematic orientations (e.g. environment, gender, human rights) and types of activity. They include church-related groups, trade unions, cooperatives, service organizations, community groups and youth organizations, as well as academic institutions and others (UNDP 1993: 1).

\section{I.2. Shaping the Development Agenda from the ig8os to the Present Day}

Since the early 1980s, a pervasive and powerful global discourse on poverty and development has emerged that places political liberalization alongside the economic liberalization of markets as the principle policy objectives of developing countries. Due to the crisis caused by the failure of the policy of state-led development in the 1950s and 60s in A frica and South America, as well as the debt crisis of the 1970s, the IMF and the WB (specifically the Bretton Woods Institutions) introduced new policies in the developing countries of Africa and later those of South America. A set of Structural Adjustment Policies (SAPs) was designed which were fully reliant on market-based economic development. The main issues applied to cutting state budgets, downsizing government apparatus, withdrawing from the sphere of production and from anti-poverty spending on food subsidies, introducing user fees in the core services of delivery sectors, decentralisation, and - finally - privatisation. As in the case of Western Europe, in order to cut public expenditures, a part of the state's responsibilities were handed over to non-govermmental organisations. During that period, civil society was seen in the context of controlling the state's policies and promoting democratic principles. The core idea was that a strong civil society stands in opposition to a weak state (borrowed from Lerche 2005; Thorbecke 2007: 15-19).

Despite early optimism about the reforms employed, the economic downturn was not overcome through SAP implementation and the so-called Washington consensus policies. ${ }^{21}$ Instead, poverty became more acute. The critics of the SAP pointed out its lack of interest in policies aimed at helping the poor and its concentration on benefiting a small elite group who were using the state's resources for private purposes. The failure of the SAP and increasing poverty necessitated re-thinking the new de-

121 The term 'Washington Consensus" or so called neo-liberalisın, in the most common understanding refers to "development strategies persuaded by International Institutions focusing around privatization. liberalization, and macro-stability (meaning mostly price stability); a set of policies predicated upon a strong faith - stronger than warranted - in unfettered markets and aimed at reducing. or even minimizing. the role of government" (Stiglitz 2004). 
velopment discourse. At the beginning of the 1990s, the agenda shifted towards the concept of 'good governance' which aims to reinforce the market-based reforms with policies for assisting the poor. In short, 'good governance' means "good rules [regarding the exercise of institutional power] and their effective implementation" (Lerche 2005; also see Thorbecke 2007: 15-19).

The most important change in the new policy agenda (the post-Washington consensus) is linked to designing mechanisms which can contribute to building an efficient state, able to cooperate with market forces based on anti-poverty development principles. The main difference in comparison to the previous concept was that the new one adapted multi-dimensional and participatory approaches to poverty and introduced ideas of democratic accountability and civilian participation in order to guarantee the effective implementation of reforms. The main goal of the new agenda was "the development of liberal democratic capitalism in the South, within the era of globalisation" (Cammock and Stiglitz qtd. in Lerche 2005).

On the theoretical level, this agenda was conceptualised by Peter Evans. He edited a special issue of the leading academic WB journal "World Development" in 1996. He expressed his ideas using the idea of creating 'synergy' between the state and civil society. Evans writes that "the combination of strong public institutions and organised communities is a powerful tool for development" (1996: 1130). This marks a departure from the extreme state-civil society dichotomy and underlines the importance of developing a strong state alongside a strong civil society in the process of democratic development. This 'synergy' argument quickly became the standard policy line in international development agencies (Evans 1996).

In the World Bank's significant report entitled "Working Together: World Bank-Civil Society Relations" (2003), the term 'civil society' is used to describe "the wide array of non-governmental and not-for-profit organisations that have a presence in public life, expressing the interests and values of the members or others based on ethical, cultural, political, scientific, religious, or philanthropic consideration" (World Bank 2003: 1). The report further states that:

...civil society organizations (CSOs) are increasingly seen as one of the most effective ways to reduce poverty and achieve sustainable development. Within these multi-stakeholder partnerships, the World Bank recognizes that CSOs play a critical role in helping to amplify the voices of the poorest people in the decisions that affect their lives, improve development effectiveness and sustainability, and hold governments and policymakers publicly accountable. (World Bank 2003: 1)

Together with the development of a new concept, a number of policies were introduced, such as the UN and UNDP's Millennium Development Goals (in 2000), Heavily Indebted Poor Countries (HIPC) Initiative (launched by the IMF and WB in 1996) to address the high debts of low-income countries and the so-called adjusted SAP: Poverty Reduction Strategies (PRSs). The new strategies launched in 1999 by the World Bank and the IMF were expressed by the Poverty Reduction Strategy Papers (PRSPs), designed as a new scheme for improving the domestic accountability of poverty reduction reforms. The scheme aims at reinforcing the coordination of 
development assistance among governments and other partners in a particular country. Designing a Poverty Reduction Strategy Paper (PRSP) is a precondition for a country to obtain debt relief and/or concessional financing from either of these institutions. According to the principles laid out by the WB and the IMF, PRSs promote growth and poverty reduction through a participatory process involving a broad range of stakeholders, such as government institutions, international organizations, and civil society actors from a particular country. Civil society actors are mainly understood as representatives of local non-governmental organizations. Countries are usually obliged to prepare a PRSP every three to five years (World Bank 2003: 15-16; also see Molenaers and Renard 2009).

Aside from the above-described crisis associated with the first generation of the Washington Consensus, which forced international institutions to re-consider the course of development assistance, an important factor that contributed to the shift in aid policies was the transformation of the Soviet bloc. The newly-emerging states, as well as the old ones which were now free of their communist ties, required help in the transition process from central planning to a market economy. Introducing democratic principles constituted a great challenge for all of these countries. All intemational institutions recognized that the remains of the communist state could be removed by reinforcing participation by non-state organizations and various social groups. This process had already started in the 1990s and was later continued. The most disadvantaged countries of the former USSR, such as Armenia, Azerbaijan, Georgia, Kyrgyzstan, Moldova, Tajikistan and Uzbekistan, were requested to follow new sets of development policies designed within PRSPs. As described above, civil society was no longer associated with a power struggle against the state since the totalitarian system had been removed. Despite the new approach, several challenges emerged as a result of the transformation of the ideological perception and political system.

First of all, it should be noted that at the beginning of the 1990s Westem donors lacked basic knowledge of the social and economic conditions in the former communist countries. Apart from providing aid to the Polish 'Solidarity' movement (full name: Independent Self-Governing Trade Union 'Solidarity', Polish: Solidarność), as well as other political movements in Eastern Europe, the West had no experience in operating in this part of the world since the region's decades-long political isolation had created unfavourable conditions for exploration. Consequently, due to donors' scant knowledge at the initial stage of introducing changes, the model of providing aid was much the same as in the programs implemented in developing countries, combined with a set of policies which were a continuation of the ideological battles of the Cold War period (Carothers 1999; Stavrakis 2002: 265-266; Atlani-Duault 2007: 90-91, some information added). Thus, "communities that had just endured a massive experiment in social engineering under socialism were then subjected to an equally idealistic experiment in social engineering inflicted upon them by foreigners" (Layton 2004: 12). Reddaway and Glinski coined the term 'market bolshevizm' to describe this phenomenon (qtd. in Stavrakis 2002: 265-266). 
Carothers (1999) further elaborates that the whole structure of aid based on the experience gained from years of development cooperation with the 'Third World' was imposed on the former Soviet Union and Eastern Europe without any reflection about the differences between this region and others, not to mention without any recognition of the various social, economic and cultural conditions present in particular parts of former communist areas or in the separate countries within the sub-regions. Implemented programs pushed in the direction of accelerating transition, again with no consideration of how effective and realistic they were and what the possible outcomes of their policies might be for the region's development. In addition, no-one raised the question of how relevant this model of development would be in countries with very diverse histories and traditions, such as, for instance, Moldova and Tajikistan.

\section{I.3. International Assistance and the Emerging New 'NGO Elite'}

Regardless of the common policies introduced in the whole region, each sub-region as well as its separate countries followed their own paths of development. As Roy (2004: 2) argues, a distinction should be made between those countries which aspired to become a part of the democratic West, such as Poland and the other Central and Eastem European countries needing technical assistance at the beginning of the transformation, and those such as the authoritarian Uzbekistan or the disintegrated Afghanistan, where building democracy on the foundation of state institutions is difficult. In the case of Central and Eastern Europe, the role of the NGOs was minor, and most of the adjustments were made through bilateral agreements between the particular state and various international institutions and agencies, such as the ODIHR (Office for Democratic Institutions and Human Rights, which is an OSCE agency). In addition, the situation has changed since Central and Eastern European countries joined the European Union in 2004. They followed a different method of channelling aid, and were transformed from recipient to donor countries providing aid to other regions. However, according to Roy (2004: 2), as far as the countries categorized as failed or authoritarian states are concerned, there are only two ways to pursue democratization: regime change or building civil society.

Despite some dilemmas connected to the new development paradigms, making civil society a real actor became one of the most important development goals. From the very beginning, the development agenda included a number of programs aimed at facilitating local newly-established NGOs and training local staff to work with international organizations. At that time, establishing the third sector in the former Soviet Union and Eastern Europe was based on the assumption that civil activity did not exist during the Soviet period and that the wave of democratisation was bringing its principles to the region for the first time. For example, Seligman (1992) 
claims that civil society was absent since civil and political elements had been rejected by the state (qtd. in Layton 2004: 7-8). Nevertheless, the Soviet constitution included relevant articles concerning voluntary or public associations (Russian: $o b$ shchestvennye organizacii) and possessed the appropriate legislation, such as the "Voluntary Organizations and Associations Act" issued in 1932 and "Public Associations Act" from 1991, but existing organizations were closely supervised by the state (Atlani-Duault 2007: 50).

Regardless of the fact, however, that organizations were subordinated to the state, their members managed to pursue civil interests. These actions had further contributed to developing different interests by increasing the level of education and providing free access to various social services, especially in the disadvantaged regions, such as Central Asia. Undoubtedly communist ideology sought to merge the state and society, and the nomenclature created by the system was beneficial only for certain groups. On the other hand, people were able to participate in official associations or organizations accepted by the state, and they occupied a space situated between the household and the state (Layton 2004: 7-9). Organizations targeted young people, such as the Komsomol and the Young Pioneers ${ }^{122}$ raised interest in social issues and civic engagement among the young. In urban centres, many civil initiatives were founded, such as block councils, women's committees, and youth committees, dealing with local matters and supporting the activities of citizens. Consequently, in spite of the strongly centralized system and imposed world-view, people were able to participate in various activities and to acquire organizational skills, to pursue their interests, as well as to learn teamwork (Buxton, Earle and Giffen 2005: 71-79; Zharkevich 2010: 18).

Furthermore, centralized state policies often failed to recognize local needs, especially in remote places. Thus, members of communities had to maintain their own institutions based on the traditional social order. These dealt with local matters and acted as a link between the public and private spheres. Roy (2002: 127-129) argues that the 'traditional groups' based on qawms, mahallas, and other such groups were merged with the kolkhoz structures in rural areas, and were reformulated within the 'socialist system'. The traditional networks were absorbed into the framework of the communist system by means of local 'communist' cadres which showed loyalty to Moscow and at the same time were engaged in the traditional relationships within the communities. These so-called 'party apparatchiks' introduced a certain 'Soviet policy' which was applied, among others, to organizing clubs, circles of various interests, fostering young people's participation in the Komsomol and other related organizations, even in the far cormers of the USSR, including rural Central Asia. ${ }^{123}$ In this way, citizens were encouraged to be involved in 'the communal life of the

122 The Young Pioneer Organization of the Soviet Union was a mass youth organization for children aged 10-15 in the Soviet Union which existed between 1922 and 1991.

123 I had the opportunity to visit clubs and provincial libraries in former kolkhozes in various parts of Central Asia established during the USSR. Some of them were no longer functioning. 
state'. Obviously, the highest positions in important associations were reserved for party activists and ordinary members had to respect certain rules; nevertheless, such organizations provided a significant means for collective activity. Thus, if we do not evaluate these organizations in terms of how they inflicted a particular ideology on society, it should be acknowledged that such actions had a positive effect in the context of the development of organizational skills and social engagement.

After the transformation, paradoxically many of these former social or party activists became employees of the third sector. Frequently, people who were members of the Komsomol or other organizations in the past, presently work for local and international NGOs for the reason that they possess the relevant organizational and entrepreneurial skills, acquired during the Soviet period, which have helped them to adjust easily to the new conditions. ${ }^{124}$ Due to the existence of certain stereotypes concerning the communist system, for Western aid workers it is sometimes difficult to accept or to understand that - apart from dissidents and political opposition members - members of former 'communist' organizations have also become important actors in implementing Western policies.

Mostly, however, the Western agencies have sought new actors less associated with local notables, and therefore more likely to absorb democratic ideas and then convey them to the rest of the population. These are recruited from the well-educated part of society, i.e. intellectuals and academics, who often are not involved in politics but at the same time have a good family background. These representatives of the intelligentsia formed in the previous system were mostly left behind after the USSR collapsed. Consequently, working for international organizations is sometimes their only way to forge a career. They have quickly learned the English language so as to be able to write reports and project proposals, and they are knowledgeable about donor requirements and expectations (Roy 2002: 141, some information added). This 'NGO elite' group represents people working for international or large local organizations (usually set up by Western donors; sometimes they are a part of a chain of a particular organization with branches located in various countries).

Members of the younger generation have participated in many educational programs set up by American or EU institutions, so in a way, they learn the principles of the conventional Western concept of development, and sometimes genuinely believe that this is the right model for building global order. It should also be indicated that many of them come from families living in big cities, where during the Soviet era secularisation and the influence of European culture was stronger than in rural areas. Under the current circumstances, when there is a lot of debate about the religious and secular models of life, tradition versus modernity, and so on, these people often sup-

although in some places they are still active, despite various difficulties, thanks to the initiative of local people.

12. During the work and research I conducted in CIS countries. I had many opportunities to meet people who had formerly participated in various types of organisations (with the majority coming from Komsomol) during the Soviet period, and are now working in the NGO sector. 
port the latter, considering it to be more relevant to the contemporary world, which also corresponds with the mainstream Western mind-set. Therefore, the post-Soviet secular NGO intelligentsia, apart from enjoying the financial benefits of working for an international organization, frequently finds common ideological ground with Western thought. However, even if some of them criticize Western policies in their region and consider them unrelated or even imposed from the outside, they almost never do so openly for fear of losing the high social status they enjoy as a result of working for an IO. Although - undoubtedly - the scholarships, grants, work for international institutions, etc., do provide many opportunities, broadening their horizons, which can eventually be used to convey new ideas to the whole of society for the benefit of all. Whether this will actually happen remains an open question. Another factor which should also be perceived in a positive light is that these people create a certain intellectual environment which can be a counterbalance against the predatory behaviour of their states.

It should be noted that as a result of the failed transition in Tajikistan, the labour market has been almost completely dissolved. Hence, the International Aid sector has become one of the biggest work providers. The salaries of the members of the 'NGO elite' are high in comparison with typical earnings in the local market; therefore, such employment is considered attractive and prestigious, which in fact contradicts the ideal of the 'altruistic social worker'. In addition, not infrequently, the quality of the work of many local employees is poor, but expectations regarding the work conditions very high. Partly, this is the fault of the Western Agencies which have accustomed local staff to salaries which considerably exceed the average wages in Tajikistan. Another factor which has influenced the performance of the Tajik NGO elite group is that the bulk of well-educated people have left the country over the last twenty years. Consequently, many of those who have remained and have some knowledge useful in NGO work are considered to be valuable workers, even if their performance level differs from the general work standards. In addition, some international organizations are not concerned about the quality of their work, in this way showing the local employees that they accept poorly performed tasks.

Evidently, over time, some local employees do become competent specialists, but for many of them, the only motivation for working in international organizations is the financial remuneration. Unfortunately, many members of the local NGO elite do not have an interest in development issues or any other social work. Although they respond to the requirements of donors, they frequently fail to recognize the needs of their own society. They adopt abstract Western ideas, detached from real social needs and which often exist only in their reports for donors.

As members of the NGO elite are mostly well placed locally, they can offer protection and a network of personal contacts which are essential for international organizations working in a foreign environment. On the other hand, since they are a part of the local network and profit from working for international organizations, they are obliged to support their families, relatives and friends. 
As has already been explained in the case study from Chechnya described in Chapter 2, due to the difficult conditions of most people in poor regions, as soon as some form of wealth becomes accessible to one member of a kinship group, other relatives expect to benefit from it. Thus, even if someone is loyal to their employer and separates their professional and private lives, they are still under pressure from their network to share the profits of their labour (see also Roy 2002: 142-142; Liu 2003: 3-4; Abramson 2000).

One of the peculiarities of most developing countries is the practice of certain family-related groups monopolizing public or other structures, both traditional ones and those which have emerged in recent times. Roy (2004: 4) points out that -during the war against the Soviet Union in Afghanistan - for reasons of safety, international NGOs were often connected to local commanders, whose prestige and power also increased by having connections with foreigners. The Western powers' support for many political Afghan figures, such as Masud and Amin Wardak, was partly created on the basis of NGO networks. Thus, ironically, international organizations use local 'clientele', 'undemocratic' or 'nepotistic' relationships to pursue the 'democratic goals' of Western societies. However, under certain circumstances, this kind of behaviour is the only reasonable way for international organizations to work in the field, especially in post-conflict areas. It is sometimes essential to employ people coming from families that can guarantee a certain level of protection and safety for expats or who are able to deal with the local, mostly corrupt administration. Maintaining a good personal network is important for the success of the projects being implemented.

Another issue which should be stressed is corruption and the misallocation of funds released by donors. During numerous interviews and conversations with NGO workers and local community leaders, conducted as part of my research but also during my professional work, interlocutors said that, besides their doubts about donor policies, corruption seriously hampers the impact of development assistance. During the civil war, some people made a handsome profit out of humanitarian assistance. It often happened that after foodstuffs and other goods from international organizations were delivered to a certain place, private cars would arrive during the night and most of the aid disappeared to be then re-sold in the local bazaars. Some local NGO workers are reported to have stored these goods in their private houses to use for personal benefit. There is no need to quote all the stories about misappropriations of funds in Tajikistan. It should suffice to point out that there are many examples of local staff members working for international organizations and earning an official salary of about 500 USD monthly who have big houses, luxury flats, very good cars, and even such extravagant items as horses. Obviously, there are many people who work hard for the NGO sector to maintain their families and who do not reap informal profits from donor financial resources.

Another issue of concern is the way in which international funds are distributed, whereby a large part is channelled through government institutions and literally disappears into 'the capacious pockets' of officials. It is not uncommon for an INGO 
or LNGO to be asked to pay the state administration for 'permission' to work within a certain territory. Most Western donors are aware of this situation, but implementing mechanisms which would prevent wastage of funds is not an easy task, especially as part of the aid is channelled through the state administration.

In my opinion, the above-described trends are common in the whole region of the former Soviet Union, although their intensity varies from country to country. Although it would be unfair to say that all local employees of the international development sector work only for profit and are corrupt. Many of them are devoted to their jobs, serving their societies as best they can, but at the same time they are often frustrated by the outcomes of donor policies, while simultaneously having no means to challenge them. Others believe that the Western concept of civil society can lead to positive changes in the post-Soviet region, and this is no doubt true to some extent.

\section{I.4. The Local NGO Sector and Civil Society}

As far as the local Tajik civic sector is concerned, since the mid 1980s, a number of different informal debating circles have emerged which have been very important in terms of the involvement of various parts of society. First of all, the Marefat (English: Education) circle was formed in 1988, as well as the Rubaru (English: Face to Face) group, which was derived from the Komsomol but had a more autonomous character. Ashkara (English: Openness), a literary group with its seat in Dushanbe, brought together people from different parts of the country who were not members of the Communist Party, focused on criticizing the state and promoting cultural development and a national Tajik language (Boboroyov and Heap (2003) qtd. in Buxton, Earle and Giffen 2005: 90).

Later, on the eve of the collapse of the Soviet Union, the most important civic group was Rastokhez, founded at the initiative of the young Tajik intelligentsia in Dushanbe in 1989. Rastokhez was the largest movement in Tajikistan. It was formed by 50 people, but its meetings were attended by representatives of different independent organizations from all over the country. It was later reformulated and became a political party. Various reports reveal that it has up to about 10 thousand 'sympathizers' in Dushanbe, and about 50 thousand in other places. Another significant organization was the Ehyoi Khujand (English: Revival of Khujand), formed by Leninabad intellectuals. In Ura-Tyube, supporters of the Perestroika created the Vahdat (English: Unity). It consisted in the majority of intellectuals - teachers, civil servants, traders, and the like. It should also be noted that there were Russians and Armenians, alongside Tajiks, among this organisation's activists, and a few of them were even members of the board. In Kuliab, the social and political organisation Oshkoro (English: Publicity) was established. Yet another organisation was the Union of Democratic Youth Bokhtar (Baktria) founded in Khovaling, which is particularly interesting as it was formed in rural areas (Shamsiddin 2008: 106-112). 
Apart from organisations of a political nature, other associations were created during that time which brought together various religious and ethnic minorities. There were also some organisations which are focused on war veterans and public professionals. Despite the fact that the development of most organizations was hampered by the civil war, it should be acknowledged that many associations developed during the Perestroika were relatively autonomous bodies. Therefore, they were an important voice for Central Asian people in the broad discussion on the future of the Soviet Union which took place at that time in almost every part of the vast Empire.

On the other hand, some scholars, such as the below-cited Zharkevich (2010), hold that these organizations cannot be analysed from the perspective of the classical concept of civil society as most of their members represented the urban intelligentsia, and thus only the intellectual elite and not all of society. Consequently, Zharkevich points out that "the fact that civil society in many post-Soviet republics was not rooted in the wider society, but was rather limited to the urban educated intelligentsia, inspired by Western ideals of democracy, could partially explain the failure of the democratization process in these states" (including Tajikistan) (2010: 19). However, this point of view can be challenged in light of the fact that the intelligentsia usually tends to be influenced by innovative ideas due to its access to education, information, and so forth. Accordingly, they transfer new notions to the rest of society, as in the case of the French Revolution or the October Revolution. Therefore, despite these doubts about the real impact civic activists had on the formation of civil society in the period under discussion, they certainly contributed substantially to the creation of the fundaments of independent thinking in Tajikistan.

The mid 1990s mark the beginning of the formation of organisations that correspond to the typical concept of NGOs mostly financed by international agencies. INGOs and local NGOs were actively involved in delivering humanitarian relief during the civil war, especially in those areas most affected by the conflict (Buxton, Earle and Giffen 2005: 115).

The Law "On Public Associations" was enacted in 1991, and initially covered both non-governmental organisations and political parties. It was not until the new legislation was passed in 1998 that a distinction was made between these two types of entities. Under the law, public associations are voluntary, non-commercial organizations which cover a wide range of social activities (Akiner 2002: 173). ${ }^{125}$

Some local NGOs were established as part of international networks, such as the Mountain Societies Development Support Programme (MSDSP) or the Urban Institute and Counterpart Consortium, both financed by USAID. There are also groups, such as Sharq, Zerkala or Panorama, which employ professionals who are international consultants and simultaneously work for the state apparatus as state officials

12: NGOs in Tajikistan are mainly active in the following fields: children/youth, health. education/science, ecology, the disabled, women`s issues, business, legal/judicial, human rights, artists/artisans, families, pensioners, ethnic/cultural issues, the media (Buxton. Earle and Giffen 2005: 92). 
or even advisers of the President. Some NGOs are even reputed to have been established by the state administration to influence the NGO sector; not to mention the existence of quangos (quasi-autonomous non-government organizations), which are part of the state structure (Bliss 2013: 98-99).

The development of civil society was one of the main strategic goals of the PRSP as all stakeholders should be involved in the process of decision-making at the national level. However, as Bliss (2013: 102-103) points out, in the case of PRSP II in reality only government representatives, foreign donor organizations, and NGOs cooperating with the state administration participated in discussions. Surprisingly, donors were not concerned who the NGO representatives were and whose interests they really represented. In addition, there was a lack of relevant strategies and standards regarding the methods of including civic actors into the process of PRSP development. In terms of PRSP III, the situation improved to some extent, as external actors were invited to study the program implementation. In 2006, the NGO ASTI coordinated the works of the Design, Implementation and Monitoring Facilitation Group to monitor the PRS's performance. The Facilitation Group consisted of 19 organizations from the Sughd, Khatlon and RRS regions. However, the groups could not take part in the work of the editorial board drafting the PRSP for 20102012 , but the opinion of the group was taken into consideration by the Ministry of Economic Development and Trade of the Republic of Tajikistan and by the members of the group responsible for designing PRSP documents for 2010-2012 (Sharipova, Babadjanova and Mirpochoeva 2010: 4-5). In this way, some representatives of civil society were involved in designing the PRSP.

In 2007 , there were 2,500 registered organizations, but less than $10 \%$ of them were active (Mukhutdinova 2007: 9). In 2008, the government attempted to re-register NGOs and the number of NGOs decreased from 3,700 to 1,400, and only recently reached a level of 2,100 organizations (Zharkevich 2010: 28).

According to the NGO from Kurgan-Tyube, whose main activities involve supporting the development of the NGO sector and of new organisations, the amount of active NGOs is difficult to establish since apart from small non-governmental organizations set up by independent activists, which are weak mainly due to a lack of funds or the low skills of their employees, there are many 'phantom organizations', such as water or school associations, which have been registered within the framework of a certain project but in reality are not active. ${ }^{126}$ Another factor which should be indicated is that recently - due to the world crisis - less funds are available than a few years ago. Thus, many organizations have significantly limited their activities or even ceased to function. ${ }^{127}$

126 On the basis of an interview conducted with members of the NGO Fidokor from Kurgan Tyube in Dushanbe. November 2012.

127 On the basis of the above-mentioned interview and my own observations of the situation of the local NGO sector in Tajikistan (2010-2014). 
Unquestionably, direct access to the local population is one of the huge advantages of local NGOs. Grass-root NGOs are located in the areas where they operate; thus, they are better connected to the population they serve. NGOs are seen as more flexible, experimental, and innovative in their fields than governmental bodies and international organizations (Kuchukeeva and O'Loughlin 2003: 562).

It is also worth pointing out that in many cases communities are not aware of the activities of the third sector. In addition, due to the weak operational capacity of many organisations, which as mentioned stems mainly from their scant financial resources but also from the low professional skills of their employees, people do not see NGOs as important actors in local development. The population frequently perceives local organisations as an elite group which works only for the purpose of attracting money from donors or supporting certain clientele groups. ${ }^{128}$ This view also finds support among some state representatives disappointed in the organisations' results. ${ }^{129}$

Additionally, the activities of the local third sector are mostly dependent on the policies of donors. As Kuchukeeva and O'Loughlin (2003: 571) indicate, some aid agencies are not very democratic in their policies. Donor organizations are often driven by their own agendas and projects. Consequently, they tend to fund shortterm projects in the areas of their interests based on particular requirements, whereas most social problems need long-term sustainable solutions. Consequently, many local NGOs are aware that donors do not recognize the needs of their beneficiaries, but they still apply for funds to survive in 'the NGO market' (also see Akiner 2002: 173; Buxton, Earle and Giffen 2005: 92-93). Cooper (1999) remarks that "some aid agencies do not serve as good models for local NGOs and, in fact, resemble the Soviet organizations in their top-down management structure and detachment from the people" (qtd. in Kuchukeeva and O'Loughlin 2003: 571).

Due to the predominance of external funding, local organizations usually struggle to meet the expectations of donors, and, as a result, many of them undertake those initiatives which will actually get funded. Hence, a particular organisation can specialize in human rights, women's and children's problems, and environmental

128 On the basis of a recording from a seminar organized within the framework of the program Closer to Central Asia, with the participation of NGO representatives from Kyrgyzstan and Poland, Warsaw, Stefan Batory Foundation, October 2007, as well as research conducted in Tajikistan (also see Akiner 2002: 173-174; Zharkevich 2010: 37-39).

124 It seems that while some organizations actually work in the field, others do not and it is sometimes difficult to establish what their activities involve. Despite the fact that I have been working for the third sector for more than eight years. visiting many local NGOs in different countries of the South Caucasus, Central Asia and Eastern Europe, the most amazing NGO office I came across was in Tajikistan. In 2010, we arrived for a meeting with an NGO in the Hisor district. Their seat was located in a new house which looked like a rich man's palace. decked out in true Fastern splendour. Even if we take into account different cultural standards. it was clear that this place had been unashamedly linanced by donor funds. Unfortunately. this was not an isolated case. 
or judicial issues at the same time. All the buzzwords, such as 'empowerment', 'capacity-building', 'stakeholder', 'good governance', 'civil society', 'facilitators', 'the disadvantaged' and the like, are part of the art of writing a successful proposal. If an organization does not know a certain donor's terminology, it hardly has a chance to obtain any funds (Economist 2011).

In addition, despite the fact that local NGOs have direct access to the local population, they are rarely asked by donors to give their recommendations. Some of them do occasional survey or research work, but the outcomes of these are only sometimes made available to a wider public. Consequently, NGOs most often concentrate on delivering services rather than solving local problems (Buxton, Earle and Giffen 2005: 92-93). ${ }^{130}$

The following example can serve as an illustration of the social perception of the role of the third sector. A friend of mine is the president of a successful local NGO in Georgia, which operates in a buffer zone on the border with South Ossetia. They implemented a project aimed at developing civil society through improving the capacity of small local organizations and initiative groups. As part of the project, they provided advisory services to local people regarding establishing NGOs, writing project proposals, and so on. Surprisingly, many people who came for advice asked first of all about money or goods, such as computers and mobile telephones. They were convinced that founding an organisation is tantamount to attracting mythical Western money and therefore to seeing a profit. For them, social issues and altruistic motives did not play a significant role in their desire to establish an organisation. ${ }^{131}$ However, since the international organizations in Georgia at the time of my stay there (2009) were more concentrated on Internally Displaced Persons (IDPs) and, despite huge needs, the buffer zone had been neglected, it is understandable that people would seize at every opportunity to survive. This, unfortunately, is also the case in most parts of Tajikistan.

In addition, not infrequently many big LNGOs have quite high expectations in terms of financing their activities. Especially during the period of post-war reconstruction, some local NGOs benefited from substantial help received from international donors. They became accustomed to full provisions, such as office equipment, new cars, and business trips to foreign countries, not to mention the substantial remuneration for their work. Consequently, in many cases, their motives for working with an $I O$ depend on the received profit rather than on any desire to introduce positive changes in their country. It is especially frustrating for less affluent international organisations which implement projects in partnership with local NGOs.

Undoubtedly, a serious impediment for third sector development is the Tajik government policy toward NGOs. Those which attempt to advocate citizens' rights are

131 On the basis of infonnation gathered during interview's with eight local NGO organizations in Tajikistan in 2010 and 2012.

13 On the basis of a conversation conducted with the president of a local NGO from Georgia. Gori, September 2009. 
likely to face problems with state authorities, such as in the case of the Association of Young Lawyers (Amparo) or the Center of Civil Society, both from the city of Khujand. Amparo was actively involved in the investigation of cases of torture and inhuman treatment, as well as in monitoring human rights in the country and advocating for the rights of vulnerable minorities in Tajikistan. In 2012, Amparo was closed down by the local administration of the Sughd region, and protests and appeals did not bring any results. The activities of the Center of Civil Society were brought to a halt for similar reasons, mainly due to its campaign to increase the awareness of citizens regarding elections and other civil rights (Radio Ozodi, 2013).

Needless to say, there are organizations which do good work for the benefit of their own communities. In fact, the local third sector has great potential for development and under favourable circumstances could have a significant impact on social change. In the case of Tajikistan, in order to make the third sector an important actor, mechanisms of cooperating with government institutions should be strengthened, and its activity should be more recognized by local communities. Organisations make certain attempts to advocate for civil and human rights, although it is difficult to talk about any real understanding regarding the role and tasks of NGOs on the side of the state administration (Zharkevich 2010: 29-37).

\subsection{The Mahalla and Civil Society}

There is a lively on-going discussion regarding whether the mahalla can be considered a nucleus of civil society and how to incorporate this type of social organization into development programs. So far, no comprehensive study has been prepared which considers the various donor policies in relation to the mahalla and evaluates them in terms of their appropriateness for the needs of local communities.

Some scholars view the mahalla as a communal social organization based on traditional institutions which regulate the life of a community. The mahalla is seen as an "indigenous self-governing institution which integrates people who created a forum where local values, rules of behaviour, and common interests were defined, through which group interests were protected and joint actions organized" (Freizer 2004: 18). However, Urinboyev (2011: 40) indicates that the Western concept of civil society is not suitable in the context of the mahalla since the local understanding of civil society is strongly embedded in collectivism and reciprocal relationships, not individualism and freedom, which are Western values. Masaru (2006: 336-337), describing the relationship between NGOs and the mahalla in Uzbekistan, calls for a critical analysis of how local people understand and articulate the concept of civil society, and how this concept is formed in relation to history, culture and power relations of the studied country. The author proposes the following approach describing a civil society as: 
Research based on this approach encompasses the conception of civil society by local administrators, intellectuals, and the people governed. Simultaneously, such an approach might take into account local history, political culture, and power relations, along with external influence, all of which form and are formed by the politics of civil society in the new context of international relations (Masaru 2006: 336-337).

There are also other attempts at defining civil society in the context of non-Western cultures through including traditional or 'communal' forms of civil society into the classical concept. Since traditional institutions or kinship structures are inherent parts of social life, their integration would bring new value to the development of civil society. Moreover, traditional institutions are considered more suitable for local cultures, and consequently more appropriate for the local communities than ideas imported from outside (Buxton, Earle and Giffen 2005: 54).

Another group of scholars and NGO workers consider the mahalla to be strongly hierarchical organizations rooted in the pre-Soviet system of governance but modified. It brings together local elites and the state. The indigenous mediators, i.e. religious leaders, elders, and other actors, form the mahalla elite which shares powers with the local administration. The mahalla as a social organization relies on hierarchical practices and institutions within a community (families, religious groups, neighbourhood circles), which are an internal and hidden structure of social control. Referring to collective norms and identities, it reinforces these internal powers (see Boboyorov 2013).

Since the above opinion is shared by some donors and organizations, they prefer to create their own structures which may eventually absorb some local and indigenous elements rather than treat a mahalla as an equal partner in the process of local development. Many donor organizations consider the mahalla to have great potential as a traditional institution but they simultaneously conclude that certain of its aspects should be modified to suit the principles of development policies. An extreme approach is to see the mahalla as a weak and undemocratic institution governed by a few old men with white beards, and it must be transformed for the sake of the advancement of society (a local employee of an INGO, Dushanbe, 2010). The mahalla should be transformed in accordance with the Western concept of civil society. since its traditional hierarchy encourages gender inequality (a local employee of an LNGO, Dushanbe, 2010). According to a UNESCO report, “(...) some elements of adat promote gender and age discrimination in society. A number of international and local NGOs advocate that the preservation of traditions which discriminate against certain groups in society would curtail human development and human security" (Tabyshalieva 2006: 33).

The two points of view, i.e. that the mahalla is controlled by an elite structure which is reinforcing hierarchies and inequalities within the community, as well as the opinion that it is a traditional social organization based on mutual trust among all its members who unconditionally support each other, seem to be too polarized. First of all, due to the large diversity among communities, it would be difficult to define 
the contemporary mahalla as a particular and fixed pattern of a communal organization. The second and maybe more important point is that the above approaches attempt to judge the social system and social institutions of the mahalla according to preconceived dichotomous standards (in this case bad-good), ignoring the dynamics of relationships within communities and their real needs and aspirations.

There is little doubt that the mahalla is a hierarchical institution based on traditional social order. For instance, under customary law, all important decisions are taken by the mahalla authorities represented by the significant men of a community. In this case, women and young men are excluded from the process of formal decision-making. Consequently, if we consider that the modern concept of civil society is based on the principle of equal participation by all social actors, the above approach eliminates a part of the community, which - from the Western perspective - is highly discriminatory.

The Western experts often point out inequalities within traditional societies. Opinions also exist claiming that cooperation with mahalla committees will support local hierarchies. Hence, a popular concept involves establishing gender parity within the MC. For instance, the French organization ACTED set up a project aimed at the facilitation of the mahalla; inter alia, the project was intended to increase the skills of mahalla committees in such areas as planning, budgeting, and cooperating with local authorities. At the same time, the organization imposes certain conditions of cooperation - the mahalla committee is expected to be enlarged by up to ten people, with the compulsory participation of women, amounting to thirty per cent of the $\mathrm{MC}$ - a priority aimed at promoting gender equality. Even though this gender parity is in compliance with Tajik law, it is not realistic under current circumstances in most rural communities. ${ }^{132}$ The question arises whether IO should always follow principles which are difficult to apply in the field.

Undoubtedly, the labour migration of men has significantly influenced gender relations within communities. Due to the small number of male representatives, not infrequently women have become active members of the MC. In one of the villages where our NGO has operated, eighty per cent of the men are in Russia, and the vice rais of the village is a female social leader. During the first part of project implementation (seminars and workshops), we worked almost exclusively with women. The raisi mahalla participated in the project but he did not appear at the seminars during which only women were present. In the second stage, all project works were arranged by the female leader and raisi mahalla. Since we did not impose any rules regarding gender balance, the situation was naturally regulated by circumstances.

In more traditional and religious villages (inhabited by communities who originally came to Vakhsh Valley from the Gharm area), the mahalla committees consist of only male representatives and organizing a mixed gender group is not possible (see Chapter 7). As already mentioned, in traditional Islamic communities there is

132 On the basis of interviews with the local representatives of ACTED, Dushanbe, June 2010 and Khujand. July 2010. 
a very clear division between men and women. If foreigners attempt to change tradition (which in extreme cases can be considered by the locals to be the activities of unbelievers [kuffar]), the mahalla will do everything to avoid such innovations.

Another issue which should be analysed is the methods through which indigenous institutions are absorbed into NGO projects. Bichsel (2009), who researched the participation of international aid in conflict resolution in the Ferghana Valley in the border zones of Kyrgyzstan, Tajikistan and Uzbekistan, noticed that donors are often willing to incorporate traditional institutions (she describes a council of elders and the hashar) into a project, although mainly for instrumental and process-oriented purposes. "Elders and the hashar are not sought out by aid agencies for their substantive role, and thus, for the type of social organization that they represent, but rather for their capacity to fulfill required functions with the aim of conflict transformation" (2009: 70). In this sense, elders are not seen as noble white beards, but as active citizens who can play a certain role within a project.

As far as communal institutions and relationships are concermed, Abramson (2000) points out that donors as well as scholars are willing to reject the role of social networks and kinship groups (which are in fact the basis of the mahalla order). They consider them symbols of corruption, nepotism or exclusion. However, such behaviours can be considered rational practices within the framework of a particular culture, developed in response to social circumstances. The above point raises further questions about the level to which foreigners can adapt to circumstances they encounter during their work in the field. To what extent are aid workers able to be flexible or to accept the Central Asian mind frame, which is frequently very different from the moral standards to which they are accustomed. Thus, as far as the mahalla is concerned, perhaps the most problematic issue for donors and some NGOs is accepting all the unpredictable dynamics, practices and hierarchies which are part of the innate nature of the mahalla.

One of the ways of challenging the local hierarchies and reinforcing local development is to implement programs aimed at creating various institutions, such as initiative groups, water associations, school committees, women's clubs, brigades, mutual aid groups, savings groups, and so on. Most concepts behind the newlyfounded institutions have their origin in similar ideas from India, Bangladesh, Israel, Pakistan, Western Europe or the USA, but - surprisingly - rarely from Central Asia. The new institutions are usually founded within the framework of different social projects financed by international organizations. As far as the mahalla is concerned, most donors are willing to work with mahalla committee members (since they are the formal power in the mahalla), but only after adjustments which would make them more receptive to donor policies (Abdullaeva and Tyuryaev 2004: 3-18; some information added).

Abdullaeva and Tyuryaev (2004) conducted research on the role and place of various social institutions in the process of developing rural communities. Their research addressed the issues of the sustainability of such institutions and of their social recognition, since $96 \%$ were founded by external actors ( 142 bodies were taken 
into account). Six women's groups were founded without any external support based on local women's initiatives, and they turned out to be the most sustainable (2004: 15). The authors identified a few important points regarding the operational capacities of new bodies within local communities.

First of all, they indicate that increasing poverty undoubtedly requires changes in the social sphere. However, many international organizations have implemented their ideas at a very intensive pace, creating a multitude of institutions (especially in rural areas), which in fact do not guarantee sustainability. Donors frequently use foreign experience without adjusting it to the conditions in place in Tajikistan. Consequently, development strategies do not consider the role and place of the culture, traditions and mentality of the rural inhabitants and ignore the existing traditional institutions such as the mahalla (Abdullaeva and Tyuryaev 2004: 4).

Many respondents also argue that important community matters can be solved by organizations in cooperation with the mahalla and jamoat, without creating additional structures (which my research and the experiences we had during the implementation of our NGO project have confirmed). On the other hand, donors respond that the jamoat is considered corrupt and controlled from the top, and thus undemocratic, and that there is therefore a need to establish new institutions. However, no one can guarantee that these new bodies would not follow the same pattern, or that they would not create additional bureaucracy. Furthermore, some of the new social groups and the traditional or legal structures frequently have parallel functions which in fact create controversy concerning their respective competences (Abdullaeva and Tyuryaev 2004: 6). ${ }^{133}$

Moreover, only a small number of donors use a participatory approach when developing their concepts of new institutions. Organizations are focused on tangible results, such as building a certain facility: a school, a pump, etc. Following implementation, a project is handed over to the new groups which require constant facilitations from outside - the members of associations understand their role as monitors, not contributors. In addition, too many institutes are a burden to the community and in reality are an obstacle to people's participation in solving local issues. For instance, in the Bahmal village of the Asht district (in the Sughd region), various donors have founded 12 associations for 889 inhabitants (Abdullaeva and Tyuryaev 2004: 26-27).

The new institutions often represent the interests of a certain group, not the whole community. Membership means access to resources provided by the donor. Such a situation can contribute to the creation of tensions among community members and, under extreme circumstances, can lead to conflict among members of a particular group and other inhabitants. It is also possible, of course, for the external actors to unintentionally re-ignite past conflicts between kinship groups.

13: An extreme example of such activities was the creation of village organizations as a parallel structure to the mahalla, which obviously became a source of conflict in communities. Finally. the MSDSP moved away from this concept and merged village organizations and mahallas into a single institution (see (hapter 6). 
Another issue is that initiative groups are mostly created within a project by nongovernmental organizations, and they are a rather new idea in Tajikistan. Since there is no clear vision regarding their role and place in the communities, the purpose of establishing them is often vague. Organizations intend to establish new institutions to teach people how to apply to donors or to work on long-term projects, but there is no particular strategy for the future development of such bodies or any idea as to how they will function without external funding (Abdullaeva and Tyuryaev 2004: 14).

Clearly defined goals are crucial for the sustainability of a project. Abdullaeva and Tyuryaev (2004) argue that, for example, micro-credit groups are durable because their concept is understandable for local communities, as they aim to help people adapt to the conditions of the market economy by learning entrepreneurial skills. In addition, establishing groups aimed at increasing knowledge on particular issues, such as natural disaster prevention or concerming access to water, can be beneficial, since people deal with problems that apply to them directly (like irrigation or drinking water) or are taught specific skills. However, this will only work providing that at the same time these new structures receive long-term institutional support.

The above-described situation has been confirmed by my field analysis conducted on the Drinking Water Users Committees (DWUCs) in Spitamen district in 2012, in two villages (see Chapter 3). The EEDC, a Polish NGO, started working with the committees set up earlier by another organization, which after the project's completion left the region of its implementation. DWUCs were expected to work with the jamoats, but the latter knew neither the legal basis nor possessed the means for such cooperation with the new structures. At the time the EEDC started working in Spitamen, DWUCs were very weak institutions. Only after finally receiving long-term support was their institutional development reinforced, allowing them to function for the benefit of the mahallas ' residents. The EEDC also provided financial support to the DWUCs to develop local infrastructure for the drinking water networks.

To summarize, a flexible approach is necessary during the introduction of new institutions into communities. Whether a particular institution will be adopted in the field depends on the strategy behind its implementation as well as on the particular circumstances. Incontestably, due to various factors - such as widespread poverty or the remains of the mind-set left over from the previous political system, local communities need incentive to overcome the prevailing apathy and passivity. Launching new initiatives is a positive idea, and there are many examples where communities have benefited when new structures were compatible with the culture and needs of the target societies. However, in such a traditional society as the rural communities in Tajikistan, transformations of the social sphere have always been slow and often accepted only with difficulty by all the residents. In the case of the mahalla, which functions as an ideal of a social organization in Central Asia, ignoring this institution or introducing modifications too rapidly can be counterproductive to the goals of the initiators of changes.

Yet another aspect which has a significant impact on relationships between local communities and donors is the attitude of international organizations toward Islam. 
Most donors reject Islam as a factor which could reinforce community development. Opinions about the subordinate position of women and spreading terrorism prevent most development agencies from seeking to cooperate with Islamic institutions, in most cases regarding them as backward and reluctant to accept modern ideas. As Zharkevich indicates, despite the fact that "religious forms of civil society are gaining in popularity in Tajikistan, the secular forms of civil society are very suspicious towards the religious forms and tend to view them as a threat rather than as potential partners" (2010: 9). The exception among donors is the AKDN, which recognizes the importance of religion for Tajik society.

Nevertheless, despite the objections of international agencies, in Tajikistan as well as other regions of Central Asia, the tendency to build 'community trust' through various Islamic networks is strong. This stems from centuries of Islamic tradition (which, as indicated a number of times, shapes the mahalla), and is presently gaining popularity due to a lack of a relevant concept of social development proposed by the state. After twenty-three years of independence, the Soviet state structures have still not been replaced by strong state institutions capable of introducing positive changes. Hence, a number of people perceive Islamic institutions as an alternative model which could successfully contribute to tackling economic and social problems.

The most significant example of a political organization which refers to Islamic values is the Islamic Renaissance Party, which pursues a campaign of community work and charitable activities among ordinary people. According to beneficiaries, "the IRP does not work as the other opposition parties, which between elections only participate in seminars organized by foreign NGOs" (Najibullah 201lb). For instance, until $20^{\text {th }}$ June 2014, in the regional office of IRP in Khujand, located next to the premises of the Nuri Islam Mosque, public meetings regarding Islamic issues took place regularly. During these gatherings various matters relating to Islam as well as state legislation and policies were discussed. The people who gathered there learnt about the civic rights guaranteed by the Tajik constitution sometimes for the first time. At the end of June 2014, the authorities closed the IRP office (Ferghana News agency 2014). However, the IRP's activities can be seen as controversial since they are politically motivated. Another doubt is connected to the IRP's inclination toward Islamic orthodoxy, which stands in conflict with the view of those Tajiks who wish to follow practices and customs rooted in local tradition.

Another Muslim political organization whose influence in Tajikistan cannot be ignored is Hizb ut-Tahrir, which is also active in the social field. This Islamic party, created in 1953 in the Middle East, gradually managed to establish strong networks in other parts of the world, including Central Asia. Its ideology is mainly based on the idea of the unity of all followers of Islam, irrespective of ethnic and national background, with the goal of creating one Islamic state (the Caliphate) in opposition to the present states and institutions. Although the activities of Hizb ut-Tahrir are rather secretive (the party is illegal in Central Asia), it is known that, apart from political action, members of the movement conduct extensive social work among its followers. Despite the fact that the party proposes a rather radical approach to 
social order, which stands in opposition to the values of secular states, it is extremely popular among the underprivileged. Roy (2002: 136) argues that it is obvious that Western organizations and the Central Asian authoritarian states do not accept movements such as Hizb ut-Tahrir in any discussion on civil society. However, it cannot be overlooked that the organization represents a request from the grass-roots level to resist the predatory behaviour of the states and to create solidarity and autonomy.

In terns of the classical type of humanitarian and development organizations of Islamic origin, the most recognizable is the AKDN. However, despite its Islamaili background, the organization does not refer to Islam openly, and its pattern of channelling aid is similar to that of Western agencies. The Red Crescent Society (RCS) works in a similar manner. The organization is a part of the International Red Cross and Red Crescent Movement, and it is mainly active in the field of humanitarian assistance. Another organization which operates in Tajikistan is the Imam Khomeini Relief Foundation (IKRF), which officially is a foundation, but in practice is one of the main channels for social welfare in Iran, as well as for the Iranian government (De Cordier 2007: 10).

Informal charitable and social initiatives supported by kinship and other networks and legitimated by the authority of various religious leaders are typical for Central Asian communities, and today these are frequently supported by the remittances of religious migrants. Such initiatives include building mosques in mahallas or collecting money for the poor. In some instances, such as during the floods in 2010 in the Khatlon region, mahalla communities operating through mosques organized humanitarian aid for the victims. However, cooperation with IOs has been mainly on an ad hoc basis, and in the long run these mostly informal activities rarely mesh with the work of the big international agencies (De Cordier 2011; an observation also based on my own research and NGO work experience). During the implementation of our NGO project, we have worked through mosque networks and local religious leaders whose authority has lent our activities legitimacy in the eyes of residents.

According to the report by Zharkevich (2010: 27), Islamic organizations such as the World Muslim League (WML), the International Relief Organization (IRO) and the World Assembly of Muslim Youth (WAMY) have financed the building of some mosques and madrasas. However, the scope of their activities and their impact on local development requires further research. ${ }^{134}$ There are a number of local NGOs which included religious authorities into their projects, such as for instance INIS from Khujand, which organized trainings for local leaders mainly on issues related to law, or the aforementioned Centre of Civil Society, which implemented a program

154 The European Commission has begun to release funds for the establishment of a dialogue between Islam and secular organizations via the European Instrument for Democracy and Human Rights (EIDHR). Some funds were granted to International Alert, a UK-based NGO, for the execution of a project entitled "Dialngue for a Policy on the Relationship between the Secular State and Religion". However. the impact of such initiatives has been difficult to assess so far (Matveeva 2009b: 5). 
concerned with increasing cooperation among various social actors, such as the state administration, judges, militia, and imams. The state administration also attempted to stimulate religious leaders into social activity through establishing the Shuroi Bibi Otunho or organizing seminars for imams and otuns. However, since many policies introduced by the Tajik government in relation to Islam seem to be aimed at tightening their control over religious leaders, there are many doubts regarding the motives behind such actions. ${ }^{135}$

Islamic values are the basis of social practices at every level of Tajik society and are transmitted by means of the social institutions functioning within the mahalla; therefore, all changes introduced should take into account the existing system. Nevertheless, most of the aid agencies and NGOs which originate from Europe and the USA rarely regard Islam as a factor which could contribute to strengthening development policies. This stems from insufficient knowledge of local conditions, weak links with religious institutions, as well as a lack of well-trained personnel who would be able to establish the relevant networks. Yet another important factor is also related to the low level of confidence Western organizations have in religious institutions, which are often considered as being conservative and backward. Lastly, due to the Tajik government policy in relation to Islam and Islamic leaders, it is difficult for IOs to launch formal cooperation with Islamic institutions. This would require endless dealings with the official religious administration which rarely bring desirable results due to their suspicious attitude to the activities of foreigners focused on the religious field. Nevertheless, a few local NGO leaders with whom I interacted during my research and work expressed the opinion that raising the skills and knowledge of imams and bibiotuns regarding various social matters would positively influence work with local communities. Evidently, the implementation of such projects creates many challenges and requires a well-designed strategy.

13 On the basis of research conducted in 2014. 



\section{Chapter 5 \\ Village Organizations - the Concept of a New Mahalla}

\section{I. Introduction}

One of the major projects targeted at local communities - the Village Organization Programme (VOP) - was initiated by the AKDN and has been channelled through the Mountain Societies Development Support Programme (MSDSP). At the beginning of the civil war, the AKDN operated through local networks. In 1993, the Pamir Relief and Development Programme (PRDP) was established to facilitate coordination of humanitarian aid, providing food and other basic supplies to residents of the GBAO region. Later, the PRDP was reshaped into the MSDSP, which since 1997 has implemented development projects, expanding beyond GBAO. The MSDSP withdrew from food assistance programs and began to deal with longterm economic and social development issues. The MSDSP's activities are mainly channelled through Village Organizations (VOs; Tajik: Tashkiloti Dehoti [singular form]), and recently through the Mahalla Committees. The idea behind VOs is that local development is most successful if it is passed through village-level institutions which are independent and transparent, and therefore capable of enhancing democratic norms and contributing to the development of civil society (AKDN n.d.; some information added).

The concept of VOs is a combination of traditional Central-Asian elements with modern ideas of rural development previously implemented by the AKF in Pakistan. According to managers of the MSDSP, creating VOs was inspired by the concept of 'participatory development' (discussed in the introduction to the book). So far, rural organizations have been established in seventeen districts of Tajikistan, in three regions: the GBAO, the Rasht Valley and the Khatlon oblast. ${ }^{130}$ Since 2010 , the

lis Information gathered during an interview with a manager of MSDSP, Dushanbe. July 2010. 
MSDSP has also facilitated the development of Mahalla Committees in the Sughd region as well as in the Khatlon region. ${ }^{137}$

The introduction of innovations into local development by external actors is a very complex process. As Long and Long (1992) indicate "the concept of intervention is an ongoing, socially constructed and negotiated process, not simply the execution of an already-specified plan of action of expected outcomes" (qtd. in Lobo 2008: 21). Hence, in order to bring about a desirable result, a new development strategy requires the long-term commitment of all stakeholders as well as a flexible approach when being put into practice. Development assistance is shaped by the specific socio-economic and cultural conditions of a particular environment. In light of the fact that VOPs (Village Organization Programmes) have been set up in three regions with different economic, ethnic and religious structures as well as dissimilar political affiliations, this study applies exclusively to the VOP implemented in the Shuroobod district of the Khatlon region, and should not be considered as an evaluation of the project or of the MSDSP's activities. It is rather a voice in the discussion regarding introduction of new ideas into communities and reshaping established forms of social organizations, such as the mahalla, into new forms, in this case into a Village Organization. I conducted this study in 2010 and since then I have not updated the information about the development of VOs in Shuroobod. In order to provide a better understanding of the case study presented, some background information on all regions of VOP implementation is provided below.

The first Village Organizations were created in GBAO in 1998, during the postconflict reconstruction of the country. Badakhshan is mostly inhabited by Ismaili communities, and during the civil war they supported the opposition forces. The region survived the war thanks to humanitarian supplies of which a large part was transmitted through the AKDN. Since the end of the armed conflict, the AKDN has begun to initiate various development projects, including the VOP. The AKDN's involvement in humanitarian relief during the war and the country's post-conflict development has earned this organization respect of local communities. Moreover, particularly in Badakhshan, the AKDN is associated with the spiritual leader of the Ismaili Muslims - Aga Khan IV. This factor strongly contributes to reinforcing the legitimacy of the organization's activities in the eyes of local communities. Hence, VOP implementation might be more successful here than in other parts of the country.

Since the assistance of Aga Khan Network is provided in all four regions of the country and the organisation also cooperates closely with the Tajik government, the network is widely recognized by people. ${ }^{138}$ However, it should be noted that the increasing presence of Aga Khan-related activities is sometimes treated with suspi-

137 Information obtained during a conversation with an MSDSP employee, Kurgan Tyube. April 2014.

1:x The assistance of Aga Khan is channeled through the following organizations: the Aga Khan Development Network. Aga Khan Education Services. Aga Khan Foundation Tajikistan, the 
cion due to the general reluctance towards the 'Pamiri'. ${ }^{39}$ Some circles of Tajik society express a fear of the growing influence of 'Shiites' in the country. Such opinions also influence MSDSP activities in places populated by the Sunni. The organization is sometimes presented as a power which supports foreign as well as Ismaili interests (see Boboyorov 2013: 82-83). Nevertheless, the Aga Khan network's contribution to development in the country cannot be questioned.

In 2000, the MSDSP launched a VOP in Rasht Valley - a part of the country which was strongly affected by the civil war and is a cradle of anti-government opposition. Hitherto, the region has maintained a controversial relationship with the government in Dushanbe, by which it continues to be treated with mistrust and caution. The Rasht Valley is considered a very traditional and conservative area, where religion plays an important role. Lastly, VOs were introduced in the eastern mountainous districts of the Khatlon region: Khovaling, Muminabad and Shuroobod, i.e. an area with pro-government Kuliab influences.

The main goal of this chapter is to examine how the implementation of these new structures, i.e. the Village Organizations, transforms traditional practices within the mahalla organisation, as well as how VOs affect the social, economic, and cultural development of communities in Shuroobod. In addition, the chapter examines to what extent the activities of the new actor (the MSDSP) have impacted the distribution of benefits, access to resources and power relations in the area of VOP implementation.

\subsection{Village Organizations - A Theoretical Framework}

According to the information available on the AKDN website, the main goal behind initiating the Village Organisation Programme was to create a fundament for building civil-society institutions in selected regions of Tajikistan through increasing direct villager participation in managing community affairs in order to improve the living standards. The MSDSP aims to channel various activities through the Village Organizations to $\mathrm{CBO}$ s on a self-help basis and to provide support to strengthen their capacity for identifing and achieving their priorities (AKDN n.d.; some information added).

The MSDSP assists in establishing VOs as a form of a communal organization created in order to facilitate development in agricultural areas, as well as for reinforcing the cooperation of local communities with jamoats. The MSDSP facilitates

Aga Khan Fund for Economic Development/Industrial Promotion Services (IPS) - Asia region, Aga Khan Health Service in Tajikistan (see SCISPM 2014).

139 Most people associate Aga Khan with Badakhshan/Ismaili, since knowledge about the origins of this network is limited and few people are aware who Aga Khan is. 
young VOs by organizing training sessions, seminars, and improving infrastructure which supports the rural population. The MSDSP works with more than 1,400 VOs, and 100 VO Unions with approximately 140,000 members, of whom $40 \%$ are women. Micro-loans provided to more than 12,000 clients are a very important element of the MSDSP's activities. Financial services are channelled through The First MicroFinance Bank of Tajikistan (FMFB) established in 2003. In addition the organization has implemented over 2,500 infrastructure projects and has helped to create a number of new enterprises and business development services throughout Tajikistan (Tajikistan overview 2012). At the time my research was being conducted, there were 88 registered VOs in the Shuroobod region.

Formerly, village organizations were parallel structures to the mahallas within a village. However, as they were a new social institution, with functions similar to those of a mahalla, this frequently created tensions between the two bodies. Consequently, following the adoption of the afore-mentioned law "On Public Self-Initiative Bodies" in 2008 (Law 2008), gradually, the MSDSP began to merge mahallas and VOs into a single body termed a 'self-governance organization' (Tajik: Mekomoti Khudfaoli Jamoati - MHJ).

In one of the villages of the Shuroobod district, there was a two-year-long conflict between the raisi mahalla, backed by the mufti of the Shuroobod region on the one side, and the rais of the VO on the other: Both sides attempted to control the village's resources and fought for popularity among different interest groups. Finally, the prolonged disagreement reached the hukumat of Shuroobod. Upon the decision of the MSDSP to merge the VO and mahalla structures, the raisi mahalla and the head of the VO stood for election, and the rais VO w'on the vote. Nevertheless, the new community leader decided to take revenge on his enemy, and to once and for all get rid of his inconvenient competitor: He managed to accuse the former raisi mahalla and his associates of embezzlement, corruption and taking advantage of their public function, etc. Using every means possible, he proved that his opponents were guilty, and in the end they were sentenced to prison. ${ }^{1+1}$

This rather extreme example is a good illustration of the power struggle mechanisms functioning between the VO authorities and the mahalla. Obviously, the VO and mahalla leaders were not always enemies, although frequently they belong to two different groups of interests, and so, according to the MSDSP, merging these two structures was inevitable. Boboyorov (2013: 81-82, 117-173), who conducted research in Shuroobod, describes cases in which the local elite did not acknowledge the VOs, treating them as competitors aiming to undermine existing relationships.

In order to avoid the decentralization of village organizations and to make them capable of cooperating appropriately with the jamoats, the MSDSP established the Social Union for the Development of Village Organisations (SUDVOs), which supervises the work of VOs. SUDVOs are registered as non-governmental organiza-

I+1) Interview with a former raisi jamoat, July 2010 in Shuroobod district. 
tions, and they coordinate and monitor VOs and cooperate with jamoats (one SUDVO supervises the work of the VOs within the area of a single jamoat; in 2010, in Shuroobod there were 7 SUDVOs). SUDVOs are responsible for organizing seminars, training sessions, and other similar events. They are also expected to help VOs write and submit project proposals, and to assist the process of project implementation. SUDVO employees receive remuneration for their work while VO activity is unpaid (this situation raises controversy, since often the authorities of VOs also want to be paid). Additionally, not long ago, another body was created, the ASUDVO (Association of SUDVOs), which intends to work on the district level together with hukumats and to supervise SUDVOs.

Under the rules set up by the MSDSP, in a system of village organizations, the chairperson (rais $V O$ ) and other members of the management board (vice-chairman, chairperson of the women's committee) are elected in open competitive public elections during a general assembly of the people (majlis), in which no less than 80 per cent of the villagers should participate. An accountant, who is also a member of the board, is assigned by the chairman and approved by the majlis. The majlis is expected to be organized once every three months. It brings together the board of VOs, community members, SUDVO employees, as well as representatives of the jamoat. In addition, a shuro, comprising the management board and representatives of all guzars, is expected to be organized every month to discuss important community matters. Since 2008 , VOs have been registered as formal entities with their own budget, bank account, status, and stamps. As in the case of the traditional mahalla, registration allows a VO to function as a formal entity, and therefore to submit grant proposals, enter into contracts, and so on.

In practice, however, most VOs are too weak to function independently, and they depend to a large extent on the SUDVOs. The SUDVO gathers project proposals. First of all, the proposals are discussed with the jamoats and all chairmen of the VOs with the approval of the majlis. Next, the most appropriate project proposals are selected and sent to the MSDSP, which takes a decision as regards their funding. The community is expected to contribute to a project financed by the MSDSP mostly through hashar or other forms of free services. VOs can also implement their own projects, which are financed and carried out by residents. Such projects are usually small but they have a positive effect on the process of integrating a particular community. The previous structure of VOs differed, with the current approach being a combination of the traditional mahalla structure and that of a VO. The SUDVO's composition is similar to that of the VO - there is a head of the SUDVO, a deputy, a women's representative, an accountant, etc. However, as already mentioned, a SUDVO operates more as a professional social organization, and thus working in a SUDVO is treated as regular employment.

Apart from VOs, there are other entities within a village structure which have been founded at the initiative of the MSDSP. These include the Water Users Associations (WUAs; there were 10 WUAs in Shuroobod in July, 2010), Micro-Lending Organizations (MLOs), community-based savings groups, and the aforementioned 
Common Interests Groups (i.e.: sports committees, youth committees, and so on). The Common Interests Groups resemble similar committees set up within the mahalla structure during the Soviet period. Most of these institutions, however, are rather insignificant and require constant facilitation from the outside. The low efficiency of the WUAs can also be explained as resulting from the conflict over access to water resources among different kinship groups, as well as the badly implemented land reform.

One of the most important innovations introduced by the MSDSP is the microfinance organization. The micro-bank provides loans to residents to facilitate activities related to farming, family events (weddings, circumcisions, funerals, etc.), as well as loans for migrants to cover travel expenses. In total, the organization had 350 clients at the time I conducted my research. Despite the fact that the bank is popular among residents, in 2010 its operational capacity was fragile due to its small portfolio.

Figure 2. Diagram of a Village Organization based on MSDSP materials

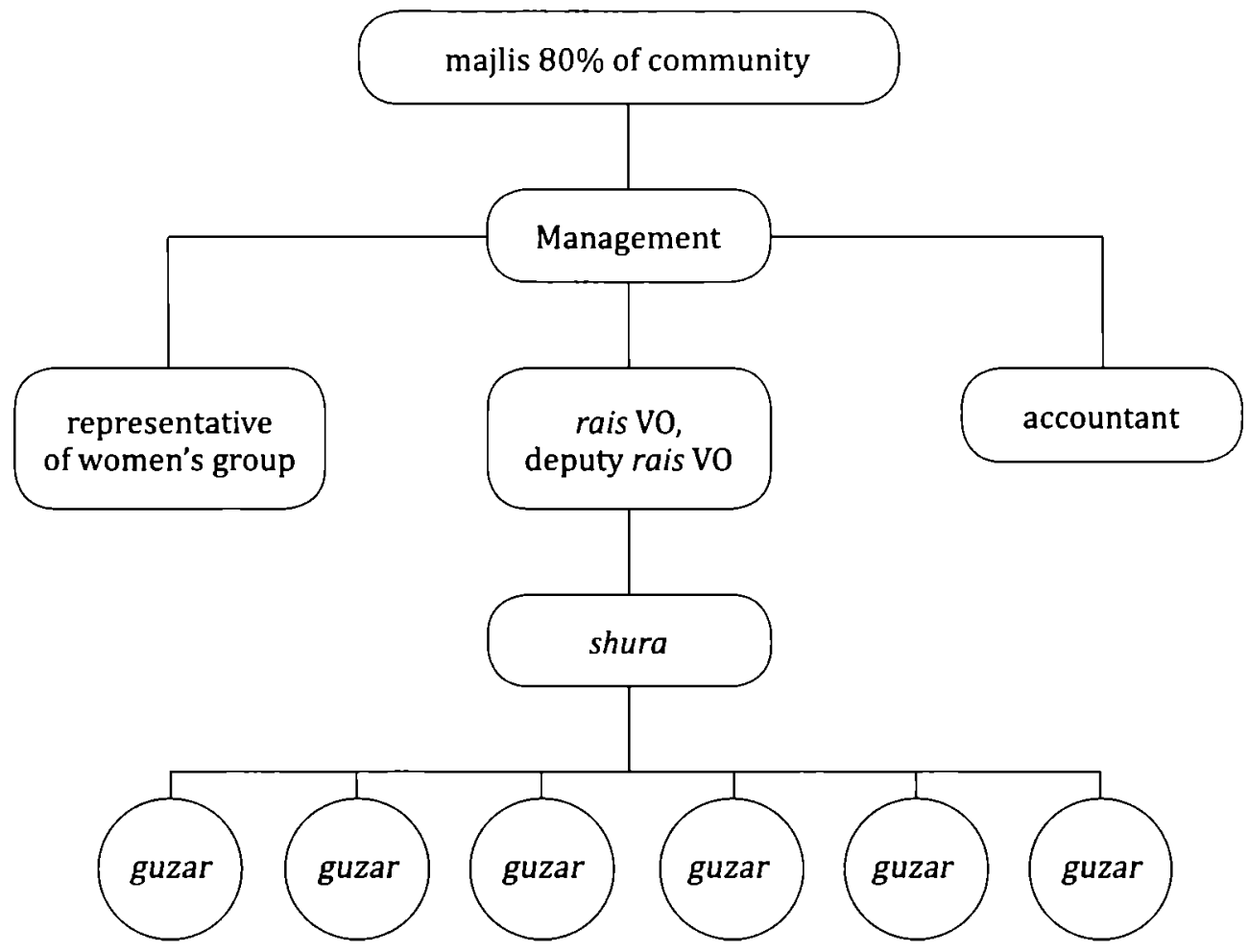

In terms of traditional functions and practices, the VO took over responsibilities which had previously belonged to the mahalla. Consequently, the rais of the VO should fulfil traditional obligations, such as facilitating weddings, circumcisions and funerals in the village, and dealing with antagonisms between neighbours, disagree- 
ments over land distribution, and other conflicts within the community. In addition, he is also expected to cooperate closely with formal and informal authorities.

In some cases, the offices of VOs are located in a room which belongs to the village mosque. The formal support provided to VOs by religious leaders entrenches this structure within the community and gives its activities greater legitimacy.

\subsection{The Shuroobod District - A Quick Overview}

The district of Shuroobod is a remote and destitute area bordering Afghanistan, situated in the eastern part of Khatlon Province. The main settlement (also named Shuroobod) is about $50 \mathrm{~km}$ from Kuliab city, although the road runs through a mountainous area, making the district difficult to access in the colder months. Both during the Soviet era and now, Shuroobod has played an important strategic role. For this reason, the district draws the special attention of the Tajik government and is the target of the intensive activities of international organizations. The meandering Panj River is a natural, though rather porous, border between the two countries, and separates the ethnically similar population living on the Afghan side.

During the Red Revolution, the area of present-day Shuroobod was the site of intense fighting between the Red troops and the Basmachi movement. Some families supported the Soviets, which was also connected to feuds among kinship groups, and possibly ethno-regional ones. Collectivization and persecution of religion resulted in part of the local population immigrating to Afghanistan (especially during the repressions of the 1930s). However, despite strict control during the entire Soviet period (the border was closed in 1936), people crossed the border informally, including the unofficial Muslim clergy. ${ }^{141}$ Koehler (2004: 30) points out that the movement of people across the border re-intensified during the chaos of the first years of Tajik independence (1991-1996) up until the re-establishment of border control by the Russians. Nevertheless, Shuroobod has always been a provincial territory 'on the fringe of the state', and, despite the fact that the district belongs to the pro-government coalition of the privileged Kuliab region, it has been the most underrepresented in terms of government posts at the provincial and national levels (Wiegmann 2009: 64).

IN One informant told the story of his grandfather, who had been a mullo as well as a representative of the local intelligentsia. As he faced repression, he had escaped to Afghanistan in 1937. Later, his brother, who was sent by the Soviet authorities to Afghanistan, met the mullo by accident in a chaikhana, where the latter was working as a waiter. The two brothers did not communicate officially for fear of persecution; they only spoke in monosyllables and whispers. The uncle of our interlocutor told his family about this ineeting just before his death in the Perestroika period in the second half of the 1980s. I also had the opportunity to visit the tomb of a significant mullo educated in Bukhara who belonged to the basmachi. His tomb is considered a mazar by locals. 
The Shuroobod district consists of seven jamoats: Dashtijum, Shuroobod, Sarichashma, Langardara, Chagam, Doghiston, and Yol. The total population of the district in 2010 was 43,000 people. The district is based on rain-fed agriculture, mainly wheat and fruit farming, while other agricultural activities include maintaining livestock (UNTJ n.d.; TAJSTAT 2010). The main hindrance to the district's development is its distant location and poor infrastructure - especially roads, the water system and electricity (in the winter power is provided for only a few hours a day). There is also a constant danger of natural disasters, especially floods and mud flows. Despite the fact that many people have been working in Russia in recent years, the economic situation of the population is difficult, with average official (cash) earnings per family of about 50-100 USD. In-kind transactions play an important role in the local economy. ${ }^{142}$ The region is strongly subsidized by international organizations, with the main donors being as follows: SIDA, AKDN, IFAD, EU, UNDP, WB, SCO, and others. In fact, Shuroobod is dependent on international aid ( 80 per cent of all investments in 2010). ${ }^{143}$

Most residents are ethnic Tajik (Sunni Muslims), who settled there at different periods. However, it seems that some of the Tajik population is comprised of incoming groups who ousted the semi-nomadic Uzbek/Turkic tribes. There are two jamoats in which most of the population are Uzbeks (Sarichashma and Chagam). Nevertheless, Uzbek influences are visible. In the past, there were also some small groups of Arabs, as well as other minorities. ${ }^{144}$

The relationship between Uzbeks and Tajiks is a complex issue. Not all Uzbek groups are included in one kinship group, and so there are also specific hierarchies among them. Some Uzbek groups have intermingled with Tajik families and consequently have become a part of the same networks. It should be mentioned that the status of a particular group also depends on the period in which the group arrived in Shuroobod. Accordingly, those groups which came in the earliest periods should have a higher status within the local relationships.

At the beginning of the Soviet period, in 1938, the district of Shuroobod was founded with its centre in the settlement of Sarichashma, as a result of the planned organization of the border territories by the Soviet authorities. ${ }^{145}$ Until the 1960s, the district consisted of three administrative units: Sarichashma, Dashtijum, Shuroobod. In the early 1960s, a large part of the population was moved to the moskovsky. farkhorskii and voseiskii districts, and Shuroobod was dissolved, to be formed again in the 1980s. However, some groups continued to live there throughout this period,

1+2 According to different interlocutors, in some villages 80 per cent of the men are working in Russia, although this information has not been confinmed by any survey.

143 Information taken from an interview with the head of the hukumat of the Shuroobod region. July 2010 .

HA Information based on interviews, partly confirmed by Karmysheva's research (1976).

145 The region was always very important from a strategic point of view; for example. a small airport was established in the remote Yol jamoat during the Soviet period. 
working in agriculture. In the mentioned areas, comprehensive modernization work was carried out to adapt the marshy fields to cotton cultivation, and these became the most modern districts of Kuliab. Some people began to return illegally as early as in the 1970s, while a majority decided to go back to Shuroobod in the early 1990s, after the issuance of an official directive by the state authorities.

However, at that time, it became clear that due to the high birth rate in the Soviet era, many more people retumed than had previously lived in Shuroobod before the re-settlement in the 1950s and 1960s. Consequently, post-Perestroika poverty and decreasing economic opportunities led to conflicts among different groups over access to the available resources.

The entire district had to be reorganized and new administrative entities, the $j a$ moats, were created. In addition, it was necessary to patrol the border with Afghanistan (both during the Soviet-Afghan war in the 1980s as well as later during the civil war in the 1990s, when the anti-government coalition was supported by supplies and volunteers from Afghanistan). Some jamoats were established during the war to enable the state structures to maintain control over the area, such as for example, the Doghiston jamoat, approved in $1994 .{ }^{146}$ The chairmen of the new jamoats frequently became local leaders who enjoyed enough prestige and authority to be able to organize residents' lives. As in the other regions, self-defence groups were also created on the basis of jamoat structures during the war period. Jamoats were also responsible for supervising the distribution of humanitarian aid, which gave them the economic means they needed to influence local communities and to deal with various informal actors who operated during the civil war. Nevertheless, due to Shuroobod's remote position, the border with Afghanistan and extensive drug trafficking, various informal leaders, including local warlords, de facto exercised control over local affairs. After the war, some of these leaders were incorporated into the official structures.

The newest jamoat, which is populated by an Uzbek minority, is Chagam, established in 1998. Due to its isolated location as well as a scarcity of water and other resources, it is one of the poorest parts of Shuroobod, yet, at the same time, the presence of international organizations was limited (situation in July 2010). This can be explained by the fact that the jamoat is a new entity, and almost exclusively inhabited by the Uzbek minority, who had a smaller share of power in the district and thus little influence on the distribution of wealth (including humanitarian and development assistance). ${ }^{147}$

$1+6$ On the basis of an interview with the former rais of jamoat D., July 2010.

147 The above assumption is based on one conversation with an employer of a local organization living in another jainoat (also Uzbek but related to an important local kinship group of local shaikhs), who - upon being asked a question about the reason behind the absence of IOs in the area of Chagam - answered that the residents of this jamoat do not know how to attract potential donors. In addition, another person stated that "people who live in jamoat Chagam are L'zbeks, who in the past led a semi-nomadic way of life, so they do not need water and other facilities". It is also worth mentioning that the local authorities mostly select candidates of Tajik origin for the post of raisi jamoat, despite the fact that the area of Chagam is primarily 
One of the major problems facing the district is drug trafficking across the border from Afghanistan, mainly heroine. In the opinion of many respondents, the most extensive drug trade took place up until the withdrawal of Russian troops a few years ago. Due to the high level of poverty and lack of solid state structures during the civil war and shortly after the conflict, many people in Shuroobod (especially those living in the bordering jamoats) were involved in drug smuggling. The road from the border through jamoat Yol to the central jamoat Shuroobod is commonly called the 'drug highway'. Only the introduction of very severe penalties (according to respondents, 15-20 years in prison) led to a reduction in the scale of this practice. Presently, a considerably smaller number of poor residents draw profits from drug trafficking, though this business is still in the hands of a certain group of people who benefit from it, including officials at different levels. Koehler (2004: 31) remarks that drug trafficking posed a threat to the safety of many border villagers, who were afraid to leave their houses after dusk. Some villages located in the border region were abandoned by residents because of the dangers related to drug smuggling.

Nevertheless, press releases and various reports claim that normal inhabitants and border guards continue to be involved in this practice. For example, in 2008, one of the villages in the Shuroobod region was attacked by an armed group from Afghanistan due to some unsettled issues related to drugs, and only the intervention of the Tajik army held off the attack. Not infrequently, there are also reports of people being kidnapped as a result of drug debts, or of young girls being sold to pay off debts to drug traffickers (Abdulvahhobov 2011; Ferghana News agency 2008).

Moreover, according to some informants, a considerable number of people are drug users. ${ }^{148}$ Drug trafficking has affected the district's development, and despite high subsidies from international organizations, Shuroobod is still considered a sensitive part of the country.

The resettlement of people, uncertainty during the war period and drug trafficking have all resulted in a weakening of the traditional social structures in Shuroobod. As a result, the district has become a good place for implementing new formations, such as the Village Organizations presented as an alternative solution for rural development. Moreover, the underprivileged position of Shuroobod, the lack of economic opportunities for its inhabitants, together with the need to protect the unstable

populated by Uzbeks. This can also be an indicator of the unequal power relationship between Uzbeks and Tajiks. In fact, the person functioning as raisi jamoat has changed a few times in recent years, including an Uzbek at one point, who even managed to maintain his position for a longer period (information from July 2010).

1+8 One former state official said that during an informal gathering of men in his village he raised the issue of drug addiction and asked the participants to show their pockets to prove that they did not have any drugs. Only a few people agreed to do this, so he assumed that the others possessed some drugs. He also indicated that nowadays drug use takes a more severe form than in the past. Previously, during meetings, people smoked a bit of anasha (marijuana). Currently. people often use hard drugs, such as heroine (conversation with one of the MSDSP managers, July 2010). 
Afghan border are reasons behind increasing interest on the part of various international actors, and hence, explain the intensification of development aid.

\subsection{Village Organizations in Practice}

In any analysis of the structure of VOs, first of all, it is necessary to identify the hierarchies that determine local relations. The social composition of a VO, as earlier of a mahalla, is defined by the roles and status of the avlods and various networks based on gap/gashtak principles. In addition, the place of each individual in the community is decided by his/her position within certain social groups (see Chapter 2). These hierarchies interweave with each other, creating a complicated pattern of social relationships. Priority is given to religious leaders, aqsaqals, managers of collective farms, businessmen, etc. These elite groups control the decision-making process, and - consequently - access to resources. Thereby, an emerging new structure, such as a VO, is highly dependent on the correlations existing among these actors. ${ }^{1+9}$

In the recent past, the kolkhoz constituted the core around which most social relationships in the rural areas were formed. After most of the kolkhozes collapsed in the 1990s or were restructured, the pattern of kolkhoz relationships was transformed, creating new ground for the post-Soviet order at the local level. People who occupied high posts during the Soviet period also benefited from the change of the system in the country, including the land reform (see Chapters 3 and 6). Having a good network of personal contacts in governmental, business, and other structures, these people have access to most of the available resources. Therefore, every opportunity which appears 'in the market' is firstly filtered through various networks, and only then further redistributed according to certain hierarchies within groups. Since development assistance is also considered to be an asset, it is 'natural' for the elite to benefit from it, for instance, by placing members of their network in the posts offered by international and local organizations, or giving priority to their own group when providing aid.

For an international organization to bypass such local relationships is very difficult, if not impossible, because they exist at every social level and are embedded in the social structure. Nevertheless, the elite does not always reach a consensus over the distribution of wealth, since everyone has their own interests and priorities, including with respect to how development assistance is to be channelled. Therefore, conflicts of interests are likely to arise.

As far as a VO is concerned, there are three main actors who influence local relationships: the MSDSP (represented by the authorities of the VO and SUDVO), the jamoat, and the management of the collective farms. In addition, there are other

It On the role of various networks in shaping the VO, see Boboyorov 2013. 
actors involved in the local decision-making process with various informal and formal functions, such as religious leaders and local businessmen, who intermingle with the above-mentioned authorities. ${ }^{150}$ As already mentioned, the MSDSP is a local organization, and thus, needless to say, its employees belong to local networks. Most of them have a good understanding of local conditions since they represent a whole cross-section of the society, including various local authorities with different ethnic backgrounds (the majority being Tajiks). ${ }^{151}$

For instance, the first head of the regional office of the MSDSP in Kuliab (founded in 2002) was a former field commander who had fought on the government side (Bahromsho Rahmatoloev), while his close associate as well as comrade-in-arms was the head of the local security forces (Wiegmann 2009: 172). The current manager of Shuroobod worked as an agronomist in the recent past, and he has a sound knowledge of agriculture and local conditions, allowing him to supervise activities related to the implementation of projects. One of the local managers of the MSDSP used to be a teacher and raisi jamoat, which gives him good social standing in his community as well as the relevant organizational skills. Beyond a doubt, the high social status of MSDSP employees in the local networks increases the legitimacy of the organization's activities in the eyes of the local community and is advantageous in terms of project implementation.

According to information gathered during my research, in the first stage of establishing a VO, MSDSP employees meet informally with representatives of all kinship groups to define the power structure in place in the village and to select candidates recommended by the local elite. Consequently, the rais of VO is elected from among the members of the most influential kinship groups upon the approval of the MSDSP. Other VO functionaries are selected in the same way. However, it is worth mentioning that, according to the theoretical framework of a VO, the rais should be elected by all residents during an open vote.

Despite the unquestionable rationality of the MSDSP's approach, a danger always exists that prioritizing the elite may grant access to development assistance only to certain privileged groups. Here, I would like to refer to the Introduction to this book, where a theoretical framework of the participatory method (used by the MSDSP) is described together with its criticism. Among other things, it indicates that unless power and inequalities are taken into account as well as the means to alter such factors for the benefit of all, participatory practices (in this case the method of selecting VO authorities) can encourage inequalities within the community, creating a 'tyranny of the group' and fossilizing already existing relationship pattems. As a result, the poorest and most vulnerable members of the community remain marginalized. "Participatory approaches, it is asserted, tend to work on the basis of a binary per-

150 It is difficult to create 'a model pattern of powers' in a jamoat or VO due to the fact that one person can have a number of roles; for example, the head of one jainoat was a famous drug dealer in the district, while his family headed a collective farm.

is On the basis of data gathered in 2010. 
ception of power, where the community is seen as a homogeneous unit of 'lowers' subordinated to the power of macro level "uppers"' (Hauschildt and Lybæk 2006: 9).

Unsurprisingly, the rais is often obliged by his kinship group to put his network's matters ahead of the interests of the village. He tends to follow the instructions of the head of his kinship group, which might stand in conflict with the needs of the whole community. Moreover, the rais $\mathrm{VO}$ is often not the most respected member of the community; he is rather someone who possesses the operational capacity to ensure the implementation of a project. Thus, in many cases, the rais is a kind of project coordinator rather than a community leader. However, the changing circumstances in the region require someone who possesses the relevant organizational skills in addition to life experience and a high level of respect within the community.

The position of the rais VO depends on the relationships within a village, and potential disagreements also affect how he is perceived. There are settlements where limited access to natural resources has triggered conflict between kinship groups, as in the case of VO Y., where - in the 1960s - most families moved to the moskovskii district. For about thirty years, only a few families lived in the village (today VO Y.). Along with the changes in the 1990s, people who had migrated in the 1960s, together with new generations, returned to their previous homes. Consequently, the population of $Y$. increased rapidly within a very short period of time, resulting in all the available land in the village becoming occupied. People began to struggle for access to water, land and other resources, which affected relationships among kinship groups in the VO, and consequently also undermined the position of particular leaders. At the time of my research, the rais was married to the daughter of a powerful landlord and businessman (a representative of the kolkhoz elite); however, a short time ago both families entered into a conflict. The landlord wanted his daughter to divorce her husband, but she refused to leave him. Nevertheless, it should be indicated that the elite of each kinship group is involved in various dealings with the local administration, the MSDSP, collective farm management and other relevant parties; therefore, mutual animosities often extend beyond the boundaries of a given village.

There is yet another issue related to the function of the rais. In line with the theoretical framework of the VO, all villagers should be granted an equal opportunity to participate in community affairs, since every village is expected to be managed jointly by its residents, while the role of the rais involves supervising all VO issues as well as representing the interests of the people to the local authorities.

However, while conducting interviews with four heads of VOs, I had the impression that at least two of them understood their role as representatives of the state administration in the particular village rather than as community leaders. Such an approach can be explained by the fact that, as a result of the introduction of the law "On Public Self-Initiative Bodies" (Law 2008), VOs became the lowest unit of state administration, and consequently, the duties of a rais were also formalized. However, as a result, VOs should no longer be treated as grass-roots organizations, since they are tied to the state through the MSDSP network. In my opinion, the ambiguity of the VO's status creates confusion about its actual role, since it is difficult to form 
a community-based organization which at the same time is controlled by an authoritarian regime.

On the other hand, the mahalla committee has also been subordinated to the jamoat, and so the present top-down approach is not a new phenomenon. Nevertheless, some interlocutors have indicated that, although the mahalla was obliged to fulfil the jamoat's requests, these two entities were in fact detached from each other, mainly because of the low financial and operational capacity of the jamoat, limiting its ability to exercise power over the mahalla.

Further analysis of the relationship between the $\mathrm{VO}$ and the jamoat reveals more doubts. In reality, a large part of the financial resources designated for facilitating local development is channelled through the MSDSP, while the local administration is dependent on aid assistance. Thus, the question arises as to who the main player in Shuroobod is - the hukumat or the MSDSP? Moreover, SUDVOs and jamoats should design long-term plans for local development together; the same applies to the hukumat and the ASUDVO (whose main task it is to supervise the work of all SUDVOs, but at least in 2010 in Shuroobod, it was a fragile and unsustainable institution). ${ }^{152}$ Thus, it seems that the MSDSP, which is an external actor, contributes to shaping local state policy.

In July 2010 , I interviewed the rais of jamoat $\mathrm{S}$. in the presence of the head of the jamoat SUDVO. The rais was not able to answer almost any of my questions, while the head of the SUDVO provided me with all the information I needed regarding the jamoat's development as well as concerning various administrative matters. After we left the jamoat, the head of the SUDVO commented that the rais did not know anything, which was why he had been forced to help him answer the questions I had asked. One peculiarity of this situation is that, in theory, the SUDVO should only be a body which facilitates the jamoat. In this case, however, because of a lack of funds in the local administration, the roles have shifted and the jamoat depends on the offer provided by the SUDVO/MSDSP and other international donors.

As circumstances suggest (and as has already been emphasized a number of times), in some regions of Tajikistan many state functions have been taken over by local and international NGOs or international agencies, though these actors are not officially a part of the government.

Wiegmann (2005: 9) provides an example of the impact of the MSDSP on the land reform in Mountain-Badakhshan (in which the German Organization for Technical Cooperation (GTZ) also participated). In 1997, the MSDSP introduced certain

152 In jamoat Yol, a Jamoat Resources Center is also operating. making the situation even more complex. Interestingly enough. the head of the JRC and the president of the ASUDVO was the same person in July 2010. According to the MSDSP managers, there is an agreement between the MSDSP and UNDP that a SUDVO and a JRC should not function in the same place, but jamoat Yol is an exception to this rule. This was explained by the fact that the JRC is very weak there, relying only on UNDP funds, and so in reality it is not able to facilitate the jamoat. However. at the same time, no one was able to explain why the JRC had not been closed down if its work was inadequate. 
conditions for the hukumat, whereby if the latter did not redistribute land equally during land reform, the MSDSP would not facilitate agriculture by providing seeds and fertilizer. Another version of the story exists, according to which the MSDSP had implemented some mechanisms regarding distribution of land from state farms before the land reform legislation was officially issued. It is said that the land reform in Badakhshan was implemented in a much more honest way than in the rest of Tajikistan. Nevertheless, the above situation is a good depiction of the degree to which the MSDSP exerts influence over formal government institutions, such as the hukumat.

Going back to the main thread of this chapter, i.e. the VOP in Shuroobod, despite the VOP having been implemented in this district for almost 10 years, some residents still do not fully understand the concept of the Village Organization. Many interlocutors (who were not part of the MSDSP circle) still referred to the mahalla when talking about the VO. The modification of the mahalla, brought about as a result of the creation of the VO, is mostly seen as an innovation brought from the outside. People accept the VO because it introduces some improvements in the destitute environment of Shuroobod, even if the equal distribution of aid or its effectiveness are questioned.

However, it remains unclear why a mahalla should be replaced by a new structure, such as a VO. In reality, the whole process of VO implementation in some ways resembles the controversial and ideologically-coloured modernization ideas introduced by the USSR when the state imposed a certain concept of local development from above, such as collective farms. With time, the Soviet model was adjusted and merged with local structures, adapting to local conditions.

Thus, it may be that VOs will also be absorbed by mahalla structures, especially as for the time being traditional institutions dominate over the VO model. According to a local manager of the MSDSP, at this stage, VOs have $80 \%$ of the features of a mahalla, and only $20 \%$ of the attributes of VOs in the form planned by the MSDSP. Another employee of the MSDSP, upon being asked why VOs was being established

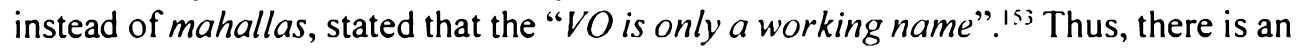
impression that the differences between the two structures have begun to finally fade.

Yet another noteworthy issue is related to the micro-projects which are implemented by the MSDSP through the VOs. According to the rules, project ideas should be proposed by the management of a VO upon agreement with all the residents. In practice, however, decisions about projects or investments are frequently made by the VO authorities in accordance with the suggestions made by the MSDSP. A majlis is often arranged only at the initiative of the MSDSP. The residents of the village frequently attend the gathering as they are obliged to participate and not because they feel the necessity to organize such a meeting. In some cases, the required minutes from the majlis gathering are falsified to provide the necessary proof that such a meeting took place. Another issue is connected to the system of selecting priority projects. In many cases, the communities' requests do not comply with a donor's of-

15: On the basis of a meeting with an MSDSP manager, June 2014. 
fer. As a result, the specific actions of donors are misdirected and projects do not represent the true needs of the people.

In consequence, people can refuse to participate in a hashar or to contribute in another form to the project implementation because they do not feel that it is their own concept. ${ }^{154}$ On the other hand, if villagers wish to organize a certain undertaking, they are usually able to mobilize themselves without the help of the VO. Wiegmann (2009: 167) argues that a VO is not the best way to involve people in community development, since - due to the generally difficult situation and high level of poverty - communities tend to take everything given by intemational donors even when they actually have other needs. Finally, this arrangement does not encourage independent initiatives, but makes communities dependent on international assistance.

Yet another aspect makes project implementation through VOs a very complex issue. As previously mentioned, Islam is the base on which most social relations are formed, including those within the mahalla. The set of customs, practices and rituals that make up mahalla institutions are observed by its residents on the grounds that they are part of Islamic tradition. Consequently, all innovations have always been evaluated in the context of their compliance with the principles of Islam.

Therefore, some concepts proposed by a VO can be rejected by a community as they are not sanctioned by traditional practices. For instance, traditionally, in a mahalla all important decisions are taken by the elite of the community; however, according to the VO's rules, in order to grant equal opportunities to all villagers to participate in the decision-making process, $80 \%$ of the residents should take part in a majlis. In practice, at the request of the MSDSP, inhabitants gather for meetings but decisions are still taken by a small group of influential inhabitants.

Who makes the decisions in the mahalla (here the VO)? Of course, we do (the elders)! We usually meet with the raisi mahalla (rais of VO), the mullo and other respected members of the community and debate on how to deal with a particular problem. Then, our opinion is presented during the majlis, and the participants approve our decision in an open vote (by raising their hands). ${ }^{\text {ss }}$

Thus, there is often a rift between donor principles and the situation in the field. In fact, the MSDSP attempts to maintain a balance between these two frequently conflicting realities. To change tradition so as to make it conform to donor principles would require continuous supervision from the outside, which in turn would contradict the concept of participatory development.

The next point of the above discussion is related to the equal participation of women and men in decision-making, as promoted by the MSDSP in line with the requirements of Western donors. In one VO, I had the opportunity to observe a majlis organized by the International Fund for Agriculture and Development (IFAD). The

Is. My opinion about the issues connected to setting up projects is confinmed by Wiegmann (2009: 167).

1s: From an interview with a former teacher July 2010. 
meeting was held on the premises of a school, under a big tree. The main participants of the meeting were men, who were seated according to the traditional order typical for Tajik society, in keeping with the hierarchy of age. Thus, the oldest members of the community were located under the tree next to the table of the IFAD representatives, the middle-aged men were sitting in the first row opposite the elders and the IFAD, and the young men were squeezed together in the last row. There were also seven women, who were standing on the porch, and they did not actually participate in the discussion but rather chatted amongst themselves. The debate was mainly conducted between the elders and the IFAD, with some participation of the middleaged men. The young men remained silent. After signing the attendance list (a donor requirement), the women quickly moved to leave the meeting. They were stopped, however, at the request of the IFAD representatives, who asked them how many litres of milk their cows deliver per day. After providing an answer, the women were finally allowed to leave the meeting.

I discussed this incident with the managers of the MSDSP as well as with the employees of other local organizations. All respondents agreed on one point: in Tajik culture, especially in the rural areas, a woman does not express her opinion openly in the presence of other men as such behaviour could be considered degrading to her husband. This does not mean, however, that she does not say anything at home, and her opinion may have a significant influence on her husband's views, and her ideas may later be repeated by him during the majlis. Moreover, the traditional gender separation does not encourage women's participation in public meetings including the presence of outsiders. Nevertheless, Western donors require transparent and clear procedures to prove the participation of all residents in gatherings (and presumably, therefore, in the decision-making process). Consequently, women are expected to appear at meetings and sign the attendance list, although frequently they do not take part in the discussion.

Undoubtedly, under the current circumstances, the intensification of women's participation in public life has become a necessity. Due to the high emigration rate among males (one of the social consequences of which is an increasing number of divorces), women have become more involved in communal activities, since they are often forced by circumstances to work and thus function outside the close community circle (see Chapters 4 and 7).

However, at the same time, the traditional division into men's and women's responsibilities, competences and privileges places a limitation on the involvement of the female part of the community in public affairs and thereby also affects their activities within a VO. The social involvement of women often does not go beyond the traditional roles they perform in the mahalla, such as organizing festivals and rituals. Boboyorov (2013: 164-165) makes some interesting remarks on women's involvement in the VO structures, suggesting that the traditional femalemale distinction led MSDSP to establishing Women's Councils within the VOs, which are expected to organize female meetings to discuss women-related problems, but, simultaneously, women are excluded from mainstream decision-making 
processes in the VO. The female meetings are often organized irregularly upon the request of the MSDSP.

During my research in Shuroobod, I spent an evening in the house of a female SUDVO representative in one of the jamoats I visited, during which we had a very interesting conversation regarding various issues related to women. Despite her very positive attitude toward the work of the MSDSP and the AKDN, the concept of gender equality and the equal participation of women and men in community life presented during seminars and training sessions differed significantly from the reality in which she lived and worked. The point is not that they were wrong in principle, but that they were often perceived as too abstract in the remote villages of Shuroobod, in which most residents have limited access to water and electricity, medical services are almost non-existent, and unemployment endemic.

My interlocutor intuitively understood the issue of equal opportunities and rights for women and men, but at the same time was fully aware that they were difficult to transpose into the social conditions of her community. A lot of the men were working in Russia, including her husband and two sons, and the majority of women struggled to make ends meet. People irrespective of gender had very little opportunities enabling them to fulfil their basic needs, not to mention achieving personal advancement. The most important priority for this woman activist was finding the financial resources needed to train a qualified midwife who would be able to work in the jamoat where there was no medical facility or trained personnel. This fact has significantly contributed to an increase in the rate of infant mortality since women deliver children in their homes; therefore, if any difficulties were to occur, the probability of the mother and infant dying is very high.

She also told me a story about a woman in the late stages of her pregnancy, who was taken by her husband and the rais of the mahalla to the nearest hospital on horseback through the mountains in winter since the road was inaccessible for cars. Ultimately, the woman died, but my interlocutor concluded that this situation would have been avoidable if the jamoat had even some basic medical facilities or at least a professional midwife. She also added that she considers the more practical seminars, such as those concerning hygiene, health issues, infant care as well as microfinance, to be the most effective ${ }^{156} \mathrm{Her}$ aunt - a local spiritual leader - was also involved in social work aimed at helping women. Another important person in this jamoat included a social activist, whose young daughter used to be a raisi jamoat for a short period. ${ }^{157}$ Notwithstanding, while all these women enjoy a high social status and are respected by the residents of their community, their work

1.56 The MSDSP initiates local savings groups and the majority of their members are women. This is a good opportunity to make people familiar with budget management and savings.

157 We were told during an interview with a UNDP representative in Khujand that President Rahmon issued a directive to increase women's participation in higher administrative posts. Thus. women are often appointed to a certain position to fulfil a quota, but in fact their role is not significant (August 2010). 
does not go beyond 'women's issues', thus the responsibilities which belong to the 'women's world'.

Let us, however, once again return to the issue of the extent to which the activities of the VO contribute to women's involvement in decision-making processes at the village level. In addition, will this participation significantly impact on the relationship between the two genders in an environment in which the male and female worlds are traditionally separated from each other? Certainly, encouraging women's involvement in community life is a positive course of action, since the changing socio-economic conditions in Tajikistan have created a need for at least a partial transformation of the traditional roles. Additionally, the new phenomenon related to male migration has an enormous influence on the current situation in Tajikistan, due to the increasing amount of abandoned women with little children to maintain. As the experience of the Polish Center for International Aid has shown, resulting from the implementation of a project related to initiating and supporting women's microenterprises in the Shartuz district, due to the traditional role of women, one of the most difficult issues to overcome are the mental barriers in place concerning women working outside the family circle. Additionally, often acquiring basic skills, such as using even small amounts of money, is very difficult for someone who has never been economically active. In many cases, it is only when women risk facing extreme poverty that they decide to become involved in economic activities.

In Shuroobod, eight times more men than women have a higher education (Wiegmann 2009: 61), and it is not rare for girls to be taken out of school by their parents to be married off. The MSDSP, through the VOs, has to face various problems related to the current situation of women in the region, alongside other pressing social and economic issues. It is undeniably positive to encourage women's participation through the creation of various groups and circles, since in this way people can learn some useful skills, such as financial management or organizational skills.

Nevertheless, if economic development does not follow as a result of the structures created by donors (in this case the MSDSP), the situation of people, irrespective of gender, will not improve. One former official in the Shuroobod region posed the following question:

Why don't donors stop spending all that money on VOs, but instead build one factory which will produce goods for the European or American market? We do not need charity, we need jobs. The USSR created places of work because it needed at least some production and trade to maintain its statehood. Foreign donors are not particularly concerned with our economy. However, some institutions have a vast interest in channelling huge amounts of aid, to be absorbed formally or informally by various parties in the process of its delivery (including by donor organizations themselves). ${ }^{15 *}$

Regrettably, I have also heard such bitter remarks from local NGO workers and officials in other countries of the Former Soviet Union.

1:8 Part of an interview with a former governınent official, June 2010. 


\subsection{Summary}

The VOP is an experiment aimed at modifying the mahalla and creating its modem version in the form of Village Organizations. Some additional goals of founding VOs in Shuroobod were the creation of development opportunities and extending control over communities living in sensitive border regions, as well as ensuring protection of the area against the potential spread of Islamic extremism and drug trafficking. In the first stage of implementing the programme, structures parallel to those of a mahalla were created but they failed in principle, since they triggered unintentional competition between the old and new constructs. Consequently, the mahalla was dismantled and reshaped into the $\mathrm{VO}$ as the designers of the programme considered the new structures to be more suitable for modern communal development.

However, if participatory development is understood in terms of integrating traditional structures into development projects, why is so much effort put into building new structures, such as the VO, rather than reinforcing the mahalla? This is especially the case as the new law has now created good conditions for cooperation with indigenous grass-roots institutions. Consequently, in the case of the VOP, participatory principles are observed in a selective way - some traditional elements of the mahalla are accepted, while others are considered unsuitable. Nevertheless, as my research has shown, such undesirable elements have often dominated over new ideas brought in by the VOs.

One possible scenario is that the VOs will be tolerated by communities as long as the programme benefits the residents of Shuroobod. In fact, facilitation of communal development in the form of trainings, loans, new investments, and other such incentives are beneficial from the practical point of view.

Under current circumstances in the Shuroobod district, VOs require substantial supervision and assistance from the MSDSP to enable this structure to survive. The MSDSP has become an important actor in Shuroobod, since many residents, including representatives of the local administration, frequently refer to the Aga Khan Foundation as an organization which has contributed to local development significantly and to a higher extent than the state administration. Thus, there is nothing to replace foreign funds. It is therefore very probable that, in the case of the withdrawal of donor support, the entire structure of the VOs will collapse. 


\section{Chapter 6}

\section{The Kolkhoz, Selsovet, Mahalla and Jamoat Resource Centre on the Fringes of the State}

\section{I. Introduction}

Vorukh is a Tajik enclave situated in a small valley surrounded by Kyrgyz lands. Its remote location makes it difficult to visit as well as to conduct research there. Under certain circumstances, however, the distant location of Vorukh is beneficial for its inhabitants. For a long period of time, the small community of Vorukh has lived according to its own rules. They prevailed over the formal state system even in the Soviet period. This factor contributed to preserving a unique 'Vorukh culture' which, despite a turbulent history, has survived until today.

Nevertheless, the living conditions on the border between two states are difficult, and border tensions with the Kyrgyz have resulted in the increasing isolation of the Vorukh community. One of the main reasons for the conflict is a lack of any common agreement about the demarcation of the border, which in turn has led to endless disputes regarding access to land and water resources. The Tajik enclave and the adjacent Kyrgyz territories are important from a strategic point of view for the governments of both states. As a result, the region has also drawn the attention of international donors, who have implemented a number of conflict prevention programs with special focus on ethnic issues and the disputes over natural resources.

One of the main goals of the international donors is to encourage institutionbuilding in order to reinforce cooperation between the state administration and local communities. As described in Chapter 3, within the framework of this strategy, the UNDP launched a Jamoat Resource Centre programme in different regions of Tajikistan. In Vorukh, the local NGO Adolat was reshaped into a JRC for the purpose of strengthening the jamoat's capacities and furthering collaboration between the latter and the residents of the enclave. 
Since its foundation, the organization has been involved in a number of projects. It also established a microfinance institution which has ultimately become an important actor facilitating local development and dealing with various responsibilities nominally belonging to the jamoat, which - here as in other regions of Tajikistan - is a weak institution without an independent budget; however, before the division of land in Vorukh (2011), the former kolkhoz authorities remained the most important power in the enclave. The relationship between the collective farm (kolkhoz) and the jamoat (still called a selsovet by the locals) had not changed significantly since the Soviet period when the director of the kolkhoz ruled over the head of the selsovet. This hierarchy was reflected in the way the residents referred to the manager of the collective farm as 'big rais - a raisi kalon'. Correspondingly, the head of the jamoat was known as 'little rais - raisi khurd'.

The main purpose of this chapter is to examine the extent to which a local NGO (in this case - the Jamoat Resource Centre), facilitated by funds from an international donor (the UNDP), has contributed to changes in the pattern of local relationships, becoming 'a third power' and challenging the influences of the jamoat and the former kolkhoz in the specific context of the Vorukh enclave. Another issue of importance for this analysis is the impact of the activities of the JRC on mahalla development and on its relationship with the jamoat.

First of all, in order to provide some background and context for the analysis of the role of the various actors in Vorukh, some brief information on the history, culture and political affairs of the enclave will be provided. The subsequent part of the chapter will deal with the nuances of the relationships between the jamoat, the kolkhoz, the JRC and the mahalla.

\subsection{Vorukh and Its Surroundings}

Vorukh is located in the Ferghana Valley - a geographically cohesive territory of the basin of the Syr-Darya River, surrounded by the Tien Shan mountain range to the north, and the Alai and Turkestan Mountains to the south. The basin of the valley stretches over an area of 22 thousand $\mathrm{km}^{2}$, at an altitude of $350-1000 \mathrm{~m}$ above sealevel, with slightly higher foothills. The natural environment provides excellent conditions for the development of agriculture and irrigation systems. The Valley is one of the most densely populated areas of Central Asia, with many ethnic groups having lived here side by side for centuries. As a result of the demarcation established by the Soviets, the Valley was divided into the Kyrgyz SSR, Uzbek SSR and Tajik SSR. After the collapse of the Empire, these materialized as separate states. Presently, the Ferghana Valley spreads across eastern Uzbekistan, Kyrgyzstan and Tajikistan, divided by frontiers which artificially separate various ethno-regional groups previously linked to each other. 
The enclave of Vorukh is another peculiar phenomenon which was formed following a further adjustment of the borders during the process of collectivization, when a number of isolated areas which had been located within the territory of one republic were constructed as a region belonging to another one. ${ }^{159}$ Since the borders separating republics were of lesser importance during the Soviet period, such enclaves naturally merged with their surrounding territories and were only nominally assigned to another republic. After the dissolution of the USSR, small pieces of lands became administrative units, 'isolated islands' located within the territory of other states (Reeves 2007: 284-285).

According to Bushkov (2004: 68), the name of Vorukh is derived from the word vara (English: fortress, an enclosed place). Some locals, however, believe that the real meaning of Vorukh is ' a pure soul'. Both terms are a good reflection of the character of Vorukh - an isolated place, a 'fortress' or 'island', where a genuine culture has been preserved, creating a unique atmosphere of spiritual purity. Vorukh is located on the territory of the Batkenskaia oblast of Kyrgyzstan and covers an area of 130 (or 97) $\mathrm{km}$ (Enclaves of the World n.d.). ${ }^{160}$ Vorukh has the status of a jamoat within the administrative Isfara district situated in the Ferghana Valley in the north-eastern part of the Sughd region, which borders Uzbekistan to the north and Kyrgyzstan to the south. The main city of the district is also named Isfara. Vorukh, together with nearby Chorku, are the two main settlements of the Upper Isfara district. The population of Vorukh is somewhere between 28,000 and 31,000 people, the majority of which are Tajiks (95 per cent) with an insignificant number of Kyrgyz (Enclaves of the World n.d.; information from the jamoat in Vorukh), who mainly occupy lands in the upper part of the enclave. Surrounded by mountains, Vorukh is situated in a valley at a terrace of the Say Kshemysh, located on the right-bank of a tributary of the River Isfarasay.

The earliest information on the beginnings of settlement in Vorukh was provided following archaeological excavations conducted by Boris A. Litvinskii in the 1950s, which showed that between the $2^{\text {nd }}$ and $7^{\text {th }}$ centuries (CE), a group of people whose main occupation was animal husbandry lived on the territory of Vorukh. The estimated number of people who came to this area in the $2^{\text {nd }}$ century was about 100 to

159 There are eight enclaves within the territory of present-day Tajikistan, Uzbekistan and Kyrgyzstan: 1) Sokh belongs to Uzbekistan and is located in the territory of Kyrgyzstan; it is populated by Tajiks; 2) Shakhimardan, an Uzbek enclave placed within the boundaries of Kyrgyzstan, whose main population comprises Uzbeks; 3 ) the Tajik Vorukh with a mainly Tajik population located within Kyrgyzstan; 4) the Uzbek Kalacha contiguous with Kyrgyzstan, populated by Tajiks; 5) the Barak enclave belongs to Kyrgyzstan within the borders of Uzbekistan, its main residents - Kyrgyz; 6) Kairagach - a Tajik area contiguous with Kyrgyzstan. populated by Uzbeks; 7) the Tajik Sarvak, within Uzbekistan. inhabited by Uzbeks; 8) Jangy -Aiyl belongs to Uzbekistan but is located within Ky rgyzstan, populated by Ky rg: z (Bichsel 2009: 20).

161) Additional information concerning population numbers in 2010 obtained from the jamoat in Vorukh. 
200 (probably a single kinship group). As regards the later period, there is a remark about a valley made in passing by an Arabic historian named Islam ben Abdallaha alBahili. Historical sources also state that in the first quarter of the $8^{\text {th }}$ century, the Ferghana King Alutarom expelled the local population in order to settle a few thousand Sogdians who had escaped from the Arab conquest. Since the second half of the $18^{\text {th }}$ century, Vorukh has experienced several migrant flows into the valley of the River Isfara from the southern regions. Some of these settled in Vorukh and consequently drove away part of the Vorukh population (Bushkov 2004: 69-70).

Only since the $19^{\text {th }}$ century has there been reasonably comprehensive information about Vorukh. The settlement grew considerably in size in the 19 century. Up until the Soviet period, Vorukh was divided into two parts: the western Maidon (apricot orchard) and the eastern Tihidon (internal part), which corresponded with the two main ary $k s$ of the same name splitting the settlement. Each part consisted of separate quarters, with a total of 12 mahallas. At that time, the population of Vorukh was comprised mainly of Tajiks. According to Kisliakov (qtd. in Tursunov 1991: 391392), some of the inhabitants of the settlement came from a few Matcha villages, while many arrived from different places in the Kokand Khanate. Others were autochthons which had been settled there for generations. There is also speculation that several families came from the Karategin region. Bushkov (2004: 69-70) indicates that some residents of Vorukh resettled to other regions, such as precincts of Kokand city, and inhabited several villages of the Isfara district and the Kuramin range in Khujand. Moreover, people from Vorukh also moved to Isfara city and its environs in the 1980s and 1990s.

With regard to ethnic background, the residents of Vorukh are believed to descend from a group commonly known as the Ferghani (residents of the Ferghana Valley), who used to speak the Eastern Tajik language, related to the Sogdian language. According to Babur (at the beginning of the $16^{\text {th }}$ century), the local population was called galcha (English: highlanders), like other inhabitants of the mountainous regions of Tajikistan (qtd. in Bushkov 2004: 70). Presently, the residents of Vorukh describe themselves using the term 'local Tajiks' (Russian: mestnye Tajiki) or sometimes Vorukhis in order to emphasize that they come from Vorukh.

Both in the past and now, the main occupation of Vorukh's inhabitants has been agriculture, which expanded following the development of an irrigation system. Some families combined agricultural activities (mainly fruit-farming and rice cultivation) with different kinds of arts and crafts which they re-sold or exchanged on the domestic market. There were also people involved in trading and delivering goods from other parts of the Isfara district. They exported dried fruit, rice and imported wheat, textiles, various manufactured goods, coal, salt, paraffin, oil, and the like. An integral part of the economic and social life of Vorukh was the neighbourhood of the Kyrgyz, who specialized in animal husbandry (Tursunov 1991: 391-392). That situation was maintained until the October Revolution. 


\subsection{Disputes over Natural Resources}

Until the collectivization in the 1930s, the Kyrgyz led a traditional, nomadic or seminomadic lifestyle. Land was divided among the different Kyrgyz tribal groups and the Tajiks, and there was no reason for conflict. The various forms of production of both groups provided a base for symbiosis, expressed in the exchange of goods and services. As a result of such activities, bazaars were created in Vorukh and Chorku, with the latter later being moved to the Kyrgyz village of Samarkandek (Bushkov 1990: 5).

As already mentioned, due to Vorukh's location on the sidelines of the main routes, the old social structure did not change significantly in the aftermath of the October Revolution. Nevertheless, the partition of the Ferghana Valley and the foundation of the new republics provided fuel for later antagonism between different ethno-territorial groups which began to lay claims to land and water on the basis of the new territorial division. The situation was further exacerbated by the fact that, due to Vorukh's unique geographical position, the lines of demarcation between the Tajik Soviet Socialist Republic and the Kyrgyz Soviet Socialist Republic were never definitively drawn. Consequently, the social tensions which had begun during the Soviet Union were reshaped after its disintegration into border conflicts between the independent countries of Tajikistan and Kyrgyzstan. Another factor which contributed to increased competition for access to land and water recourses was the rapid population growth. Between 1870 and 1990, the population of Vorukh increased twentyfold; and has doubled since $1990(16,621)$ to reach about $28,000-31,000$ in 2014 (Bushkov 1990: 4-6; information from the jamoat in Vorukh).

The first conflict between the Tajiks and Kyrgyz in Vorukh began in the 1930s. The policy of settling nomads without taking into account traditional social relationships based on the particular roles of each of the ethnic groups (Kyrgyz - cattle breeders, and Tajiks - producers of agricultural products and crafts), together with the transformation of winter encampments ${ }^{161}$ into permanent Kyrgyz settlements (the lands reputedly belonged to Tajik avlods), disrupted the traditional balance of power between the two groups. Due to a scarcity of places for comfortable settlement (primarily due to water shortages), some Kyrgyz groups re-settled close to the Isfarasay River (Bushkov 1990: 4-6, some comments added). Bichsel (2009: 107) reports that conflict erupted in the 1930s over the expansion of the Tajik settlement into the Kyrgyz winter encampment, Bedek. As a result of the disagreement, several people were killed and many more injured. Finally, the Soviet authorities decided to incorporate Bedek into the Tajik SSR and to relocate the Kyrgyz to another place. However, as far as pre-revolutionary relationships are concerned, it is difficult to judge the rights

161 Winter encampment (Russian: zimovka) - a kind of permanent settlement where nomads lived during the wintertime; people used to live in simple huts made of stones and clay. called $k a l l a-$ -uilars. or in yurts. 
of each ethnic group to a particular patch of land. The Tajiks believe that the lands in question have always belonged to the Tajik avlods, who only made them available to the Kyrgyz tribe for their winter encampments. ${ }^{162}$

Further territorial disputes took place during the 1940s and 50s in the area of southwest Batken and Isfara, following which - in 1958 - an inter-republican commission re-organized the borders between the area of the Osh district in the Kyrgyz SSR and Leninabad in the Tajik SSR. Earlier, in 1955, the Soviet Ministry of Agriculture allowed the Kolkhoz 'Pravda' (English: the truth), which was located on the territory of Vorukh belonging to the Isfara district, to lease 1000 ha of pasture land from the Sovkhoz 'I00 Letia V.I. Lenina' situated in today's Batken district. According to the agreement, the kolkhoz could use the leased land until 1980. Most of this land was located in the area of the present-day Tojikon and Ak-say villages as well as in the surrounding areas. The land was used for pasture during the late 1950s and early 60s. However, in 1967, Kolkhoz 'Pravda' started constructing the Mekhnatobod-Aksay canal in order to extend the area suitable for cultivation. This was necessary due to rapid population growth and the scarcity of land in Vorukh. The Kyrgyz villagers lodged a complaint that Kolkhoz 'Pravda' wanted to take over their lands and that it was not complying with the terms of the agreement, which stated that the leased land should be used for pasture. Consequently, further conflicts were triggered in 1969 and 1970, and continued in 1975 (Bichsel 2009: 108; some comments added; also see Jamoat Resource Centre of Vorukh and UNDP 2011).

According to one interlocutor, in the 1960s the Kyrgyz were forced to leave the mahallas in Vorukh due to a disagreement which was started by one of the foremen from the kolkhoz and then spread to all the mahallas. Gradually, the Kyrgyz moved downriver and took over a place where in the past they had sent their herds out for grazing (according to the Tajiks, the land belonged to them). At first they built yurts, and later a regular settlement. Thus, the last remains of long-term coexistence between Kyrgyz and Tajiks disappeared during that period. ${ }^{163}$

The conflict in 1975 is well remembered by both sides of Ak-say and Vorukh. According to the Ak-say elders, the director of the kolkhoz expanded to areas which were believed to have belonged to the sovkhoz. When the collective farm workers began to work, the Kyrgyz took up action against the Tajiks. Following an escalation in the conflict, a few people were injured. The disagreement ended only after armed intervention by the militia (police forces). The kolkhoz and the sovkhoz signed an agreement under which 1000 hectares of land would be divided between involved

162 During that time, the Kyrgyz village Ak-Say (English: white water) bordering with Vorukh was established. The oldest part of the village, named Kapchygai, was set up on the east bank of the River Isfarasay. The former Kyrgyz winter encampment of Vorukh Tang reputedly belonged in the past to the Tajik avlods. The central part of the settlement is situated on the west bank of the river and was founded in the 1970s. The newest part - Bakai - is also located on the westem shore and was created in the 1990s (Bichsel 2009: 29; some comments added).

16: On the basis of an interview with a local resident, August 2010. 
parties. In order to resolve the conflict, an inter-republic commission was set up to assess the claims of both sides. It also evaluated the contribution to the area's development made by the parties and finally concluded that the kolkhoz had made larger investments. Consequently, the kolkhoz received 402 hectares and the sovkhoz 316 hectares, with the remaining part of the land granted on a long-term lease to the kolk$h o z$. The Kyrgyz SSR did not receive any compensation for the land transfer to the Tajik SSR, but the kolkhoz was obliged to provide water from the new canal to the sovkhoz during the irrigation period (Bichsel 2009: 109-110). ${ }^{164}$

Shortly after the clash, the central part of the settlement of Ak-say was established. The Kyrgyz population from different villages was relocated to Ak-Say. However, according to the Kyrgyz, they did not receive the promised access to water, and all their complaints remained unanswered. The Tajiks replied that the central government had forced them to sign an unrealistic agreement and that the water obtained from the canal was barely enough to irrigate the kolkhoz lands. Another commission failed to solve the problem, and riots took place in 1982 in the Vorukh/Ak-say area. Next, conflict broke out on a larger scale in various parts of southwest Batken and Isfara in 1989 (known as the ketment war; ketmen (English: a hoe), and spread to the area of Vorukh and Ak-say. According to one interviewee, Vorukh was temporarily cut off from Tajikistan, as the Kyrgyz blocked the road for over a month and during the conflict many people were seriously injured. Finally, the violence was ended by police and military forces (Bichsel 2009: 109-110; some comments added). ${ }^{105}$

An inter-republic commission gathered again to resolve the disputes over the border between Kolkhoz 'Pravda' and Sovkhoz 'I00 Letia V.I. Lenina', as well as other neighbouring collective farms. Under the commission's decision, 280 hectares were to be transferred from Kyrgyzstan to Tajikistan. However, the final report was not signed by the appropriate authorities of the Kyrgyz SSR and Tajik SSR; thus, subsequently, Kyrgyzstan decided to build a textile factory in Kapchygai and a clothing factory in Ak-say in order to strengthen the border area, though neither enterprise survived the collapse of the USSR. During that time, the settlement of Tojikon was established in the land bordering directly with Ak-Say (Bichsel 2009: 109-110). It seems that the name Tojikon was selected intentionally to underline that the Tajiks owned the land.

The disagreement between Vorukh and Ak-say has been difficult to resolve due to the shortage of land and water in the area and the increasing population. Subsequent to the new borders being established, the nature of the conflict changed, from turmoil about access to natural resources to a disagreement with an international dimension and ethnic tensions in the background. In the Soviet times, all infrastructure was interconnected through a common network for water management, energy supply, and

16t The local informants confinned that this conflict was one of the most severe during the Soviet period. Reputedly; the director of the kolkhoz was dismissed from his post for his active involvement in the clash between the Kyrgyz and the Tajiks.

16: In interview with a local resident, August 2010. 
transport lines. The division of borders resulted in the disconnection and partition of infrastructure, which had a negative impact on the lives of local communities, as well as contributing to border conflicts.

The current demarcation of the borders is also questioned by both parties. Tajiks recognize the map designed in 1927 and legally accepted by both the Tajik and Kyrgyz sides at that time. On the other hand, the Kyrgyz authorities refer to a map from 1989, which was also drawn up during the Soviet period by a Tajik-Kyrgyz Joint Commission, according to actual usage of land by Tajik and Kyrgyz communities (Jamoat Resource Centre of Vorukh and UNDP 2011: 27). ${ }^{160}$

The majority of the disputes erupt during the agricultural seasons, and they sometimes develop into serious clashes, when so-called 'roadblock wars' are initiated. Such an event occured as recently as in 2014, when the Kyrgyz erected a blockade of Ak-say for a short period, as a result of which the residents of Vorukh were not able to travel to Isfara. The conflict in 2014 was sparked by the construction of a road passing through the Vorukh enclave by workers from Kyrgyzstan, which resulted in an exchange of fire and reportedly left at least seven border guards from both sides injured (one person died). This situation triggered further disputes, with the border blocked on a number of occasions and tension escalating on both sides (Sabyrbekov 2014). After months of negotiations, the Tajik and Kyrgyz governments have agreed to lay two separate highways for use by the Tajiks and Kyrgyz, replacing the road which was a source of tension. However, this has only partially resolved the situation, since the border demarcation has not moved forward yet, while the issue of the distribution of natural resources remains unresolved (Abdulghani 2014).

To this day, in order to travel to the Batken district of Kyrgyzstan, the Kyrgyz have to pass through the enclave, which means through the territory of Tajikistan. Conversely, when inhabitants of Vorukh wish to visit the Isfara district or other parts of Tajikistan, they have to take a road through Ak-Say and other settlements located within the borders of Kyrgyzstan. Therefore, the residents of both Vorukh and Ak-say are trapped between the bizarrely-designed borders of two different countries. This makes their lives complicated and is the reason behind endless squabbles and conflicts.

Small skirmishes between young Tajiks and Kyrgyz occur practically on a daily basis. Needless to say, due to the widespread poverty and unemployment in the area, young people frequently vent their frustrations on strangers - in this case, on representatives of a hostile group: Kyrgyz or Tajiks, respectively.

Since the dissolution of the USSR, new generations have grown up in isolation from each other, and so it is easy to invoke nationalist sentiments fueled by politicians from both countries trying to construct a fragile national identity. Consequently, minor problems quickly turn into larger conflicts, and men armed with sticks and hoes regularly gather at the border to exchange threats.

166 Yet another map was published in 1957. but it is also not recognized by the Tajiks. Some Tajiks told me that both maps from 1957 and 1989, respectively, were designed as a favour to the Kyrgyz. due to their good contacts in 'Moscow'. 


\subsection{Islamic Practices in Vorukh}

Numerous international meetings and projects financed by international donors aimed at conflict resolution have failed to achieve their goals. Despite organizing gatherings, seminars, common enterprises and declarations, little has changed. At present, the frontiers of Vorukh from the side of the Tojikon mahalla are separated from Ak-say village only by a road, thus when someone travels using one lane he/ she is on the territory of Tajikistan, and if on the other - he/she is in Kyrgyzstan. A similar situation exists with regard to some fields and pastures.

However, despite mutual grievances, the populations of both settlements are strongly interconnected. The Wednesday bazaar in Vorukh is still visited not only by Tajiks but also by the Kyrgyz. As in the past, representatives of both ethnic groups make pilgrimages to the same mazars, performing similar rituals and prayers, and Kyrgyz from Ak-say visit healers (tabibs) and clairvoyants (bakhshy) in Vorukh. The two settlements cannot function without each other. They are linked not only economically and logistically but also in terms of their spiritual life, and, despite the unfavourable circumstances, both settlements need to find common ground for reconciliation so as to enable their residents to achieve peaceful coexistence.

\subsection{Islamic Practices in Vorukh}

In order to understand the peculiarities of the relationships in Vorukh, it is necessary to discuss Islamic practices, which - as in other parts of Tajikistan - are the nucleus around which community life is formed. Until the October Revolution, due to the isolated location of the settlement, religion in Vorukh was strongly dominated by the local syncretic religious traditions of Central Asian cultures.

Soon after the Revolution, when the Soviets came to power, at the onset of persecution of the clergy in the 1930s, Vorukh - due to being surrounded by mountains and secluded - became a retreat for many theologians from the former Kokand and other important Islamic centres of Mawarannahr. Protected by local party officials and kolkhoz authorities, they continued their religious activities, including underground teaching. Poliakov (1992: 40-42) makes the interesting remark that Vorukh provided religious professionals for the Western Ferghana Valley during the whole Soviet period. ${ }^{107}$

According to one imam, religious classes took place in teachers' homes. In his youth, he was the student of a famous imam from Kokand. Upon completing his

167 According to Poliakov (1992: 40-42), one of the imams employed in the official "state" mosque in Leninabad also served in the informal masjid in Vorukh in 1985. This situation is a good depiction of the fluidity of the boundaries between 'formal ' and 'informal' Islam, but it is also an indication of the ambiguous attitude of the autochthon Soviet authorities to Islamic practices. 
religious education, the interviewee worked in an informal mosque. Following the Perestroika, the mosque was registered and he was officially employed in the same place. ${ }^{108}$ Poliakov (1992: 40-42) points out that a number of unregistered mosques in Vorukh in the late 1980s were the same as during the time of the Kokand Khanate, and there were bakeries which acted as façades, where in fact mosques and mazars were located. ${ }^{169}$

However, other interlocutors pointed out that apart from the old 'red mosque', which is on the list of UNESCO World Heritage sites, other masjids in Vorukh were closed. For example, the central mosque was transformed into a storehouse, although some prayers continued to be performed there. In contrast, religious celebrations frequently took place in remote mountain areas. In the words of the above-mentioned imam, "Communism was a good system for society; the only problem was the attitude of the authorities to religion". Nevertheless, it seems that Islam was practiced in Vorukh under the umbrella of the communist kolkhoz system, which significantly contributed not only to its survival, but also to spreading Islamic thought throughout the Ferghana Valley.

The religious leaders I interviewed included a bibi otun - the granddaughter of a renowned scholar from Kokand. The grandfather was reputed to have been a clairvoyant and a healer. She and her siblings were taught the Arabic language and prayers by their grandfather. Later, he decided that she should receive further education on religious matters, specifically designed for women. Finally, the bibi otun was educated in the house of a famous otun in Vorukh for several years, where after a certain time she received the customary blessing and was finally allowed to be an independent religious professional. At present, however, due to pressure from the authorities, she has strongly limited her religious activities. ${ }^{170}$

It should also be mentioned that the activities of the IRP supported by some strong avlods are a significant factor shaping the way that religion functions in Vorukh. Both female and male IRP members enjoy a relatively high amount of esteem among the people. However, as mentioned repeatedly in this book, the increased control by the secret service, with a special focus on the supporters of the IRP, has made it difficult for them to continue with their activities. Religious leaders are subjected to close scrutiny, including house searches, police interrogation, and so forth. Nevertheless, in Vorukh, which has experienced various economic and safety constraints, the IRP's popularity is considerable. For instance, it was said that during the parliamentary elections in 2010 about 20 per cent of the residents voted for the IRP in Vorukh,

168 On the basis of an interview with an imam. August 2010.

169 I was told that there are about 5 or 6 holy places in Vorukh, but 32 saints about whom people tell legends.

170 There are other religious leaders (both men and women) who are former students and descendants of famous teachers who were active in the Soviet period. Not infrequently. people have old religious books at home inherited from their ancestors. written in the Arabic script and printed in different Islamic centres of the former Russian Empire, such as, for example. Kokand. Bukhara or even Kazan. 
while an estimated 80 per cent of the population in the whole of Isfara. However, it is difficult to establish to what extent this information is accurate. ${ }^{171}$

Notwithstanding, in my opinion the IRP religious leaders have strongly influenced Islam in Vorukh, including the attempt to purify Islamic practices and rituals of any local traditions. Unlike other remote places located far from urban centres, the level of knowledge of Islam is relatively high and people tend to adhere to Islamic orthodoxy. However, it should also be indicated that many religious people do not support the IRP. They neither trust the IRP leading figures nor support the model of development proposed by the Party. They also doubt that the IRP is capable of bringing about any significant changes in the country.

Despite the various dimensions of religiousness in Vorukh, the fact that Islamic tradition remains strong in this area contributes to maintaining social order, which under current circumstances connected to the border conflict with Kyrgyz has a consolidating impact on the residents.

\subsection{The Kolkhoz, the Jamoat, the )RC and the Mahalla in Vorukh}

\subsection{The Kolkhoz}

When I conducted research in Vorukh in 2010, upon approaching the centre of the enclave for the first time, I had the impression that time had stopped and we were still living in the Tajik SSR, with the old kolkhoz order in place. Only upon careful observation could one discem the cracks in the anachronistically preserved remains of the Soviet world. In 2014, I was in Vorukh only for a few days to visit friends. The enclave had changed drastically. It was not 'the same Vorukh' which I had left four years earlier.

In the centre of the former kolkhoz, one can find the building of the jamoat (selsovet) with the adjacent office of the Jamoat Resource Centre. In 2010, a statue of Lenin was located in front of the jamoat premises. Nearby, a second empty pedestal stood, which in the past had held the figure of Stalin, removed during the turbulent

171 By and large, the Isfara district is considered to be a very religious place, with its famous Chorku settlement, reputed by some to be the "source of wahabbizin'. Even in the period of the civil war, during which the former Leninabad (with some exceptions, such as the Upper Matcha district) supported the 'government forces', the IRP had its devoted followers in Isfara, including Vorukh. Bushkov and Mikulskii (1996) describe that after the civil war had begun and the tensions between the two political forces increased, one of the relatives (emissaries) of Turadzhonzoda - his nephew - escaped from Khujand to Vorukh for fear of persecution, to the relatives of the head of the mosque in Khujand, M. Mukarramov. with whom Turadzhonzoda maintained close ties. 
1990s. On the opposite side of the street, the administrative buildings of the former kolkhoz were located, occupied by the administration of the collective farm.

To this day, on the same side of the street, there is a fairly large building decorated with beautiful mosaics depicting the fertile Tajik soil and its inhabitants. Inside, a cultural centre with an event hall can be found, not renovated since Soviet times but still open. Slightly to the rear, there is an old hospital built in the 1930s, equipped with a new labour and delivery ward, financed by foreign funds with a significant contribution by the UNDP and Japan. As one walks along the main street, various businesses and chaykhonas are located on both sides, while a bit further up the road, one comes upon the central mosque and the gates of the 'old bazaar'. Vorukh also has a certain amount of schools, primary-care clinics, a few private businesses, shops, some other mosques, cemeteries and mazars. With all these facilities, until recently the enclave had functioned as an almost independent entity - an imperium in imperio.

According to a local history teacher, collectivization in the settlement began after the Basmachi revolt had been put down at the end of the 1920s. In 1930, one kolkhoz was established, later divided into two collective farms in 1932. Subsequently, in 1934, four kolkhozes were created, and - in 1936 - yet another was founded. By the beginning of the 1950s, five collective farms were functioning in Vorukh, reshaped into two units in 1950. Finally, in 1951, Kolkhoz 'Pravda' was launched, to be dissolved only in 2005. The most well-known kolkhoz director in Vorukh was Haji Abdurazzoq Rakhimov. He contributed to the enclave's development to a great extent. A plaque in commemoration of Rakhimov was placed by his children on the main road in Vorukh. People continue to remember him and his achievements. The majority of the residents of the kolkhoz belonged to kinship networks which had lived there for generations; therefore, the social structure had only changed to a slight extent in comparison to the pre-revolutionary period.

Despite the fact that formally Kolkhoz 'Pravda' was converted into a collective farm named 'Vorukh', the residents of the enclave referred to it as the 'Kolkhoz'. In 2010 , the farm covered an area of over 1,300 hectares, of which 1,000 was taken up by orchards (mostly apricots), with only some land being rented out to farmers. As stated by the head of the farm in 2010, it employed 1,300 people, but due to very low incomes, provided mostly in kind, not allowing them to earn enough to support their families, 80 per cent of the men work in Russia. Thus, mostly women are employed in the agricultural sector.

The manager of the collective farm enjoyed great influence both in Vorukh and in the Isfara district. He is said to have made a handsome profit from various sources, including the collective farm. He was also the main antagonist of the JRC and the raisi mahalla, as described later in this chapter. The conflict continued for many years and originated in the long-standing animosity between the avlods. The collective farm was divided into small plots in 2011. Since then, everything has changed in Vorukh. The former farm manager was accused of participating in informal land transactions and corruption, which led to his imprisonment. Later, he was released and eventually went to Russia to try his luck in business activities. 
In addition to the land division, the situation in Vorukh has been affected by the intensification of the conflict with the Kyrgyz. The Tajik authorities decided to establish Secret Service and Militia OMON (Russian: Otriad Mobilnyi Osobogo Naznacheniia, English: Special Purpose Mobile Unit) offices, and these buildings were erected in 2014. It is worth mentioning that until recently, apart from a small police station in Vorukh, there were no armed forces in the area, whereas Ak-say has always been guarded by a military unit.

The presence of these structures has definitely changed the balance of power in the enclave. At this moment, OMON troops regularly patrol the border with the village of Ak-say. The office of the secret service is one of the most impressive buildings in the Vorukh town centre. It is separated from the premises of the jamoat by a newly-constructed wall. As a result, the statue of Lenin is invisible from the main street, which can be understood metaphorically as a symbol of the transformation of Vorukh from the socialist-kolkhoz system into a new form.

Vorukh is no longer governed by its own laws. Since the establishment of the secret service and OMON, the internal affairs of the enclave have begun to be closely supervised by the state. The residents complain about being monitored and under the surveillance of the 'kagebeshniki' (KGB employees). The previously open and trusting Vorukhis have become circumspect and wary, which is perceptible on the street and differs from the situation during my first visit in 2010. Moreover, an increasing number of the residents have migrated to Russia or to other parts of Tajikistan, selling their houses, due to their fear of an uncertain future in the politically insecure enclave.

\subsubsection{The Jamoat}

The jamoat in Vorukh continues to be called the selsovet by the locals. It is a poor institution, whose functions are limited to administrative tasks and following the instructions provided by the hukumat and the former kolkhoz. Its jurisdiction extends over 15 mahallas, of which 30 representatives (councillors, Tajik: vakils) are members of the jamoat council. According to information gathered in 2010, the rais at that time was a former policeman. During an interview, he stated that one of the most important problems was the drafting of army conscripts. As many young men have migrated to Russia, there are almost no candidates eager to serve in the army. Another important project mentioned by the rais was the construction of a new jamoat building. In contrast, new investments and other issues related to local development were listed as an afterthought. It seemed that the rais did not consider such issues to be important tasks for the jamoat due to a lack of funds and the politically unstable situation in Vorukh, which are obvious barriers to setting up any type of business. ${ }^{172}$

172 On the basis of an interview conducted in $\Lambda$ ugust 2010 . 
By and large, as in many other places, the jamoat authorities understand their role in the context of performing administrative duties. The rais did not even once mention any possible cooperation with the communities on joint ventures or local development plans or collaboration with the JRC, whose office adjoined the jamoat building and which was created to support the jamoat.

\subsubsection{The lamoat Resource Centre in Vorukh}

The Jamoat Resource Centre is an important social actor in Vorukh. According to the UNDP representative in Khujand, the JRC was created at the initiative of a local organization, and not - as in most cases - because the UNDP had made such a decision. As another interlocutor (a local NGO worker) commented, "that is why it works well'. A local organization called Adolat, which had been operating in the area since the 1990s, was transformed into the JRC (which was officially registered in 2003). The organization implements approximately two projects per year, mainly funded by the UNDP but also by other donors, i.e.: the IREX, USAID, UE, IOM, OSCE, and others. Many initiatives deal with border issues (the JRC also cooperates with the Kyrgyz), as well as conflict resolution, improving the water system or other types of infrastructure. Others focus on social problems, including gender and migration issues. However, according to the employees of the JRC, most donors do not ask what kind of projects would be most beneficial for the community; thus, they frequently submit proposals according to the available offer and not in line with real local needs. Therefore, it is self-evident that such a situation strongly influences the effectiveness of the assistance provided.

Following registration of the JRC in 2003, the organization established the Microfinance Institution 'Vorukh' with a starting portfolio of 250,000 USD, with the assistance of the Swiss Development Agency, UNDP and UE. Mini-loans are provided to Vorukh residents for the development of agriculture, business, or other activities, such as organizing family events or migration expenses. JRC employees stated that it would be difficult for the JRC to be sustainable without the micro-finance institution due to the uncertainty of financial resources.

From the profit made by MI 'Vorukh', the JRC erected a big building next to the jamoat premises for a new office, as well as financing other activities. At the time of my research in 2010 , the building was about to be finished, and the JRC had various ideas about what should be organized there, such as, for example, a small hotel for visitors, a bakery, and the like. When I came in 2014, the building was finished and the office of the Micro-fund and JRC opened and newly furnished. In the basement, a bakery financed by the OSCE was established to provide employment for women. The new building dominates over the whole jamoat premises and it makes the impression of being much better designed and more prosperous than the modest local administration facilities. 
As regards the cooperation between the JRC and the jamoat - despite the fact that the main purpose of funding the JRC was to reinforce the jamoat's capacity - the two units do not collaborate unless a project is part of a joint initiative not launched directly by the JRC but by the UNDP or another organization (for example, projects related to border conflicts). ${ }^{173}$ There are common gatherings with the jamoat authorities and the jamoat council with the participation of the JRC, but most initiatives regarding local development are usually proposed by the latter, and the jamoat's involvement is limited to writing a letter of recommendation to the donor organization.

The employees of the JRC, when asked how they understood their role, answered as follows: "Jamoat Resource Centre means 'organization which supports the community', since a literal translation of the word 'jamoa' is community. Jamoat in the context of the lowest level of state administration is a relatively new phenomenon invented to underline the national character of this entity, to be distinguished from selsovet". Thus, they consider their role to be that of an organization which deals with social problems but independently of the state administration. The JRC employees are of the opinion that cooperation with the jamoat is difficult if not impossible, since the latter perceives the JRC as a competitor. In addition, the jamoat has almost no interest in local development or social issues; it is mainly busy dealing with administrative matters and fulfilling the requests of the hukumat. ${ }^{174}$

Another area of controversy, which contributes to the shaky relationship between the JRC and the official state administration (including the jamoat), is the organization's involvement in the process of border conflict resolution, including gathering information on its course and performing different tasks for donors within this framework. In 2011, JRC 'Vorukh' released a controversial report, which was an analysis of the conflict prepared for the project implemented by the UNDP in Tajikistan and funded by the Government of Norway (Jamoat Resource Centre of Vorukh and UNDP 2011).

173 In August 2010, I was able to participate in a meeting in Ak-say organized within the framework of a UNDP project. The authorities of the jamoat were invited to participate as were the authorities of Ak-say, some border guards, aqsaqals (from both sides), representatives of the press and other officials. The JRC was also present but no one from that organization was invited to take part in the round table. The meeting focused on three main issues: land division, problems relating to water resources, and pastures. Apart from the seminar, there was a football match between young Kyrgy $\mathrm{z}$ and Tajiks, the opening of a new bakery (funded by the UNDP, but the raisi jamoat of Vorukh solemnly cut the ribbon). as well as artistic performances. Nevertheless, as one person commented, "those kinds of events are organized regularly. but unfortunately they have no real impact on conflict resolution. Simall skirmishes benieen young people are not a problem: people would manage to find an agreement, but politicians have a vested interest in continuing the conflict".

174 Summary of a few conversations with different employees of the JRC conducted in 2010. 
Chapter 6. The Kolkhoz, Selsovet, Mahalla and Jamoat Resource Centre...

\title{
6.5.4. The Mahalla
}

According to three of my interlocutors, the mahallas in the oldest part of Vorukh date back several hundred years, with families living side by side for many generations. This should be an indication of strong community bonds, as well as of the high level of integration of the Vorukh communities. However, as in many other places, the mahalla as a social organisation has decayed over the last twenty years. Due to a shift in the traditional kolkhoz relationships, the gap between the rich and the poor has increased. The rich are members of the local elite well-connected within the district hukumat, and they make arbitrary decisions without considering the opinions of respectable but not wealthy members of the community. Additionally, the high level of migration and unstable border situation are both contributing factors which have led to the relaxing of social bonds. ${ }^{175}$

For my case study, I have selected a relatively new community established at the turn of the 1980s and 1990s on the border with Ak-say. I had the opportunity to live there during my research in 2010. Mahalla $\mathrm{T}$. is populated by about 2,000 people, thus, it is rather a qishloq than a traditional mahalla. Despite the fact that the community was established a short time ago, it is relatively integrated due to the strong leadership skills of its rais. He was nominated for this position by the kolkhoz director at the time, about twenty years earlier. According to his own words:

\begin{abstract}
Before I became the rais of mahalla T., I was a hooligan. I also participated in illegal fights organized by the sports clubs in Russia, in the city of Samara. The director of the Kolkhoz gave me a chance but simultaneously somehow forced me to accept the proposal of becoming the community's leader: At that time, I had participated in a brawl in Vorukh, and this was about to bring lawsuit against me. He gave me an ultimatum, "Accept the proposal or they will bring the issue to court". So, in this w'ay, I became the rais. ${ }^{176}$
\end{abstract}

At that time, the mahalla had been newly founded and consisted of families from different communities in Vorukh who were at variance with each other, mainly about access to water for irrigation. During the 20 years of his work, the rais managed to integrate the community and restore order. In 2010 , the rais also collaborated with the JRC (its employees also lived in the mahalla). Since the rais has a reputation as a good manager and organizer, he quickly learned how to work with NGOs, although he expressed concern that donor funds do not cover all the needs of the community and that they deal only with select issues, and thus their impact on local development is limited. ${ }^{177}$

In 2010, the mahalla maintained a fund for repairs, organizing events, and other similar tasks, which was administered by a few members of the community, such as

\footnotetext{
175 An excerpt from an interview' with a local teacher. August 2010.

176 Quotation from an interview with the raisi mahalla. August 2010.

177 An excerpt from an interview with the raisi mahalla. August 2010.
} 
the rais, a medical doctor, teachers, an engineer, a driver, and a mullo. Each street was also supervised by a sardori kucha (a head of the street). There were also a few women who held some influence over issues concerning the female part of the community. ${ }^{178}$

At the time my research was being conducted (2010), the mahalla was not formally registered. Two interlocutors commented that this was not necessary and that the mahalla law would be difficult to implement in Vorukh, especially since most investments at the local level are made by private people or donors. They also added that the jamoat's participation in local development was almost non-existent. The described community had already worked with NGOs and had undertaken a number of independent initiatives. ${ }^{179}$

A significant problem in this mahalla is access to water. The mahalla uses water from a channel connected to the water system of neighbouring Ak-say. Due to waterrelated conflicts, a neighbourhood water brigade was established to control equitable water distribution in line with a schedule for water users. In 2010, during the season, people were on watch to make sure that no one broke the rules. In addition, a Water Users Committee was established. However, arguments over water still took place, but the main dilemma of the community remained the immediate proximity of the Kyrgyz, who were seen as serious competitors for water and land resources. As already mentioned, this continues to create constant tension along the border. As a result, there have been a number of anti-conflict projects set up by IOs, which also launched CBOs in this mahalla; although, according to the interlocutors, they did not last very long. To date, the countless attempts to find a means of reconciling with the Kyrgyz have not brought tangible results.

Due to economic difficulties, the rais left for Russia to find work. During the last armed conflict with the Kyrgyz, he was asked by the locals to return and organize a self-defence group. The residents who live close to the border were afraid that the Kyrgyz would set fire to their houses. Thus, they began to organize patrols along the border. The rais returned from Russia to lead the self-defence group but he was asked by KGB authorities to come to the regional office located in Khujand city, where he was accused of being a provocateur inciting people to violence. Following this incident, he once again decided to migrate to Russia. ${ }^{180}$

The future of this community is uncertain and the same is true of the entire Vorukh region. It is dependent mainly on how policymakers will deal with the border disputes in the coming years. An increasing number of enclave's residents state that either one group or the other should stay in the area, showing that they are slowly losing hope for peaceful resolution of the conflict.

17x Information obtained from the rais and his associates. August 2010.

174 On the basis of interviews with two members of the community (a local teacher and local medical doctor). August 2010.

Ixt Information obtained from a resident of the community. May 2014. 


\subsection{Summary}

Due to border conflicts, the situation in Vorukh is very complex. The enclave has caught the attention of international donors, who are involved in negotiations between the Tajiks and Kyrgyz and implement a number of projects, including founding organizations such as the JRC to facilitate the jamoat.

Paradoxically, and most probably contrary to donor aspirations, while the JRC was thriving it became a counterbalance to the traditional kolkhoz-jamoat relationship in Vorukh creating a 'third power'. The JRC network became a competitor for the jamoat, which is squeezed inside an old building, while the JRC is located in a newly-built space, from which it launches its own projects and ideas. The land division initiated in 2011 has certainly changed the power-relations in Vorukh, as did establishing the offices of the Secret Service and OMON. However, the JRC's position remains strong due to the income generated by the Micro-fund, as well as the fact that international organizations perceive the JRC as a relatively independent actor suitable for cooperation.

The above-described situation also shows how the activities of an organization funded by an outside power (international donors) can affect the relationship between the community and the jamoat. In the case of the discussed mahalla, the traditional avlod/gap/gashtak principles continue to determine this relationship; although it must be noted that the JRC employees live within the community they work for, which obviously influences its level of integration with the organisation. The mahalla functions as a partner for cooperation for the local NGO, which among other things has resulted in weakening the jamoat's influence on the community's affairs. The extent to which the involvement of donors has reinforced the residents' independent initiatives remains an open question. Nevertheless, the rais of this particular community advocated issues not only pertinent to 'his people' but also to the whole of Vorukh, the jamoat and even the hukumat in Isfara, despite the fact that his actions were not welcomed by the local authorities. In addition, the above case study provides evidence that a mahalla is able to cooperate with NGOs without the formalization of its indigenous institutions, contrary to the conventional view promoted by some international donors and the state administration. 


\section{Chapter 7 \\ Working with Communities, \\ the Experiences of the Polish Center for International Aid in the Khatlon Region}

\section{I. Introduction}

The main goal of this chapter is to provide information on the underpinnings of the cooperation between external actors - such as international and local NGOs - and local communities in the context of the project implemented by the Polish Center for International Aid and the Tajik NGO Mehrangez. The chapter also discusses the role and function of mahalla committees taking into account the specific example of fifteen communities concentrated in the area around the city of Kurgan Tyube. Given my role in the project, I do not intend to evaluate its effectiveness or assess the results. This should be carried out by external experts with relevant experience and knowledge of the socio-cultural and political conditions in Tajikistan. I will only describe the origins of the project's concept and some aspects of its implementation.

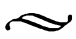

While conducting research on the relationship between self-governments and informal traditional institutions on the one hand, and international and local NGOs in Tajikistan on the other, I began to wonder whether it would be possible to put the research findings into practice, and to design a community development project for the mahalla.

In 2008, I worked as a trainer in a project which aimed to increase knowledge about global education among Polish rural leaders. ${ }^{181}$ During that period I came

Ix| The project was entitled "A Step to the South, Local Communities for Global Developınent". organized by the Institute of Rural Areas (Polish: Instytut Obszarów Wiejskich) and ETC Netherlands. 
across the idea of 'endogenous development', introduced by experts from the ETC/ Compas network. This experience dramatically influenced my overall approach to work with local communities in the context of development programmes implemented by Western organizations in developing and transitional countries. According to Haverkort, van't Hooft, Hiemstra:

Endogenous growth refers to development that is mainly. though not exclusively, based on locally available resources and the way people organize themselves. External knowledge and resources are often used to complement these local resources. Endogenous Development, therefore. does not imply isolation; nor is it limited only to local processes (...). (2003: 30)

From the moment I became acquainted with the endogenous development approach, I was very interested in introducing this idea into the development projects implemented by Polish NGOs. At the same time, I had doubts if the adoption of this concept would be possible in the context of Central Asia which had been subjected to the long-term influence of European culture and communist ideology. As far as the mahalla is concerned, despite the fact that this type of communal organization had already been targeted by development programs, I was still uncertain whether the methods and strategies invented by foreign NGOs would be accepted by local communities; and also how these communities would respond to new concepts brought in by outsiders.

While research was on-going, in July 2010 , I spent some days in the town of Hisor, located about 25 to 30 kilometres from Dushanbe. There, our team met a local female activist, about sixty years of age, living in a mahalla of a mixed urban-rural character located in the suburbs of Hisor. Originally she had come from Leninabad (now Khujand), and her father had been a high-ranking official of the Communist Party. Before the USSR collapsed, she had held the post of the head of the local selsovet; while at the time of research she was leading a women's initiative group founded by a local NGO. I was asked to use the experience I had gained while working with various NGOs and to conduct an informal workshop for her mahalla on formulating project proposals. The workshop was organized at her home. She invited ten men and women who represented the communities from two mahallas. ${ }^{182}$

The group was composed of the raisi mahalla, the communities' accountants (two people), a beekeeper, a sanitation engineer, a construction foreman, a farmer, a leaseholder, and a student (the woman's daughter). The informal workshop lasted about three to four hours during which the representatives of the mahallas identified the needs of their communities and talked about the initiatives which they had so far undertaken in order to resolve important local problems. Subsequently, I provided a short explanation of the rules of writing project proposals for external donors.

1*2 These two mahallas were only established quite recently. Fonmerly. they had constituted one community but due to the increasing number of residents (and hence - households). the local authorities had decided to create two separate units. 
Finally, we discussed how to obtain external funds for their communities. All the participants were very active and keen to find out about new opportunities; however, while conducting research, we could not offer these people much more than some basic information regarding cooperation with NGOs. Nevertheless, this informalworkshop spurred me on to think that close cooperation between NGOs and the mahalla community would be possible to launch.

Two years later, I carried out a study in the mahallas during my work as a volunteer and consultant for the project "Increasing access to potable water in the Ferghana Valley through the technical and institutional support to local Drinking Water Users Committees (Kyrgyzstan and Tajikistan)" implemented by the Polish NGO, the East European Democratic Center, in the Spitamen and Ganchi districts located within the Sughd region. During the research, I conducted a number of conversations with community members (including the former vice-rais of a kolkhoz), and the raises of mahallas on topics related to cooperation between the community and NGOs. This experience allowed me to gain a better understanding of the mechanisms behind possible cooperation between mahallas and external social actors.

In November 2012, I was invited by the Polish Center for International Aid to carry out a seminar in Tajikistan on the topic of the development of the lowest level of municipality in Poland (Polish: gmina), and to compare the Polish experience with the Tajik forms of local governance, such as the jamoats and mahallas. The participants attending the seminar were members of Tajik NGOs, including the president of the NGO Mehrangez. Following the seminar, the PCIA and the NGO Mehrangez entered into cooperation, and we submitted a project proposal entitled "Reinforcing local community development through institutional support for mahalla committees in Tajikistan". ${ }^{183}$ The proposal was based on my research and the experience of Mehrangez in work with rural communities within the framework of a long-term development project financed by the British organization "Christian Aid", as well as in other social projects.

The pilot project was implemented from March until November 2013 in the area of Kurgan Tyube (Khatlon region), in the districts Jillikul, Qumsangir and Bokhtar, and it included ten villages in total. In 2013, I was the coordinator for the project on the Polish side. In March 2014, the second edition of the project was launched, entitled "Supporting local communities in rural areas in Tajikistan", with five more communities being invited to cooperate with us. At the moment of submitting this book for publishing, I continue to work as a consultant for this project.

1x: The project is tinanced by the Polish donor - the Solidarity Fund within the framework of the "Support for Democracy" program. Ministry of Foreign Alfairs of Poland. 


\subsection{Project Outline}

The main objectives of the project are to strengthen cooperation between local communities, the local government, and international and local non-governmental organizations by providing trainings, and also to enable communities to access financial and legal support. The planned result is to make people familiar with the skills which would give them the confidence necessary to implement their own initiatives and to launch effective cooperation with external actors.

The project envisions cooperation with members of mahalla committees and other active residents of the communities. The project aims to strengthen existing structures and not to establish new forms so as to avoid further defragmentation of communities. At the same time, PCIA and NGO Mehrangez have sought to ensure that the highest amount of community residents possible will benefit from the results of the cooperation between the MCs and NGOs; for instance, the construction of a primary-care clinic within the framework of micro-projects undertaken by the MC serves the whole community or the instalment of a water pump which helps to irrigate a certain amount of land used by various farmers. We assume, however, that at some point communities will work without our assistance; therefore, our cooperation aims to provide support which would allow the social activists and village authorities to deal independently with various issues related to local development.

At the beginning of the first edition of the project (2013), ten communities were selected during a preliminary analysis. Subsequently, the communities' representatives participated in workshops concerning legal rights and the responsibilities of mahallas within the framework of the 2008 law, ${ }^{184}$ and they took part in seminars on community mobilization as well as on project planning. One person from each community attended a course on accounting for bookkeepers working in mahalla committees (MCs). The seminars were organized in such a way so as to not only present theoretical issues but also the methods of putting the acquired knowledge into practice. At the time, alongside the seminars, we conducted regular monitoring and organized meetings with community leaders to gain more knowledge regarding the individual situation of each community.

After a set of courses, seminars and workshops, all the communities prepared project proposals and received micro-funds amounting to about 3,800 USD, which accounted for up to $40 \%$ of the total budget of the community projects. As a result of the micro-projects, three communities built primary-care clinics and one such clinic was equipped, a kilometre-long rural road was levelled, one pump was replaced in the main channel, and another water pump was also exchanged at a big pumping station. One village decided to install a transformer supplying electricity, another financed a roof for their local primary school, and one village bought a car for deliver-

184 The Law "On Public Self-Initiative Bodies" (Russian: Zakon ob Organakh Obshchestvennoi Samodeiarelnos(i) is discussed in detail in Chapter 3. 
ing water. Most of the work was voluntary (based on hashar) and included financial contributions from the communities (PCIA 2014).

Five new communities were invited to participate in the second edition of the project (2014). They followed a similar work model as had been designed in 2013 . The old communities were further reinforced during trainings on communication and effective dialogue with governmental bodies. The women activists in these villages were supported through seminars on health and hygiene. In addition, a one-day meeting with all communities and potential donor organizations was organized. Two of the new communities decided to build primary-care clinics, while one village repaired a water pump, another levelled a road, and - finally - a school canteen was also built thanks to the efforts of one village MC.

It should be noted that infrastructural projects, such as building primary-care clinics or other facilities for the villages, were not the goal of the project. The financial aid was only expected to introduce incentive supporting social participation. Hence, each community made an independent decision regarding a problem to be solved within the framework of a micro-project. The PCIA and NGO Mehrangez only fulfilled advisory roles during the writing of the project proposals by the representatives of the communities.

According to the rules of endogenous development, the staff of the PCIA and NGO Mehrangez work in the field, on a daily basis, regularly visiting the communities and gathering data, including ethnographic information. All Polish employees have the relevant education and experience of having worked in Tajikistan and the CIS region, as well as possessing a sound knowledge of the Russian language, while some of them also speak the Tajik/Farsi languages. While implementing the project, a lot of attention is given to identifying the communities' needs and to preparing evaluations, conducted by both the Polish researchers (cultural anthropologists, experts on the Former Soviet Union) and the Tajik experts. The PCIA and the NGO Mehrangez are planning a continuation of the project with the participation of the same fourteen communities. ${ }^{185}$

Due to the experimental character of this project, various challenges emerged for the PCIA during its implementation. First of all, especially at the first stage of cooperation with its local partner, the NGO Mehrangez, both parties differed to some extent in how they understood the project's objectives and strategies.

The NGO Mehrangez is a partner with extensive experience in the area of project implementation; however, until recently, the organization worked mainly with Western donors with approaches which differ from the methods of work of a small Polish organization with a limited budget. The mentioned donors mostly delegated tasks to Mehrangez, which functioned as the main organization implementing the projects. The PCIA has always been present throughout the whole duration of a particular project, attempting to be very close to the local population. Thus, initially this type

Ix: One community was excluded from the third edition of the project due to various problems related to communication with the authorities of the MC. 
of coordination and the methods used evoked surprise, both on the part of Mehrangez as well as our beneficiaries. They were accustomed to short-term monitoring undertaken by the representatives of foreign organizations, except for cases in which permanent project consultants were present.

Other issues involved the difficulties in establishing collaboration with the local authorities or the rotation of people due to migration (as described below in detail). Lastly, the PCIA put a vast amount of effort into overcoming the existing stereotypes regarding the work of international organizations, including claims that they mainly provide short-term assistance and that they do not often cooperate with communities directly or observe the whole process and implementation of project activities.

\subsection{A Short Overview of the Area of Project Implementation}

The Khatlon region was formed in 1992 by connecting two regions, Kuliab and Kurgan Tyube (which is also the name of the capital of the Khatlon region and the centre of the Vakhsh Valley). In the 1930s and 1940s, the Vakhsh Valley was targeted for the construction of an irrigation system in order to increase the area under cotton cultivation (Russian: Vakhshstroi). Between 1931 and 1938, a huge irrigation system was constructed which eventually covered an area of 130 thousand hectares. Many thousands of people were brought to the Vakhsh Valley to be settled in the newly established collective farms. About 90 per cent of the population of 'new Vakhsh' came from different parts of the Soviet Union, creating a diverse ethnic mosaic of Russians, Belarusians, Ukrainians, Germans, Armenians, Tatars, Tajiks, Uzbeks, Kazakhs, Kyrgyz, and many other ethnic groups. A majority of the people were relocated by force, though others came to the new areas encouraged by promises of the improvement of living standards. By the 1960s, the Vakhsh Valley was a welldeveloped area with an adequate network of social services and good economic conditions (Sarsembekov et al. 2004; Kholdzhuraev 2003: 55-56; Gomart 2003: 87). ${ }^{186}$

In the aftermath of the collapse of the Soviet Union, during the civil war in Tajikistan (1992-1997), the ethnic diversity of this region became one of the main incentives behind severe fighting among different groups of society. Until 1993, the region was the hub of the Tajik opposition represented mainly by the Gharmis and Pamiris of Kurgan Tyube, who were later driven out by the Kuliabis and the National Front. The Vakhsh Valley faced some of the bloodiest warfare during the civil war in Tajikistan. People who due to their ethnicity were associated with the

1*6 The construction of the irrigation sy'stem in the Vakhsh Valley was described in a book written in 1933 by Bruno Jasieński , a Polish communist of Jewish origin, "Man Changes His Skin" (Russian: Chelovek meniaet kozhu. Polish: Czlowiek zmienia skórę). In 1979, a TV series entitled 'Man Changes Skin' was made by the film director Boris Kamiagarov. 
political opposition fled to Afghanistan and other places. People of European origin and others also escaped to save their lives. The region was plunged into chaos and poverty; a large number of houses, agricultural households and infrastructure were completely destroyed. The main threat for civilians were the police (militia) and armed gangs committing crimes, such as rape, looting, mass murders and other wrongdoings, which left deep scars in the collective consciousness of the people (Gomart 2003: 87; Akiner 2001: 23; information gathered in the field).

Subsequently, various international organizations started operating in the region, providing humanitarian assistance to the local population, but a considerable amount of aid was redistributed informally through networks of people for whom it was accessible. The villages and mahallas organized self-defence groups; thus, the humanitarian aid was also distributed by jamoats and community leaders.

When refugees began to retum, most humanitarian assistance was provided for the restoration of houses and to cover people's basic needs. Following stabilization, the region became the target of development assistance. Nevertheless, until the present day, a number of people continue to associate the activities of international organizations primarily with humanitarian aid, and it is very difficult to overcome existing stereotypes. The residents of some settlements became accustomed to receiving different sorts of goods; thus, they continue to wait for supplies of flour, sugar and other products, understanding the role of NGOs as aid providers, simultaneously positioning themselves as passive aid recipients. ${ }^{187}$ Despite signs of improvement, the communities are polarized and the hidden and informal division into the former opposition and those who supported the government is still perceptible. ${ }^{188}$

Despite post-war reconstruction, the destruction of infrastructure (including the water irrigation system), the decay of education and health care systems, as well as persistent unemployment have led to a sharp lowering of living standards. Consequently, many people have migrated to Russia or other countries in search of economic opportunities. Analogically as in other parts of Tajikistan, despite intensification of control over the society, the state has almost ceased to participate in local development. Moreover, the endemic corruption and inadequate law enforcement mechanisms have contributed to the deterioration of public services.

187 Information based on lieldwork conducted in 2013 and 2014.

Ixn Two years of work in the Kurgan Tyube region have convinced me that most people affected by the war due to their ethnic affiliation were normal poor people who were not interested in politics. Hence, the distinction between the 'former opposition' and 'pro-governmental people is in many cases purely artificial. 


\subsection{Cooperation with Communities in the Districts: Bokhtar,}

jillikul and Qumsangir

All the villages invited to cooperate within the project had been established in the Soviet period. The residents of the villages had been resettled to the Kurgan Tyube region from areas such as Gozimalik, Rasht Valley, Dangara, Kuliab, Nurek and Faizabad. Uzbeks and Tajiks from Ferghana Valley and Zaravshan Valley had been relocated because of their experience in agriculture, as were Tatars and some Europeans. In addition, we cooperate with the indigenous inhabitants of this area, such as the tribal Uzbeks, mostly Kungrats, a few Lakai and Durman families, and Turkmens. Before the Red Revolution, they had led a nomadic/semi-nomadic lifestyle. At present, some Kungrats live in separate settlements, others together with the Tajik communities.

The residents of the villages can be classified as belonging to two groups: 1) homogeneous communities, such as the Gharmis or Kungrats, and 2) settlements composed of various ethno-regional groups. The mono-ethnic communities or those with the substantial predominance of one group are usually better integrated. This factor further influences their relationships with outsiders, such as for instance with NGOs. This can have positive or negative implications - depending on the circumstances and the willingness of a community to interact with others.

Most of the residents of these communities are involved in agriculture. The majority of the families also have presidential land apart from their own small plots. Some families have established family farms. One village in the Jillikul district remains a part of a collective farm which produces cotton. In other places, there are also families who have small shares of land in big farms. In addition to agriculture, Kungrats are involved in animal husbandry. A large number of families depend on remittances sent by migrant workers. A small number of people work in schools, hospitals, and other public institutions or services, but their income is usually not high enough to cover even their most basic needs.

In places such as the Vakhsh Valley, where most communities arrived during the industrial boom, the mahalla as a social organization was preserved only partially (among traditionally sedentary populations), and it was mainly exercised according to traditional practices and Islam. In places where the homogenous group/mahallas settled together, the traditional institutions often merged with formal institutions; for instance: one kinship group or one mahalla could work together as one brigade within the kolkhoz (see Chapters 1, 2 and 6). Notwithstanding, the kolkhoz organized people's entire lives at the social and economic level.

As previously mentioned, during the war some communities strengthened their structures so as to defend their members from the ravages of the conflict, but others were completely disintegrated. Previous ethnic and regional divisions rose to the surface. Subsequently, each group fought for the best access to resources using all available means. Alongside the typical consequences of war, one of the most impor- 
tant factors that influenced the further relaxing of social ties was the disintegration of the collective farm system which contributed to the collapse of the infrastructure.

Decentralization and unequal distribution of wealth (including land resources) led to polarization of the society. The changes have deepened the differences between the rich and the poor. The former have gained access to privileged positions. This has impacted the integration of people at each social level, such as the avlod/ qishloq/mahalla, jamoat, and the like.

The project activities have been carried out in qishloqs with very diverse sociocultural patterns. Thus, the communities have reacted in different ways to various forms of cooperation with the NGOs as well as to the implementation mechanisms and to the knowledge conveyed during the seminars and workshops.

\subsection{Bokhtar District}

In Bokhtar, the PCIA and Mehrangez cooperated with three communities. Two of them - village F. and village $H$. - were invited to participate in the project in 2013, while settlement $Z$. joined us in 2014 .

Village F. is inhabited by different ethnic groups with a Tajik majority from Faizbad, but also some Kuliabis and Gharmis. Despite its ethnic diversity, the residents of mahalla F. are well integrated and they can also be characterised as religious and traditional. According to the raisi mahalla, even during Soviet times, there were two informal mosques functioning within the chaykhonas. At present, the village has three mosques, including the Friday mosque which also serves as a place for $\mathrm{MC}$ meetings. Each regional group attends its own mosque. During the war, due to ethnic differences, the various groups were in conflict with each other. The Gharmis fled to Afghanistan, but most of them returned. "Slowly. people have begun to live together once again," the rais said.

The MC is a relatively new idea, and its structures are not firmly established. All committee members are comprised of the 'elderly of the village'. These well-respected men are the main decision-makers alongside the raisi mahalla, who used to be the kolkhoz's engineer and a member of the Communist Party. In the religious and traditional mahalla $\mathrm{F}$., the members of the MC are exclusively men. Despite their age, however, they quickly absorbed the knowledge conveyed within the framework of the project, and properly organized all project activities, including money collection and hashar for the primary-care clinic built on a plot given from land belonging to the conciliar mosque.

Village $\mathrm{H}$. is inhabited by Tajiks, originally from Dangara and Nurek. Similarly to mahalla F., before the project started the MC had not been firmly established. However, the authority of the raisi mahalla is based on traditional institutions according to which the community is organized. The presence of the NGO encouraged social participation and the integration of the mahalla's activists around a common goal - building a primary-care clinic. Funds for the initiative were collected by the 
MC from the qishloq's residents. A significant part was donated by the owner of a large farm (a local businessman, a resident of the mahalla).

Mahalla Z. was established in the centre of a former collective farm located not far from the district centre. It is more like a settlement (Russian: posiolok-gorodskogo tipa) than a village. It also has relatively well-developed infrastructure: a high school, a large sports hall, and other facilities. Before the war, many ethnic groups lived here side by side, such as Tajiks from Faizabad, Badakhshan, Dangara, Leninabad, Samarkand, Bukhara, and other places in the Ferghana and Zarafshan Valleys; also Uzbeks, Kungrats, Lokai, Katagans, Toz (indigenous inhabitants of this area; before the October Revolution, Toz were engaged in gold mining and goldsmithery); as well as Tatars, Ossetians, Chechens, other Caucasians, Germans, Ukrainians, Russians, and others. Thus, it was a very diverse community which had fully adapted the Soviet model of development together with a specific model of Soviet multiculturalism. During the war, Europeans, Caucasians and Tartars emigrated with only a few people from among these groups remaining. The majority of the Tajiks supported the National Front and the governmental side, while a small percentage of the population joined the opposition. As in the whole region of Kurgan Tyube, also here a self-defence group was organized.

Due to the ethnic diversity and strong influence of the Soviet model, traditional institutions have remained marginalized; therefore, the mahalla has not developed strong roots in the area. The MC has huge intellectual potential with the majority of its members being teachers or other representatives of local intelligentsia. Nevertheless, in spite of the fact that they came to us with a request to participate in the project, cooperation with this MC brought with it many challenges. The MC consists of members of the local elite who have a good relationship with the administration, but they are not connected with their own community. They neither understood the principles of cooperation nor had the ability to consolidate the people around a common goal. The MC was imposed by the jamoat, but at the same time, the local administration failed to reinforce its structures. As a result, without the indigenous mechanisms of self-regulation and the traditional institutions on which the MC could be based (such as the elderly and the mosque in mahallas $\mathrm{F}$. and $\mathrm{H}$.), the $\mathrm{MC}$ of $\mathrm{Z}$. is a façade body with weak operational capacities.

\subsubsection{Jillikul District}

The Jillikul area is the poorest of the districts in which the project has been implemented. The PCIA and NGO Mehrangez have worked in five settlements in this area. The most acute problem in Jillikul is the decaying irrigation system which is the reason behind a vast part of the land having being turned into a semi-desert. In the USSR, the irrigation system was managed centrally. At the level of the region (Russian: oblast), the water network was coordinated by the regional Water Management Bureau (Russian: Oblastnoie Upravleniie Melioracyi i Vodnykh Resursov), 
in turn the district level infrastructure, including big channels, was supervised by the district Water Management Bureau (Russian: Raionnoe upravleniie melioracii $i$ vodnykh resursov). The collective farm authorities controlled the water system located within the territories of the farms. Despite the well-organized water management, the irrigation systems were in poor condition, which further deteriorated after Tajikistan became independent. Following the land reform, the water system was decentralized. The infrastructure of the main irrigation channels remains supervised by the state but funds for its maintenance are scarce. Irrigation networks previously belonging to collective farms (including equipment) were redistributed to different landholders who are responsible only for the part of the water network located on their plot of land. Frequently farmers have different needs and priorities. Water theft from irrigation channels is also widespread, which creates tension among the people. In order to re-organize the water management system, water-user associations have begun to be formed, but they do not operate properly yet, often being unable to handle the disputes or to maintain the infrastructure. Moreover, as drainage systems deteriorated, a part of the land became salinized due to extensive irrigation and several decades of using chemical fertilizers, especially in the cotton fields (see Cieślewska and Makowska 2013).

In Jillikul, a number of farmers decided to give back plots of land to the state, as they could not afford to repair the water network and simultaneously did not want to pay taxes for the lands they were not using. Consequently, people are often forced to abandon cultivation. Some have turned to animal husbandry; others have migrated or become day labourers, alternatively they work in the local bazaars. The growing phenomenon of ecological migration can be observed in Jillikul, as in the case of village A., where some empty houses have slowly fallen into disrepair, merging with the semi-desert landscape. There are no reliable statistics but many families or even settlements have moved to other places. ${ }^{189}$

In many places in Tajikistan, water is delivered through electric pump systems. The frequent shortage of energy supply during the winter season results in poor accessibility to water, which is often obtained from melting snow or rainwater. In the hot summers with scarcely any rainfall, some villages are deprived of direct access to water sources. For instance, in village A. water is delivered from the channel which is located three kilometres from the village. People transport big cans of water on donkeys or two-wheeled carts called arba. In 2013, as part of our project, the community purchased a large truck with a tank to deliver water (Russian: vodo$-w o z$ ). Since then, these types of vehicles have also been bought by other residents, thus the situation has improved slightly. Village D. has also faced difficulties in water supplies since the system of pumps collapsed a few years ago. During our project in 2013 , the community decided to repair the damaged pump, which can now irrigate twenty hectares of land. However, due to difficulties in payments for electricity, the pump operates at intervals. Reparation of the whole water system in Jillikul requires

Ixy Information gathered during project implementation. 
a systemic solution and significant financial and technical support, which cannot be realized within a small community-based project.

Villages A. and D. are mostly inhabited by Kungrats (with a few Tajiks in village A.), and as has been explained in Chapter 3, the very idea of an MC is a new phenomenon for people. An important factor which determines the implementation of new institutions in Kungrat communities is the low level of trust toward outsiders, including state representatives and NGOs. Due to the cultural and linguistic differences from the Tajiks, many Kungrats feel neither a part of the Tajik nation nor do they have any confidence in the Tajik state structure. Despite the seventy years of Soviet intervention, as well as over twenty years of interaction with the Tajik administration, they still regulate community matters within their own traditional institutions and have lived in relative isolation from the external world. Our experience over the two years of project implementation shows that a significant number of Kungrats do not speak the Tajik language, since many of them intermingle only with members of their own ethnic group.

The Kungrats were the largest Uzbek tribe of the Eastern Bukhara (after the Mangits). They are divided into five larger tribal organizations and many smaller groups. Presumably, the Kungrats arrived in Central Asia with Genghis Khan. At the beginning of the $20^{\text {th }}$ century, their main settlement area encompassed a large region located between Guzar and Termez, including the western part of Babatagski Pass. Before the Red Revolution, some Kungrats had also been settled on the territory of the Eastern Bukhara, including the Kurgan Tyube duchy. During the October Revolution, a few groups moved to Afghanistan, others remained on the territory of contemporary Tajikistan. After the Revolution, during the period of the reconstruction of the Vakhsh irrigation system, they settled in the Jillikul, Kobadian, Shartuz, Vakhsh and Kolkhozabad (currently Jalalladin Rumi) districts (see Karmysheva 1976; Abdunazarov et al. 2014: 158-166).

According to my informants, the Kungrats of village D. and village A. belong to the Oyinli (Oyinna) subgroup, which is further divided into twelve kinship groups. ${ }^{190}$ The Kungrats of village D. are members of the Beshbolo kinship group, which resettled to Vaksh from the territory of present-day Uzbekistan at the end of the $19^{\text {th }}$ century. In the late 1960s, they were moved to the Jillikul district, to work in the kolkhoz. Altogether twelve ayils were located in village D. (120 small families). At present, about 540 small families live there, still organized according to the traditional ayil system. Another six Beshbolo ayils, which had come to Jillikul in the same period, were settled in the neighbouring area. At the beginning, all relocated Kungrats were headed by one leader, while with time they split into two groups. The Beshbolo from village $\mathrm{D}$. is divided into twelve qawms (altogether 3,000 people). Every ayil is populated by one qawm (with a few newcomers). The qawms are organized ac-

190 Oyinli -.. Mullo Murod Avloddari, 12 ota divided into Qovqa. Churoq. Beshbola. Qachay: Oqtana. Qora. Turkman. K'hozhabachcha, Tupqara, Oytamghali. Tulpor (Abdunazarov et al. 2014: 160; some information added). 
cording to a certain hierarchy; the head of the most important ayil is also the raisi mahalla (formally registered in jamoat), while the mahalla committee is composed of members of all twelve ayils. ${ }^{191}$

As mentioned before, the MC is only a nominal state body. Customarily, each qawm is headed by an aqsaqal who is responsible for all qawm affairs. Analogically as in other traditional tribal systems in Central Asia, ayils have a high degree of autonomy. Joint decisions of all the qawms (the whole village) are taken only in particular cases, with the consensus of all the ayils. Every qawm attempts to protect the interests of its members; thus, not infrequently qawms have contradictory goals and tension among them erupts easily. Nevertheless, disagreements rarely go outside the community as they are addressed through mediation between the involved parties.

In village D., the most numerous and influential of the qawms is qawm Bek. Thus, its members are also dominant in various formal structures, such as the MC which is associated with the jamoat. In this way, the group has access to various resources (including development aid). The MC of village $\mathrm{D}$. also includes members of other qawm; however, since the committee has little recognition in the eyes of its residents and is dominated by one group, others are less interested in its development. Notwithstanding, during project implementation, the representatives of other qawms also participated in our activities, but they were outnumbered by Beks. For instance, one of the most committed participants was a forty-year-old schoolteacher who is also a local bakhshy, ${ }^{192}$ a tribal performer of the epic Gurguli. He belongs to another qawm and is a member of the MC. As a performer of the national epic, the bakhshy enjoys high social esteem; he also willingly becomes involved in various matters related to his community. In my opinion, the bakhshy's involvement in our project contributed to it gaining recognition among other community members.

It should also be mentioned that villages inhabited by traditionally tribal or semitribal populations are organized differently than Tajik villages. The latter are usually densely populated, with households very closely adjacent to each other, situated along streets and small lanes. The settlements of Uzbek tribal populations are spread across large areas. All houses are built at a certain distance from one other. Families living in the same ayil are concentrated in defined territories, but never as close to each other as Tajik households.

141 As mentioned, however, in the case of the Kungrats, it is difficult to find out who the members of the MC are, since even the jamoat administration does not have a list with the names of the MC members.

142 In the Uzbek. Turkmen and Karakalpak languages, the term bakhshy (as well as its other phonetic variants) means an oral epic performer, or as in the case of the Karakalpaks, a particular kind of singer. The Kyrgyz and Kazakhs associate the bakhshy only with shamans or healers. In the past. the Uzbek bakhshy could sometimes also play the role of a shaman. Currently. people who perform epics still enjoy a high social status, resulting from the fact that they possess a particular gift which allows them to perform the epic which is an important component of national/ethnic identity (see Reichl 2008). 
Village $O$. is another place where the project has been implemented since 2013. The settlement is poor and populated by different ethnic groups with the predominance of Kungrats, but also Tajiks, Lakais, a few Durmans and one Uzbek family from Ferghana Valley. At the beginning of our project, the members of the community were not well consolidated. People did not trust each other and in practice the MC functioned only formally. In addition, the high number of men working in Russia (according to our rough estimation - about 80 per cent) also influenced the overall organization of the village's affairs.

In spite of the small amount of men available who could contribute their work to the community, there are a few committed women informally led by Mavluda, a middle-aged woman and owner of the village shop. All workshops and seminars were organized in her home with the participation of about ten to twelve female activists, mostly local teachers and farmers. The raisi mahalla did not attend any of the seminars due to the gender division rules in place (only women were present). The community decided to build a primary-care facility, and submitted a project proposal which was later accepted by the PCIA and NGO Mehrangez.

Problems started only during the implementation of the community project, and stemmed from the low level of money collection. Moreover, due to the small number of men in the village during the summer season, the community was forced to hire paid workers, which generated additional expenses. At this stage, the rais of the MC became involved in the project and Mavluda supported him. Finally, with the participation of the local mullo (see Chapter 3), money was collected from the residents and the construction of the primary-care clinic was finalized. An important role in the social mobilization was also played by a local jamoat employee (a member of the community); his involvement was favourable for the legitimization of the initiative. Nevertheless, after erecting the building, the further process of its completion was long, due to the scarce funds of the community and inertia of the local authorities. Finally, the primary-care clinic was opened in June 2014. Due to the delay, many people did not believe that it would actually be made available to the community.

The people began to trust us as they saw the results of our work. Before, a lot of people thought, "Akaily3 Nusrullo (the rais) will take money from us and he will use it for his own benefit" or "Apai Mansura will cheat us." There was a lot of talk of this kind, but we did not pay attention to it. But at present, they trust us and they are all grateful! !'-1

In the case of the primary-care clinics implemented during the projects at different locations, at the stage of planning the project proposal by the mahallas, the PCIA and NGO Mehrangez visited the relevant authorities to be certain that they would

19j Aka Ako: Apa (English: older brother or sister, respectively'). In the Tajik language, it is also used to show respect in relation to work colleagues, as well as people encountered in the street or in a daily life situation.

14t On the basis of a conversation with the raisi mahalla during project monitoring. June 2014. 
take responsibility for the facilities after their completion. Consequently, the second stage of the mini-initiative - to equip the primary-care clinic and to make it available for the residents - was expected to be the joint action of the community and the main hospital of the district, without the financial participation of the PCIA and Mehrangez. In practice, however, most of the equipment was delivered by the community with little contribution from the authorities. In most cases, they only provided employment for the medical staff. For this reason, conditions in the primary-care clinics vary noticeably depending on the financial capabilities of a particular village as well as the relationships with local authorities.

In rural areas in Tajikistan, lack of basic access to medical care is a common phenomenon. Even in the villages which are located not far from the district centres, primary-care clinics play an important role in providing first aid services. Not infrequently, for the poor villagers even a trip to the hospital - which is a few kilometres away - is problematic, especially during the winter season. Unfortunately, many of the primary-care clinics built during the Soviet Union have been abandoned. Those which continue to function need renovation. New medical facilities are usually opened within the scope of projects financed by international donors. A community sometimes collects money and builds a primary-care clinic independently.

Village $\mathrm{O}$. is the only place among all the communities where we have worked with a majority of woman. This case could represent a valuable contribution to the discussion on how gender roles and identities have been affected by the migration of the male part of the population, which among other things has resulted in the increased involvement of women in public life.

In this particular community, the migration of men has provided stimulus for increased female activity. The presence of organizations (the PCIA and the NGO Mehrangez) was an additional factor which contributed to women's mobilization, since the trainings and small grants have created new opportunities for them. Paradoxically, an element that contributed to the intensification of women's participation in our project was the lack of strong MC structures, which could have resulted not only from a high level of male migration but also the ethnic diversity of this particular community. Consequently, there is a low level of mutual trust among the ethnic groups and avlods. Mavluda, owing to her authority and organizational skills, managed to integrate a group of women willing to cooperate within the project. It should also be noted that her involvement in building the primary-care clinic and seminar organization strengthened her position in the village. Not long ago, Mavluda was elected for the position of the deputy of the rais of MC.

The above-described situation has stimulated women's involvement in community affairs, while showing the dynamics of social changes resulting from the migration of the male population and the weak MC structures. The withdrawal of male authorities has created space for a group of women to cooperate with external actors (NGOs). However, during fund collection and the construction of the primary-care clinic, the women's esteem within the community was insufficient to mobilize the community. In this case, a significant role was played by male leaders, such as the mullo, the rais of the village and an employee of the jamoat. 
Needless to say, the absence of men has had a considerable impact on changing the social relationships in Tajikistan. Women are increasingly involved in public life, undertaking tasks and occupying positions traditionally reserved only for men. Undoubtedly, the recent changes have created new opportunities for them but also many challenges. The current situation requires a more flexible approach to gender relations, but the mental transformation is gradual. Women continue to have less power than men in terms of decision-making within the communities. To a certain extent, this stems from the fact that the traditional division into male and female spaces has ascribed a limited role for women in public life, but also they are often less educated than men and have less experience in managing community affairs. Even so, more and more women are becoming involved in community affairs, especially in matters related to health, water and the education of children.

In Jillikul, the PCIA and NGO Mehrangez implemented their project in mahalla $\mathrm{N}$. This is a newly-invited mahalla with which cooperation began in 2014. Mostly Tajiks from the Gozimalik district located not far from Dushanbe live in the area; they came to Jillikul in 1956. Other inhabitants - such as the Durmans and Lakais (approx. 35 families) - are its original residents. To this day, mahalla N. remains part of the collective farms which replaced the kolkhoz named after Eshbek Sotorov, who was an Uzbek Gieroi truda (English: a hero of work), as well as a respected kolkhoz director. The farm is involved in cotton cultivation and cotton seed production. The farm also focuses on processing plant seeds. The farm is supported by a company which is also its main investor (Rusti Chatlon), supplying the necessary technical equipment and buying cotton from the farmers. The mahalla consists of five brigades; the representatives of each of them are members of the committee. The raisi mahalla and other MC members actively participated in all project activities. The community decided to build a primary-care clinic, which was completed in the record time of forty-two days and has operated since September 2014. The fact that the land was not divided could have played a vital role in terms of community integration, which was present within the former kolkhoz structures even after they were merged with the traditional mahalla order.

Village $\mathrm{K}$. has participated in the project from the beginning of our activities in Jillikul in 2013. The village is populated by Tajiks and a few Kungrat families. The community levelled a one-kilometre-long rural road as their initiative within our project. ${ }^{195}$ Mahalla Sh. is a community invited to cooperate within our project only in 2014. The mahalla is populated by a majority of Tajiks from the Gozimalik district, but also Gharmis, Lakais and some Kungrats. The residents decided to build a primary-care clinic within the scope of their project; however, the local jamoat authorities did not want to issue a permit for a plot of land for the construction. It should be indicated that the local administration did not show any initiative in solving the problem of lack of access to basic medical care. Finally, the land was provided by one of the MC members from his own house plot.

195 The MSDSP has also operated in this village since February 2014. 
The example of the diverse communities from the Jillikul district shows the importance of an individual approach to each of them while implementing development programs. Regardless of the project methodology, the PCIA and NGO Mehrangez had to use a variety of strategies to work out the relevant mechanisms for cooperation with each community.

\subsubsection{Qumsangir District}

In Qumsangir, the PCIA and NGO Mehrangez have cooperated with six communities. The relatively prosperous Qumsangir district is populated by different ethnic and regional groups. The four mahallas that have cooperated with us since 2013 are inhabited mainly by Tajiks from the Gharm region and a few representatives of other groups. The new villages invited to the project in 2014 are inhabited by Gharmis; Tajiks from Kuliab, Hisor, the former Leninabad, Faizabad and Nurek; Uzbeks from Ferghana Valley; a small number of Kungrats, as well as Turkmens. During the war, all the Gharmis fled to Afghanistan and returned only after the end of hostilities to the ruins of their homes. The area was targeted for extensive humanitarian assistance, facilitating the transition to post-war reconstruction and development.

Until this day, international organizations operate in the area. The results of their work are visible in many places in the form of new facilities and infrastructure. Despite the intensive warfare which took place in this area, the vestiges of war are barely noticeable and most of the houses have been rebuilt. The Gharmi villages look comfortable and orderly, with the homes located along streets, and clean aryks and delightful flowers in the gardens; therefore, the settlements make a very good impression. The Gharmi communities live according to the rules set out by Islam and Tajik traditions. An important role in the communities is played by religious leaders, with whom we worked closely at every stage of the project.

The fact that the Gharmis belonged to the opposition during the war resulted in the extensive control of local authorities, which remains observable until this day. Special attention is paid to the mosques and religious leaders. In Chapter 4, I described the case of village $\mathrm{H}$., where until recently the post of the raisi mahalla was held by a person who worked in the district hukumat, but real power belonged to the mullo and the village elders. Gharmi communities are ruled in accordance to their own principles. They are hermetic, and for obvious reasons, they do not trust the authorities. They prefer to resolve their problems using their own means and methods. The strong traditional structures contribute to the consolidation and organization of their mahallas. This fact was beneficial for our mutual cooperation within the project.

Apart from mahalla B., the members of the MC in the Gharmi communities are exclusively men; women traditionally do not perform public functions. Within the framework of the project, we have also organized modules regarding the improvement of knowledge on hygiene and childcare for women. In the first stage, with the help of local leaders, we selected energetic and committed women who were invited 
to participate in the trainings. Subsequently, they were expected to pass all the information on to young women with children. Initially, in the two Gharmi mahallas, work with the female activists was difficult; also the organization of the seminars for women during the second stage of the project did not bring the desired results. Despite the previous declarations from the mahalla authorities, some families were reluctant to give permission to women to attend the seminars.

Fortunately for our further cooperation, in mahalla Q., a local teacher - Ghuzal (a Ferghana Uzbek by origin), who also performs the role of bibi otun - became the women's leader within the project. Until recently Ghuzal had taught the basic principles of Islam to women and children, but now she says that it is forbidden by the government which has tightened control over religious figures. She conducts religious rites primarily among the Uzbek minority, only sometimes visiting Tajiks. Besides her religious activities, she performs some forms of healing, as well as lifting spells. Some orthodox mullos consider the rituals that she performs as being at odds with mainstream Islamic teaching; therefore, her position as a religious figure is debatable. Nevertheless, Ghuzal enjoys respect and popularity among the village women, and our cooperation with her brought positive outcomes. Together, we arrived at a strategy of working with women which should be done through the male religious leaders and the mosque, so as to persuade men to give permission to their female relatives to participate in the seminars.

One of the most active communities in the project is mahalla B., inhabited mostly by Gharmis but also some Uzbeks from Ferghana Valley and a couple of elderly Russians. In 2013, the community started the construction of a primary school building. The hukumat gave a plot of land but did not provide the financial resources, which ultimately the mahalla had to collect from the residents. Each of the ninety-five households donated two hundred bricks and one hundred Tajik somoni (about 20 USD). All construction works were carried out voluntarily by locals. According to some mahalla activists, our presence in the village gave them motivation to make the decision; previously people had thought that such a huge enterprise was beyond their capacity. Since opportunities in the form of trainings and a micro-grant became available, the residents decided to start the construction of the school building. From funds obtained within the framework of our project, they financed part of the roof. Finally, the hukumat also contributed by providing some elements, such as windows, doors, and so forth. The opening of the school is planned to take place in September $2015^{196}$.

In the other three Gharmi mahallas, the communities undertook the following initiatives: mahalla $\mathrm{Q}$. installed a transformer and poles to provide electricity to seventy houses in 2013, while mahalla $\mathrm{H}$. equipped a medical point, also in 2013. Shortly before we arrived at the village, the community had erected a primary-care clinic building using their own funds. All the work and money collected had been

146 The opening of the school is delayed due to a lack of equipment which should be provided by the local authorities. 
organized by the local mosque, while a large part of the financial resources had been provided by migrants and local businessmen, but all the money had been spent on constructing the building, with nothing left for the necessary equipment. Thus, again the presence of a donor (in this case the PCIA and NGO Mehrangez) was positive incentive to finish the initiative. This primary-care clinic holds the opinion of being the best facility in the whole district. The other Gharmi mahalla M., with which we have cooperated since 2013, decided to purchase and exchange a pump at one of the water pumping stations.

In 2014, in Qumsangir district, the PCIA and Mehrangez invited two more villages to cooperate in the project. Qishloq J. is populated by Gharmis, Kuliabis, Tajiks from Hisor, and migrants from the former Leninabad. The mahalla was separated out from a large village, and was registered only in 2014. Thus, it is a new community which needs some incentive for integration. Within the micro-project, the residents decided to repair a water pump. Mahalla T. is made up mostly of Tajiks from Faizabad, also some Kungrats and Turkmen. Prior to the war, the settlement was inhabited by Kungrats, but most of them fled to Uzbekistan during the hostilities and did not return. Tajiks took over their houses; therefore, it is also a new community. At the beginning of the project, a middle-aged man occupied the post of raisi mahalla. In the former kolkhoz, he had played the role of foreman (Russian: brigadier); ${ }^{197}$ he is also the son of the man who 'founded the village' in 1992. While the project was in progress, the community decided to change the rais for one who has been an agronomist and who enjoys respect due to his organizational skills and willingness to work for the community. For the last few years, he has also cooperated with Mehrangez, thus he possesses relevant work experience. Within the micro-project, the mahalla constructed a one-and-a-half-kilometre-long fragment of a road.

Cooperation with traditional communities such as the Gharmi qishloqs requires a high degree of flexibility and knowledge of local conditions from 'Western' organizations. Working with indigenous institutions is a prerequisite for implementing community-based projects. Sometimes, however, these institutions uphold certain social norms which are contrary to the system of values accepted by international organizations (i.e. gender exclusion). In this case, a compromise should be found in order to establish sufficient cooperation between the NGO and a given community. As the case of the Gharmis shows, this can be achieved also through close work with local leaders.

147 A brigadier was a person who was responsible for all works within a certain part of the $k \mathrm{kl}$ khoz land (Russian: uchastek). Brigadiers often enjoyed respect and popularity, and in some cases they also performed traditional practices, such as organizing rituals and ceremonies. mediation, and so forth. Thus, the role of brigadier in the Tajik community was frequently inerged with the traditional tasks of the raisi mahalla. 


\subsection{Summary}

The research and experience gleaned from two years of project implementation show the need for a flexible and context-specific approach towards the issue of cooperation with communities.

Needless to say, encouraging local development through launching the communities' independent activities is a positive phenomenon. As mentioned a number of times, since the participation of the Tajik state in local development is minor, the local communities are burdened with responsibilities which often exceed their capacities. The village can undertake various tasks, even as complicated as building a school, but without external support people will not be able to maintain it. In addition, most villages will not take on the difficulties connected to carrying out more complex investments, as for instance the reconstruction of the entire irrigation system. This should be managed by the state and funded from the state budget.

During Soviet times, all public services were guaranteed by the state; in rural areas, the kolkhoz was responsible for taking care of most state tasks. The collective farm authorities decided about repairs of the infrastructure or new investments. Under the current circumstances, the situation is reversed; the state has not only withdrawn from local development but frequently the authorities are not interested in cooperation with communities (as has been shown on the example of the village which unsuccessfully applied to the jamoat for a plot of land to build a primarycare clinic). Consequently, the communities have been forced to adjust to the new conditions, receiving only a little support from the outside. Frequently people do not understand the mechanisms of such a shift in state policy and continue to wait for the situation to be restored to the conditions in place before the collapse of the USSR. For this reason, one of the project goals was to reinforce the collaboration of local communities with external actors, such as international donors and the state administration.

Another challenging factor for a small Polish NGO with modest funds is that due to the war the communities have become used to receiving unconditional aid from Western donors. Consequently, the stereotype that intemational organizations should provide certain goods and their role is only limited to fulfilling these tasks continues to exist today.

The above issue has also influenced the model of cooperation between donors and communities. Most MC members are not informed that according to the mahalla law (Law 2008) a community can apply for funds to donors.

At the seminar (during the project), w'e learned that information which we see on the $T V$, in the radio, newspapers about donors is information for us. We learned that grant competitions are advertised through the media. (....) and we might be able to apply for it. (a conversation with a member of the MC of village K.: see Stryjewski 2013). 
However, donors rarely collaborate with village authorities (the exception is the MSDSP); in most cases, international organizations prefer to entrust locals with some specific tasks. In this case, MC activity is limited to organizing hashar for public works (see Chapters 3 and 4). In addition, aid is provided in an irregular way and not every community can benefit from it.

Yet another issue is related to the unprecedented wastage of aid resources which also influences communities' attitudes towards international organizations. A number of broken and abandoned facilities funded through various projects can be observed in various places around Tajikistan. For instance, in the village of M., there is a large water container located along the main street. According to the raisi mahalla, the container was part of a bigger water system funded by an international organization which cooperated with the jamoat. During project implementation, part of the financial resources vanished. The organization employed a local worker who was expected to control the construction of the infrastructure to prevent further waste of funds but in vain. As a result, the project was implemented at low costs, and all work was of poor quality. Finally, the water system was handed over so that it could be used by the people, but shortly afterwards it stopped functioning. "Nobody even tried to work through the mahalla", said the rais. ${ }^{198}$

Another example of fund misallocation is connected to a big program which aimed to establish a network of Associations of Water Users. The budget for the project amounted to $1,000,000$ USD. Twenty per cent of the whole sum was taken by the World Bank for technical assistance, another twenty per cent was absorbed by the district administration; the remaining sixty per cent was not enough to implement the project. As a result, some project tasks were never completed and they were only implemented on paper (in the reports of donors). Nevertheless, nobody took responsibility for this situation. ${ }^{199}$ In most cases, organizations do not monitor the implemented projects after they have been finished. The local communities also do not feel responsible if they do not participate in project realization. In addition, the local authorities are rarely interested in the facilities located within their territory. In this way, a lot of aid is wasted but many people continue to live in extreme poverty. It is hardly surprising, therefore, that local communities do not trust various organizations and international donors.

As previously mentioned, knowledge regarding the socio-cultural and economic conditions of a particular community is necessary for the implementation of community-based projects. The organization should have a critical approach to identifying and investigating the complex array of circumstances in the field. At each project stage, different data should be gathered, including information on social norms and traditions, the livelihood of the residents, the ethnic composition, the traditional institution linkages, and so forth.

1\%x Information gathered during implementation of the project in 2013.

ivo Conversation with an employee of a local NGO. June 2013 



\section{Concluding remarks}

My study focuses on changes in the traditional institutions within the mahalla and the transformation of this form of social organization following recent economic and social changes, as well as analyses the reactions to state policies and those introduced by intemational organizations in Tajikistan. It provides background for further discussion about the future direction of the development of the mahalla as well as concerning the nature of the interaction among communities, the state and non-governmental organisations.

The mahalla, as other types of communal organizations, has neither a consistent homogeneous structure nor a fixed pattern which would fit into one concept of a 'model mahalla'. However, this communal form functioned as an ideal of a social organization for the sedentary population of Central Asia in the past. Regardless of how persistent the mahalla was in terms of preserving communal practices and Islam rooted in tradition, during the Soviet period, some of its social functions were taken over by the state which contributed to the reshaping of this social organization.

The civil war in the 1990s, increasing economic hardship and inequalities, the division of formerly communal land properties, together with the increased migration of the male population in recent years have led to further transformation and fragmentation of the social structures. Consequently, competition for access to resources has generated various pathological forms, also within communities of which many are dominated by an elite group redistributing wealth within its own networks. Other communities still follow the traditional pattern of integration and there social bonds are strong enough to protect their members. My research and work with the mahallas and other communal forms show that preconceived assumptions and stereotypes fail when confronted with reality and an individual approach is necessary during establishing collaboration with each community.

The mahalla is also a part of an entire economic, social and political system, and it has recently become the subject of insensitive state policies. According to the law "On Public Self-Initiative Bodies" (Law 2008), the inahalla should be a self-governing organ, cooperating with the local administration and other actors. In practice, however, joint activities rarely take place. The local administration represented by 
the jamoat is an organ subordinated to the state, and - apart from administrative tasks - its main role is to control communities, including its religious activities and religious/spiritual leaders. Another important jamoat task is to supervise the course of the organization of celebrations, on the basis of the law "On Re-ordering Traditions, Celebrations, and Customs in the Republic of Tajikistan" (Law 2007/2008). The mahalla authorities are also expected to participate in the monitoring of such events.

Independent community activities are not encouraged (with some exceptions). The state administration creates façade structures, such as the mahalla committees, irrespective of how relevant they are in a particular context. The institutionalized and bureaucratized mahalla has gradually become the new model of social organization in Tajikistan. As shown on the example of the Kungrats, the 'mahalla regime' is imposed even in those communities which have other forms of social organizations and where the mahalla has never been an indigenous institution.

This inevitably leads to the limiting and curbing of the traditional self-governance capacities of the mahalla. Sievers, while describing the relationship between the state and the mahalla in Uzbekistan, concludes that "Uzbekistan is pioneering grassroots absolutism" (2002: 152). Unfortunately, Tajikistan is following the same path. On the other hand, all responsibility for services that during the Soviet Union were provided by the state administration (such as repairs, garbage disposal, etc.) is now being passed on to the mahallas. Thus, the mahalla is expected to fulfil the duties of the state administration.

Most mahalla residents and their authorities are not aware of the legal implications of the mahalla law or they are sometimes not even aware that such a law has been passed. Some mahalla activities are performed in the same way as before and are based on informal relationships, so changes are being introduced very gradually. At the time of my research and work (2010-2014), most urban mahallas had been formally registered, and the majority were working as if they were a part of the state administration, with some remnants of their traditional functions. In the villages, the situation differed from community to community, with some of them still unregistered. The formalization of the mahalla may result in over-bureaucratization but will not bring any progress, since no effort is made on the side of the government to reinforce the organizational capacities of communities.

Our project has shown that institutional development and raising the awareness and competences of mahalla members is long-term work. The ideas introduced by non-governmental organizations require a shift in thinking within communities in terms of cooperation with external actors. In most cases, the residents need time to become accustomed to working with a donor. Furthermore, the rules of cooperation should be clearly defined, since not infrequently the understanding of certain issues by local people differs from the perception of the programme designers or even that of local NGO employees.

As regards international organizations, despite various strategies, their attitude to community development remains hesitant. The IOs have criticized the authoritarian rule of Rahmon and the corruption of public administration, but at the same time, 
they agree to cooperate with the Tajik government; for example, by participating in the creation of the above-mentioned law on the assumption that the mahalla needs to be upgraded in order to meet the standards of self-govermment existing in developed democracies (see Chapter 4).

This is an illusion, as any real change requires first of all the transformation of existing relationships. However, even if such changes do occur, they might follow a different direction than is expected by development policy makers. This is especially true since the outcomes of similar policies implemented in Uzbekistan are well known - there the mahalla was reshaped into a state agent. Lastly, the mahalla is based on traditional practices and customs. Even if some of them do not fully correspond with the idea of social development proposed by IOs, there is no guarantee that the modifications introduced will bring benefits for the beneficiaries of development programs.

I am of the opinion that the core problem of the current policies targeted at the local communities is that neither the state nor the international organizations are attempting to develop a model of cooperation based on partnership. Aid agencies acknowledge the merits of the different forms of communal practices but with some exceptions. The strategies tend to be designed in the forms of templates which are expected to fit all targeted communities. As Kendie and Guri indicate, "the benefits do not derive from mere participation, but from the extent to which people are able to infuse ideas generated from their daily life situation into project design and implementation" (2007: 333). Moreover, development agencies are trying to adjust local traditions and practices to ideas for which the conceptual and cognitive criteria were defined within the framework of different categories of thought. There is an assumption that the understanding of certain ideas and values is universal, and therefore that any practices or institutions developed by a society can be adapted to the proposed concept. The "importance that is given to a display of 'responsible citizens' and collective self-help as a virtue in itself, without closer inquiry into form and direction, may be characteristic of other aid-receiving contexts, and generally, of neo-liberal aid reforms" (Mosse 2005 qtd. in Bichsel 2008: 125).

As regards the practical dimensions of cooperation with mahalla communities, despite the fact that under the new law mahallas can function like NGOs in terms of work with various agents, there is no long-term systematic approach to linking communities with potential donors providing grants or other forms of support for settlements, qishloqs or mahallas. Perhaps a national fund to support communities should be created with the participation of international donors and the state administration. It would announce grant competitions and run trainings for active residents of mahallas.

There have been various attempts at entering into cooperation with local communities, such as the Village Organization Programme (see Chapter 5). However, while the VOP has certainly succeeded in dealing with various infrastructural problems as well as in its activities aimed at increasing people's knowledge and skills regarding agriculture, microfinance, and so forth, the question remains why the mahalla should 
be re-modelled into a new structure - the village organization. Another question should be put forward concerning the potential consequences of such social engineering on the traditional social pattern of the targeted communities. Furthermore, doubts about the ability of 'the new mahalla' to function independently without external assistance continue to exist. In addition, as various experiences have shown, the VO is absorbed by the traditional structures. Thus, perhaps it is for this reason that in some regions the MSDSP has recently shifted from the concept of Village Organizations and has pursued work with Mahalla Committees.

The cooperation with fifteen communities within the framework of the joint project of the PCIA and NGO Mehrangez provides evidence that the imposition of new structures does not bring the desired results (as portrayed by the case of the Kungrats), and work with mahalla committees can be efficient in those places where there are structures based on endogenous institutions related with the traditional mahalla organisation.

The case study from the Vorukh enclave focuses on the Jamoat Resource Centres created by the UNDP and the influence the JRC's activities have had on other social actors, including the mahalla. Originally, the JRC was supposed to be a unit which would cooperate with the jamoat on local development issues. Instead, since the JRC of Vorukh is a separate entity with independent funds, it has become a counterbalance to the jamoat, and cooperation between the two units only takes place if other social actors arrange it. In most cases, these are international donors - at least according to the information gathered in 2010 . Yet another issue which should be considered is related to cooperation with the communities, which the JRC promotes strongly. Finally, the study demonstrates that the policy of the donor (the UNDP) aimed at establishing an institution to support the local administration in order to facilitate local development has taken on a completely different and unexpected dimension. This raises further questions about the influence of donor strategies on changing patterns of local relationships.

With this work, I present a critical insight into various approaches to the mahalla by exploring their theoretical frameworks and providing examples of the implementation of different policies. Moreover, I have examined particular concepts and their potential social, economic and cultural effects on local communities when put into practice. My inquiry into different ideas of transforming the mahalla reveals that there is uncertainty about the impact of such models on social development. This raises further questions about the long-term prospects of the policies implemented. While I certainly advocate the idea of supporting local communities in Tajikistan, at the same time I am inclined to the view that most of the current approaches should be revised in order to bring tangible benefits. Evidently, it is difficult to foresee the course of interaction with a particular community. Some communities will always be more willing to cooperate with external actors, while others will be less capable of undertaking joint actions or absorbing ideas brought in from outside.

Nevertheless, despite the fact that the encouragement of communities to undertake independent activities is beneficial to the local population, local development 


\section{Concluding remarks}

cannot only involve the mahallas or other forms of communal organization but must also take into account the jamoat, hukumat, local businesses, and so forth. Hence, it should not be forgotten that with the great effort of the residents, the mahalla is capable of building a school or a primary-care clinic, but in principle, these are tasks which should be the responsibility of the state. The mahalla can assist in organizing works or other activities but should not be the main actor. Unfortunately, under the current circumstances in place in Tajikistan, one of the signs of the crisis of the state structures is that communities are forced to take over the responsibilities of the state administration. Consequently, until relevant mechanisms of cooperation between communities and the state are designed, any programs aimed at reinforcing local development will not bring long-term benefits. 



\section{Bibliography}

Abashin, S. N. (2001) Potomki sviatykh v Uzbekistanie, Tadzhikistanie, Kazakhstanie, Profi. 1-2. p. 60-64.

Abashin. S. N. (2004) Naselenie Ferganskoi Doliny: k stanovleniu etnograficheskoi nomenklatury v konce XIX- nachale XX veka. In: Abashin, S. N., Bushkov, V. I. (eds.) Ferganskaia dolina: etnichnost, etnicheskie processy, etnicheskie konflikty. Moskva: Institut Etnologii i Antropologii, Nauka.

Abashin, S. N. (2006) The Logic of Islamic Practice: a Religious Conflict in Central Asia, Central Asian Survey 25.3. p. 267-286. [Online] dx.doi.org/10.1080/02634930601022542.

Abashin, S. N. (2011a) "Idealnyi kolkhoz" v sovetskoi Srednei Azii: istoriia neudachi ili uspekha?, Acta Slavica laponica 29. p. 1-26.

Abashin, S. N. (201lb) Sovetskaia vlast i uzbekskaia mahallia, Neprikosnovennyi zapas 4.78. [Online] Available from: http://magazines.russ.ru/nz/2011/4/all.html [Accessed: March 20131.

Abazov, R. (2008) The Palgrave Concise Historical Atlas of Central Asia. New York: Palgrave Macmillan. [Online] dx.doi.org/10.1080/02634930903421889.

Abdulghani, A. (2014) Reducing Tensions on Central Asian Borders. The Institute for War \& Peace Reporting. [Online] Available from: https://iwpr.net [Accessed: December 2014].

Abdullaeva, M., Tyuryaev, F. (2004) Role and Place Social Institutions in a Process of Development Village Communities. Khujand: ASTI.

Abdulvahhobov, A. (2011) Uslovnaia granica... afganskie bandity i narkotorgovcy na territorii Tadzhikistana chustruiut sebia, kak doma. [Online] Available from: http://www. russianskz.info [Accessed: March 2012].

Abdunazarov, Kh., Saidmuminov, A., Saifulloev, N., Abdunazarov, P. (2014) Kungraty Vakhshskoi doliny. In: Masov, P. M. (eds.) Nauchnyi vklad Mikhaila Stepanovicha Andreeva $v$ izuchenie istorii i etnografii tadzhikskogo naroda. Materialy mezhdunarodnoi nauchno-prakticheskoi konferencii Dushanbe, 22 oktiabria 2013, Dushanbe: Akademia Nauk Respubliki Tadzhikistan. Posolstvo Rossiiskoi Federacii v Respublike Tadzhikistan. Predstavitelstvo Rossotrudnichestva v Respublike Tadzhikistan.

Abramov, M. M. (1989) Guzary Samarkanda. Tashkent: Izdatelstvo „Uzbekistan”.

Abramson, D. M. (2000) Constructing Corruption: Foreign Aid, Bureaucratization, and Uzbek Social Networks. Watson Institute for International Studies, Brown University (presented at Harvard University).

Action Aid International (2005) Real Aid Agenda for Making Aid Work. [Online] Available from: www.actionaid.org.uk [Accessed: May 2011]. 
Aga Khan Development Network (n.d.). [Online] Available from: http://www.akdn.org/tajikistan_overview.asp [Accessed: March 2015].

Aga Khan Foundation (2003) Annual Report. [Online] Available from: http://www.akdn. org/.../2003_akf_annual_report.pdf [Accessed: September 2009].

Akiner, Sh. (2001) Tajikistan: Disintegration or Reconciliation?' London: Royal Institute of International Affairs.

Akiner, Sh. (2002) Prospects of Civil Society in Tajikistan. In: Say oo, A. B. (eds.) Civil Society in the Muslim World: Contemporary Perspectives. London \& New York: I. B. Tauris. Aminjanov. R., Kholmatov, M., Kataev, F. (2009) Case Study on Aid Effectiveness in Tajikistan. The Brookings Global Economy and Development. [Onlinc] Available from: http:// www.brookings.edu [Accessed, December 2014].

Arato, A.. Cohen. J. L. (1992) Civil Society and Political Theory: Cambridge: MIT Press.

Arifhanoea. Z. (2009) Tashkentskaia mahallia v nachale XX veka. In: Alimova, D.. Mustafaev, Sh.. Khakimov, A., Bald, B.. Khan. V. (eds.) Socialnaia zhizn narodov Centralnoi Azii v pervoi chetverti XX Veka: Tradicii i innovacii (Materialy Mezhdunarodnoi Konferencii). Tashkent: Institute of History of The Academy of Sciences of The Republic Uzbekistan.

ASIA PLUS (2012) Tajikistan Welcomes USS6 Million Donation from Russia. [Online] Available from: http://www.asiaplus.tj [Accessed: May 2012].

Atlani-Duault, L. (2007) Humanitarian Aid in Post-Soviet Countries: An Anthropological Perspective. London \& New York: Routledge.

Bichsel, Ch. (2009) Conflict Transformation in Central Asia, Irrigation Disputes in the Ferghana Valley. London \& New York: Routledge. [Online] dx.doi.org/10.1080/02 634931003765605 .

Biliang. Hu (2007) Informal Institutions and Rural Development in China. New York: Routledge.

Bliss, F. (2013) Poverty; Governance, and Participation in Central Asia: The Example of Tajikistan. In: Ahrens, J.. Hoen, H. W. (eds.) Institutional Reform in Central Asia: Politico-Economic Challenges. New York: Routledge. [Online] dx.doi.org/10.1080/02634937. 2013.866735 .

Bobbio. N. (1988) Gramsci and the Concept of Civil Society. In: Kean, J. (eds.) Civil Societr and the State (New European Perspectives). London \& New York: Verso.

Boboyorov, H. (2013) Collective Identities and Patronage Networks in Southern Tajikistan (ZEF Development Studies). Berlin: Lit. Verlag.

Bobrovnikov, B.O. (2006) Adat. In: Prozorov, S. M. (eds.) Islam na territorii byvshei Rossiiskoi imperii (Enciklopedicheskii Slovar I). Moskwa: Rossiiskaia Akademiia Nauk.

Bolshaia Sovetskaia Enciklopediia (n.d.) Ferganskaia Kotlovina. [Online] Available from: http://bse.sci-lib.com [Accessed: May 2011].

Bushkov, V. I. (1990) O Niekotorykh aspektakh mezhnacionalnykh otnoshenii v Tadzhikskoi SSR (Seriia A: Mezhnacionalnye otnosheniia v SSSR, Sovetskaia etnografiia 9), Institut Etnologii i Antropologii, Akademia Nauk SSSR.

Bushkov, V. I. (2004) Osobennosti formirovania naseleniia iugo-zapadnoi Fergany. In: Abashin, S. N., Bushkov. V. I. (eds.) Ferganskaia dolina: etnichnost, etnicheskie processy, etnicheskie konflikty. Moskva: Institut Etnologii i Antropologii. Nauka.

Bushkov, V. I., Mikulskii, D. V. (1996) Anatomiia grazhdanskoi voiny v Tadzhikistane (etno-socialnye processy i politicheskaia borba, 1992-1995). Moskva: Institut Etnologii i Antropologii. RAN, Institut Prakticheskogo Vostokovedeniia. 
Buxton, Ch., Earle, L., Giffen, J. (2005) The Development of Civil Society in Central Asia (NGO Management \& Policy Series 17). Oxford: INTRAC

Carlson, Ch. (2003) Uzbekistan: The Changing Role of the "Mahalla". [Online] Available from: http://www.rferl.org [Accessed: March 2011].

Carothers, T. (1999-2000) Think Again: Civil Society. Foreign Policy 117. p. 18-29.

Carothers, T. (1999) Western Civil-Society Aid to Eastern Europe and the Former Soviet Union, East European Constitutional Review 8/4. p. 54-62.

CIA (n.d.) Tajikistan country information (The World fact book). [Online] Available from: https://www.cia.gov [Accessed: February 2011].

Cieślewska, A. (2014) Kobiece autory tety religijne w Tadżykistanie - między tradycją a nowoczesnością. Pomoc Rozwojowa 1/2014. p. 13-21. Warszawa: Polskie Centrum Pomocy Między narodowej.

Cieślewska, A., Makowska, A. (2012) Gdzie jest ta woda? Dostęp do wody w kontekście problematyki rozwojowej regionu Azji Centralnej. Warszawa: The East European Democratic Centre.

Collins, K. (2006) Clans Politics and Regime Transition in Central Asia. Cambridge: Cambridge University Press.

Crisis Group (2009) Tajikistan: On the Road to Failure (Asia Report 162). [Online] Available from: http://www.crisisgroup.org [Accessed: December 2010].

Dadabaev. T. (2013) Community Life, Memory and a Changing Nature of Mahalla Identity in Uzbekistan, Journal of Eurasian Studies 4. p.181-196.

Davydov, A. D. (1969) Afganskaia derevnia, selskaia obshchina i rassloenie krestianstra, Moskva: Nauka

De Cordier. B. (2007) Shiite Aid Organizations in Tajikistan, ISIM Review 19. p. 10-11.

De Cordier, B. (2011) Tajikistan: the Influence of Migration on Religion. [Online] Available from: http://religion.info [Accessed: December 2011].

Dziekan, M. (eds.) (2001) Arabowie. Slownik Encyklopedyczny. Warsaw: PWN.

Economist (2011) Jargon of Aid. Anyone Here Speak NGOish? [Online] Available from: http://www.economist.com [Accessed: December 2011].

Enclaves of the world. [Online] Available from: http://enclaves.webs.com [Accessed: February 20111 .

Eshonkulov, U. (2007) Istoria zemledelcheskoi kultury Gornogo Sogda (s drevneishikh wemen - do nachala .XX v.). Dushanbe: Devashtich.

Eurasianet.org (2009) Tajikistan Financial Scandal Brings Fresh Disgrace to Dushanbe. [Online] Available from: http://www.eurasianet.org [Accessed: February 2012].

Eurasianet.org (2012) Tadzhikistan: Razvody uvelichivaiut armiiu trudovykh migrantok. [Online] Available from: http://www.russian.eurasianet.org [Accessed: June 2012].

Evans, P. (1996) Government Action, Social Capital, and Development: Reviewing the Evidence on Synergy, World Development 24/6. p. 1089-1103. [Online] dx.doi. org/10.1016/0305-750X(96)00021-6.

Falkowski, M., (22/2009) Tadżkistan w obliczu kryzysu państwowości. Warsaw: Center for Eastern Studies 2009/22.

Ferghana News Agency (2008) Tadzhikistan: Pogranvoiska oprovergaiut soobshchenie o zakhvate qishloqa afganskimi boevikami. [Online] Available from: http://www.lerghana news.com [Accessed: April 2011].

Ferghana News Agency (2014) PIFT "Zakryte dveri ili snesennye zdaniia ne oslabiat nash dukh". [Online] Available from: http://www.ferghananews.com [Accessed: July 2014]. 
Fourth High Level Forum on Aid Effectiveness. [Online] Available from: http://www.aideffectiveness.org [Accessed: October 2011].

Freizer, S. (2004) Tajikistan Local Self-Governance: A Potential Bridge Between Government and Civil Society? In: De Martino, L. (eds.) Tajikistan at a Crossroad: The Politics of Decentralization. Geneva: Cimera Publications.

Gabrieli. F. (1986) Adab. In: Gibb, H. A. R., Kramers, J. H., Lévi-Provençal, E., Schacht. J. (eds.) Encyclopaedia of Islam 1. Leiden: E. J. Brill.

Garbutt, A., Heap. S. (eds.) (2002) Growing Civil Society in Central Asia (INTRAC's First Central Asia Regional Conference, Occasional Papers Series 39). Almaty: INTRAC.

Garcés de Los Fayos. F. (2014) The World Bank Considers Feasible the Building of the Tajik Rogun Dam (The Policy Department, DG EXPO). [Online] Available from: http://www. europarl.europa.eu [Accessed: December 2014].

Gomart, E. (2003) Between Civil War and Land Reform: Among the Poorest of the Poor in Tajikistan. In: Dudwick, N., Gomart, E., Kuehnast, K., Marc, A. (eds.) When Things Fall Apart: Qualitative Studies of Poverty in the Former Soviet Union. Washington: World Bank.

Gorshunova, O.V. (2006) Uzbekskaia zhenshchina, socialnyi status, semia, religiia. Moskva: Institut Etnologii i Antropologii RAN.

Hauschildt, L. S., Lybæk, R. (2006) The "Tyranny" of Participation. A Discussion of Potentials and Pitfalls in the Application of Participatory and Social Capital Approaches to Development. [Online] Available from: http://www.ulandslaere.au.dk [Accessed: April 2011].

Haverkort. B.. van't Hooft. K., Hiemstra, W. (eds.) (2003) Ancient Roots, New' Shoots. Endogenous Development in Practice. London: Zed Books.

Heathershaw, J.. Roche, S. (2011) Islam and Political Violence in Tajikistan, An Ethnographic Perspective on the Causes and Consequences of the 2010 Armed Conflict in the Kamarob Gorge. Exeter: Exeter Centre for Ethno-Political Studies, University of Exeter.

Hedfors. A. (2011) Korrupcia v Kirgizii - eto ne prosto odna iz problem gosudarstva. Korrupciia $i$ est gosudarstvo. [Interview]. [Online] Available from: http://www.Ferghana.ru [Accessed: February 2012].

Huntington, S. P. (1987) The Goals of Development. In: Weiner. M., Huntington, S. P. (eds.) Understanding Political Development. Boston: Little Brown.

larlykapov, A. (2012) Rol islama v formirovanii ekonomicheskogo soznaniia i povedeniia musulman, Kavkazskaia Politika. [Online] Available from: http://www:kavpolit.com [Accessed: April 2012].

Ilolov, M., Khudoiyev, M. (2001) Local Government in Tajikistan. In: Munteanu. I. (eds.) Developing New Rules in the Old Environment. Local Governments in Eastern Europe, in the Caucasus and in Central Asia. Budapest: Open Society Institute.

IPHR (2013) International Partnership for Human Rights report: Tajikistan: New Report Details Human Rights Violations During July 2012 Special Security Operation. [Online] Available from: http://www.iphronline.org/ [Accessed: December 2014].

Jamoat Resource Centre of Vorukh and UNDP (2011) Potential for Peace and Threats of Conflict, Development Analysis of Cross-Border Communities in Isfara District of the Republic of Tajikistan (Vorukh. Chorkhuh, Surkh, Shurob) and Batken District of the Kyrgyz Republic (Ak-Sai, Ak-Tatyr; and Samarkandek). [Online] Available from: http:// www.undp.tj [Accessed: February 2012]. 
Jasiewicz, Z. (2004) Rodzina, spoleczność lokalna i grupa etniczna w Polsce i Azji Środkowej. Poznań: Wydawnictwo Poznańskie.

Jennings, R. (2000) Participatory Development as New Paradigm: The Transition of Development Professionalism (Conference paper presented at the Community Based Reintegration and Rehabilitation in Post-Conflict Settings Conference). Washington: Kabemba.

Kaczmarski, M., Wierzbowska-Miazga, A. (62/2011) Rosyjska pomoc rozwojowa. Warsaw: Centre for Eastern Studies.

Kamoludin, A. (2004) Current Local Government Policy Situation in Tajikistan. In: De Martino, L. (eds.) Tajikistan at a Crossroad: The Politics of Decentralization. Geneva: Cimera Publications.

Kandiyoti, D., Azimova, N. (2004) The Communal and the Sacred: Women's Worlds of Ritual in Uzbekistan, Journal of the Royal Anthropological Institute 10. p. 327-334. [Online] dx.doi.org/10.1111/j.1467-9655.2004.00192.x.

Karmysheva, B. H. (1976) Ocherki etnicheskoi istorii iuzhnykh raionov Tadzhikistana i Uzbekistana. Moskva: Institut Etnografii, Nauka.

Kassymbekova, B. (2003) Uzbekistan's Mahalla - a Democratic Tool for Authoritarian Rule? (Issue 11/19/2003 of CACI Analyst). [Online] Available from: http://www.cacianalyst.org [Accessed: February 2011].

Kendie, S., Guri, B. (2006) Indigenous Institutions as Partners for Agriculture and Natural Recourse Management. In: Millar, D., Bugu, S., Kendie, S. B, Apusigah, A. A, Haverkort, B. (eds.) African Knowledges and Sciences: Understanding the Ways of Knowing in Sub-Saharan Africa. Lausden: Compas.

Kendie, S., Guri, B. (2007) Indigenous Institutions, Governance and Development: Community Mobilization and Natural Resources Management in Ghana. In: Balasubramanian, A. V. and Nirmala Devi. T. D. (eds.) Endogenous Development and Bio-Cultural Diversity. Lausden: Compas.

Khamidzhanova, M. A. (1974) Materialna kultura Matchincev. Do i posle pereceleniia na novye oroshennye zemli. Dushanbe: Donish.

Kholdzhuraev, H. H. (2003) Irrigacionnaia ciwilizacia Tadzhikistana 20 veka. Khujand: Umed.

Koehler, J. (2004) Assessing Peace and Conflict Potentials in the Target Region of Tajikistan, the GTZ Central Asia and Northern Afghanistan Programme to Foster Food Security. Regional Cooperation and Stability. Berlin: ARC. [Online] Available from: http://www. arc-berlin.com [Accessed: January 2012].

Koroteyeva, V., Makarova E. (1995) The Assertion of Uzbek National Identity: Nativisation or State-Building Process? (Conference paper presented at the Fifth European Seminar on Central Asian Studies, Copenhagen University). [Online] Available from: http://iias. leidenuniv.nl [Accessed: April 2011].

Kramër, A. (2006) Otin. In: Prozorov, S. M. (eds.) Islam na territorii byvshei Rossiiskoi imperii (Enciklopedicheskii Slovar). Moskva: Rossiiskaia Akademia Nauk.

Kuchukeeva, A., O'Loughlin, J. (2003) Civic Engagement and Democratic Consolidation in Kyrgyzstan, Eurasian Geography and Economics 4/8. p. 557-587.

Lang, J., Matusiak, M.. Strachota. K. (2012) Nowy etap w relacjach NATO/USA z Azja Centralnq. Warsaw: Centre for Eastern Studies. [Online] Available from: http://www.osw. waw.pl [Accessed: May 2012].

Law (1978) Law of the Tajik Soviet Socialist Republic "On the Settlement, and Village Council of People's Deputies Tajik SSR". (Zakon Tadzhikskoi Sovetskoi Socialisticheskoi Respubliki o Poselkovom, Kishlachnom Soviecie Narodnykh Deputatov Tadzhikskoi SSR). 
Law (1994) Law of the Republic of Tajikistan "On Self-Government in Towns or Townships”. I December 1994. (Zakon Respubliki Tadzhikistan ob Organakh Samoupravleniia $v$ Poselke i Sele).

Law (2007/2008) Law of the Republic of Tajikistan "On Re-ordering Traditions, Celebrations and Customs in the Republic of Tajikistan", 9 June 2007, No. 6, with amendments in 2008. (Zakon Respubliki Tadzhikistan ob Uporiadochenii Tradicii, Torzhestv i Obriadov v Respublike Tadzhikistan).

Law (2008) Law of the Republic of Tajikistan "On Public Self-Initiative Bodies", 5 Januany 2008. No. 347. (Zakon Respubliki Tadzhikistan ob Organakh Obshchestiennoi Samodeiatelnosti).

Law (2009) Amendment to the Law of the Republic of Tajikistan "On Self-Government in Towns and Townships“ from 1994, 5 August 2009.

Layton. R. (2004) Civil Society and Social Cohesion - a reassessment. Halle/Saale: Max Planck Institute for Social Anthropology (Working Paper 63).

l.erche. J. (2005) The End of Development? II: Neo-liberalism, Market and the State [Lecture] Course: Theory, Policy, and Practice of Development, School of Oriental and African Studies, University of London.

Lerman, Z... Sedik, D. (2008) The Economic Effects of Land Reform in Tajikistan. Rome: EC/FAO Food Security Programme. [Online] Available from: hup://www.fao.org [Accessed: February 2012].

Lewis, D. (2002) Civil Society in African Contexts: Reflections on the Usefulness of a Concept, Development and Change 33/4. p. 569-586.

Litvinskii, B. A., Mukhtarov, A. (1992) Istoria tadzhikskovo naroda 8/9. Dushanbe: Maorif.

Liu M. Y. (2003) Detours from Utopia on the Silk Road: Ethical Dilemmas of Neoliberal Triumphalism. Central Eurasian Studies Review 2. p. 2-10.

Lobacheva. N. P. (1989) Sversiniki i siemia ( $k$ voprosu o drevnei polovozrastnoi gradacii obschestva u narodov Srednei Azii i Kazakhstana), Sovetskaia Eınografiia 5. p. 87-89.

Lobo, C. (2008) Institutional and Organizational Analysis for Pro-Poor Change: Meeting IFAD's Millennium Challenge. Rome: IFAD. [Online] Available from: http://www:ifad. org [Accessed: March 2012].

Lukawski, Z. (1996) Dzieje Azji Środkowej. Kraków: Nomos.

Malikov. M. (2010) The Cult of Saints and Shrines in Samarqand Province of Uzbekistan. International Journal of Modern Anthropology 3. p. 116-124.

Mamurzoda. N. (2011) Zdies byla mechet... [Online] Available from: http://www.ozodi.org [Accessed: February 2012].

Marat, E. (2008) Tajik Government Regulates Wedding Splendor (06/11/2008 issue of the CACl Analyst). [Online] Available from: http://www.cacianalyst.org [Accessed: December 2011].

Masaru, S. (2006) The Politics of Civil Society, Mahalla and NGOs: Uzbekistan. In: Osamu, I., Tomohiko, U. (eds.) Reconstruction and Interaction of Slavic Eurasia and Its Neighboring Worlds. Sapporo: Slavic Research Center. Hokkaido University.

Matveeva. A. (2009a) The Perils of Emerging Statehood: Civil War and State Reconstruction in Tajikistan. Working Paper 46: Development as State-making. London: Crisis States Research Centre.

Matveeva. A. (2009b) Tajikistan: Revolutionary situation or a resilient state? EUCAM Policy Brief 12. 19 December 2009. 
McChesney, R. D. (1996) Central Asia: Foundations of Change. Princeton \& New Jersey: Darwin Press.

Molenaers, N., Renard, R. (2009) The Trouble with Participation: Assessing the New Aid Paradigm. In: Kremer, M., Lieshout. P. v., Went, R. (eds.) Doing Good or Doing Better, Development Policies in a Globalizing World. Amsterdam: Amsterdam University Press. Mukhtarov, A. (1996) Guzari (Streets) of Ura-Tyube. Tashkient: Chulpon.

Mukhutdinova, R. (2007) Nations in Transit 2007. Freedom House. [Online] Available from: http://www.freedomhouse.org [Accessed: October 2011].

Muminov, A. (1999) Tradicionnye i sovremennie religiozno-teologicheskie shkoly v Centralnoi Azii, Central Asia and Caucasus 4/5. [Online] Available from: http://www.ca-c.org [Accessed: June 2011].

Muminov, A., Gafurov, U., Shigabdinov, R. (2010) Islamic Education in Soviet and Post-Soviet Uzbekistan. In: Kemper, M., Motika, R., Reichmuth, S. (eds.) Islamic Education in the Soviet Union and Its Successor States. London \& New York: Routledge.

Najibullah, F. (2011a) Tajik Government To Issue List Of Approved Sermon Topics. [Online] Available from: http://www.rferl.org [Accessed: February 2012].

Najibullah, F. (201 lb) Tajikistan's Islamic Renaissance Party Rebrands, Using Social Projects To Reach Voters. [Online] Available from: http://www.rferl.org [Accessed: January 2012].

Niyazi, A. (1998) Islam in Tajikistan: Tradition and Modernity, Religion, State \& Society 26/1. p. 39-48.

Niyazi, A. (1999) Islam and Tajikistan's Human and Ecological Crisis. In: Ruffin, M., Waugh, D. (eds.) Civil Society in Central Asia. Washington: Center for Civil Society in Asia.

Niyazov, A. (2007) Mahalla - muzułmańska wspólnota samorządowa w Azji Centralnej, Bliski Wschód: Spoleczeństwo, Polityka, Tradycje 4. p. 153-162.

Nourzhanov, K., Bleuer, Ch. (2013) Tajikistan: A Political and Social History. Canberra: Griftin Press.

Olimova, S. (2002) Regionalism and its Perception by Major Political and Social Powers of Tajikistan. In: De Martino, L. (eds.) Tajikistan at a Crossroad: The Politics of Decentralization. Geneva: Cimera Publications.

Olimova, S., Mamadzhanova, N. (2006) Torgovla lıdmi v Tadzhikistanie. Duszanbe: MOM, Shark.

Olimov, M., Olimova, S. (n.d.) Musulmanskoe dukhovenstvo v sredneaziatskikh obshchestvakh (Paper released within the framework of research 'Muslim Leaders in the Contemporary Muslim Societies of Central Asia'). [Online] Available from: http://www.eawarn. ru [Accessed: May 2011].

Olimov, M., Olimova, S. (2001) Etnicheskii faktor i mestnoe samoupravlenie v Tadzhikistane. In: Tishkov, V., Filippova. E. (eds.) Mestnoe upravlenie mnogoetnichnymi soobshchestvami v stranakh SNG. Moskva: Aviaizdat.

Ozodi (2013) "Amparo" gotovitsia k kassacionnomu sudu, "Grazhdanskoe obshchesno" likvidirovano. [Online] Available from: http://rus.ozodi.org [Accessed: July 2014].

PCIA (2014) Polish Center for International Aid website information Our projects/Tajikistun. [Online] Available from: http://www.pcpm.org.pl [Accessed: November 2014].

Peshkova, S. (2009) Muslim Women Leaders in the Ferghana Valley: Whose leadership is it any way?, Journal of International Women's Studies 11/1. p. 5-24.

Pisarczyk (Pisarchik). A. K. (1974) Narodnaia arkhitektura Samurkanda XIX-XX vv. (po materialam 1938-19+1 gg.). Dushanbe: Donish. 
Pisarczyk, A. K., Kisliakov, N. A. (1970) Tadzhiki Karategina i Darraza (2). Dushanbe: Donish.

Poliakov, P. S. (1980) Istoricheskaia etnografiia Sredniei Azii, khoziaistvo, socialna organizaciia, etnicheskaia istoria. Moskva: Izdatelstvo Moskovskogo Universiteta.

Poliakov, P. S. (1992) Everyday Islam: Religion and Tradition in Rural Central Asia. Armonk. New York, M. E. Sharpe.

Pyatibratova, A. (2011) V Oshe na forumie NPO obsudzili factory; kotorye mogut obostrit obstanovku na inge strany. [Online] Available from: http:/Www.Ferghananews.com [Accessed: May 2011].

Qayumarsi, A. (2014) Tajikistan's Islamic Opposition Under Pressure. The Institute for War \& Peace Reporting. [Online] Available from: https://iwpr.net [Accessed: December 2014].

Rakhimov, R. R. (1990) "Muzhskie doma" v tradicionnoi kulture Tadzhikov. Leningrad: Nauka.

Rakhimov, R. R. (2007) Koran i rozovoe plamia (Razmyshleniia ob radzhikskoi kulture). Sankt-Petersburg: Nauka.

Reeves. M. (2007) Travels in the Margins of the State: Even'day Geography in the Ferghana Valley Borderlands. In: Sahadeo, J., Zanca, R. (eds.) Everyday Life in Central Asia, Past and Present. Bloomington: Indiana University Press.

Reichl, K. (2008) Tiurskii Epos, Tradicii, formy;, poeticheskaia struktura. Moskva: Vostochnaia Literatura PAN.

Roche, S. (2014) Domesticating Youth: Youth Bulges and Their Socio-Political Implications in Tajikistan. New York \& Oxford: Berghahn.

Roy. O. (1999) Kolkhoz and Civil Society in the Independent States of Central Asia. In: Ruffin. M., Waugh. D. (eds.) Civil Society in Central Asia. Washington: Center for Civil Society in Asia.

Roy: O. (2000) The Foreign Policy' of the Central Asian Islamic Renaissance Party: New York: Council on Foreign Relations.

Roy. O. (2002) Soviet Legacies and Western Aid Imperatives in the New Central Asia. In: Sajoo, A. B. (eds.) Civil Society in the Muslim World: Contemporary Perspectives. London: I. B. Tauris.

Roy, O. (2004) The Predicament of "Civil Society" in Central Asia and Greater Middle East. [Lecture] School of Oriental and African Studies. University of London.

Sabyrbekov, A. (2014) Shootout at the Kyrgyz-Tajik Border: [Online] Available from http:// w'w'w.cacianalyst.org [Accessed: December 2014].

Sarsembekov, T. T.. Nurushev, A. N., Korzakov. A. E.. Ospanov, M. O. (2004) Ispolzowanie i okhrana transgranichny'kh rek v stranakh centralnoi Azii. Almaty: Atamura.

Sarvinoz, R. (2013) Nevinnaia smert: film o grazhdanskoi voine [Online] Available from: http://www.rus.ozodi.org (Radio Ozodi) [Accessed: December 2014].

SCISPM (2010) The State Committee on Investments and State Property Management of the Republic of Tajikistan's Foreign Aid Report. Dushanbe. [Online] Available from: http://www.tajikinvest.com [Accessed: May 2011].

SCISPM (2011) The State Committee on Investments and State Property Management of the Republic of Tajikistan's Development Partner Profile - 2011. Dushanbe. [Online] Available from: http://ww'tajikinvest.com [Accessed: August 2011].

SCISPM (2013) The State Committee on Investments and State Property Management of the Republic of Tajikistan`s Foreign Aid Report. Dushanbe. 
SCISPM (2014) The State Committee on Investments and State Property Management of the Republic of Tajikistan's Development Partner Profiles - 2014. Dushanbe. [Online] Available from: http://amcu.gki.tj/ [Accessed: December 2014].

Shamsiddin, K. (2008) Rol NPO v formirovanii grazhdanskogo obshchestva v Tadzhikistane. Istoriko-politologicheskoe issledovanie. Dushanbe: Fond Razvitiia Tadzhikistana.

Shaniiazov, K. Sh. (2011) Sosedsko-territorialna obshchina. In: Arifkhanova, Z. Kh., Abashin, S. N., Alimova, D.A. (eds.) Uzbeki. Moskva: Nauka.

Sharipova, G., Babadjanova, I., Mirpochoeva, N. (2010) Public Monitoring of Selected PRS Measures, Analytical Report, Cooperation Group for Implementation and Monitoring PPS. Asti [unpublished].

Shustov, A. (2010) Tajikistan on the Verge of Civil War. [Online] Available from: https:// inteltrends.wordpress.com [Accessed: April 2012].

Sievers, E. W. (2002) Uzbekistan's Mahalla: From Soviet to Absolutist Residential Community Associations, The Journal of International and Comparative Law at Chicago-Kent 2. p. $91-158$.

Stavrakis, P. J. (2002) East Goes South: International Aid and the Production of Convergence in A frica and Eurasia. In: Beissinger, M. R., Young, C. (eds.) Beyond State Crisis?: Post -Colonial Africa and Post-Soviet Eurasia in Comparative Perspective. Washington D.C.: Woodrow Wilson Center Press.

Stefan Batory Foundation (2007) Closer to Central Asia. [Seminar record]. Warsaw: Stefan Batory Foundation.

Stiglitz. J. E. (2004) Post-Washington Consensus (Working Paper Series, Initiative for Policy Dialog, Columbia University). [Online] Available from: http://www.policydialogue.org [Accessed: January 2011].

Stryjewski, R. (2013) Raport z ewaluacji końcowej projektu ,. Rozwój spoleczności lokalnych poprzez wsparcie instytucjonalne komitetów mahalli w Tadżykistanie". Warsaw: Polish Centre for International Aid [unpublished].

Sublet, J. (1995) Nisba. In: Bosworth, C. E., Van Donzel, E., Heinrichs, W. P., Lecomte, G. (eds.) Encyclopedia of Islam 8. Leiden: E. J. Brill.

Sukhareva, O. A. (1965) O terminologii sviazannoi s istoricheskoi topografiei gorodov Sredniei Azii (ku, mahalla, guzar), Narody Azii i Afriki 6. p. 101-104.

Sukhareva. O. A. (1966) Bukhara XIX-nachalo XX v. (Pozdniefeodalnyi gorod $i$ ego naselenie). Moskva: Nauka.

Sukhareva, O. A. (1976) Kvartalnaia obshchina pozdnefeodalnogo goroda Bukhary (v sviazi $s$ istoriei kvartalov. Moskva: Nauka.

Sultanova, R. (2011) From Shamanism to Sufism, Women, Islam and Culture in Central Asia. London: I. B. Tauris.

Tabyshalieva, A. (2006) Promoting Human Security: Ethical, Normative and Educational Frameworks in Central Asia, UNESCO. [Online] Available from: http://www.unesdoc. unesco.org [Accessed: September 2010].

Tajikistan Foreign Aid Map. [Online] Available from: http://map.gki.tj (Accessed: August 2011).

TAJSTAT (2010) Agency of Statistics Under the President of the Republic of Tajikistan Chislennost i razmeshchenie naseleniia Respubliki Tadzhikistan, TOM I. [Online] Available from: http://www.stat.tj [Accessed: January 2013].

TAJSTAT (2012) Agency of Statistics Under the President of the Republic of Tajikistan Perepis naseleniia i zhilishchnogo fonda Respubliki Tadzhikistan 2010 goda. [Online] Available from: http://www.stat.tj [Accessed: February 2015]. 
TAJSTAT (2014) Agency of Statistics Under the President of the Republic of Tajikistan A number of administrative area units as of January I, 2014. [Online] Available from: http://www.stat.tj/ru [Accessed: February 2015].

Tajikistan overview (2012). [Online] Available from: http://www.akdn.org [Accessed: March 2015].

TJKNEWS.COM (2010) Tadzhikskoe chudovishche. Smozhet li strana pobedit korrupciiu. [Online] Available from www.tjknews.com [Accessed: April 2011].

Thorbecke. E. (2007) The Evolution of the Development Doctrine, and the Role of Foreign Aid, 1950-2005. In: Shorrocks, A. (eds.) Studies in Development Economics and Policy. Helsinki: UNU-WIDER. [Online] dx.doi.org/10.4324/9780203461761.p1 1.

Trilling, D. (2014) Badakhshan Unrest, In Tajikistan's East, New Castralties Portend Tit-forTat Violence. [Online] Available from: http://www.eurasianet.org [Accessed: December 2014].

Troschke, M. (2012) Social Capital and the Formation of a Market Economy: the Case of Uzbekistan. In: Ahrens, J., Hoen, H. W. (eds.) Institutional Reform in Central Asia: Politico-Economic Challenges. New York: Routledge.

Tursunov, N.O. (1991) Razvitie gorodskikh i selskikh poselenii severnogo Tadzikistana $v X V I I I-i$ nachale $X X V V$. Dushanbe: Irfon.

UNDP (1993) UNDP and Organization of Civil Society. Oxford University Press: New York.

UNDP (2004) Environmental Learning and Stakeholder Involvement as Tools for Global Environmental Benefits and Poverty Reduction. UNDP Project document. UNDP-GEF Medium-Size Project (MSP). [Online] Available from: www.undp-alm.org [Accessed: January 2011].

UNDP (2007) Communities Programme (2007 - 2009). Programme Document. Government of Tajikistan and United Nations Development Programme. [Online] Available from: http://bdpfunds.org [Accessed: December 2009].

UNDP (2014) Trade and Human Development. [Online] Available from: http://ww.eurasia. undp.org [Accessed: December 2014].

UNHCR (2004) Uzbekistan: Role of "Mahalla" in Uzbek Society; Whether Mahalla is Involved in Extortion; State Protection. Immigration and Refugee Board of Canada. [Online] Available from: http://ww'w.unhcr.org [Accessed: March 2012].

UNMOT (2000) United Nations Mission of Observers in Tajikistan Unmot. [Online] Available from: http://w'w'w.un.org [Accessed: March 2011].

UNTJ (n.d. [a]) United Nations in Tajikistan Coordination Mechanisms. [Online] Available from: http://www.untj.org [Accessed: October 2011].

UNTJ (n.d. [b]) Disaster Management Resources. [Online] Available from: http://www.untj. org [Accessed: May 2012].

Urinboyev, R. (2011) Law, Social Norms and Welfare as Means of Public Administration: Case Study of Mahalla Institutions in Uzbekistan, The NISPAcee Journal of Public Administration and Policy 4/1. p. 33-57.

USAID (2006) Review of Current Legal Framework of Local Self-Government in Tajikistan. Organization, Functions Finances and Property [unpublished].

USCIRF (2011) Annual Report 20II - The Commission's Watch List: Tajikistan. [Online] Available from: http://www.unhcr.org [Accessed: January 2012]. 
Vasilev, D. V. (2008) Centralnaia Aziia vo vnutrennei politike carskogo pravitelstva. In: Abashin, S. N., Arapov, D. Iu., Bekmakhanova, N. E. (eds.) Centralnaia Aziia v sostave Rossiiskoi imperii. Moskva: Novoe Literaturnoe Obozrenie.

Wiegmann, G. (2005) Loyal Alliances Providing Local Governance in Tajikistan? Berlin: Ost-Europa Institut, Freie Universität.

Wiegmann, G. (2009) Socio-Political Change in Tajikistan. The Development Process, its Challenges Since the Civil War and the Silence Before the New Storm? [Phd dissertation]. Hamburg University.

Williams, G. (2004) Evaluating Participatory Development: Tyranny, Power and (Re)politicization, Third World Quarterly 25/3. p. 557-578.

Wikipedia (n.d.) Kolkhoz [Online] Available from: http://en.wikipedia.org [Accessed: February 2011].

World Bank (2003) Working Together: World Bank Civil Society Relations. Washington: World Bank. [Online] Available from: http://siteresources.worldbank.org [Accessed: January 2013].

World Bank (2013) Indicators for Tajikistan. [Online] Available from: http://www.worldbank.org/indicators [Accessed on September 2014].

Yusufbekov, Y., Babajanov, R., Kuntuvdiy, N. (2007) Civil Society Development in Tajikistan. Dushanbe: Aga Khan Development Network.

Zapaśnik, S. (n.d.) Społeczeństwo tradycyjne Azji Centralnej [unpublished].

Zapaśnik, S. (2006) „,Walczący islam" w Azji Centralnej. Wrocław: Wydawnictwo Uniwersytetu Wrocławskiego.

Zapaśnik, S. (2010) Tolerancja a odmienni kulturowo. In: Jakubowska-Branicka, I. (eds.) O tolerancji we wspólczesnym świecie demokracji liberalnej. Warsaw: Trio.

Zharkevich, I. (2010) The Role of Civil Society in Promoting Political Accountability in Fragile States: The Case of Tajikistan. INTRAC. [Online] Available from: http://www. intrac.org [Accessed: March 2012]. 



\section{Illustrations}

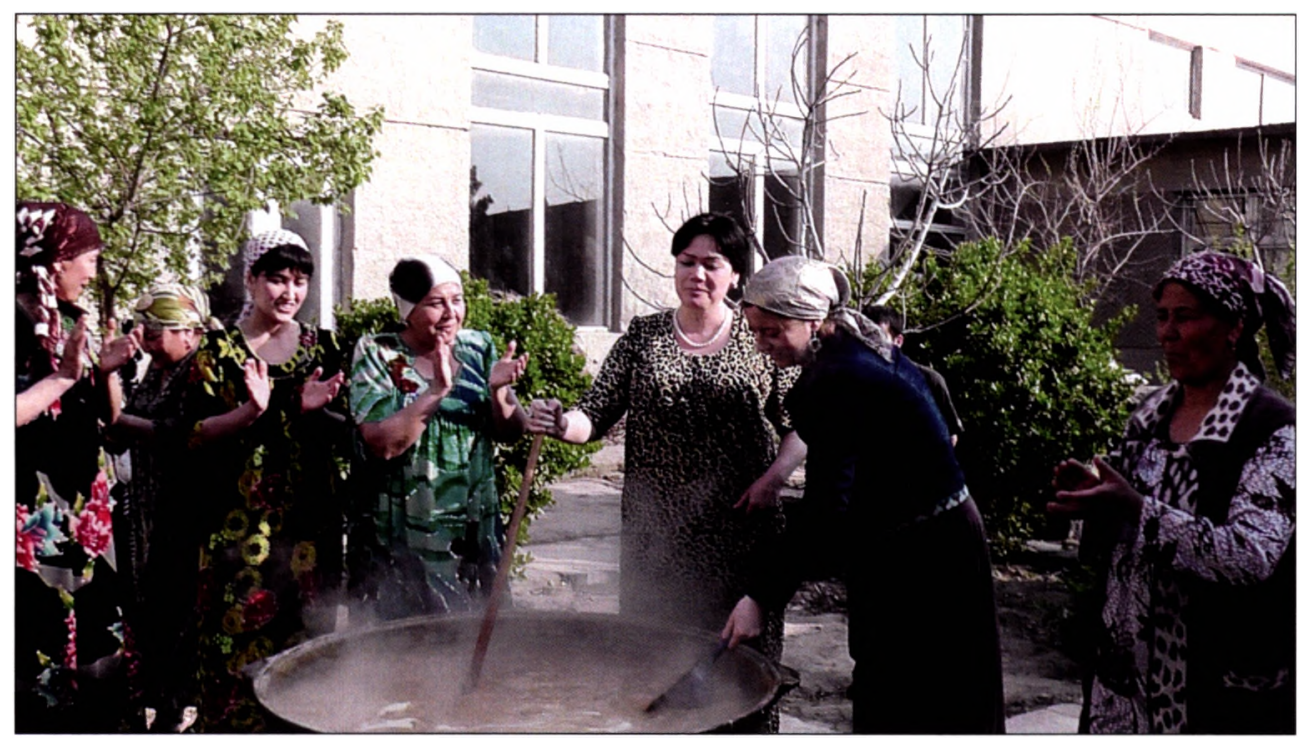

1. Cooking sumalak at the beginning of spring, Khujand (photo A. Cieślewska)

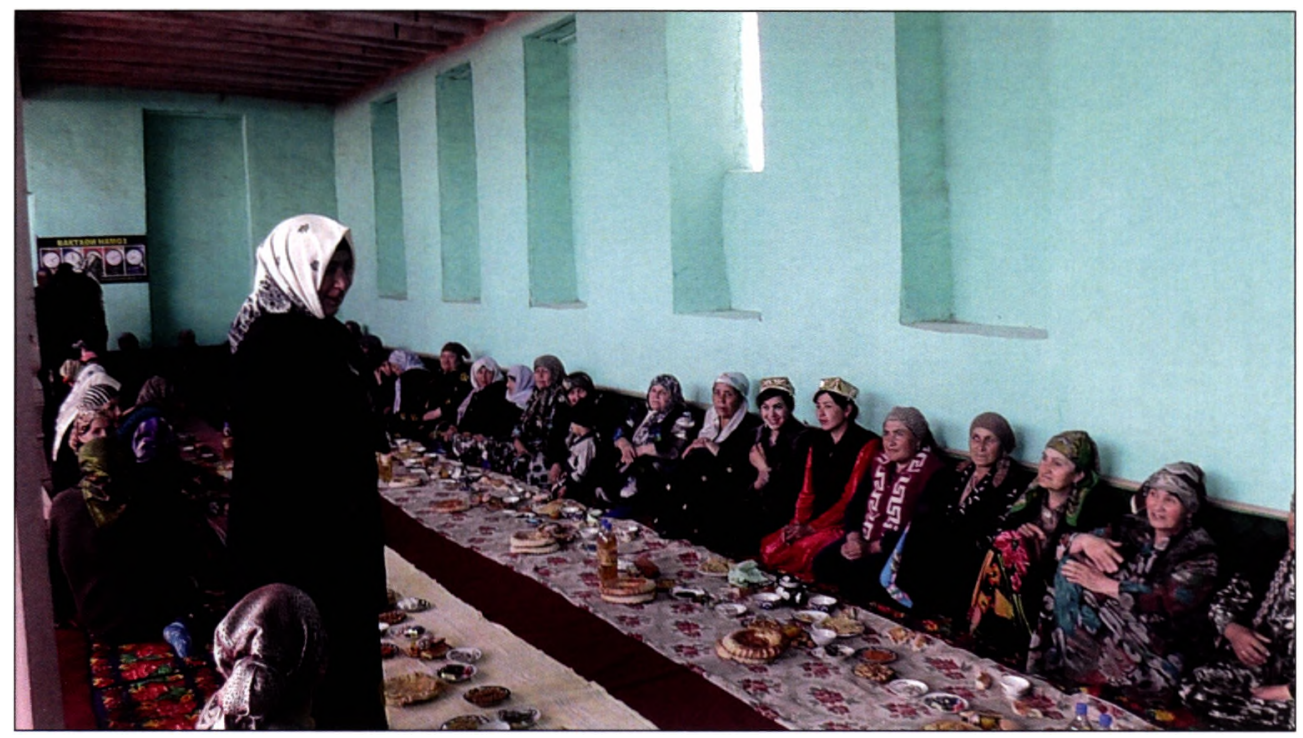

2. Hodoi (an offering) organized by women at the beginning of spring in the mazar in Istpisor village, Sughd region (photo A. Cieślewska) 


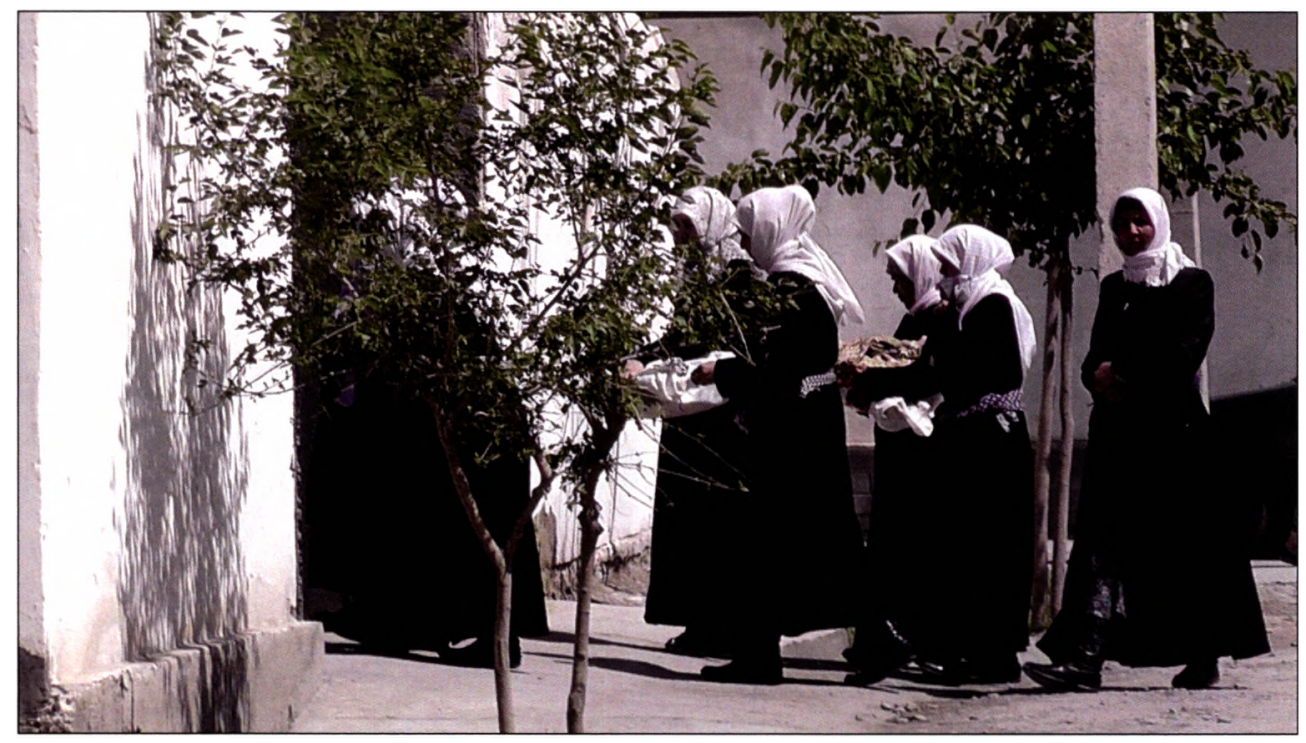

3. Mourning women, old mahalla, Khujand (photo A. Cieślewska)

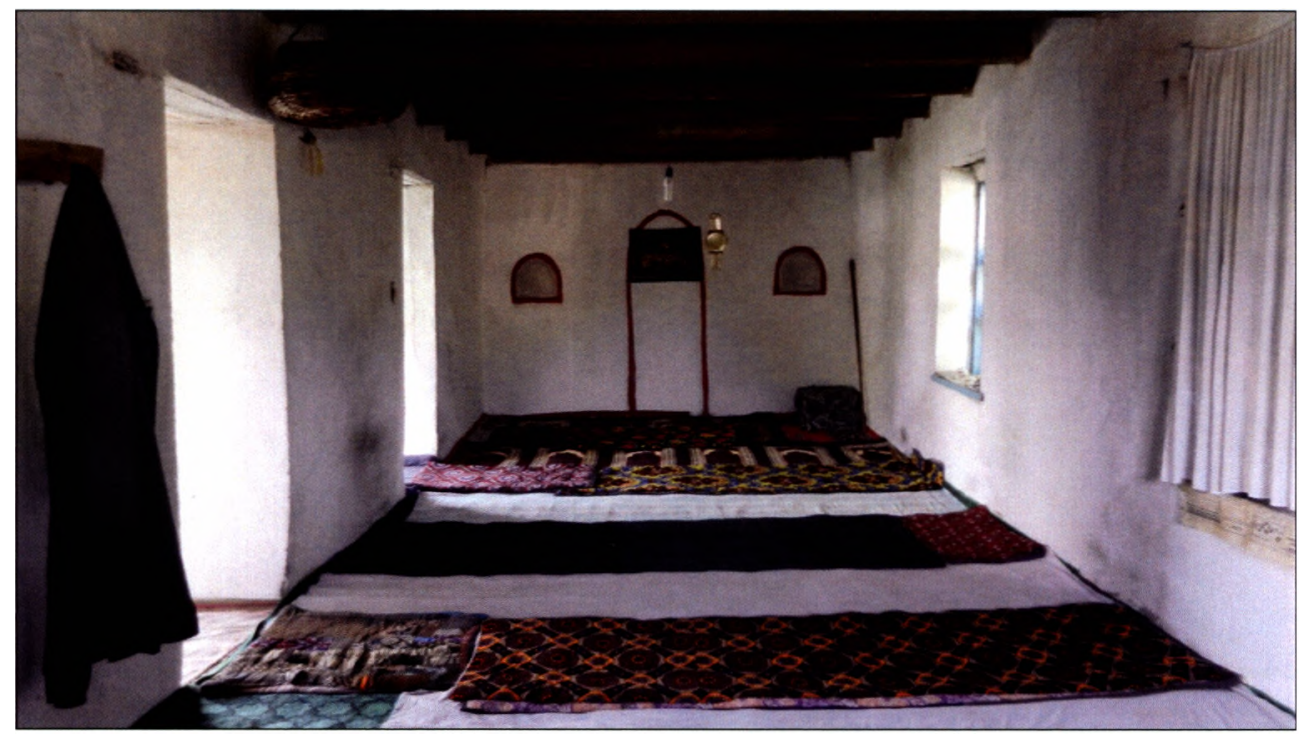

4. A village mosque, Spitamen district (photo A. Cieślewska) 


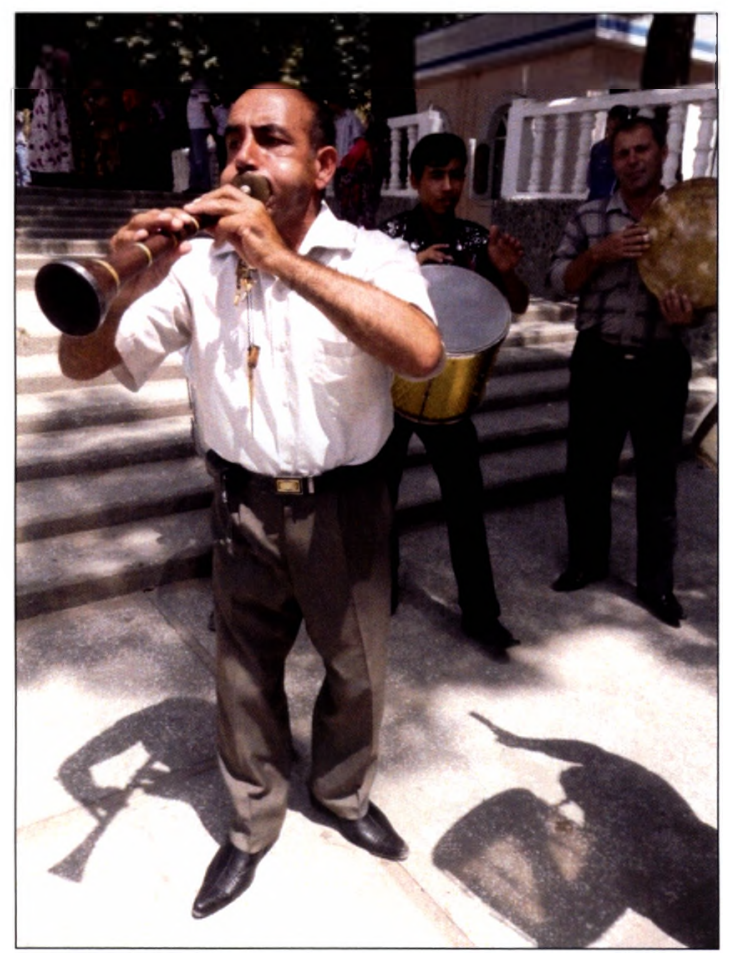

5. Musicians, Hisor Town

(photo A. Cieślewska)

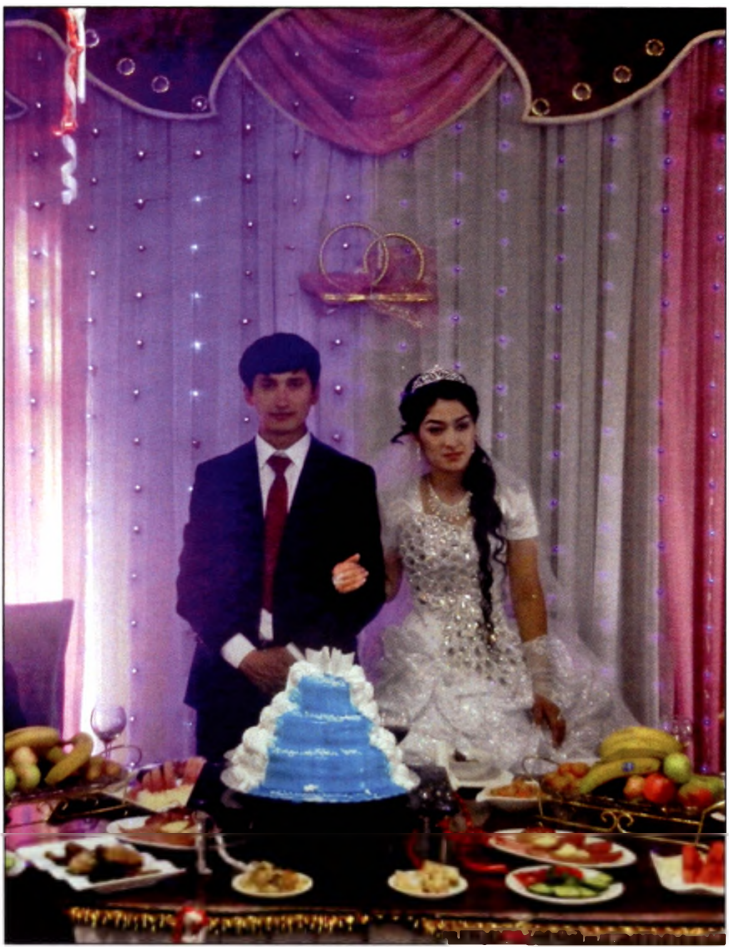

6. Newlyweds at a wedding ceremony, Kurgan Tyube (photo A. Cieślewska) 




7. A mazar on the border with Afghanistan, jamoat Sarichashma, Shuroobod (photo A. Cieślewska)

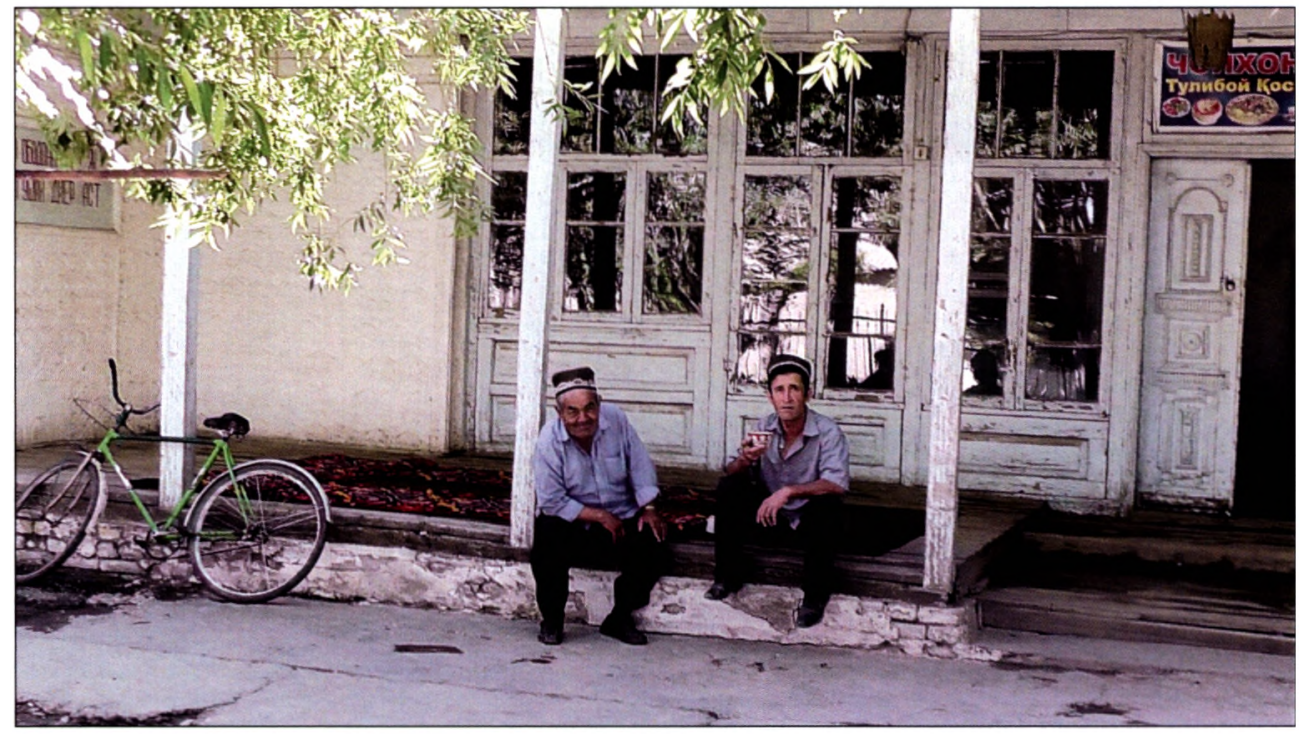

8. Chaykhona, jamoat Kistakuz, Sughd region (photo A. Cieślewska) 


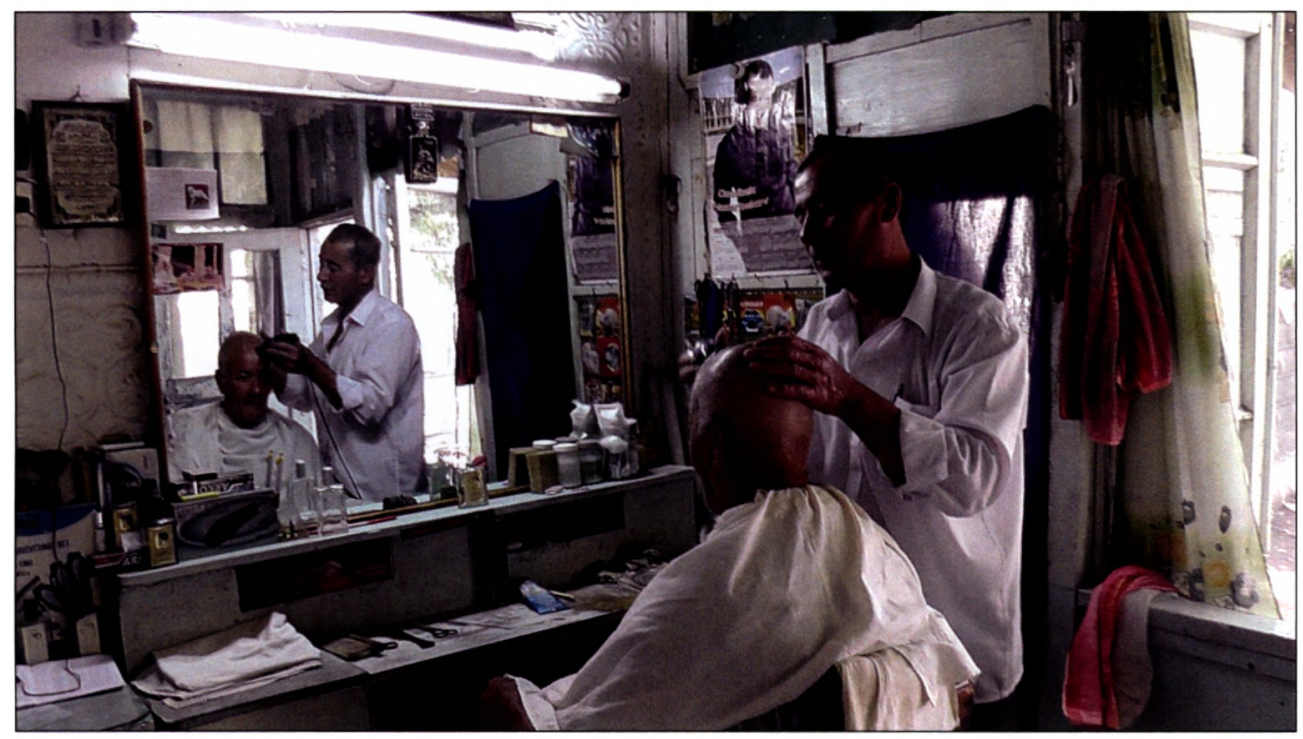

9. The mahalla's barber located next to the chaykhona building, jamoat Kistakuz, Sughd region (photo A. Cieślewska)

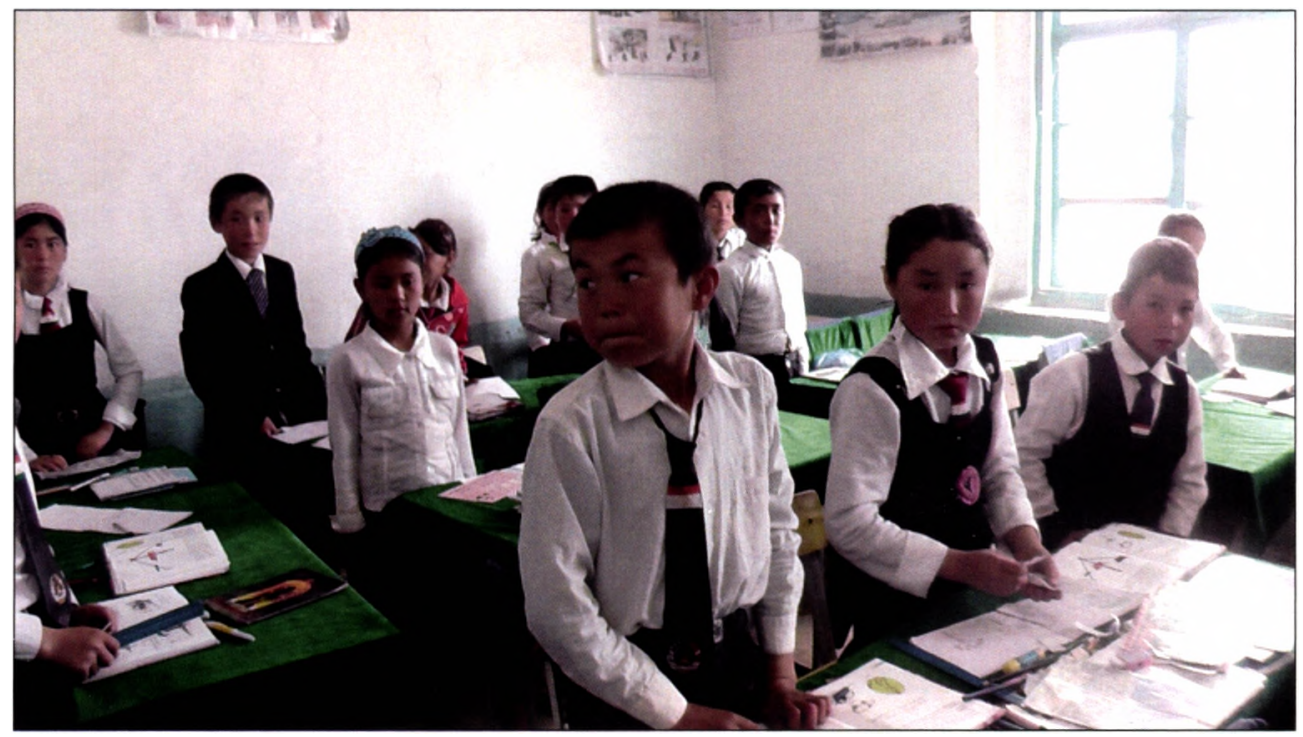

10. School students, qishloq O., Jillikul districı, Khatlon region (photo A. Cieślewska) 


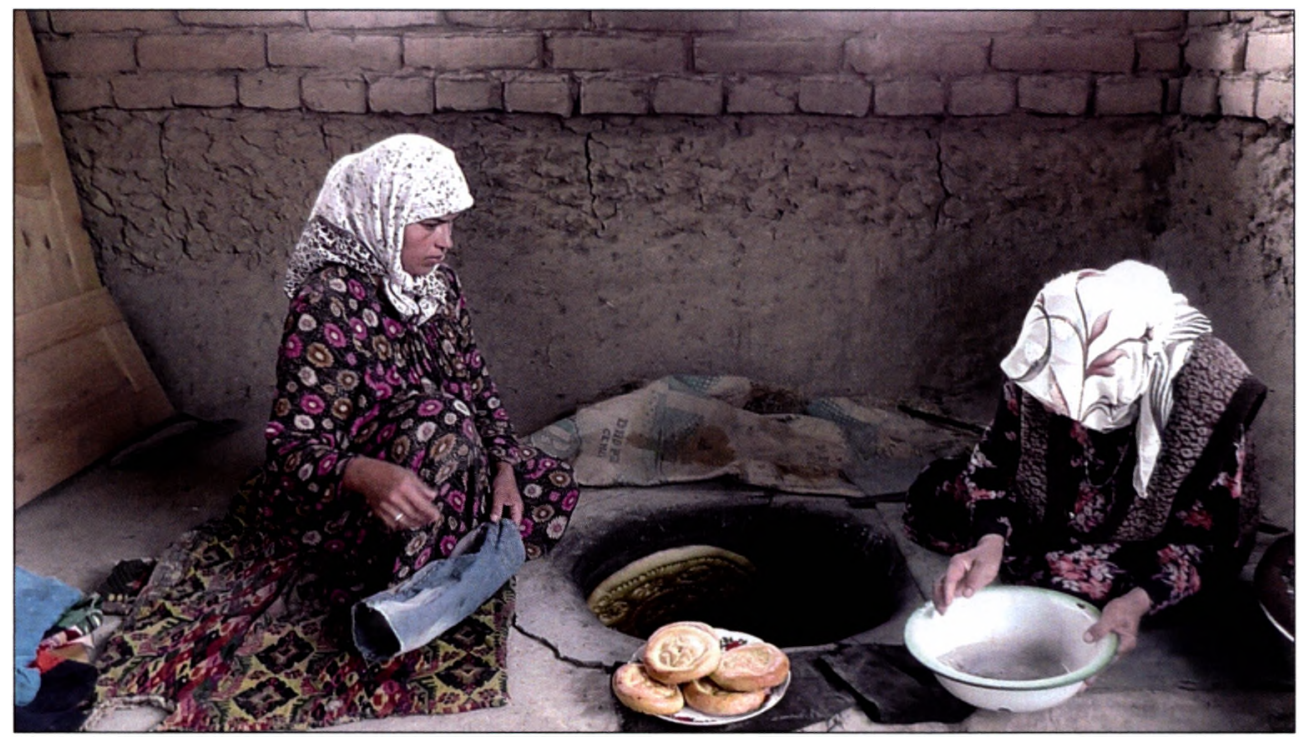

11. Making bread, mahalla T., Qumsangir district, Khatlon region, (photo A. Cieślewska)

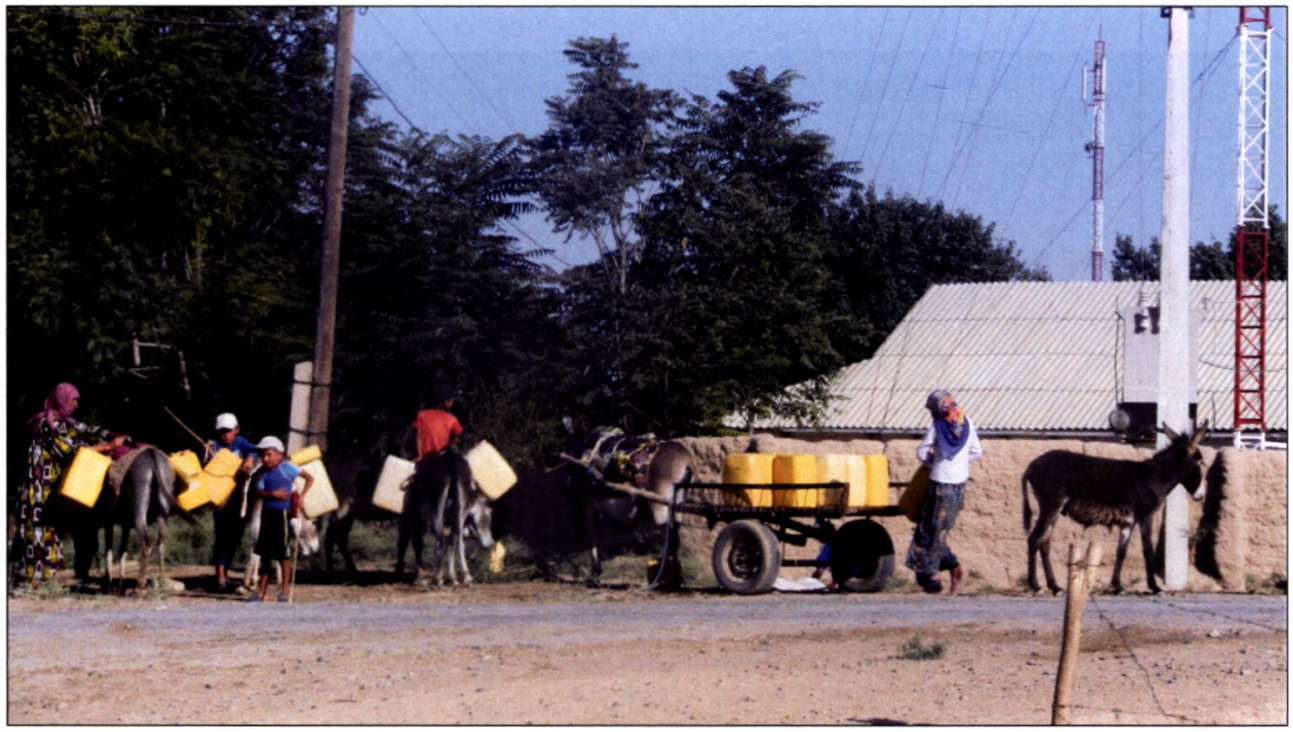

12. Taking water from the irrigation canal located three kilometres from qishloq $\mathrm{O}$. populated by Kungrats, Jillikul district, Khatlon region (photo A. Cieślewska) 


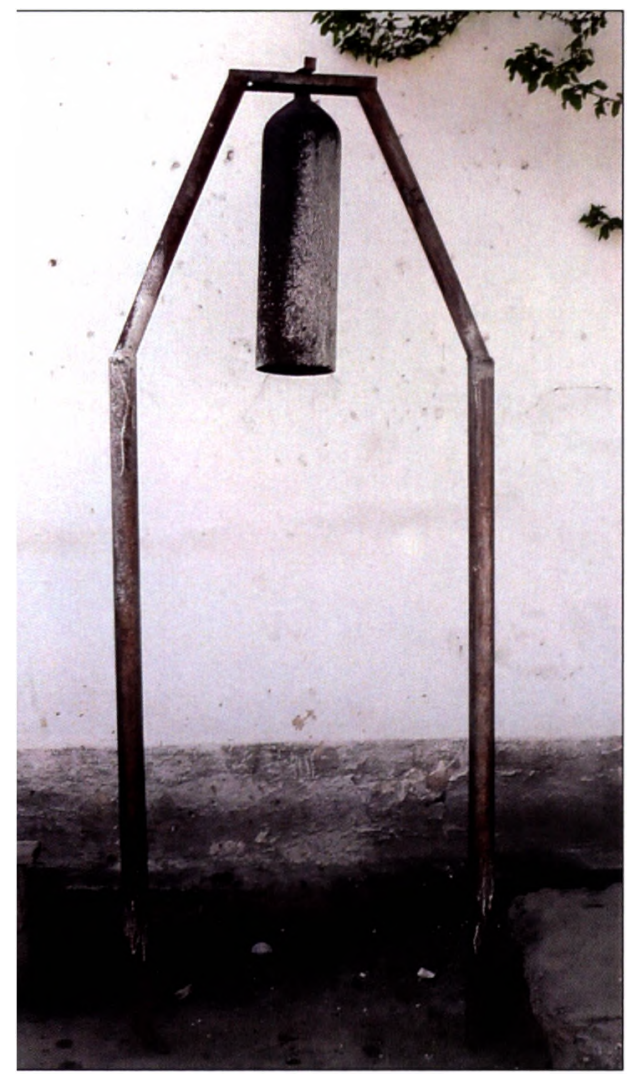

13. Bell in front of the mosque to call residents for special events, old mahalla in Khujand (photo A. Cieślewska)

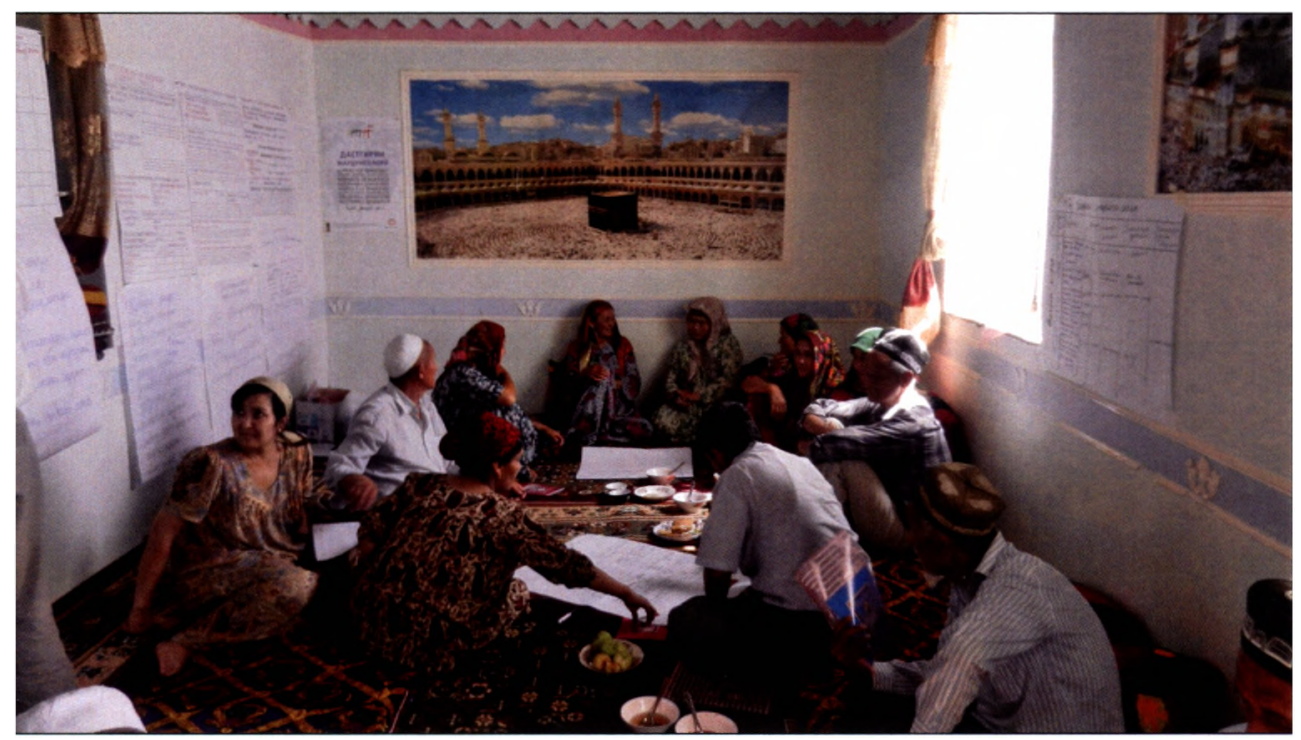

14. A seminar organized by the Polish Center for International Aid and NGO Mehrangez, qishloq D. populated by Kungrats, Jillikul district, Khatlon region (photo A. Cieślewska) 


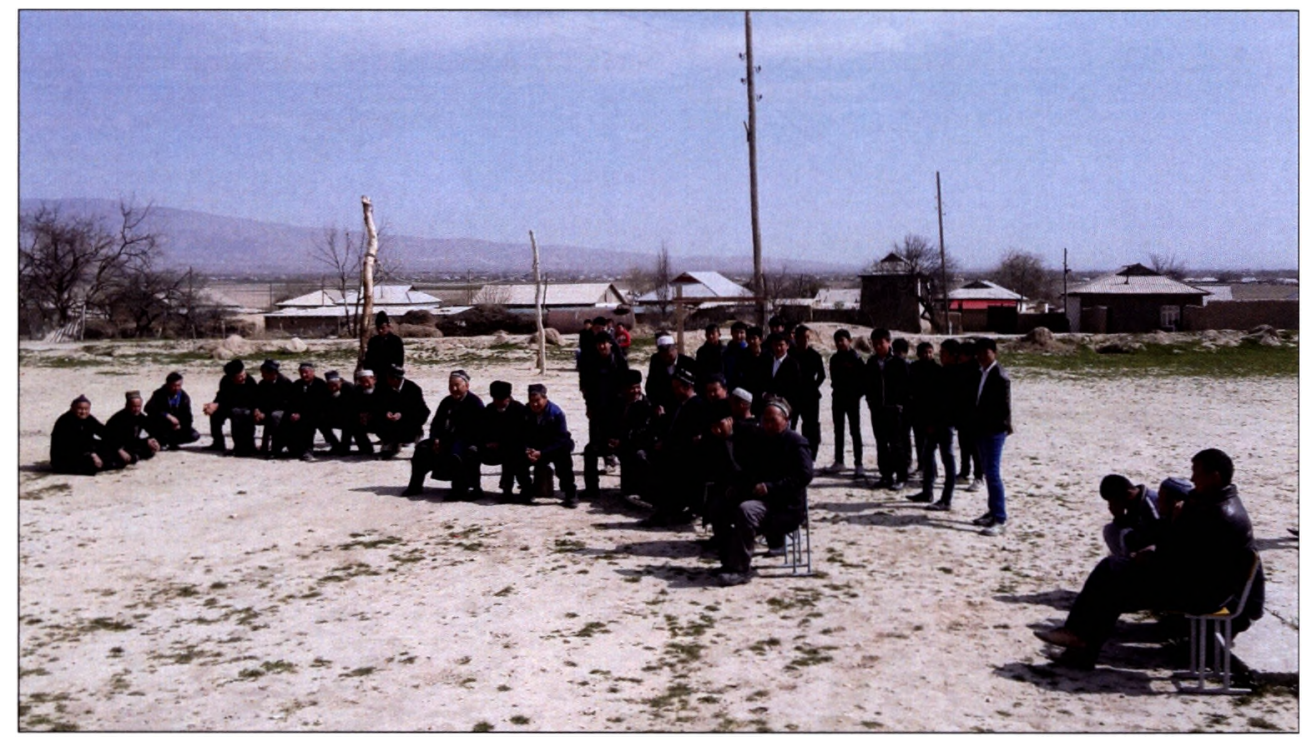

15. A majlis with the participation of the PCIA and NGO Mehrangez, qishlog O. populated by Kungrats, Jillikul district, Khatlon region, (photo K. Szalbot)

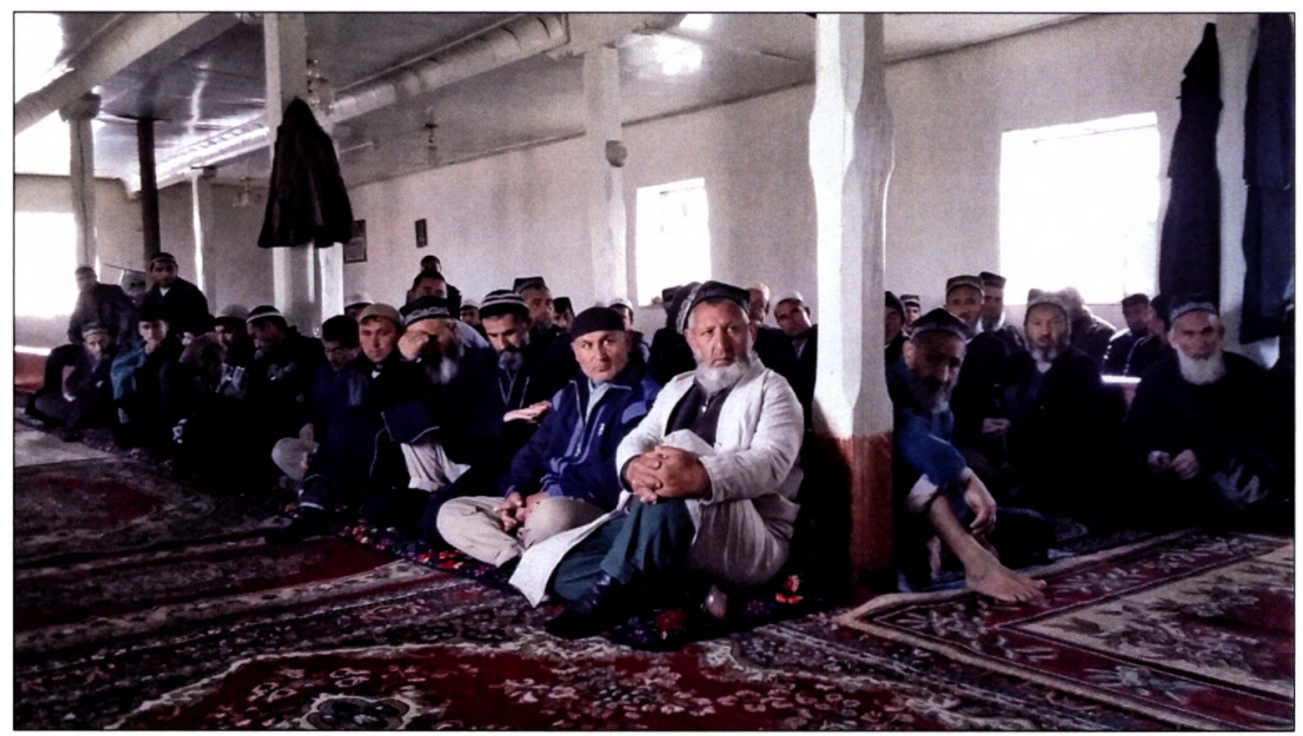

16. A majlis with the participation of the PCIA and NGO Mehrangez, mahalla $\mathrm{H}$. populated by Gharmis, Qumsangir district, Khatlon region (photo K. Szalbot) 


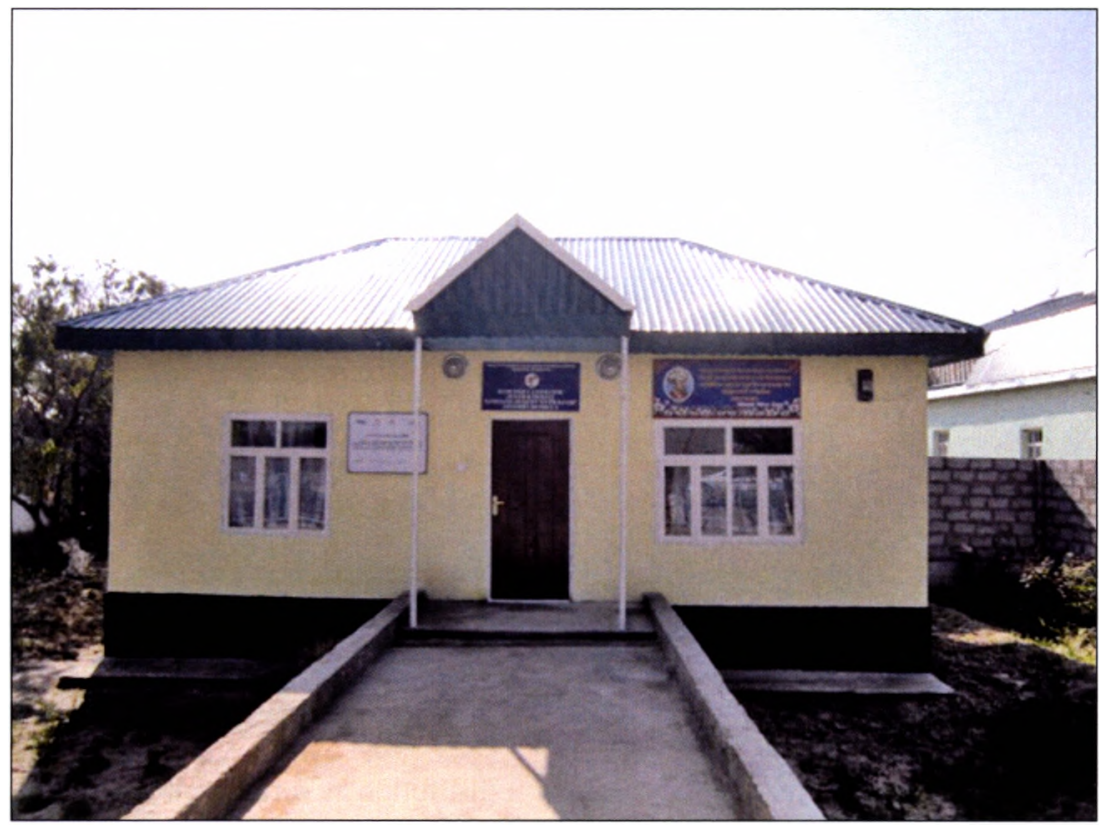

17. A primary-care clinic built by the community with the assistance of the PCIA and NGO Mehrangez, mahalla N., Jillikul district, Khatlon region (photo A. Cieślewska)

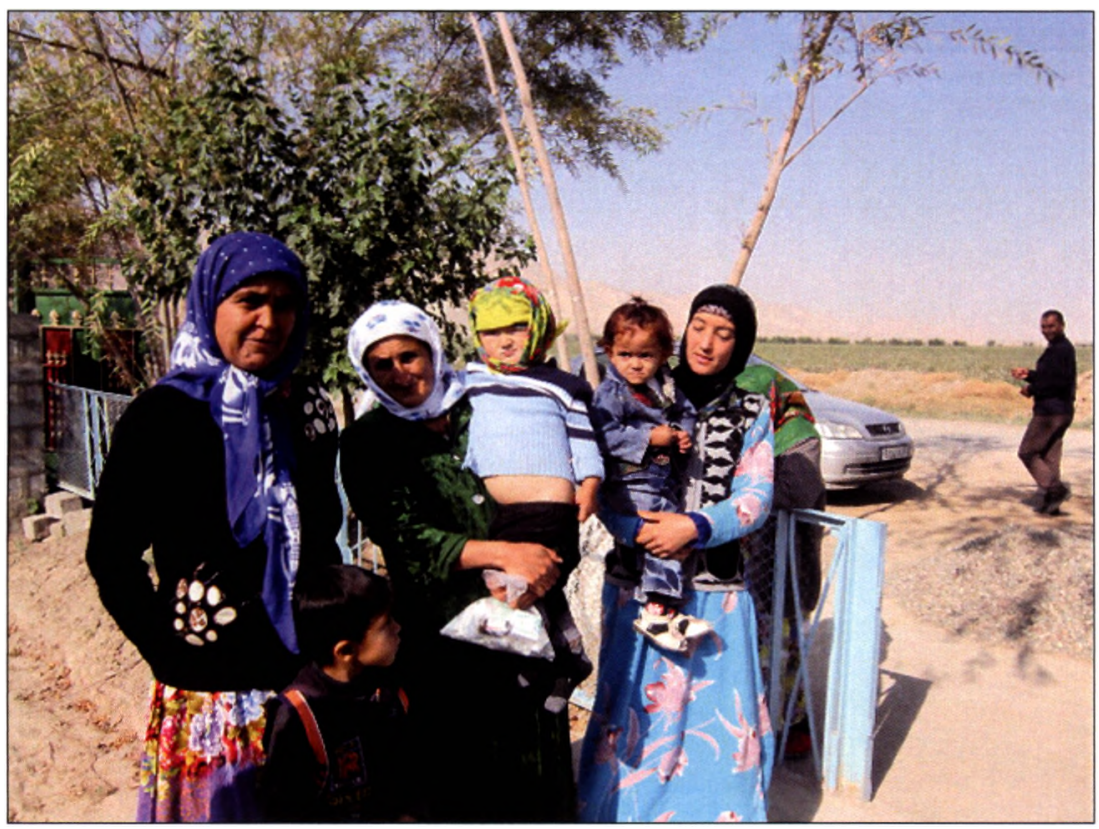

18. The patients of a primary-care clinic, mahalla N., Jillikul district, Khatlon region (photo A. Cieślewska) 


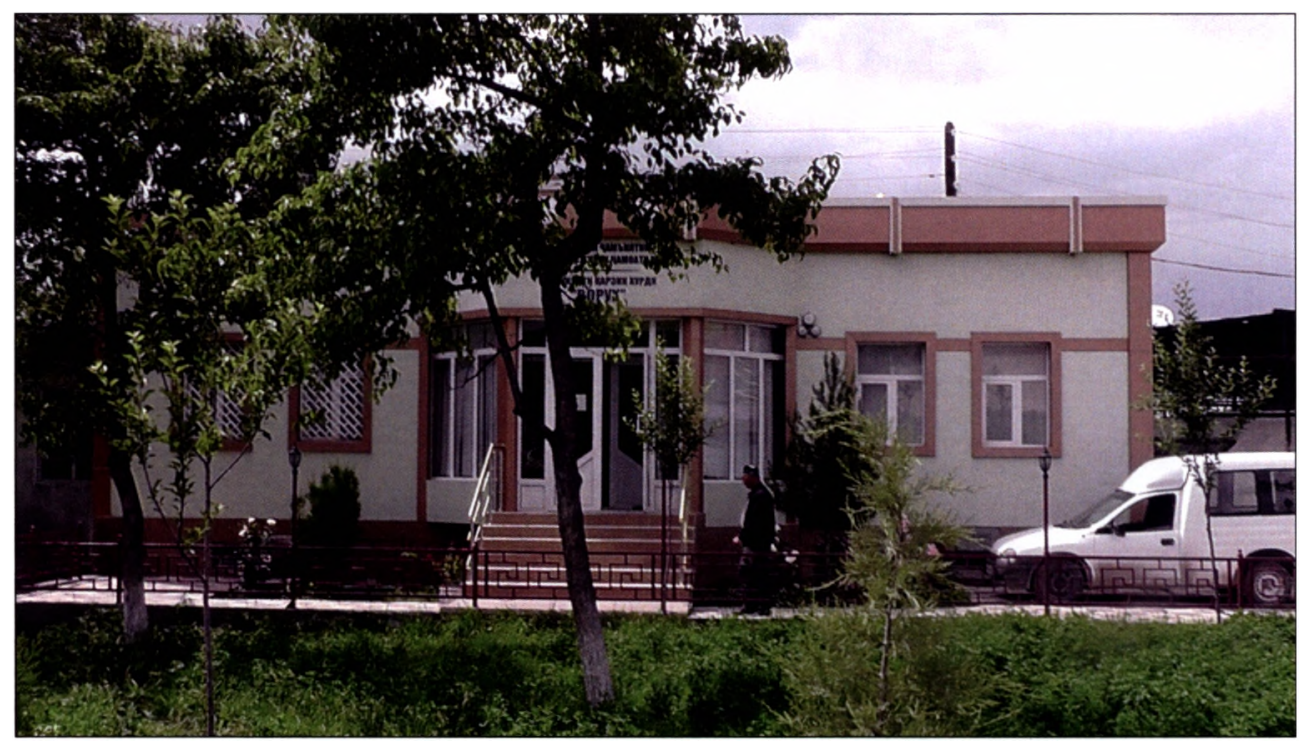

19. The Jamoat Resource Centre and Microfinance Institution in Vorukh (photo A. Cieślewska)

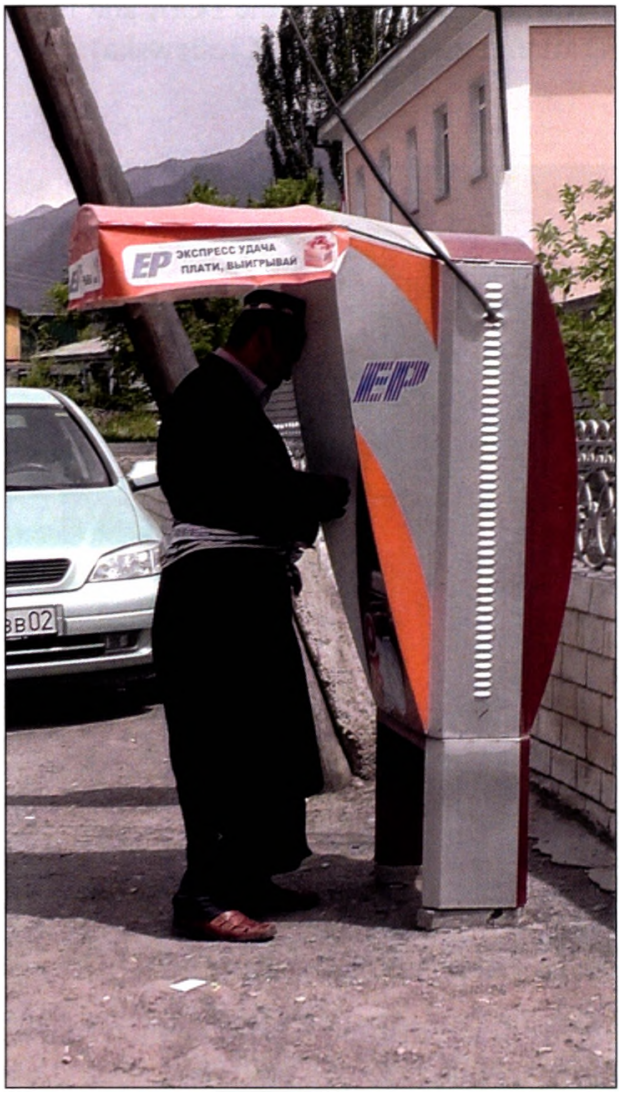

20. In the street in Vorukh (photo A. Cieślewska) 


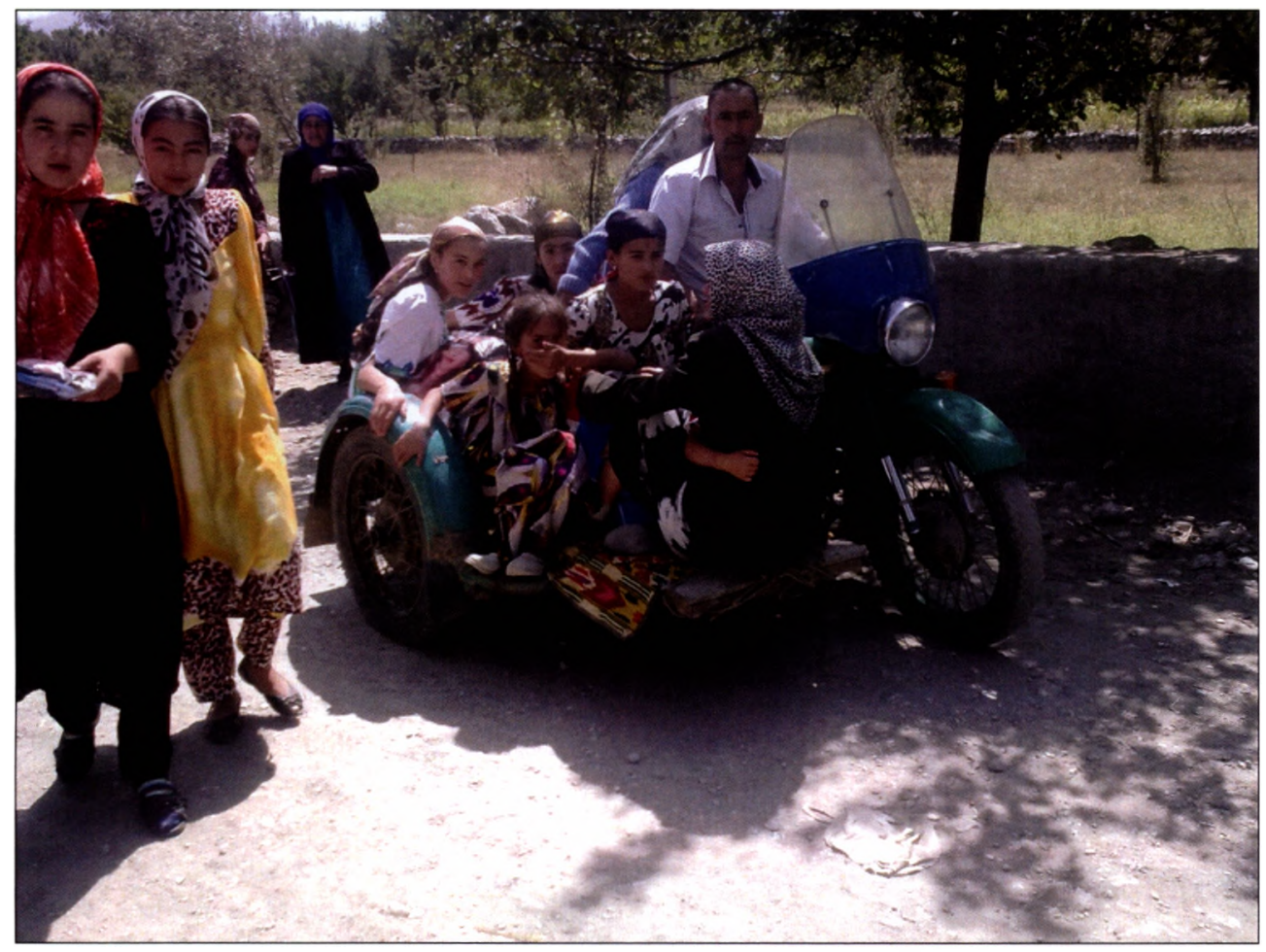

21. On the way to the bazaar in Vorukh (photo A. Cieślewska)

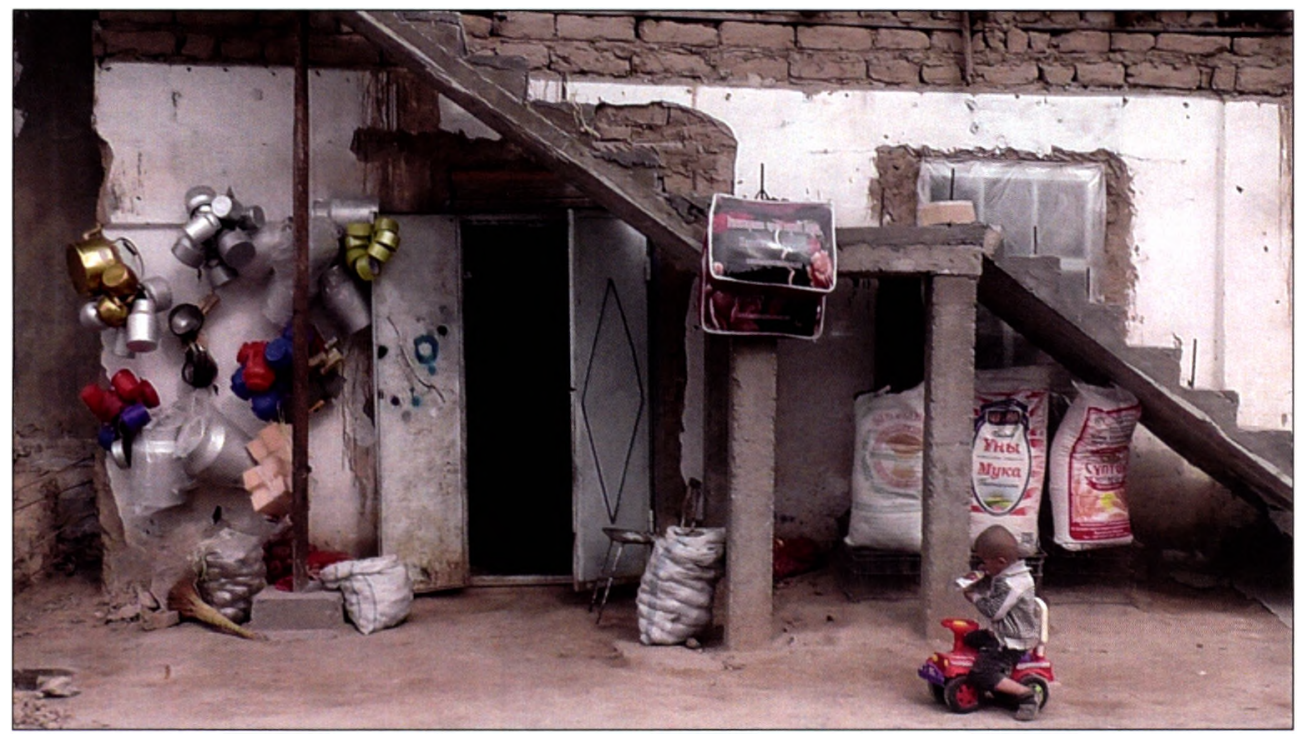

22. A village's shop, mahalla $\mathrm{H}$. populated by Gharmis, Qumsangir district, Khatlon region (photo A. Cieślewska) 


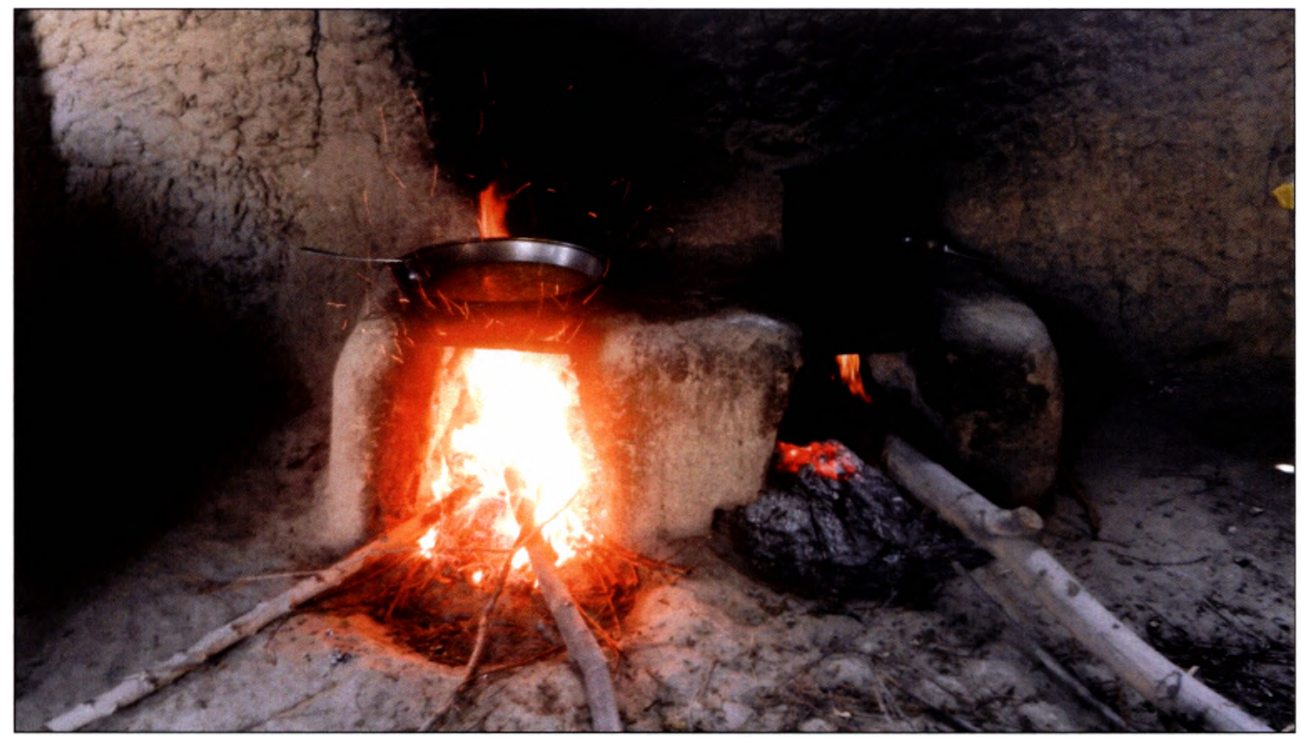

23. A cooking place, mahalla M. populated by Gharmis, Qumsangir district, Khatlon region (photo A. Cieślewska)

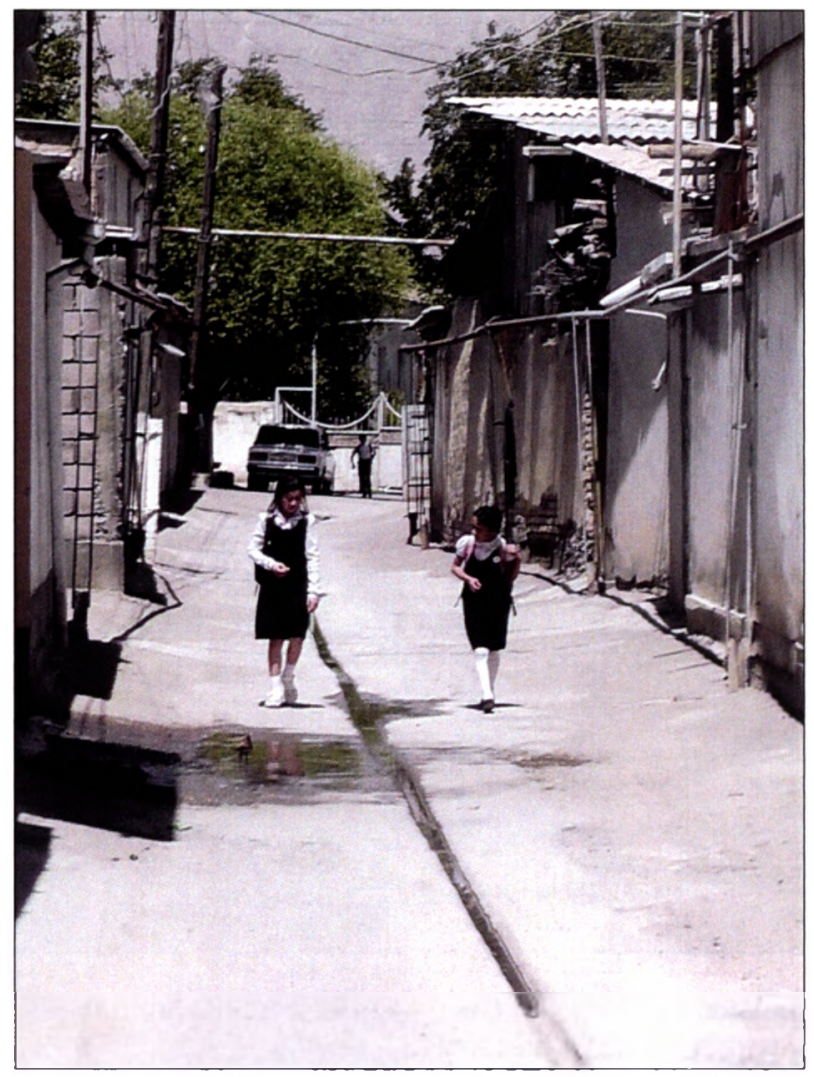

24. In the street, old mahalla in Khujand (photo A. Cieślewska) 


\section{Index of Names}

Abashin Sergei XII. 20, 61-64, 76, 78, 97-98,

217-218, 225-226

Abazov Ratis 18, 217

Abdulghani Abdulvahob 178, 217

Abdullaeva Makhtirat 57, 144-146, 217

Abdulvahhobov Abdunazar 160, 217

Abramov Manoshe 53-55, 217

Abramson David M. 3. 117, 135, 144, 217

Aga Khan IV 152-153

Ahrens Joachim 218, 226

Aitmatov Chingiz 99

Akiner Shirin 24-26, 28-29, 45, 137, 139 , 195, 218

Alimardon Murodali 38

Alimova D. 218, 225

Alutarom, king 174

Arato Andrew 127. 218

Arilkhanova Z. 225

Ata Abdu Rahmon 76

Atlani-Duault Laëtitia 130, 132, 218

Azimova Nadira 71. 78, 221

Babadjanova I. 138, 225

Babajanov Rustam 49, 52, 72, 227

Babur 174

Bahili Islam ben Abdallaha al- 174

Bald B. 218

Banna Hassan al 26

Beissinger Mark R. 225

Bichsel Christine 39, 144, 173, 175-177. 213. 218

Biliang $\mathrm{Hu} 52.218$
Bleuer Christian 19, 223

Bliss Frank 38, 101-102, 110-111, 138, 218

Bobbio Norberto 126-127, 218

Boboyorov Hafiz 3, 77, 83, 87, 92, 101-102. $110,142,153-154.161,167,218$

Bobrovnikov Vladimir 59, 218

Bosworth Clifford 225

Bushkov Vladimir 21-22, 24-27. 29, 42-45. 173-175, 181, 217-218

Buxton Charles 3-4, 132, 136-137, 139-140, 142, 219

Carlson Charles 117, 219

Carothers Thomas 127. 130-131, 219

Chagatay-Khan 22

Chambers Robert 3

Cieślewska Anna XIII-XIV, II, 78, 199, 219

Cohen Jean L. 127, 218

Collins Kathleen 45, 57. 219

Dadabaev Timur 61-62, 65, 219

Davydov Aleksandr 45, 219

De Cordier Bruno 148, 219

De Martino Luigi 220-221. 223

Dudwick Nora 220

Dziekan Marek 45. 58-59.91. 219

Earle Lucy 3-4. 132. 136-137, 139-140, 142. 219

Elcin Boris 29

Engels Friedrich 126

Engvall Johan 31 
Eshonkulov Usmon 101, 219

Evans Peter 129, 219

Falkowski Maciej 31, 219

Filippova Elena 223

Freizer Sabine 3, 141, 220

Gabrieli Francesco 91, 220

Gafurov Uygun 64, 223

Gagarin Jurii 55

Garbutl Anne 220

Garcés de Los Fayos Fernando 32, 220

Genghis Khan 20, 22, 76, 200

Gibb Hamilton Alexander Rosskeen 220

Giffen Janice 3-4, 132, 136-137, 139-140, 142,219

Gomart Elizabeth 194-195, 220

Gorbachev Mikhail 28

Gorshunova Olga 52, 78, 220

Gramsci Antonio 126-127

Guri Bernard 3, 213.221

Hauschildı Line Skou 4-5, 163, 220

Haverkort Bertus 190, 220-221

Hawwa Said 26

Heap Simon 136, 220

Heathershaw John 30, 220

Hedfors Andreas 31, 220

Hegel Georg Wilhelm Friedrich 126

Heinrichs Wolfhart P. 225

Hiemstra Wim 190, 220

Hoen Herman W. 218, 226

Huntington Samuel P. 13, 220

Husaini Saidumar 27

Iarlykapov Akhmed 97, 220

Ilolov Mamadsho 103, 220

Ismail Muhammad ibn 16

Jakubowska-Branicka Iwona 227

Jasieński Bruno 194

Jasiewicz Zbigniew XI, 42-43, 53, 61, 221

Jennings Ray 3,221

Kaczmarski Marcin 34, 221

Kamiagarov Boris 194

Kamoludin Abdullaev 221
Kandiy oti Deniz 71, 78. 221

Karimov Islam 117

Karmy sheva Balkis 21-22, 63, 158, 200, 221

Kassymbekova Botagoz 117, 221

Kemper Michael 223

Kendie Stephen 3, 213, 221

Khachilaiev Nadirshah 26

Khakimov A. 218

Khamidzhanova Mukaddama 53, 56, 221

Khan V. 218

Kharazi Kamal 29

Kholdzhuraev Habibullo 194, 221

Khrushchev Nikita 89

Khudanazarov Dawlat 26

Khudoiyev Mirodasen 103, 220

Kisliakov Nikolai 63, 174, 223

Koehler Jan 157, 160, 221

Koroteyeva Victoria 62. 221

Kramers Johannes Hendrik 220

Kuchukeeva Altinay 139. 221

Kuchnast Kathleen 220

Kuntuvdiy Natalya 49. 52, 72, 227

Lang Józer 221

Layton Robert 130, 132, 222

Lerche Jens 128-129, 222

Lerman Zvi 101, 222

Lewis David 126, 222

Lévi-Provençal Evariste 220

Litvinskii Boris 173, 222

Liu Morgan Y. 135, 222

Lobacheva N. P. 222

Lobo Crispino 152, 222

Lukawski Zygmunt 17. 222

Mahkamov Qahhor 25, 28

Makarova Ekaterina 62, 221

Makowska Agnieszka XI, 11, 83, 199, 219

Malinowski Bronislaw 13

Mamadzhanova Nigina 49, 223

Mamurzoda Nosirdzhon 79, 222

Marat Erica 89, 222

Marc Alexandre 220

Marszewski Mariusz XI. 9

Marx Karl 126

Masaru Suda 61-62, 141-142. 222 
Massoud Shah Ahmad 29, 135

Matusiak Marek 221

Matveeva Anna 24, 28-29, 148, 222

Mawdudi Abulalo 26

McChesney Robert D. 86, 223

Mikulskii Dmitrii 21-22, 24-27, 29, 42-45, 181, 218

Mirpochoeva N. 138, 225

Mirzoyev Karomatullo 30

Molenaers Nadia 130, 223

Motika Raoul 223

Muhammad, Prophet XX, 42, 58, 76, 78, 91

Mukhtarov Akhror 54-55, 59-60, 222-223

Mukarramov 181

Muminov Ashirbek 59, 64, 223

Munteanu Igor 220

Mustafaev Sh. 218

Nabiev Rahmon 26, 28

Najibullah Farangis 122, 147. 223

Narshakhi 53

Niechciał Paulina 30

Niyazi Aziz 64, 74, 85, 123, 223

Niyazov Abdurasul 54, 223

Nourzhanov Kirill 19, 223

Nuri Said Abdullo 26

Olimov Muzaftar 46, 74, 105-107, 114, 223

Olimova Saodat 23, 46, 49. 74, 105-107. 114,223

O'Loughlin John 139, 221

Olzacka Elżbieta 30

Osamu Ieda 222

Peshkova Svetlana 78-79. 223

Pisarczyk (Pisarchik) Antonina 63, 85, 223

Poliakov Sergei 18, 54, 56, 58. 96-97, 179$-180,224$

Prozorov Sergei 218, 221

Pyatibratova Alla 224

Qayumarsi Ato 27, 224

Qutb Muhammad al 26

Qutb Said al 26

Rahmatoloev Bahromsho I62

Rahmon Emomali (formerly Rahmonov Emomali) 29-32. 168. 212
Rakhimov Haji Abdurazzoq 182

Rakhimov Rakhmat 45, 49-52, 56, 72, 84$-85,224$

Rapińczuk Magda XI, 69

Reeves Madeleine 173, 224

Reichl Karl 201, 224

Reichmuth Stefan 223

Renard Robrecht 130, 223

Roche Sophie 19, 30, 220, 224

Roy Olivier 26, 97-98, 101, 131-133, 135, 148, 224

Ruffin M. Holt 223-224

Sabyrbekov Arslan 178, 224

Sadiq Jafar al- 16

Sahadeo Jeff 224

Sarsembekov Tulegen 194. 224

Sarvinoz Rukhullo 30, 224

Schacht Joseph 220

Sedik David 101, 222

Shamsiddin Karimov 136, 225

Shaniiazov Karim 55. 225

Sharipova G 138, 225

Sheibani Khan 22

Shigabdinov Rinat 64, 223

Shorrocks Anthony 226

Shustov Aleksandr 30, 225

Sievers Eric W. 55, 62, 117, 212. 225

Sotorov Eshbek 204

Stalin Iosif 181

Stiglitz Joseph 128-129, 225

Stryjewski Radosław XI, 118, 120, 208, 225

Stavrakis Peter 130, 225

Strachota Krzysztof 221

Sublet Jacqueline 42, 225

Sukhareva Olga 43, 53-54, 59, 66, 70-71, 84. 87-88, 225

Sultanova Razia 77-78, 225

Szalbot Kasia XI, XIII-XIV

Tabyshalieva Anara 142.225

Thorbecke Erik 128-129. 226

Tishkov Valerii 223

Tocqueville Alexis de 126

Tomohiko Uyama 222

Trilling David 31, 226

Troschke Manuela 117, 226 


\section{Index of Names}

Turadzhonzoda Haji 181

Tursunov N. 174. 226

Tyurjacv Farrukh 57, 144-146, 217

Urinboyev Rustamjon 92, 117, 141, 226

Van ,t Hooft Katrien 190, 220

Vasilev D. 60. 226

Wali Muhhamad Amoni 76. 87,

Wardak Amin 135

Waugh Daniel 223-224

Weiner Myron 220

Wiegmann Gunda 33, 39, 57, 157, 162, 164, Ziazikov Murat 47

$166,169,226$

Williams Glyn 5, 227

Young Craw ford 225

Zanca Russell G. 224 98,227

Zarathustra 55 227

W'ierzbow ska-Miazga Agata 34. 221

Yassavi Khoja Ahmat 76

Yusufbek ov Yusuff 49, 52, 72, 227

Zapaśnik Stanislaw XI, 9, 14, 42-44, 50-51.

Zharkevich Ina 132, 137-139, 141, 147-148. 


\section{Index of Places}

\section{List of abbreviations}

c. - city

d. - district

c. - enclave

j. - jamoat

m. - mountains

r. - river

reg. - region

t. - town

v. - valley

vil. - village

Afghanistan XIII, 15-16. 18. 21, 24, 28, 33, 38, 45. 131, 135. 157. 159-160. 195, 197, 200. 205

Africa 40, 128

Ak-say, vil. 176-179. 183, 185-187

Alai, m. 16, 172

Almaty. c. 39

America

Latin America 127

South America 128

Andijan. c. 16

Aral Sea 18

Armenia 40, 130

Asht, d. 145

Asia 40, 153

Central Asia XI, XVI, XX, 1-2, 4, II, 14-17, 20-22, 26-28, 31, 33-34, 36, 39. $41-44,49,52-57,59,65,73-74.76-77$. $82,85-86,96-99,119,122,132,139$. 144, 146-147, 172, 190, 200-201, 211 South Asia 79
Astrakhan, c. 26

Azerbaijan 25, 40, 130

Badakhshan, reg. $16.25,38,152-153,164-$ $-165.198$

Gorno-Badakhshan Autonomous Oblast (GBAO) XV, 18, 21, 30, 103-104, $151-152$

Bahmal, vil. 145

Baldzhuan. reg. 21

Bangladesh 144

Barak, e. 173

Batken, d. (Batkenskaia oblast) 6, 24, 31, 173, 176-178

Bishkek, c. 39

Bokhtar, d. 6. 11, 85, 191, 197

Bukhara, c. 16, 20, 43, 53-54, 58, 85, 157. 180,198

Bukhara SSR 17

Chagam, j. 158-159

Chechnya 47,73, 135

China 15-16, 34-35, 38

Chorku, t. 173, 175. 181

Dagestan 97

Dangara 30, 196-198

Darvaz. reg. 20-21

Dashtijum. j. 158

Doghiston. j. 158-159

Dushanbe. c. XI, 10, 17, 23, 25, 27, 30, 32, $39,43,46,50,56-57,63,84,102-104$, 
$108,111,114-115,122.136,138,142-$ $-143,151.153,190.204$

Eastern Bukhara 17-18, 41, 96, 200

Emirate of Bukhara 16-17, 96

Estonia 40

Europe 16-17, 34, 96, 149

Central Furope 95, 131

Eastern Europe 95, 127, 130-131, 139

Western Europe 17, 128, 144

Faizabad, t. 85, 196, 198, 205, 207

Ferghana, c. 16

Ferghana, v. 10-11, 16, 18. 21, 38-39, 50, 78, 119. 144, 172-175, 179-180. 191, 196, 198, 202. 205-206

France 34

Ganchi, d. 10. 24. 64, 108, 191

Georgia 40, 130

Germany 34, 37

Ghafurov, d. 9-10. 52. 62. 67, 71. 90

Gharm, d. 24. 69. 85, 143, 205-207

Gori. c. 140

Gozimalik. d. 196, 204

Grozny, c. 47

Hisor, d. 9-10. 21-22, 38 139, 205, 207

Hisor. 1. XIII. 190

India $16,35,144$

Ingushetia 47-48

Iran 29, 34-35, 148

Isfara, d. 6, 9, 24, 27, 31, 64, 70, 79, 90, 173$-174,176-178,181-182.188$

Isfara, t. 174

Isfarasay, r. (Isfara) 173-176

Israel 144

Istaravshan, t. (formerly Ura Tyube) 43, 57. 63, 136

Istpisor, v. XIII, 52

Italy 34

Jalalladin Rumi, d. (formerly Kolkhozabad) 200

Jangy-Aiyl, e. 173

Japan 33. 182
Jillikul, d. XIII-XIV, 6, 11, 118, 120, 191. 196. 198-200, 204

Kairagach. e. 173

Kalacha. e. 173

Karategin, reg. 21, 174

Kazakhstan 37, 41, 57

Kazakh Autonomous Soviet Socialistic Republic (formerly Kirgiz Autonomous Soviet Socialistic Republic) 17

Kazakh SSR 18

Kazan. c. 180

Khanate of Kokand 16-18, 96. 174, 180

Khatlon. reg. XIII-XIV. 6, 9. II, 24. 38. 68. 76, 83, 103-104, 109, 113, 119. 138. $148,151-153,157,191.194$

Khorasan 22, 53

Khoresm SSR 17

Khorog. c. 27. 30

Khovaling, v. 136. 153

Khujand. c. (formerly Leninabad) XI. XIII. 9-10, 20, 27. 57, 63-64, 68, 71, 73, 76. $79,84,100,102,107,118-119,141$, $143,147-148,168,174,181,184,187$, 190

Kistakuz j. XIII

Kokand, c. 174, 179-180

Kuliab, c. 76, 157

Kuliab, d. XI, 21. 24, 27, 29. 136. 157, 159. $162,194,205$

Kuramin, m. 174

Kurgan Tyube, XIII, c. 6, 21. 23-24, 43, 69. $73,113,138,152,189.191,194-196$. 198. 200

Kyrgyzstan 6, 10-11, 15, 24, 31, 41, 53, 62. $73.83,97.130,139,144,172-173.175$. $177-179,191$

Kirgiz Autonomous Oblast (formerly Kara-Kirgiz Autonomous Oblast) 18

Kyrgyz SSR 18, 24, 172, 176-177

Langardara. j. 158

Latvia 40

Leninabad, c. (now Khujand) 17, 24, 27-29, 136, 176. 179, 181, 190. 198, 205, 207 Lithuania 40 
Mawarannahr 20, 22, 179

Mecca, c. 54, 86

Middle East 16, 79, 147

Moldova 40, 130-131

Moscow, c. 26, 28-29, 132, 178

Muminabad, d. 153

Namangan, c. 16

Naryn, c. 62

Naryn, reg. (Naryn oblast) 97

Nazran, c. 47-48

Nogai, d. 97

Norway 34, 185

Nurek, t. 32. 196-197, 205

Osh, c. 16

Osh, d. 176

Pakistan 144, 151

Pamir, m. 16

Pamir, reg. 21, 26

Panj, r. 157

Penjikent, t. (Panjikent) 24, 27, 38, 63

Poland 34, 70, 131, 139, 191

Qabodiyon, reg. 21-22, 24, 200

Qumsangir, d. XIII-XIV, 6, II, 69, 191, 205. 207

Rasht, v. $30,38,151,153,196$

Riyadh, c. 46

Russia 17, 26, 28-29, 31-32, 34-35, 39, 57, $60,70,72-73,80,92,143,158,168$. 182-183, 186-187, 195, 202

Russian Empire 180

Russian Federation 40, 97

Russian Soviet Federative Socialist Republic (Rossiiskaia Sovetskaia Federativnaia Socialisticheskaia Respublika) 18

Samarkand, c. 16, 20, 50, 198

Samarkandek, v. 175

Sarichashma, j. XIII, 158

Sarvak, e. 173

Shakhimardan, e. 173

Shartuz, d. 169, 200
Say Kshemysh, r. 173

Shuroobod, j. 157-158, 160

Shuroobod, d. XI, XIII, 6, 9, 62, 75-76, 90 , $109,113,152-155,157-160,162,164-$ $-165,168-170$

Sogdiana 21

Sokh, e. 53, 173

South Caucasus 139

South Ossetia 140

Spitamen, d. XIII, 10, 27, 62, 76, 89, 98, 107 . $110,119,146,191$

Sughd, reg. (Sughd oblast) XI, XIII, 9-10, $17,62,67,70,90,103-104,107,110$, $119,138,141,145,152,173,191$

Switzerland 34

Syr-Darya, r. 172

Tajikistan IX, XII-XIII, XX, 1-2, 4-7, 9-13, $15-43,45-46,49-51,53-54,56,61-$ $-66,68-73,79-80,83-86,88-89,93-97$. $100-102,104-105,107-111,113-118$, $121-123,125-126,130-131,134-141$. $145-149,151-154,164-165,169,171-$ $-175,177-179,183,185,189,191,193-$ $-195,199-200.203-204.209 .211-212$. 214-215

Republic of Tajikistan 4, 108, 116, 121

Tajik SSR 17-19, 25-26. 28. 31, 63-64, 97. $172,175-177.181$

Tashkent, c. 50

Termez, c. 200

Tien Shan. m. 172

Tojikon, vil. 176-177, 179

Turkey 17

Turkestan , m. 172

Turkestan Autonomous Soviet Socialist Republic (Turkestan Socialist Federal Republic, TASSR) 17.61

Turkistan Governor-Generalship 17. 60-61

Turkmen SSR 17

Tursun-Zade. t. 31

U'kraine 40

Union of Soviet Socialist Republics (Soviet Union, USSR) XVII, XX. 2, 5, 17-19, $22-26,28-29,31,39-40,53,61-62,64-$ $-65,75-76.97 .99,102,104,114,123$, 
126-127, 130-133. 135-137, 165, 169, Vakhsh, d. 113

173, 175, 177-178, 190, 193-194, 198, Vakhsh, v. 23. 38, 69, 143, 194, 196, 200 203, 208, 212

United Kingdom (UK) 18, 127. 148 Vorukh, e. XI, XIV, 6, 9, 24, 70, 97, 171-188. 214 British Empire 17

United States of America (USA) 2, 34, 36, Warsaw, c. XII, 48, 50, 139 126-127, 144. 149

Washington, c. 3, 128-130

Upper Matcha d. 181

Uzbekistan 2. 15, 29, 31-32, 41. 43, 53. 55, Yagnobi. v. 21-22

61-63, 65-66. 116-117. 125. 130-131,

$141,144,172-173.200,207,212-213 \quad$ Zarafshan, v. 21. 198

Uzbek SSR 17-18.61-63.172 


\section{Index of Ethnographic Terms}

Adab XIX, 91

Adat (Odat, Urf) XIX. 59-60, 142

Afghans 19,22

Aka (Ako) 202

Ak-suyak (Ok-suyak) XIX, 20

Aloykhona XIX, 5I, 84

Amliak 96

Anasha 160

Aqsaqal (Aqsaqol, Muysafed, Arbob) XIX$-\mathrm{XX}, 50,57,60,66,118,161,185$. 201

Apa 202

Arabs 19,21.24, 54, 158

Arba 199

Arwohlar (e(a)rvah) 43

Aryk XIX. 58, 174, 205

Avlod (Qaw'm, Gru, Tuhm, Heysh, Qabila,

Toyfa, Kynda) XIX-XX, 27, 42-46, 48-

$-49,53,57.76,87,96-97.102,118-119$,

132, 161, 175-176. 180, 182, 188, 197. 200-201, 203

Ayils 62, 118, 200-201

Bakhshy 77. 179. 201

Baraka 20

Barlas 19, 21-22

Bartang 21

Basmachi 18, 157, 182

Berun (Tashkari) 77

Beshbola 200

Bibi otun (Bibi khalifa, Bibi halfalholpa,

Bibi mullo, Bibi otin, Bi otun, oy (u). otyncha) XIX, 52, 71, 77-79. 82, 90, 92 ,

$119,149,180,206$

Bibi Mushkul-kushad 52.78

Bibi Seshanba 52, 78

Bida 79

Chagatay 22

Chakar 53

Chaykhona XIII, XIX, 58, 61, 84-85, 93, 98. 182. 197

Chikon (Dugona) 50

Chilla 85

Chillkhona 85

Churoq 200

Dargah (Astanah) 86

Darun (Ichkari) 77

Darvozi kalon 54

Dastarkhan 71

Dowra 49

Dehqon(s) 97, 100-101

Dehot (Deha) XIX-XX, 53, 103-104

Dua 76. 78

Durmans 19, 202, 204

Eid al Fitr (Uraza-Bayram) 87

Elat 53

Eshoni-bobo 51

Fatwa XIX, 58. 84

Ferghani 174

Fiqh 58 
Gadamgah 86

Galcha XIX, 22, 174

Gashtak (Gap) XIX, 44, 50-52, 161, 188

Garora bandon 81

Gharmis XIV, 27, 194. 196-197, 204-207

Guanxi 52

Guzar XIX-XX, 53, 72, 81. 119, 155-156

Guzarashtan 53

Guzarkoms 61

\section{Hadiths 91}

Hajis 74

Hajj 74

Hanafi 58-59

Hanbali 58-59

Hashar (Ashar; Assar) XIX. 69, 82-83, 110 , 144, 155. 166, 193. 197, 209

Hat 53

Haus XIX, 58

Hayyit 78

Hazars 21,

$\mathrm{Hel} 49$

Hisoris 24

Hujras 64

Hukumat XIX, 69, 79, 106-108, 110, 154$-155,158,164-165,183,185-188,205-$ $-206,215$

Hutba 75

\section{Ichkilik 21}

Ijma 58

Imam (Imom) XIX, 1, 16. 54, 58, 64, 66, $73-74,78,81,86,89,121-122,148$, 179-180

Imam-khatibs 74

Ishan (Ishon) XIX, 42, 73-74, 76-77, 87, 89, 119

Ishkashimi 21

Ismaili 20, 26, 152-153

Ismailism XIX, 16

Ivan 85

Jafari 58

Jamoat (Jamomat) XIX, 51-53

Jamoat (Jamomat) XIII-XIV, XXI, 5-6, 10$-11,14,38,62,67,69-72,76,80-81$, 83, 89-90, 92, 95, 102-116, 118-123,
145-146, 153-155, 158-162. 164. 168. 171-173, 175-176, 178, 181, 183-185. 187-188, 191, 195, 197-198, 201-204, 208-209, 212, 214-215

Jamoati shahrak XX, 102, 105

Jamoati dehot XX, 102, 105

Janoza-namoz 74, 88

Javon (Yosh) 50,

Jura 49,

Jura-boshi 51

Kafirs (Kuffar) 16, 144

Kalla-uilars 175

Kalonikhona (Qalandarkhona) XX.

Kaloniavlod XX, 43

Kaltatai 22

Kampir 50

Karakalpaks 201

Karapches 21

Karateginis 24

Karluks 21

Katagans 19, 21, 198

Katar (Katarlar) 49-50

Kazakhs 19-22, 194, 201

Khat lon 103

Khizmat 66

Khodim (Koybonu, Dastarkhani, Raisi sano/ bonu) XX, 71-72, 81-82, 90, 92

Khodimi guzar 71

Khoja 76

Khozhabachcha 200

Khutbah (Khutba)

Kipchaks 21

Kolkhoz XX, 2, 6, 18, 22, 24, 29, 45. 55, 64. 73, 75, 80-81, 89, 95-102, 106, 110. 119. $132,161,163,172,174,176-177.179-$ $-183,186-188,191,196-197,200,204$, 207-208

Kucha XIX-XX, 72, 81, 85, 119

Kuhistoni XX. 22

Kuliabis 24, 194, 197, 207

Kungrats XIII, 19, 118, 120, 196, 198, 200$-202,204-205,207,212,214$

Kurban-Bayram 87

Kurdas 50

Kyrgyz 16, 19, 21-22, 24, 171, 173-179, 181, $183-185,187-188,194,201$ 
Lakais (Lokais) 19, 21, 202, 204

Madhhab (Madhahib) 58, 85

Madrasa (Madrasah, Madrassah) 55, 58 $60,64,73,75,98,148$

Mahalla (Guzar; Ku) IX, XI-XIV, XIX-XXI, $1-7,10-15,27,38,41,51,53-73,75-85$, $87-93,95,97,103-106,108-111,115-$ $-123,125-126,132,141-149,151-156$, 158. 160-161, 164-168, 170-172, 174, $176,179,183,186-192,195-198,201-$ $-202,204-209,211-215$

Mahalla-dom-kom 119

Maidon 174

Majlis XIII-XIV. XX, 66-67, 72, 155-156. $165-167$

Maliki 58-59

Mangits 21, 200

Marcad (Mazja) 86

Mashhad (Nazargah) 86

Mashvarat (Shuroi Muysafedon, Shuroi Aqsaqal) XXI, 72,

Masjids 122, 180

Matcheni 42

Mauquf 45

Mavlud 78.

Mazar (Mazor) XIII, XX, 78-79, 81, 84-87, $97-98,119,157,179-180,182$

Mechetkoms 61

Mehmonkhona (Oshkhona) XX, 51

Merishkors 21

Mingis 19

Mirob XX. 72, 81, 119

Miyonsolo 50

Momo-doya 81

Mudarris 73

Mufti XX, 58-59, 73, 154

Mugols 21

Mujohids (Mujahideens) 30

Mukhtasib 58

Mulk 96

Mullah (Mullo) XX, 69, 71, 73-78, 81-82, 90, $119,157,166,187.202-203,205-206$

Musabazari 22

Nafa 55

Namaz (Namoz, Salat) XX, 74, 85
Namoz al-jamah 84

Naqshbandiyya 122

Navruz 87

Nikoh 74

Nisba XX, 42

Omoch 52

Oqtana 200

Oshkhur-u obkhur (Toy-khur) 88

Ota 200

Otun $52,77-81,90,149,180$

Ovlyad 20

Oyinli 200

Oytamghali 200

Pamiris 24, 27, 194

Pir 50

Plov (Pilav) 87, 89

Poykor (Vakil) XX-XXI, 70-7I, 119, 183

Qachay 200

Qadi (Qozi) XX. 58-60, 73

Qara-suyak XX, 20

Qiyas 58

Qishloq XIII, XX. 57, 64, 68-69, 103, 110 , $118,120,186,197-198,207,213$

Qora 200

Qovqa 200

Qozi-kalon 58

Qumsangir 103

Rais (Amin) 58-60, 66-73, 76, 80-81, 90, 92, $106-111,113,117-120,143,154-156$, 159, 162-164, 166, 168, 172, 183-184, 186-188, 191, 197, 202-203, 207, 209

Raisi guzar XX, 72

Raisi kalon 172

Raisi khurd 172

Raisi mahalla XX, 66-71, 75, 83, 115-116. $119,143,154,166,182,186,190.197$. 201-202, 204-205, 207. 209

Raion (Nohiya) XX. 103

Ramadan 58, 75.78. 87

Rawzah 86

Ray $\mathbf{5 8}$

Rijal ad-din 59

Rushani 21 
Ruh XX, 43

Ruhoniyat (Ruhāniyat) 59

Savob 85

Sayid XX. 42, 76

Sardori kucha XX. 72. 187

Sart XX, 22

Shafii 58-59

Shaikhs 73-76. 81. 86, 97, 119, 159

Shajaranoma XX, 42, 45

Shia XIX. 16. 20, 56, 58-59

Shiaria (Shiariah, Shariah) XX. 58-60, 91, 101,122

Shirk XXI, 79.87

Shughni 21.42

Shura (Shuro) XXI. 79. 121, 155-156.

Sogdians 174

Sorkhoz XXI, 18. 45. 55, 64, 96-97, 100 , $102,176-177$

Sufi XIX, XXI. 20, 27, 59, 73-74, 76, 122

Sunna (Sunnah) XXI, 58, 74, 91

Sunni 16, 20-21. 56. 58-59. 153, 158

Surras 74

Tahibs 77. 179.

Tajiks XIX. 16. 18-22. 24-25. 28. 42, 44-45, 49-51, 53, 64. 76, 120, 136, 147, 158. 160. 162, 173-179, 185, 188, 194, 196$-198.200,202.204-207$

Takhorat 85

Takhoratkhona 85

Tanzim 89-90. 120

Tarawih 78

Tashkiloti Dehoti XVII, 151.

Tat 22

Tatars 19, 194, 196, 198
Tawhid XXI, 86

Tengkur (Tenggur, Tenggurlar) 49

Tihidon 174

Toy XXI, 88

Toz 198

Tukma 50

Tulpor 200

Tup 43

Tupqara 200

Tura 76

Turkman 200

Turkmens 21, 196. 205

Ulama 73-74. 84. 121

Umma (K'halqiyat, Omma) XXI. 58

Uzbeks XIX. 19-22. 24. 26. 46. 50-51. 57. 76. 119. 158-160. 173. 194. 196. 198. 205-206

Vara 173

Viloyat XXI. 103

Wahabbizm. 181

Wakhis 21,42

Wali (Aw'liya') 20

Waqf (Vaqf) XXI. 45, 58. 60, 85, 96-97

Waqfir 45

Yazgulami 21, 42

Yuz 19, 21-22

Zakat (Zakot) XXI

Zakat-Al Fitr 75

Zimovka 175

Ziyaratgah 86

Ziyofat XXI. 50 



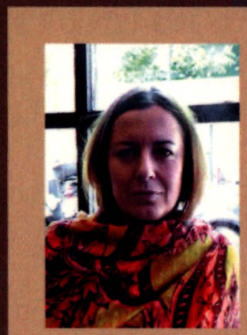

Anna Cieślewska, PhD, is a researcher at the Department of Iranian Studies, Institute of Oriental Studies at the Jagiellonian University and cooperates with the Polish Center for International Aid. She wrote her doctoral thesis at the Institute of Applied Social Sciences, University of Warsaw. She graduated from the University of Warsaw's School of Cross-culture Relations with an MA degree, and earned an MSc degree in Development Studies from the School of Oriental and African Studies at the University of London (MSc), as well as completing the Academy of Fine Arts in Warsaw. As a result of her interest in Central Asian socio-economic development issues and the geopolitics of Central Asia, as well as in Islam and local traditions in the post-Soviet region, she has spent the last nine years working on various research and development projects in the CIS region.

For centuries, the mahalla as a quarter within cities and villages, regulated the life of sedentary communities maintaining relative autonomy at the grass-root level. During the Soviet period, the mahalla underwent transformation, nevertheless, its practices and traditions still shaped local relationships. The rapid changes after the collapse of the USSR also affected the mahalla, which has been included into the legislative framework of Tajikistan, and since 2008 has become the smallest administrative unit, partly losing its traditional functions. In the meantime, the mahalla have also become popular as an indigenous form of communal organisation among the Western aid agencies operating in the region. 